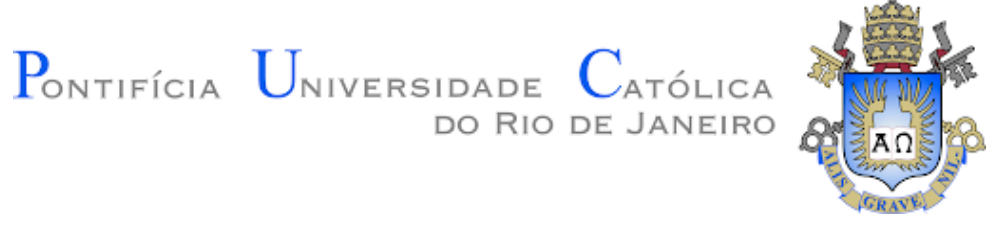

Diego Nascimento Maia

\title{
Avaliação Econômico-Financeira de Usinas Híbridas no Brasil
}

Dissertação apresentado como requisito parcial para obtenção do grau de Mestre pelo Programa de PósGraduação em Engenharia de Produção do Departamento de Engenharia Industrial da PUC-Rio.

Orientador: Prof. Luiz Eduardo Teixeira Brandão Coorientador: Prof. Fábio Rodrigo Siqueira Batista 


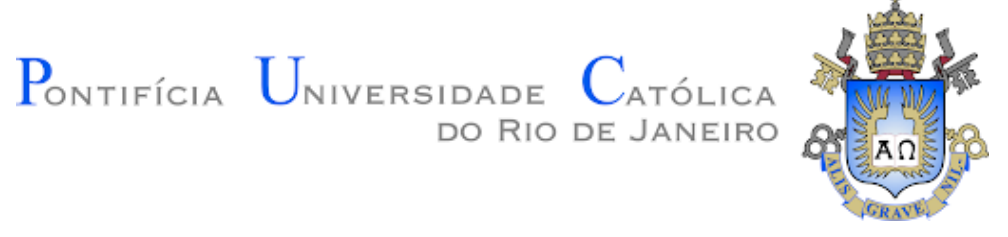

Diego Nascimento Maia

\section{Avaliação Econômico-Financeira de Usinas Híbridas no Brasil}

Dissertação apresentado como requisito parcial para obtenção do grau de Mestre pelo Programa de PósGraduação em Engenharia de Produção da PUC-Rio. Aprovada pela Comissão Examinadora abaixo:

Prof. Luiz Eduardo Teixeira Brandão

Orientador

Departamento de Engenharia Industrial - PUC-Rio

Prof. Fábio Rodrigo Siqueira Batista

Coorientador

Departamento de Engenharia Industrial - PUC-Rio

Prof. Albert Cordeiro Geber de Melo UERJ

Prof. Bruno Fânzeres dos Santos

Departamento de Engenharia Industrial - PUC-Rio 
Todos os direitos reservados. A reprodução, total ou parcial, do trabalho é proibida sem autorização da universidade, do autor e do orientador.

\section{Diego Nascimento Maia}

Graduou-se em Engenharia de Computação pelo IME (Instituto Militar de Engenharia) em 2010. Possui MBA em Gestão de Investimento pela PUC/IAG. É engenheiro pesquisador do CEPEL - Centro de Pesquisas de Energia Elétrica desde 2015, atuando atualmente na área de avaliação econômico de empreendimentos de geração e transmissão de energia, e na área de comercialização de contratos de energia.

Ficha Catalográfica

Maia, Diego Nascimento

Avaliação econômico-financeira de usinas híbridas no Brasil / Diego Nascimento Maia ; orientador: Luiz Eduardo Teixeira Brandão ; coorientador: Fábio Rodrigo Siqueira Batista. - 2021.

156 f. : il. color. ; $30 \mathrm{~cm}$

Dissertação (mestrado)-Pontifícia Universidade Católica do Rio de Janeiro, Departamento de Engenharia Industrial, 2021.

Inclui bibliografia

1. Engenharia Industrial - Teses. 2. Usinas híbridas. 3. Avaliação econômica. 4. Preço horário da energia elétrica. 5. Energia eólica. 6. Energia solar fotovoltaica. I. Brandão, Luiz Eduardo Teixeira. II. Batista, Fábio Rodrigo Siqueira. III. Pontifícia Universidade Católica do Rio de Janeiro. Departamento de Engenharia Industrial. IV. Título.

CDD: 658.5 


\section{Agradecimentos}

Aos meus pais, José Edvar e Rosenilde, e aos meus irmãos, Anderson e Vanessa, por toda atenção, carinho e companheirismo.

Ao orientador Luiz Eduardo Teixeira Brandão, pelo compartilhamento de sua experiência e ensinamentos.

Ao orientador Fábio Rodrigo Siqueira Batista, pelo compartilhamento de sua experiência, incentivo, ajuda e dedicação ao longo desta pesquisa.

Ao Albert Cordeiro Geber de Melo, pelo compartilhamento de sua experiência e conhecimentos.

A todos os professores e funcionários do Departamento pelos ensinamentos e pela ajuda.

Ao CEPEL por fornecer condições e estímulo para conclusão do mestrado.

A todos amigos e colegas do CEPEL que estiveram presentes nessa fase com ajuda e estímulo.

Aos colegas da CHESF, Eduardo Sodré e José Bione, pelo compartilhamento de experiências e ensinamentos.

O presente trabalho foi realizado com apoio da Coordenação de Aperfeiçoamento de Pessoal de Nível Superior - Brasil (CAPES) - Código de Financiamento 001. 


\section{Resumo}

Maia, Diego Nascimento; Brandão, Luiz Eduardo Teixeira; Batista, Fábio Rodrigo Siqueira. Avaliação Econômico-Financeira de Usinas Híbridas no Brasil. Rio de Janeiro, 2021. 156p. Dissertação de Mestrado - Departamento de Engenharia Industrial, Pontifícia Universidade Católica do Rio de Janeiro.

No atual ciclo de expansão do setor elétrico brasileiro está previsto um forte crescimento de fontes renováveis não despacháveis, por exemplo, as fontes eólica e solar fotovoltaica. Neste contexto, o conceito de usinas híbridas tem surgido como uma alternativa para que os riscos dos empreendimentos de geração de energia possam ser melhor gerenciados, além de proporcionar alternativas mais rentáveis no desenvolvimento de projetos desta natureza. A combinação de diferentes tecnologias tem o potencial de propiciar efeitos sinérgicos no desenvolvimento e na operação das usinas e, consequentemente, provocar redução de despesas e custos. O objetivo desta dissertação é apresentar uma abordagem metodológica para avaliar uma usina híbrida composta pelas tecnologias eólica e solar fotovoltaica, considerando dois dos principais fatores de riscos associados, ou seja, a aleatoriedade da geração do empreendimento e do preço da energia no mercado de curto prazo. Para o estudo de caso considerado, a aplicação da metodologia foi capaz de mensurar o ganho sinérgico com o desenvolvimento do arranjo híbrido. As análises de fluxo de caixa foram feitas em base mensal e horária, cujos resultados se mostraram próximos para a maior parte das situações estudadas. Foram realizadas análises de sensibilidade acerca do Montante de Uso do Sistema de Transmissão contratado, as quais indicaram a viabilidade de se contratar $30 \%$ a $40 \%$ menos do que hoje é obrigatório no setor elétrico brasileiro. Estas análises vieram acompanhadas do dimensionamento do quanto de sua produção o empreendimento deixa de injetar na rede básica em função de diferentes valores do MUST contratado.

\section{Palavras-chave}

Usinas Híbridas; Avaliação Econômica; Preço Horário da Energia Elétrica; Energia Eólica; Energia Solar Fotovoltaica. 


\section{Abstract}

Maia, Diego Nascimento; Brandão, Luiz Eduardo Teixeira (Advisor); Batista, Fábio Rodrigo Siqueira (Co-Advisor). Assessing Investiments of Hybrid Power Power Plants in Brazil. Rio de Janeiro, 2021. 156p. Dissertação de Mestrado Departamento de Engenharia Industrial, Pontifícia Universidade Católica do Rio de Janeiro.

In the current expansion cycle of the Brazilian electricity sector, a strong growth of non-dispatchable renewable sources is expected, for example, wind and solar energy. In this context, the concept of hybrid power plants (HPP) has emerged as an alternative so that the risks of energy generation projects can be better managed, in addition to providing more profitable alternatives in the development of projects of this kind. The combination of different technologies has the potential to provide synergistic effects in the development and operation of plants and, consequently, to reduce expenses and costs. The aim of this work is to present a methodological approach to evaluate a HPP composed of wind and solar photovoltaic technologies, considering two of the main associated risk factors, that is, the randomness of the project's generation and the price of energy in the short-term market. For the case study considered, the application of the methodology was able to measure the synergistic gain with the development of the hybrid arrangement. Cash flow analyzes were performed on a monthly and hourly basis, whose results were similar for most of the situations studied. Sensitivity analyzes were carried out on the Amount of Use of the Transmission System (MUST) contracted, which indicated the feasibility of contracting $30 \%$ to $40 \%$ less than what is currently mandatory in the Brazilian electricity sector. These analyzes were followed by the dimensioning of how much of its production the project doesn't inject into the basic network due to different values of the MUST contracted.

\section{Keywords}

Hybrid Power Plants; Assessing Investment; Hourly Price of Electric Power; Wind Energy; Solar Energy. 


\section{Sumário}

1 Introdução 9

1.1 Motivação para o Surgimento de Usinas Híbridas 9

1.2 O Conceito de Usinas Híbridas 10

1.3 Exemplos de Usinas Híbridas 12

1.4 Desafios Enfrentados com o Surgimento das Usinas Híbridas 14

$\begin{array}{lll}1.5 & \text { Objetivo do Trabalho } & 15\end{array}$

1.6 Contribuições e Descrição dos Capítulos 16

2 Análise de Viabilidade Econômica de Usinas Híbridas - Revisão da Literatura

3 Desenvolvimento de Usinas no Contexto do Setor Elétrico Brasileiro 22

3.1 Principais Características da Expansão do Setor Elétrico Brasileiro 22

3.2 Despacho e Formação do Preço de Liquidação das Diferenças

(PLD) 24

3.3 Contratação de Energia Eólica e Solar Fotovoltaica no Mercado Brasileiro

3.4 Regras de Contratação do MUST

3.5 Ganhos de Escala com Investimentos e O\&M em Projetos Híbridos 32

3.6 Cálculo da Garantia Física em Empreendimentos Eólicos e Solares

Fotovoltaicos

4 Abordagem Metodológica $\quad 35$

4.1 Premissas Técnicas, Econômicas e Financeiras 36

4.2 Definição de Cenários de Geração de Energia Elétrica 37

$\begin{array}{lll}4.3 & \text { Cenários de PLD } & 38\end{array}$

4.4 Análises Econômico-Financeiras 38

4.5 Análise dos Resultados 41

5 Geração de Cenários de Produção de Energia Eólica e Solar 43

5.1 Séries Temporais 43

5.2 Série "Histórica" 44

5.3 Ajuste do Modelo BOX \& JENKINS 52

5.4 Análise dos Cenários Sintéticos de Produção de Energia 57

5.4.1 Tecnologia Eólica 58

5.4.2 Tecnologia Solar Fotovoltaica 63

$\begin{array}{lll}5.5 & \text { Desagregação da Produção de Energia em Base Mensal para } & \\ \text { Base Horária } & 67\end{array}$

6 Geração de Cenários para o Preço da Energia Elétrica no Mercado de Curto Prazo 
6.1 Geração de Cenários de PLD em Base Mensal 72

6.2 Geração de Cenários de PLD em Base Horária 75

6.2.1 Série Histórica de PLD Horário $\quad 75$

6.2.2 Estratégia de Cálculo dos Fatores de Desagregação 77

6.2.3 Distinção entre Dias Úteis e Não Úteis 83

6.2.4 Obtenção de Fatores de Desagregação para Cada Dia da Série Histórica

6.2.5 Estratégia de Desagregação de PLDs Mensais em Horários 89

7 Aplicação da Abordagem Metodológica Proposta 92

$\begin{array}{ll}7.1 & \\ 7.1 .1 & \text { Estudo de Caso }\end{array}$

$\begin{array}{ll}\text { 7.1.1 Marcos Temporais } & 94\end{array}$

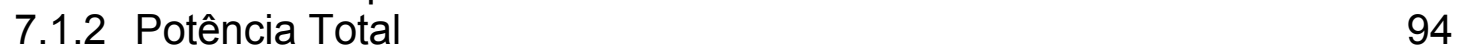

7.1.3 Investimento Total 95

$\begin{array}{ll}\text { 7.1.4 Fator de Capacidade } & 95\end{array}$

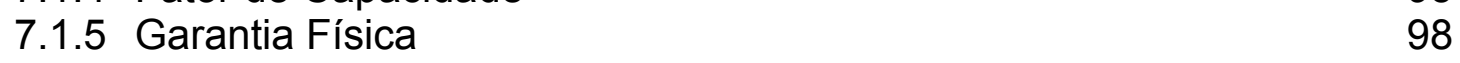

$\begin{array}{llr}\text { 7.1.6 Preços dos Contratos } & 99\end{array}$

$\begin{array}{ll}\text { 7.1.7 Percentual de Contratação no ACR/ACL } & 100\end{array}$

$\begin{array}{lll}\text { 7.1.8 } & \text { Arrendamento da Terra e Seguros } & 100\end{array}$

7.1.9 Tarifa de Uso de Sistema de Transmissão (TUST) 100

$\begin{array}{ll}\text { 7.1.10 Operação \& Manutenção (O\&M) } & 101\end{array}$

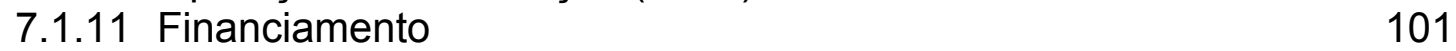

$\begin{array}{ll}\text { 7.1.12 Depreciação } & 102\end{array}$

$\begin{array}{lll}7.2 & \text { Resultados } & 102\end{array}$

$\begin{array}{ll}\text { 7.2.1 Análises Determinísticas } & 103\end{array}$

$\begin{array}{ll}\text { 7.2.2 Análises Probabilísticas } & 105\end{array}$

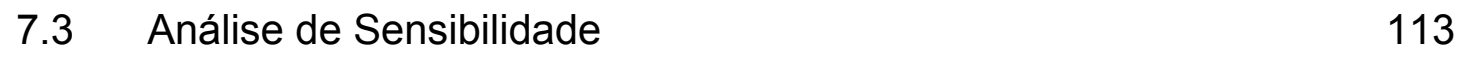

$\begin{array}{ll}\text { 7.3.1 Análise de Risco-Retorno } & 122\end{array}$

$\begin{array}{ll}\text { 7.3.2 Avaliação do Curtailment } & 125\end{array}$

8 Conclusão 131

9 Trabalhos Futuros $\quad 134$

10 Referências 135

11 Apêndices 147

11.1 Apêndice A - Boxplots para cada Mês da Série Histórica de PLD 147

11.2 Apêndice B - Resultados Complementares da Análise de

Sensibilidade com Diferentes Contratações do MUST 


\section{Introdução}

\section{1}

\section{Motivação para o Surgimento de Usinas Híbridas}

A matriz elétrica brasileira apresenta elevada participação de fontes renováveis, representando mais de $80 \%$ do consumo de energia elétrica do país. Apesar da predominância de usinas hidrelétricas (UHE), as tecnologias eólica e solar fotovoltaica têm apresentado expressiva expansão ao longo dos últimos anos. De acordo com o Plano Decenal de Expansão de Energia 2020-2029 - PDE 2029 (EPE, 2019), essa evolução continuará ao longo da próxima década, havendo a previsão de que a participação conjunta das fontes de geração eólica e solar fotovoltaica passe de $11,87 \%$ da capacidade instalada do Sistema Interligado Nacional (SIN) em 2021 (ANEEL, 2021) para 22,67\% em 2029 (EPE, 2019).

Esse aumento esperado para a capacidade instalada possibilita o surgimento de novos modelos de negócio, tal como o desenvolvimento de usinas híbridas, compreendendo as fontes de geração eólica e solar fotovoltaica. Neste tipo de arranjo, diversos benefícios podem ser citados como forma de incentivo para o seu desenvolvimento. Ambas as tecnologias são fontes de geração intermitentes, mas que podem apresentar complementaridade diária, o que possibilita o uso mais eficiente do sistema de transmissão. Consequentemente, a rede de transmissão existente poderia ter capacidade para acomodar novas usinas com menores necessidades de reforços, ou mesmo prescindir de alguns investimentos em expansão (EPE, 2018).

No que tange aos investimentos para o desenvolvimento de usinas híbridas, o compartilhamento de equipamentos elétricos e de infraestrutura de transmissão podem gerar ganhos de escala, reduzindo a necessidade de investimentos, em $\mathrm{R} \$ / \mathrm{kW}$, quando comparado à necessidade de investimento em usinas de mesmo fator de capacidade, porém com apenas uma tecnologia de geração (ANEEL, 2020). 
Finalmente, também pode haver sinergia operativa entre as tecnologias empregadas em um empreendimento híbrido, ocasionando redução nos custo fixos de operação e manutenção (O\&M).

\section{2}

\section{O Conceito de Usinas Híbridas}

LAZAROV et al. (2005) define usina híbrida como um sistema de energia que usa uma fonte de energia renovável e uma convencional, ou mais de uma fonte renovável, com ou sem fontes de energia convencionais, que funciona no modo 'independente' ou 'conectado à rede"'.

CLEVELAND (2015) diz que usinas híbridas são caracterizadas como um sistema que combina duas ou mais formas de produção de energia ou de potência para prover um serviço de suprimento particular, o qual pode incluir o armazenamento.

A (WINDEUROPE, 2019) define usina híbrida como uma instalação de geração de energia que converte energia primária em energia elétrica e que consiste em mais de um modo de geração de energia conectado a uma rede em um ponto de conexão. No caso de uma configuração formada por uma usina eólica e uma usina solar fotovoltaica, estas usinas podem compartilhar a mesma subestação (Figura 1) e ponto de conexão à rede, ou os painéis fotovoltaicos podem estar integrados às turbinas eólicas (Figura 2).

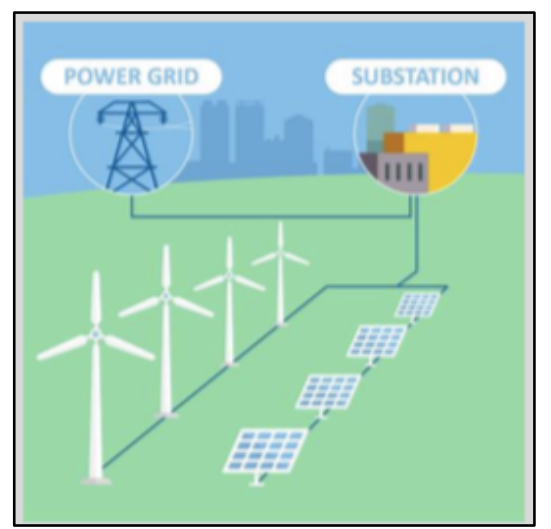

Figura 1 - Usina Híbrida Conectada a mesma Subestação e Ponto de Conexão à Rede (WINDEUROPE, 2019)

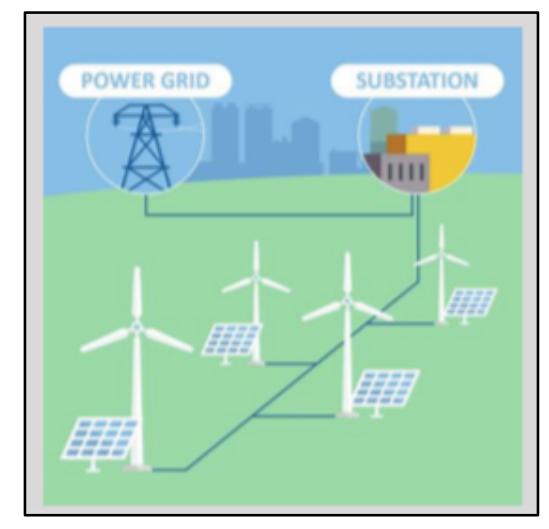

Figura 2 - Usina Híbrida com Painéis Fotovoltaicos Integrados às Turbinas Eólicas (WINDEUROPE, 2019) 
No Brasil, a EPE (2018) apresentou os conceitos de usinas adjacentes, associadas e híbridas, sendo que todas, de alguma forma, combinam mais de uma tecnologia em um sistema de geração e poderiam ser considerados sistemas híbridos.

As usinas adjacentes consistem naquelas construídas em localidades próximas entre si, podendo compartilhar o mesmo terreno. Neste caso, a conexão com a rede básica é contratada separadamente, compatível com a potência instalada nominal de cada usina. A vantagem observada neste arranjo reside na redução do custo com o aluguel do terreno e com o custo de operação e manutenção (O\&M). O esquema de conexão com a rede básica de uma usina adjacente é apresentado na Figura 3.

Já as usinas associadas, segundo a EPE (2018), são caracterizadas por duas ou mais fontes energéticas distintas, com características de produção complementar. Usinas nesta classificação caracterizam por estarem próximas e por compartilharem física e contratualmente infraestrutura de conexão e acesso à rede básica. Ademais, estas usinas podem manter medidores individuais. Neste tipo de configuração, as usinas poderiam contratar menos capacidade de uso da rede do que a soma das potências nominais das usinas. O esquema de conexão com a rede básica de uma usina associada é apresentado na Figura 4.

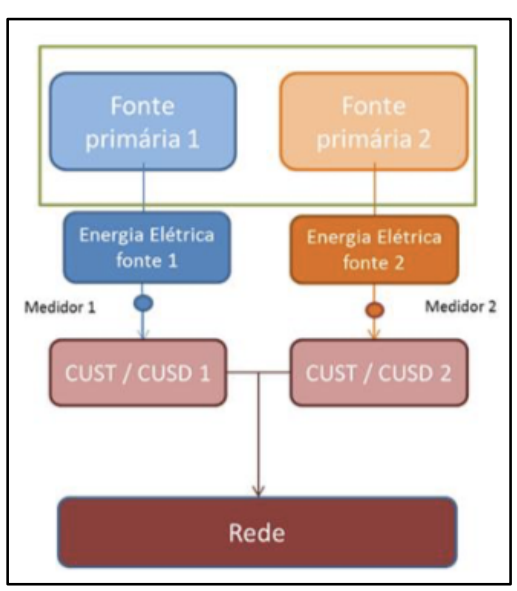

Figura 3 - Usinas Adjacentes (EPE, 2018)

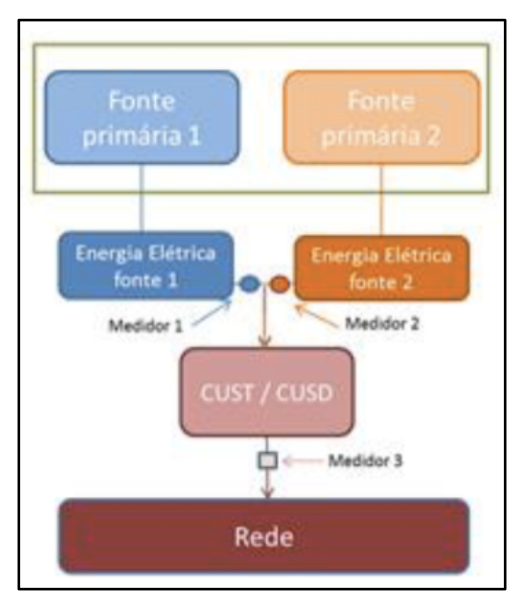

Figura 4 - Usina Associada (EPE, 2018)

Para EPE (2018), usina híbridas são aquelas que se combinam no processo de geração de energia elétrica. Dessa forma, não se diferencia a origem da energia. $O$ esquema de conexão com a rede básica de uma usina híbrida é apresentado na Figura 5. Destaca-se a presença de um único medidor. 


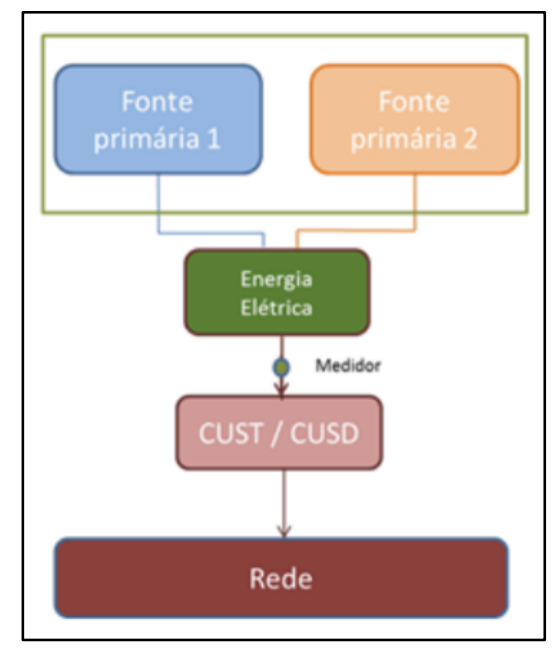

Figura 5 - Usina Híbrida (EPE, 2018)

Esta dissertação adotará como base esta definição de usina híbrida. Complementarmente, de acordo com a Minuta em anexo à Nota Técnica $\mathrm{N}^{\mathrm{o}}$ 079/2020-SRG-SRT-SCG/ANEEL da Consulta Pública 061/2020, uma Central Geradora Híbrida ou Usina de Geração Híbrida (UGH) consiste em uma instalação de produção de energia elétrica a partir da combinação de diferentes tecnologias, objeto de outorga ${ }^{1}$ única.

\section{3}

\section{Exemplos de Usinas Híbridas}

Ao redor do mundo existem diversos projetos de usinas hibridas. Por exemplo, a empresa sueca Vattenfall possui dois empreendimentos em operação, um deles situado em Parc Cynog, no País de Gales, e o outro situado em Haringvliet, nos Países Baixos. No primeiro, o parque eólico foi construído em 2001, com potência nominal de 3,60 MW, e, como forma de se desenvolver na área de projetos híbridos, foi instalado em 2016 uma parcela solar fotovoltaica de 4,99 MW. O segundo teve a construção iniciada em 2019, e, diferentemente do primeiro, apresenta estrutura de armazenamento de $12 \mathrm{MW} / 12 \mathrm{MWh}$, que suporta potência de carga e descarga de 12 MW e capacidade de $12 \mathrm{MWh}$, além de uma parcela eólica de $21 \mathrm{MW}$ e uma parcela fotovoltaica de 31 MW (WINDEUROPE, 2019).

\footnotetext{
${ }^{1}$ Outorga de concessão de serviço público de energia elétrica consiste na delegação de sua prestação, feita pela ANEEL, mediante licitação, na modalidade de concorrência, à pessoa jurídica ou consórcio de empresas que demonstre capacidade para o seu desempenho, por sua conta e por prazo determinado. (ANEEL, 2021).
} 
A Tabela 1 apresenta outros empreendimentos híbridos desenvolvidos no exterior, por exemplo, na cidade de Kavital, na Índia, país que possui especial interesse no desenvolvimento de usinas híbridas por ter problemas relacionados a questão fundiária (EPE, 2019). Há empreendimentos também na Austrália (WINDEUROPE, 2019) e há projetos menores situados em ilhas, locais geográficos caracterizados por terem redes autônomas, sem conexão com uma rede principal (ETXEGARAI, A. et al., 2015).

Apesar de não haver norma definitiva regulamentando as usinas híbridas no Brasil, existem alguns projetos em operação que podem ser considerados projetos híbridos, por exemplo, empreendimentos solares fotovoltaicos que estão sendo “anexados" a parques eólicos (CAMARGO, L. et al., 2019). Um exemplo é o Complexo Fontes, situado na cidade de Tacaratu/PE, da empresa Enel Green Power. Este arranjo possui uma potência nominal total de 90,90 MW e é formado por um parque eólico (Fonte do Ventos) com 34 aerogeradores que somam 79,90 MW de potência. Já a planta solar fotovoltaica (Fontes Solar I e II) é composta por 16 módulos fotovoltaicos totalizando 11,00 MW. A planta eólica entrou em operação em 2014 e a planta solar em 2015 (LEONI, P. et al., 2016).

Tabela 1 - Exemplo de Usinas Híbridas ao Redor do Mundo

\begin{tabular}{|c|c|c|c|c|c|}
\hline $\begin{array}{c}\text { Localidade } \\
\text { (Cidade - País) }\end{array}$ & $\begin{array}{c}\text { Potência Parcela } \\
\text { Eólica (MW) }\end{array}$ & $\begin{array}{c}\text { Potência Parcela } \\
\text { Solar (MW) }\end{array}$ & $\begin{array}{c}\text { Armazenamento } \\
\text { (MW/MWh) }\end{array}$ & $\begin{array}{c}\text { Proporção } \\
\text { Eólico-Solar } \\
(\% / \%)\end{array}$ & Empresa \\
\hline Parc Cynog - País de Gales & 3,60 & 4,99 & - & $42 / 58$ & Vattenfall \\
\hline Haringvliet - Países Baixos & 21,00 & 31,00 & $12 / 12$ & $40 / 60$ & Vattenfall \\
\hline Kavital - Índia & 50,00 & 28,80 & - & $63 / 37$ & Hero Futures Energy e \\
Siemens Gamesa
\end{tabular}

Fonte: Elaboração Própria, com base em WINDEUROPE (2019)

Apesar dos exemplos anteriores combinarem as tecnologias eólica e solar fotovoltaica, há diversos outros arranjos possíveis para as usinas híbridas, por exemplo (EPE, 2018): 
- Usina hidrelétrica com usina solar fotovoltaica: neste arranjo, é possível aproveitar disponibilidade de área presente nas superfícies de água em usinas hidrelétricas, como os projetos piloto das UHE Balbina (2016) e Sobradinho (2019);

- Usina heliotérmica (termossolar) com outro combustível (Biomassa): possibilidade de aumentar o fator de capacidade das usinas heliotérmicas;

- Usina térmelétrica a biomassa e gás natural: a queima de gás natural em usinas a bagaço de cana é capaz de aumentar o período de despacho dessas usinas e a eficiência do ciclo térmico;

○ Usina térmelétrica a carvão com biomassa ("coqueima"): a biomassa se junta ao carvão na queima da caldeira, o que se permite a redução de emissão de $\mathrm{CO}_{2}$ por MWh produzido.

\section{4}

\section{Desafios Enfrentados com o Surgimento das Usinas Híbridas}

O desenvolvimento de usinas híbridas impõe aos gestores desses projetos desafios como, para o caso de uma usina híbrida composta por uma usina eólica e outra solar fotovoltaica, definição de uma região de instalação que permita que se obtenha ganhos sinérgicos com a complementaridade diária entre as fontes de geração.

Outro desafio relacionado a este tema reside em avaliar o dimensionamento da dos equipamentos de infraestrutura. Caso haja algum nível de complementaridade, a potência instantânea da usina híbrida pode não atingir a soma das potências nominais das usinas individuais.

Para empreendimentos de geração de energia elétrica, a legislação em vigor, normatizada pela Resolução Normativa ANEEL Nº 666, 23 de junho de 2015, define que o Montante de Uso do Sistema de Transmissão (MUST) contratado seja igual à potência nominal da usina. A possibilidade de se contratar MUST inferior à potência nominal pode permitir que se reduza o investimento total do projeto e as despesas com Operação e Manutenção (O\&M). Esta questão é uma das propostas da Minuta 
em anexo à Nota Técnica $N^{0}$ 079/2020-SRG-SRT-SCG/ANEEL no contexto da Consulta Pública 61/2020 da ANEEL que trata de aspectos relacionados ao tratamento regulatório para o estabelecimento de usinas híbridas.

\section{5}

\section{Objetivo do Trabalho}

Recentemente o mercado de energia elétrica no Brasil passou por uma mudança significativa no que tange à liquidação da energia elétrica no mercado de curto prazo. Isso se refere à implantação do preço horário da energia a partir de Janeiro de 2021. É nesse contexto que se discute sobre a concepção de projetos híbridos.

O estabelecimento do preço horário impõe um novo desafio para os gestores de empreendimentos de geração de energia, tanto para aqueles empreendimentos existentes quanto para aqueles a serem desenvolvidos: a gestão de riscos envolvida na contratação de energia. Isto tem impacto direto nas análises de viabilidade econômico-financeira de empreendimentos de geração de energia elétrica, que usualmente são realizadas em base mensal ou anual, vide (BATISTA et al., 2016; RODRIGUES et al., 2015; MELO et al., 2018). Com a introdução do preço horário, avaliar novos empreendimentos com base em projeções mensais de geração, de preço e de outros parâmetros, pode não ser mais suficiente para uma boa análise da viabilidade e dos riscos do projeto.

Diante do exposto, esta dissertação tem como objetivo principal avaliar a viabilidade econômica de projetos híbridos de geração de energia elétrica, formados por uma usina eólica e uma usina solar fotovoltaica, considerando os principais riscos não-sistemáticos associados, aqui representados pela incerteza associada à produção de energia do empreendimento e ao preço da energia no mercado à vista.

Particularmente, busca-se estabelecer uma abordagem metodológica para avaliar projetos híbridos levando em consideração os dois fatores de risco anteriormente mencionados. Também é objetivo desta dissertação que tal abordagem metodológica permita que os fluxos de caixa do empreendimento sejam projetados em base horária, permitindo avaliar os ganhos deste tipo de projeção comparados a projeções feitas em base mensal, que usualmente empregam modelos de longo prazo 
para a projeção de cenários de produção de energia elétrica, de preços e de fluxos de caixa.

Uma vez que o horizonte de projeção dos fluxos de caixa para novos empreendimentos de geração pode alcançar 30 anos ou mais, a estratégia adotada nesta dissertação será utilizar modelos de longo prazo, com discretização mensal, para projetar os fatores de risco considerados. Em seguida, com base nas séries históricas das variáveis aleatórias (produção e preço), serão construídos fatores para desagregar as variáveis projetadas em base mensal para a base horária. Tais fatores são aqui chamados Fatores de Desagregação. A sua utilização permitiu que particularidades específicas das fontes de geração analisadas fossem capturadas, tais como a sua complementaridade diária.

\section{6}

\section{Contribuições e Descrição dos Capítulos}

A contribuição desta dissertação em relação à literatura está, primeiramente, em apresentar uma abordagem metodológica para analisar a viabilidade econômica de usinas híbridas considerando o risco associado à produção de energia do empreendimento e à sua exposição no mercado à vista de energia.

Outra contribuição desta dissertação consiste na estimação do ganho obtido ao se avaliar uma usina eólica, solar fotovoltaica e uma usina híbrida com base em fluxos de caixa projetados com discretização horária, frente a projeção de fluxos mensais, mais comum na literatura.

Análises complementares também são realizadas no sentido de avaliar o impacto da redução de contratação do Montante de Uso do Sistema de Transmissão (MUST) de uma usina híbrida sobre os seus indicadores de viabilidade. Nesta análise, cada percentual de contratação do MUST é avaliado em 2.000 cenários relacionados às incertezas consideradas nesta dissertação. Esta análise de sensibilidade com diferentes percentuais de contratação do MUST ainda permite quantificar o montante de energia elétrica que se deixa de escoar para rede devido à redução do MUST, usualmente denominada curtailment.

A presente dissertação foi estruturada de modo a expor conceitos básicos de análise de viabilidade econômica de usinas híbridas, proposta metodológica, caso de estudo, resultado das análises e conclusão. 
O capítulo 2 apresenta uma revisão da literatura sobre os principais temas envolvidos na avaliação de Usinas Híbridas no Brasil e no mundo.

No capítulo 3 são expostos os conceitos relacionados ao desenvolvimento de usinas híbridas no contexto do Setor Elétrico Brasileiro (SEB). Primeiramente, apresentam-se as principais características da expansão do SEB; em seguida, uma breve explanação é realizada sobre o processo de formação do preço da energia no mercado à vista brasileiro. São apresentadas também as regras comerciais vigentes para empreendimentos eólicos e solares fotovoltaicos. São apresentadas ainda a atual norma relacionada à contratação do Montante para Uso do Sistema de Transmissão (MUST) e a proposta em análise pela ANEEL de alteração desta norma. Neste capítulo, apresenta-se também a forma de cálculo da garantia física para empreendimentos eólicos e solares fotovoltaicos. E por fim, este capítulo mostra os possíveis ganhos de escala ao se compor um arranjo híbrido.

O capítulo 4 traz o detalhamento da abordagem metodológica proposta por esta dissertação. Ou seja, os aspectos gerais da metodologia empregada são descritos, cujo detalhamento ocorre nos capítulos seguintes.

No capítulo 5 é exposta a metodologia para obtenção de cenários de produção de energia que serão utilizados como dados de entrada para as análises probabilísticas realizadas neste trabalho. Já o capítulo 6 apresenta o procedimento adotado para se obter cenários de preços de energia no mercado à vista em base mensal e em base horária.

Apresenta-se um estudo de caso no capítulo 7 com o objetivo de aplicar a abordagem metodológica proposta. Os resultados obtidos são apresentados e discutidos neste capítulo. Ainda neste capítulo são discutidas análises complementares, como a análise de sensibilidade relacionada ao percentual de contratação do MUST e avaliação da quantidade de energia gerada que, por limitações da contratação do MUST, não foi possível escoar para rede básica.

Por fim, o capítulo 8 apresenta as conclusões do trabalho e propostas de desenvolvimentos futuros da metodologia proposta. 


\section{2 \\ Análise de Viabilidade Econômica de Usinas Híbridas - Revisão da Literatura}

Este capítulo apresentará a revisão bibliográfica realizada sobre os temas que envolvem a análise de viabilidade econômica de usinas híbridas, em particular as que fazem uso das tecnologias eólica e solar fotovoltaica.

De forma semelhante à presente dissertação, (DAS, K. et al., 2019) apresentam as vantagens das usinas híbridas tendo como tecnologia principal a eólica. Estes autores realizam um conjunto de análises, entre elas a avaliação do fator de capacidade de uma usina híbrida, com base em séries temporais de energia eólica e solar, com correlação espaço-temporal, e em séries históricas de preços de mercado. (DAS, K. et al., 2019) ainda mostram a correlação do preço de mercado com a série temporal combinada eólica-solar para avaliar a flexibilidade de ter armazenamento de energia nas horas em que os preços de mercado estão baixos, para posterior venda nas horas em que os preços de mercado estão altos, sendo que o armazenamento poderia ajudar a evitar o curtailment.

Os autores ainda afirmam ser uma tendência global o aproveitamento de uma infraestrutura já instalada para aumentar sua utilização por meio da hibridização. Além de se minimizar o $\mathrm{LCOE}^{2}$, o autor afirma ser possível obter lucro em diferentes mercados (mercado de capacidade, mercado de energia e serviços ancilares ${ }^{3}$ ). Para as localidades consideradas no artigo (Dinamarca, Suécia e França), existe a possibilidade de se acrescentar energia solar a planta de energia eólica já instalada para aumentar o fator de capacidade (aumentar a capacidade de escoamento); por outro lado, também existe a possibilidade de aumentar as instalações (overplant) com energia solar caso se deseje minimizar o curtailment e maximizar a utilização da infraestrutura elétrica. Os autores mostram para o caso em análise, considerando os

\footnotetext{
${ }^{2}$ Levelized Cost of Energy (LCOE): representa o custo, por MWh, da construção e operação de uma planta geradora de energia durante seu ciclo de vida útil econômica.

3 Serviços Ancilares: serviço complementar à geracao, transmissão, distribuição e comercialização
} 
preços de mercado do Nord Pool ${ }^{4}$, que os cortes são maiores em momentos de preços mais baixos e vice-versa.

Já o trabalho de (CAMPOS, R., 2020) avalia se a otimização do dimensionamento e da operação de usinas eólicas e fotovoltaicas, em conjunto com sistemas de armazenamento em baterias, poderiam aumentar a despachabilidade destas fontes de geração de energia. Para isto, o autor também realiza a análise de complementaridade horária dessas fontes de geração no interior do estado da Bahia. Além disso, o autor discute sobre a necessidade de regulamentação e afirma que a falta de aprimoramentos da regulamentação de usinas híbridas pode levar a sobrecontratação do sistema de transmissão e, consequentemente, a uma tarifa de energia maior.

Esta dissertação apresenta um estudo de caso no estado do Ceará, que apresenta complementaridade durante o dia entre as fontes de geração. Entretanto, diferentemente do trabalho de (CAMPOS, R., 2020), esta dissertação não possui o objetivo de otimizar o dimensionamento de uma usina híbrida, mas avaliar a viabilidade econômica de projetos híbridos de geração de energia elétrica, considerando os principais riscos não-sistemáticos associados. Adotou-se como estudo de caso uma usina híbrida de 200 MW de potência nominal, dividida em 160 MW de eólica (80\%) e 40 MW de solar fotovoltaica (20\%).

Os exemplos de usinas híbridas levantados nesta revisão bibliográfica mostraram usinas híbridas com proporções eólico-solar diversas, que variaram desde $90 \%$ eólica e 10\% solar fotovoltaica até $40 \%$ eólica e $60 \%$ solar fotovoltaica. Adicionalmente, a Nota Técnica EPE-DEE-NT-025/2017 (EPE, 2017) apresenta uma análise da complementaridade entre a geração eólica e a geração solar fotovoltaica com o intuito de desenvolver um empreendimento híbrido. Este estudo utilizou o caso base para as análises com a proporção eólico-solar de 10:1, ou seja, 10MW de potência de geração eólica para cada 1MW de potência de geração solar fotovoltaica. Essa proporção corresponde, aproximadamente, a 91\% de geração eólica e 9\% de geração solar fotovoltaica em termos percentuais no arranjo híbrido.

O trabalho de (CARVALHO, D., 2018) realizou uma análise econômicofinanceira, em base mensal, considerando as incertezas associadas como o preço da energia no mercado de curto prazo, atrasos e antecipações de obras de uma planta

\footnotetext{
${ }^{4}$ Nord Pool: Bolsa de Energia na Europa
} 
híbrida formada por usinas eólicas e usina solares fotovoltaicas em operação no interior da Bahia.

Com relação ao preço da energia no mercado de curto prazo, o estudo de (CARVALHO, D., 2018) modelou, através de dados históricos mensais, uma curva de distribuição de probabilidade e aplicou uma simulação de Monte Carlo para geração de cenários. Já a presente dissertação utilizou a plataforma de dados do PDE 2029 e o modelo NEWAVE (MACEIRA et al., 2002; MACEIRA et al. 2008; MACEIRA et al. 2018), oficialmente empregado no Brasil no processo de despacho e formação do preço da energia elétrica, para se obter cenários para os preços, em base mensal, para a avaliação econômica do projeto. Diferentemente do trabalho de (CARVALHO, D., 2018), esta dissertação também realizou análise em base horária. Com relação a esta base temporal, realizou-se uma análise detalhada do preço histórico da energia elétrica negociada no mercado brasileiro com o objetivo de se realizar a avaliação econômica nesta escala temporal. Esta análise detalhada do PLD horário será apresentada em capítulo específico.

No que tange à produção de energia, o trabalho de (CARVALHO, D., 2018) também associou os dados históricos para obter curvas de distribuições de probabilidade para realizar uma simulação de Monte Carlo. Neste caso, modelou dados de velocidade de vento e de irradiância solar para obter curvas de distribuições de probabilidade e obter a geração a partir dessas curvas. Com base em séries históricas de geração eólica e solar fotovoltaica geradas por meio de reanálise, esta dissertação obteve séries sintéticas de produção de energia através de um modelo SARIMA ajustado pela metodologia Box\&Jenkins (BOX \& JENKINS, 1970). Os modelos ajustados para cada fonte de geração, eólica, solar e arranjo híbrido, serão apresentados no capítulo 5, referente à geração de cenários de produção de energia elétrica.

Além de se tratar de um modelo oficial do SEB, uma vantagem adicional em esta dissertação utilizar o modelo NEWAVE, juntamente com a metodologia de BOX \& JENKINS para geração de séries sintéticas, consiste na capacidade de preservação da correlação temporal entre os dados gerados, o que não foi considerado por (CARVALHO, D., 2018).

Com relação aos custos e despesas, (CARVALHO, D., 2018) adotou que os empreendimentos de geração em análise possuem como custos fixos os custos de Operação \& Manutenção (O\&M) e os custos referentes a Tarifa de Uso do Sistema de 
Transmissão (TUST). No caso da presente dissertação, além das despesas com O\&M e com a TUST, também foram considerados outros custos e despesas tipicamente associadas a usinas desenvolvidas no Brasil, tais como: arrendamento da terra, seguros operacionais e taxa de fiscalização da ANEEL.

O trabalho de AGRAWAL (2017) avalia a viabilidade operacional de se instalar uma planta solar fotovoltaica na área livre de uma usina eólica. Esta viabilidade é medida por um indicador de desempenho (Performance Ratio) de usinas solares. AGRAWAL (2017) utilizou o software RETScreen Expert $t^{5}$ para gerar dados de produção de energia eólica. Para gerar dados de energia solar, o trabalho de AGRAWAL (2017) utilizou o software PVsyst ${ }^{6}$. Os autores avaliaram diversas configurações para a planta eólica e para a planta solar fotovoltaica com dados de geração em base mensal. Diferentemente, esta dissertação apresenta uma análise de viabilidade econômica, e não operacional, de uma usina híbrida, tanto em base horária quanto em base mensal. Assim como a presente dissertação, AGRAWAL (2017) afirma que um dos benefícios da usina híbrida consiste em aproveitar a complementaridade intradiária das fontes que a compõem. Esta complementaridade é capturada apenas em análises em base horária, tal como realizada nesta dissertação.

Por se tratar de um tema relativamente recente, foram encontradas poucas referências sobre o tema "avaliação econômica de usinas híbridas", tanto em nível nacional como em nível internacional, sendo as principais explicitadas neste capítulo.

\footnotetext{
${ }^{5}$ RETScreen Expert: https://www.nrcan.gc.ca/maps-tools-and-publications/tools/modellingtools/retscreen/7465

${ }^{6}$ PVsyst: www.pvsyst.com
} 


\section{3 \\ Desenvolvimento de Usinas no Contexto do Setor Elétrico Brasileiro}

\section{1}

\section{Principais Características da Expansão do Setor Elétrico Brasileiro}

Usualmente, o problema de planejamento da expansão da geração consiste em determinar uma estratégia de expansão e/ou um cronograma de obras que atenda o consumo de energia elétrica previsto ao longo do horizonte de planejamento, minimizando o custo de investimento mais o custo de operação, respeitando determinados níveis de segurança e, mais recentemente, considerando aspectos de desenvolvimento sustentável (MELO et al., 2012; MELO et al., 2020).

Este também é o caso do Brasil, onde o planejamento da expansão da geração busca minimizar os custos de investimento (de novas capacidades de geração e de interligação entre os subsistemas) mais o valor esperado do custo de operação, atendendo aos requisitos de segurança energética definidos pelo Conselho Nacional de Política Energética - CNPE, incorporando ainda a dimensão ambiental nas diversas etapas do processo de planejamento.

As características particulares do sistema elétrico brasileiro - de grande porte, com um parque gerador com preponderância hidrelétrica, com potencial hidrelétrico remanescente ainda relevante, envolvendo intercâmbios de grandes blocos de energia entre as diversas regiões do país para capturar os ganhos sinérgicos devido à diversidade hidrológica; com taxas de crescimento do consumo de energia elevadas no longo prazo; com política energética que prioriza as fontes renováveis de energia, com expectativa de elevada penetração das novas renováveis intermitentes (eólica e solar) - exigem que o planejamento da expansão do sistema elétrico seja feito com base em estudos com horizontes de longo prazo (GCPS/ELETROBRÁS, 1998; ZIMMERMANN, 2007). Para tais estudos, no Brasil, pode-se adotar o modelo MELP - Modelo de Expansão de Longo Prazo (LISBOA et al., 2008) ou o modelo MDI (Modelo de Decisão de Investimento) (GANDELMAN, 2015). 
A estratégia de expansão determinada nos estudos de longo prazo é refinada na etapa de planejamento de curto prazo da expansão (horizonte de 10 a 15 anos), produzindo o plano decenal de expansão, com desagregação anual, e um programa de obras de referência, que visa à implantação de novos projetos de geração e transmissão, por meio de leilões públicos. Nesta etapa, adota-se o modelo NEWAVE - Modelo de Planejamento da Operação de Sistemas Hidrotérmicos Interligados de Longo e Médio Prazos (MACEIRA et al., 2008; MACEIRA et al., 2018), desenvolvido pelo CEPEL.

No modelo NEWAVE, o problema de planejamento da operação é representado como um problema de programação linear estocástico multi-estágio. Sua função objetivo é minimizar o valor esperado do custo total de operação ao longo de todo o período de planejamento considerando mecanismos de aversão a risco, dado um estado inicial do sistema (armazenamento e tendência hidrológica). Custos de combustível das usinas termoelétricas e penalidades para o não atendimento ao mercado consumidor compõem o custo de operação. A solução deste problema resulta em uma estratégia operativa que, para cada estágio do período de planejamento, dado o estado inicial do sistema no estágio, produz metas de geração de energia e de intercâmbios entre subsistemas. No NEWAVE, os vários reservatórios do sistema podem ser agregados em reservatórios equivalentes de energia (REEs) ou representados por meio de uma modelagem híbrida, permitindo que o modelo NEWAVE represente as usinas hidroelétricas individualmente, em todo ou em parte do seu horizonte de planejamento (MACEIRA et al., 2019a; MACEIRA et al., 2019b). Esta nova abordagem híbrida tira proveito de ambas as modelagens, sem aumentar demasiadamente o esforço computacional, pela consideração dos benefícios de uma representação individual de UHEs no horizonte mais próximo à tomada de decisão operacional, e de tantos REEs quantos forem necessários para representar a diversidade hidrológica entre as bacias hidrográficas, nos estágios temporais posteriores. Por sua vez, o estado do sistema inclui a energia armazenada dos reservatórios equivalentes e informações da "tendência hidrológica", por exemplo, as últimas $p$ energias naturais afluentes de cada reservatório, individual ou equivalente. Mais recentemente, foi desenvolvida uma metodologia para a representação das incertezas das fontes eólicas no modelo NEWAVE (MACEIRA et al., 2020).

Para resolver o problema de programação linear estocástico multi-estágio, o NEWAVE utiliza o algoritmo de Programação Dinâmica Dual Estocástica (PDDE) 
(PEREIRA \& PINTO, 1991; MACEIRA, 1993). Após o cálculo da estratégia de operação, é realizada uma simulação final adotando outros 2.000 cenários sintéticos de energias afluentes aos reservatórios, ou considerando sequências de registros históricos. A partir dos resultados desta simulação final são produzidas estatísticas (valores esperados, desvio padrão, distribuições de frequências, etc) associadas a diversos indicadores de desempenho do sistema, entre os quais, custo total de operação, custo marginal de operação, risco de déficit, déficit de energia, geração hidrelétrica e térmica, vertimentos etc (MACEIRA et al., 2002; MACEIRA et al., 2016).

\section{2}

\section{Despacho e Formação do Preço de Liquidação das Diferenças (PLD)}

O planejamento da operação em sistemas hidrotérmicos tem sido realizado em diversos países por meio da definição de problemas de planejamento de longo, médio e curto prazos, de acordo com as características específicas de seus sistemas de potência (MACEIRA et al., 2016).

No caso do Brasil, o sistema de geração de energia elétrica apresenta uma alta participação de fontes renováveis de energia, que inclui hidrelétrica, biomassa e energia eólica e solar, respondendo por mais de $85 \%$ da capacidade instalada do Sistema Interligado Nacional (ONS, 2021a). É um sistema de grande porte com predominância hidroelétrica, caracterizado por grandes reservatórios apresentando capacidade de regularização plurianual, dispostos em cascatas complexas ao longo de várias bacias hidrográficas; é acoplado espacialmente, uma vez que a água liberada por uma usina hidrelétrica afeta as outras usinas a jusante.

Adicionalmente, os volumes limitados dos reservatórios mais a variabilidade das afluências futuras produzem um vínculo entre uma decisão operacional em um determinado estágio e as consequências futuras da decisão. Por exemplo, conforme ilustrado na Figura 6, se a decisão da operação for esgotar os estoques de energia hidrelétrica e ocorrerem baixos volumes de afluência, as hidrelétricas podem não ter água suficiente para atender a demanda no futuro. Como consequência, pode ser necessário usar uma geração térmica muito cara no futuro, ou até mesmo deixar de suprir a carga. Por outro lado, se os níveis dos reservatórios forem mantidos elevados por meio de um uso mais intensivo da geração térmica a custos mais elevados, e 
ocorrerem grandes volumes de afluência, as capacidades dos reservatórios podem ser excedidas e haverá vertimento no sistema, o que significa um desperdício de energia (TERRY et al., 1986).

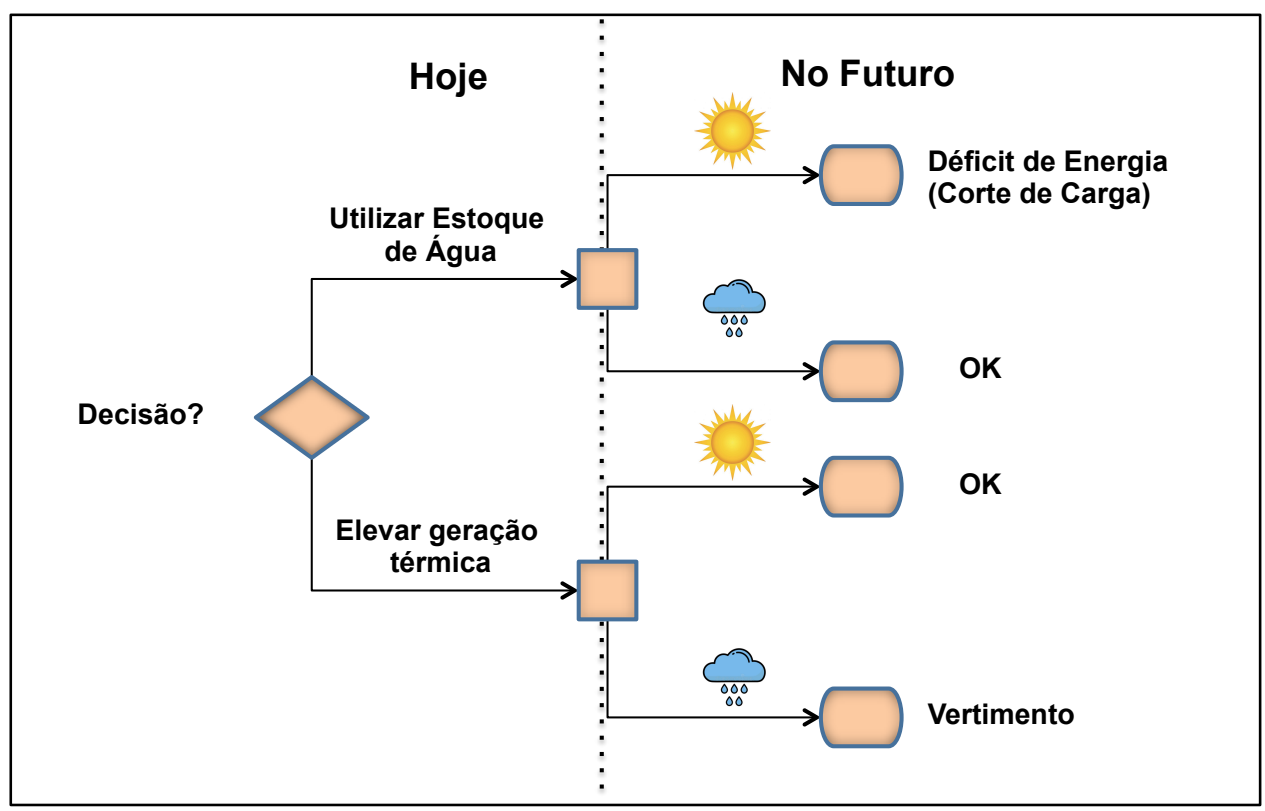

Fonte: Elaboração própria, com base em (TERRY et al., 1986)

Figura 6 - Processo de Tomada de Decisão Operativa e suas Possíveis Consequências

Por esses motivos, a coordenação do despacho das usinas hidroelétricas, térmicas e renováveis intermitentes abrange desde a otimização de longo prazo dos reservatórios plurianuais até o despacho de curto prazo horário.

Também, a operação do sistema interligado brasileiro baseia-se em um esquema centralizado de otimização, programação e despacho do sistema, realizado pelo Operador Nacional do Sistema do Sistema Elétrico (ONS), que também fornecem os custos marginais de operação, os quais formam a base de cômputo dos preços spot (PLDs), calculados pela Câmara de Comercialização de Energia Elétrica (CCEE). Como consequência, a tomada de decisão relacionada à expansão e ao planejamento da operação do sistema de energia elétrica é baseada em modelos matemáticos. Para tal, é empregada uma cadeia de modelos computacionais desenvolvida pelo CEPEL, também utilizada por órgãos governamentais, como o Ministério de Minas e Energia (MME), a Agência Nacional de Energia Elétrica (ANEEL) e a Empresa de Pesquisa Energética (EPE), além de concessionárias de energia elétrica e outros agentes (MACEIRA et al., 2002; MACEIRA et al., 2016). 
Além do cômputo do PLD, a CCEE possui, entre outras, a atribuição de realizar a contabilização dos montantes de energia elétrica comercializados no Sistema Interligado Nacional (SIN), bem como promover a liquidação financeira dos valores decorrentes das operações de compra e venda de energia elétrica no MCP, conforme estabelecido no inciso VI do Artigo $2^{\circ}$ do Decreto $n^{\circ} 5.177 / 2004$. Após a CCEE contabilizar as diferenças entre o que foi produzido (ou consumido) e o que foi contratado, estas diferenças (positivas ou negativas), apuradas para cada agente, são valoradas ao Preço de Liquidação das Diferenças (PLD).

Até 31 de dezembro de 2020, no sistema interligado nacional (SIN), os custos marginais de operação (CMOs), que formam a base dos preços de liquidação de diferenças (PLDs) eram calculados em intervalos semanais a partir do Programa Mensal de Operação (PMO), utilizando dois modelos integrados de otimização estocástica desenvolvidos pelo CEPEL para o planejamento da operação do sistema elétrico de longo/médio e curto prazos - os modelos NEWAVE (MACEIRA et al., 2008; MACEIRA et al., 2018) e DECOMP (DINIZ et al., 2018). Já a partir de $1^{0}$ de janeiro de 2020, o despacho por ordem de mérito passou a ser indicado dentro da Programação Diária da Operação, por meio do Modelo de Despacho Hidrotérmico de Curtíssimo Prazo - DESSEM (SANTOS et al., 2020) também desenvolvido pelo CEPEL e integrado aos dois modelos anteriores. Por fim, desde $1^{0}$ de janeiro de 2021, o PLD passou a ser horário, sendo calculado pelo modelo DESSEM.

O procedimento do emprego integrado desses modelos para o cálculo do PLD horário está ilustrada na Figura 7, e descrita de forma resumida a seguir (HELSETH \& MELO, 2020).

Inicialmente, o ONS elabora o Programa Mensal de Operação (PMO) ao final de cada mês, com base em: (i) informações atualizadas do cronograma de expansão da geração e transmissão, (ii) previsões de carga de energia por patamar, (iii) estado atual de armazenamento dos reservatórios e (iv) tendência hidrológica observada nos aproveitamentos hidroelétricos. O PMO é executado mensalmente, seguido de revisões semanais.

Com essas informações disponíveis, o ONS executa o modelo NEWAVE, que emprega, como já descrito, a técnica de programação dinâmica dual estocástica (PDDE), com horizonte de cinco anos e discretização mensal, obtendo a política de operação do sistema interligado nacional, representada pela função de custo futuro (FCF) de cada mês. Nesta etapa, a configuração hidrelétrica é atualmente representada 
por reservatórios equivalentes de energia, porém incluindo diversos aspectos relacionados à produtividade não linear das usinas hidroelétricas, e à operação das usinas individualizadas, como por exemplo as perdas em usinas a fio d'água. A aleatoriedade das afluências aos reservatórios é representada por uma árvore de cenários gerada pelo modelo GEVAZP (MACEIRA et al, 1999; PENNA et al., 2011) baseado em modelos auto-regressivos periódicos - PAR(p). Assim, já no primeiro mês da configuração, a incerteza das afluências é considerada por um grande número de cenários.

Em seguida, a cada semana do mês corrente, o modelo de planejamento da operação de curto prazo - modelo DECOMP (DINIZ et al., 2018), que emprega a técnica de programação dinâmica dual - PDD, é executado, com horizonte de dois meses. O primeiro mês é determinístico, discretizado em semanas e o segundo mês é estocástico e representado em base mensal. A FCF calculada no terceiro mês do horizonte de planejamento pelo modelo NEWAVE é acoplada ao final do segundo mês do modelo DECOMP, obtendo-se o despacho de operação do SIN (geração hidroelétrica, geração térmica, intercâmbios entre os subsistemas e custos marginais de operação para a semana operativa). Neste modelo, o parque hidroelétrico é representado individualmente, a aleatoriedade das vazões afluentes às usinas hidroelétricas (UHEs) no segundo mês é representada por um conjunto de cenários que reproduzem a distribuição de frequências condicionada ao único cenário de previsão de vazões semanais utilizado no primeiro mês.

Por fim, já no âmbito do Programa Diário da Operação, o modelo DESSEM (DINIZ et al., 2018; SANTOS et al., 2020), que possui horizonte de até 2 semanas, acopla-se no final do seu horizonte de tempo com a FCF fornecida pelo modelo DECOMP. O DESSEM permite o despacho e a obtenção do CMO - base do PLD em discretização temporal semi-horária, embora preço seja definido apenas em base horária. Além de funcionalidades já incluídas no DECOMP, outras podem ser citadas, tais como: modelagem do unit commitment das unidades geradoras térmicas, como tempo mínimos ligada/desligada, trajetórias de acionamento e desligamento, rampas máximas para tomada/alívio de carga, custo de partida e operação de unidades térmicas a ciclo combinado; modelagem $\mathrm{CC}$ da rede elétrica, incluindo restrições adicionais de segurança do sistema. 


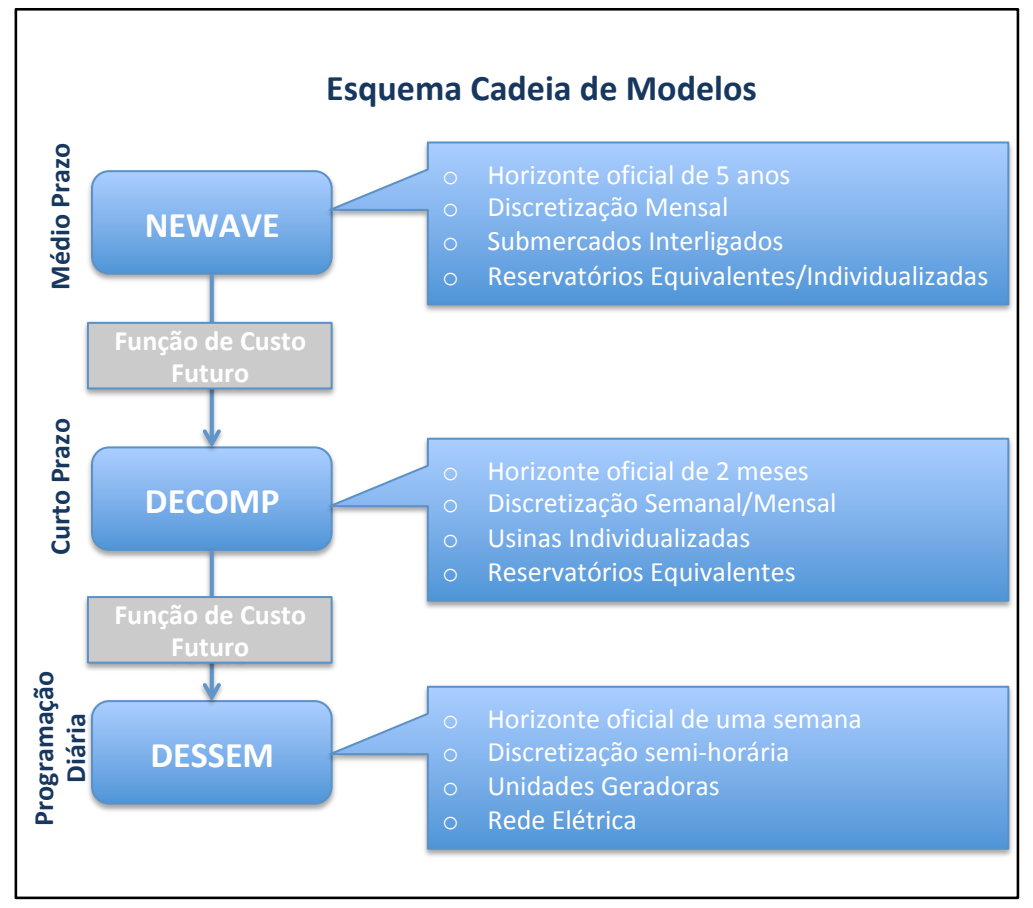

Fonte: Elaboração Própria

Figura 7 - Esquema da Cadeia de Modelos para o Planejamento da Operação

Dado o processo supracitado relativo à formação do $\mathrm{CMO}$, percebe-se a complexidade para obtenção deste parâmetro e a sensibilidade do CMO em relação a diversos fatores. Tendo em vista que o PLD é apurado a partir do CMO e aquele se mostra como uma variável que impacta diretamente os indicadores econômicos de um empreendimento de produção de energia (BATISTA et al., 2016), é de suma importância que se utilize um conjunto de cenários desta variável de modo a permitir diversas realizações do PLD. Como o PLD é um parâmetro de risco nas análises de empreendimentos de produção de energia, esta dissertação considerará este parâmetro nas análises que serão apresentadas e utilizará a cadeia de modelos oficiais do Setor Elétrico Brasileiro (SEB), apresentada neste capítulo, para projetar cenários relativos a este parâmetro.

\section{3}

\section{Contratação de Energia Eólica e Solar Fotovoltaica no Mercado Brasileiro}

No começo da década de 90 o governo brasileiro fez um grande esforço no sentido de reestruturar o setor elétrico brasileiro (SEB). Entre outras razões, isto foi 
motivado pela falta de capacidade do governo de financiar os investimentos necessários para a sua expansão. Entretanto, tais investimentos não aconteceram como o esperado, o que culminou no racionamento de energia de 2001/2002.

Como consequência, um novo modelo setorial foi estabelecido com o objetivo de promover modicidade tarifária e segurança de suprimento. Tal modelo também criou dois ambientes para a comercialização de energia elétrica: o ambiente de contratação regulado (ACR) e o ambiente de contratação livre (ACL). No ACL cada gerador tem liberdade para negociar os termos do contrato de fornecimento de energia com os seus consumidores. Por outro lado, no ACR foram implementados leilões de energia para a contratação dos consumidores cativos, sendo que neste ambiente as condições contratuais são reguladas pela Agência Nacional de Energia Elétrica (ANEEL), definidas de acordo com as particularidades de cada fonte de geração. Adicionalmente, a energia produzida e que não se encontra negociada via contratos bilaterais, pode ser negociada no mercado à vista de energia, também chamado de mercado de curto prazo.

Conforme já mencionado nesta dissertação, no atual ciclo de planejamento do setor elétrico brasileiro observa-se uma forte perspectiva de crescimento das fontes eólica e solar fotovoltaica. A viabilização econômica e financeira destes empreendimentos no mercado brasileiro, pelo caráter intermitente da sua geração, trouxe a necessidade de se estabelecer um conjunto de regras de comercialização para o mercado regulado com o intuito de atender aos seguintes objetivos: (i) comprometer o agente gerador a contratar apenas a sua produção efetiva e (ii) minimizar o custo da energia através da mitigação da incerteza sobre a receita do empreendimento. Desta forma, até 2017 , as regras vigentes determinaram que a contabilização dos contratos de venda de energia elétrica daquelas fontes fosse subdividida em períodos quadrienais, prevendo faixas de tolerância para a produção anual e quadrienal, e penalizando a produção fora de tais faixas.

De acordo com a Lei $n^{\circ} 10.848 / 2004$, no ACR, a contratação de energia elétrica no Brasil pode ser feita tanto pela modalidade de quantidade (QEE) quanto pela modalidade de disponibilidade de energia elétrica (DEE). Na primeira modalidade, o vendedor do contrato assume os riscos hidrológicos e os custos variáveis de produção, enquanto na segunda, esses riscos são assumidos pelo 
comprador do contrato. Inicialmente, a contratação do parque eólico e solar fotovoltaico seguiu a modalidade DEE, entretanto, desde 2018 a geração de ambas as tecnologias tem sido contratada na modalidade QEE.

Conforme o edital do $33^{\circ}$ e $34^{\circ}$ Leilões de Energia Nova (ANEEL, 2021), ao celebrar um contrato do tipo QEE para a venda de um determinado montante de energia no ambiente regulado (energia contratada), os geradores eólicos e solares fotovoltaicos se submeterão às seguintes obrigações (BATISTA et al., 2019):

- Entregar a energia elétrica contratada considerando a base mensal como referência;

- Sempre que a sua geração mensal for superior o montante contratado sazonalizado $^{7}$, a geração excedente será liquidada ao PLD no mercado de curto prazo;

○ Sempre que a sua geração mensal for inferior ao montante contratado sazonalizado, o gerador deverá adquirir o montante de energia faltante no mercado de curto prazo, ao PLD do subsistema em que a usina está localizada;

- A sazonalização mensal da energia contratada ocorrerá conforme o perfil de carga do agente comprador, ou seja, da distribuidora.

Em resumo, a verificação do atendimento à obrigação contratual se dá mensalmente, com eventuais sobras/déficits sendo liquidados ao PLD.

Com a adoção do preço horário no mercado brasileiro, e considerando que esta dissertação se propõe a analisar a viabilidade de empreendimentos de geração por meio de grandezas projetadas em base horária, a modulação dos contratos de energia ganha especial relevância para o cálculo dos fluxos de caixa do projeto avaliado.

Entende-se por modulação de um contrato a discretização de montantes mensais de energia contratada por período de comercialização, neste caso, por hora. Até 2019, os CCEARs ${ }^{8}$ de empreendimentos eólicos e solares fotovoltaicos determinavam que a sua modulação deveria seguir a geração da usina. Em 2021 o texto dos CCEARs passou a determinar que a modulação deve ser feita com base na

\footnotetext{
${ }^{7}$ Contrato Sazonalidado: Permite-se que os montantes de um contrato possa ser distribuído ao longo dos 12 meses do ano por meio de fatores que deve resultar em $100 \%$ ao considerar todo o ano.

${ }^{8}$ CCEAR: Contrato de Comercialização de Energia no Ambiente Regulado
} 
Carga Cativa do comprador, ou seja, a sua carga total no centro de gravidade do SIN. Esta dissertação considera em suas análises a modulação dos contratos regulados em função do perfil de geração da usina.

Sendo assim, o valor da energia contratada sazonalizada para o mês $m$, modulada para a hora $h\left(\mathrm{C}_{\mathrm{m}, \mathrm{h}}\right)$, é calculado através da Equação 1:

$$
C_{m, h}=C_{m} \times \frac{G_{m, h}}{\overline{G_{m}}}
$$

onde:

$\mathrm{C}_{\mathrm{m}}$ : corresponde ao valor da energia contratada sazonalizada para o mês $m$;

$\mathrm{G}_{\mathrm{m}, \mathrm{h}}$ : corresponde à geração do empreendimento no mês $m$ e hora $h$;

$\overline{G_{m}}$ : corresponde à média da geração horária no mês $m$;

A exposição da usina ao mercado de curto prazo, em cada hora do mês, é calculada pela Equação 2:

$$
\text { Exposição }=\left(\mathrm{G}_{m, h}-C_{m, h}\right) * P L D_{h}
$$

onde:

$G_{h, m} \quad$ : Corresponde à geração na hora $h$ do mês $m$;

$P L D_{h} \quad$ : Corresponde ao PLD na hora $h$;

\section{4}

\section{Regras de Contratação do MUST}

De acordo com a Resolução Normativa ANEEL No 666, de 23 de junho de 2015, o Montante do Uso do Sistema de Transmissão (MUST) contratado por uma central de geração deverá ter valor mínimo igual à sua potência instalada subtraída da mínima carga própria. Assim, ao considerar um arranjo híbrido composto por uma usina eólica e uma usina solar fotovoltaica, mesmo que os seus perfis de geração sejam fortemente complementares, haverá a necessidade de contratação do MUST igual à soma das potências das duas usinas. 
A regra atual de contratação do MUST pode se mostrar excessivamente conservadora para os empreendimentos híbridos, prejudicando a sua viabilidade econômica e a lucratividade do empreendimento. Para avaliar esta e outras questões relacionadas ao desenvolvimento de usinas híbridas, a Consulta Pública 014/2019 da ANEEL teve por objetivo obter subsídios para a elaboração de uma proposta de Resolução Normativa que discipline a implantação e operação deste tipo de usina. Adicionalmente, a Consulta Pública 061/2020 da ANEEL foi lançada com o objetivo de obter subsídios para a Análise de Impacto Regulatório acerca do tratamento regulatório para o estabelecimento de usinas híbridas e associadas.

No contexto da Consulta Pública 061/2020, a Minuta em anexo à Nota Técnica $\mathrm{N}^{\mathrm{o}}$ 079/2020-SRG-SRT-SCG/ANEEL propõe alterações em diversas legislações, entre elas estão a alteração na Resolução Normativa ANEEL 583/2013 que propõe que a faixa de potência injetável de uma usina híbrida esteja compreendida entre o valor da potência nominal da fonte de maior participação na usina híbrida e a soma das potências nominais de todas as unidades geradoras da usina híbrida. Tendo em vista esta proposta, esta dissertação mostrará resultados para um estudo de caso a contratação de diferentes valores do MUST.

Cabe ressaltar que este tema está presente na Agenda Regulatória ${ }^{9}$ 2020-2021 da ANEEL e, consequentemente, será objeto de regulamentação ou estudo.

\section{5}

\section{Ganhos de Escala com Investimentos e O\&M em Projetos Híbridos}

Uma possível redução na contratação do MUST de empreendimentos híbridos, citada na seção 3.4, pode gerar economia tanto na sua construção quanto na sua operação. Para a compreensão adequada deste tema, foram ouvidos especialistas da Companhia Hidrelétrica do Rio São Francisco - CHESF, a qual é desenvolvedora de projetos eólicos e solares fotovoltaicos no nordeste brasileiro. Segundo estes especialistas, o investimento em empreendimentos desta natureza usualmente se divide em:

\footnotetext{
${ }^{9}$ Agenda Regulatória (ANEEL): apresenta a relação das atividades regulatórias que serão objeto de regulamentação ou estudo nesse ciclo. Para cada atividade é apresentado seu cronograma, prioridade e responsáveis pelo processo.
} 
(i) máquinas e equipamentos (turbinas eólicas e aos painéis solares), representando aproximadamente $75 \%$ das necessidades de investimento;

(ii) obras civis, representando aproximadamente $17,50 \%$ das necessidades de investimento;

(iii) infraestrutura elétrica (linhas de transmissão e transformadores), representando aproximadamente $7,50 \%$ das necessidades de investimento.

Para as usinas híbridas, com a possibilidade de se contratar MUSTs menores, as necessidades de investimento em infraestrutura elétrica poderiam ser reduzidas em aproximadamente $20 \%$, a depender da complementaridade observada entre as fontes de geração e da possibilidade de redução no MUST contratado. Consequentemente, as despesas com operação e manutenção também seriam reduzidas ${ }^{10}$.

Tendo em vista o exposto nesta seção, neste trabalho serão apresentadas análises de sensibilidade da viabilidade econômica de um projeto híbrido tendo em vista a contratação de diferentes valores do MUST, cujo valor impacta nas necessidades de investimento e nos gastos com operação e manutenção da usina. Estas análises se encontram detalhadamente descritas no capítulo 7 (Aplicação da Abordagem Metodológica Desenvolvida).

\section{6}

\section{Cálculo da Garantia Física em Empreendimentos Eólicos e Solares Fotovoltaicos}

A Garantia Física de empreendimentos eólicos e solares fotovoltaicos foi normatizado pela Portaria 101 do Ministério de Minas e Energia (MME), de 22 de março de 2016. Esta portaria determina que o cálculo da garantia física de uma usina eólica seja realizado com base no percentil 90\% (P90) da produção anual de energia certificada $^{11}$, excluídas as indisponibilidades forçadas, as indisponibilidades

\footnotetext{
10 Essas informações foram obtidas com profissionais da empresa Companhia Hidrelétrica do São Francisco (CHESF), que possuem experiência no desenvolvimento de projetos solares e eólicos.

${ }^{11}$ A produção anual de energia certificada, em MWh, referente ao valor de energia anual com uma probabilidade de ocorrência igual ou maior a noventa por cento, constante da Certificação de Medições Anemométricas e de Produção Anual de Energia
} 
programadas, o consumo interno e as perdas elétricas, conforme a Equação 3. Já a garantia física de uma usina solar fotovoltaica é calculada de forma análoga com base no percentil 50\% (P50) da produção anual de energia certificada.

$$
G F_{\text {eólica }}=\frac{\left[P 90_{a c} *(1-T E I F) *(1-I P)-\Delta P\right]}{8760}
$$

onde:

$G F_{\text {eólica }}$ : Garantia Física de Energia de usinas Eólicas, em MW médio;

$P 90_{a c}$ : produção anual de energia certificada, em MWh, referente ao valor de energia anual com uma probabilidade de ocorrência igual ou maior a noventa por cento, constante da Certificação de Medições Anemométricas e de Produção Anual de Energia

TEIF : Taxa equivalente de indisponibilidade forçada, por unidade (pu);

IP $\quad$ : Indisponibilidade Programada, por unidade (pu);

$\Delta P \quad$ : estimativa anual do consumo interno e perdas elétricas até o $\mathrm{PMI}^{12}$, em MWh;

8760 : número de horas por ano.

A Consulta Pública 061/2020 recebeu diversas sugestões para o cálculo de Garantia Física de usinas híbridas. Entretanto, o resultado desta Consulta Pública não apresentou uma proposta oficial para este cálculo. A presente dissertação adotou como Garantia Física, para o empreendimento eólica e solar fotovoltaico, o valor médio da geração em relação à série histórica de produção de energia. Para obtenção da Garantia Física para o arranjo híbrido, somou-se os valores dos empreendimentos individuais.

\footnotetext{
${ }^{12}$ PMI: Ponto de medição da usina, referente ao primeiro ponto do sistema de interesse restrito onde é possível identificar, de forma individualizada, a geração e o consumo interno de uma usina.
} 


\section{4 \\ Abordagem Metodológica}

Para atingir o objetivo desta dissertação será realizada uma análise de risco acerca da viabilidade econômica de um empreendimento formado por uma planta de geração eólica e uma planta solar fotovoltaica, formando o que se denomina "arranjo híbrido" ou "usina híbrida".

É possível citar diversos fatores de risco que podem ser levados em consideração durante a análise de empreendimentos de geração de energia elétrica. $\mathrm{Na}$ presente dissertação, seguindo o entendimento de diversos trabalhos que avaliam empreendimentos desta natureza, como BATISTA et al. (2016), MELO et al. (2018), ZAMBELLI et al. (2019) e CAMPOS (2020), serão considerados como principais fatores de risco a incerteza sobre a geração de energia pelo empreendimento e a incerteza sobre o preço da energia no Mercado de Curto Prazo, ou seja, sobre o Preço de Liquidação das Diferenças - PLD.

A avaliação aqui mencionada será realizada em duas bases temporais: mensal e horária. Análises de viabilidade em base mensal ou anual são amplamente encontradas na literatura de finanças, como BATISTA et al. (2019) e a AGRAWAL et al. (2017). Neste trabalho, a análise em base horária também se justifica tendo em vista que, no Brasil, desde janeiro de 2021, a liquidação da energia negociada no Mercado de Curto Prazo é feita com base em um preço (PLD) horário, conforme estabelecido na Portaria $N^{\circ}$ 301, de 31 de Julho de 2019 do MME. Adicionalmente, a análise em base horária permite que o impacto da intermitência, por exemplo, a presente na geração de energia proveniente das fontes eólica e solar, seja capturado. Além disso, a depender da região analisada, é possível identificar a complementaridade entre fontes durante as 24 horas de um dia. Este fenômeno é capturado apenas em uma análise em base horária.

Em resumo, este capítulo apresenta uma visão geral da abordagem metodológica empregada para a análise de empreendimentos híbridos nas bases temporais mensal e horária. Tais análises compreenderam as seguintes etapas:

(i) especificação das premissas técnicas, econômicas e financeiras do projeto; 
(ii) geração de cenários de preço e de produção energética do empreendimento em base mensal;

(iii) determinação de fatores de desagregação dos cenários de produção e de preço para a base horária;

(iv) obtenção de cenários de produção e de preço em base horária;

(v) construção dos fluxos de caixa do empreendimento, condicionados aos cenários gerados;

(vi) cálculo dos indicadores de viabilidade econômica do projeto - determinísticos e probabilísticos.

Cabe mencionar que, após a visão geral fornecida neste capítulo, cada uma destas etapas será detalhadamente descrita nos capítulos subsequentes desta dissertação.

\section{1}

\section{Premissas Técnicas, Econômicas e Financeiras}

Com o objetivo de realizar uma avaliação econômico-financeira de um empreendimento híbrido formado por uma usina eólica e uma usina solar fotovoltaica, optou-se por se definir as premissas técnicas, econômicas e financeiras do estudo de caso considerando o desenvolvimento, em separado, de uma usina eólica e uma usina solar fotovoltaica. Isto foi feito para que seja possível aferir o impacto de eventuais economias de escala, na construção e na operação do empreendimento, ao se desenvolver um projeto híbrido.

Para a definição destas premissas, foram utilizadas informações publicadas em trabalhos científicos, disponibilizadas por instituições como o Banco Nacional do Desenvolvimento Econômico e Social (BNDES) e o Operador Nacional do Sistema Elétrico (ONS), acessíveis em documentos oficiais relativos ao planejamento da expansão do parque gerador brasileiro, como o Plano Decenal de Expansão de Energia 2029 (PDE 2029) e o Plano Nacional de Energia 2050 (PNE 2050); e por informações obtidas junto a empresas do Setor Elétrico Brasileiro (SEB) desenvolvedoras de projetos eólicos e solares.

No caso das premissas relativas ao arranjo híbrido, não se encontrou na literatura detalhes técnicos relativos às economias de escala e sinergias obtidas ao se 
avaliar empreendimentos de usinas híbridas compostas por uma parcela eólica e uma parcela solar. Desta forma, recorreu-se a profissionais da empresa Companhia Hidrelétrica do São Francisco (CHESF), que possuem experiência no desenvolvimento de projetos solares e eólicos.

As premissas do estudo de caso se encontram detalhadamente descritas no capítulo 7 (Aplicação da Abordagem Metodológica Desenvolvida).

\section{2}

\section{Definição de Cenários de Geração de Energia Elétrica}

Como forma de representar as possíveis realizações associadas à geração do empreendimento híbrido, 2.000 cenários sintéticos de produção de energia, em base mensal, serão gerados para cada uma das tecnologias, eólica e solar fotovoltaica.

A geração destes cenários foi realizada utilizando a metodologia BOX \& JENKINS (BOX e JENKINS, 1970), mais precisamente o modelo SARIMA, conforme será detalhado no capítulo 5 (Geração de Cenários de Produção de Energia Eólica). Para ajuste do modelo de séries temporais, utilizou-se dados de reanálise obtidos através de um conjunto de dados da NASA Modern-Era Retrospective Analysis for Research and Applications (MERRA-2) ${ }^{13}$. Estes dados foram coletados para a região em análise nesta dissertação, o município de Icapuí, no estado do Ceará.

Para a obtenção dos cenários de produção em base horária, a estratégia adotada foi a desagregação dos correspondentes cenários mensais, processo este denominado nesta dissertação de Desagregação Horária. Para tanto, foram aplicados Fatores de Desagregação Horários sobre as séries mensais.

Tais Fatores de Desagregação foram obtidos por meio da realização de uma análise exploratória dos dados da série de reanálise ("série histórica"), originalmente obtidos em base horária. O cálculo dos Fatores de Desagregação também se encontra detalhado no capítulo 5 .

${ }^{13}$ https://gmao.gsfc.nasa.gov/reanalysis/MERRA/ 


\section{3}

\section{Cenários de PLD}

De forma a gerar cenários sintéticos de PLD, inicialmente em base mensal, executou-se o modelo NEWAVE (MACEIRA et al., 2008: MACEIRA et al., 2018) com os dados do Plano Decenal de Expansão de Energia 2020-2029 (PDE 2029). Cabe destacar que o PDE 2029 abrange na realidade um horizonte de planejamento igual a 15 anos (2019-2033), embora apenas os 10 primeiros anos sejam utilizados para compor o plano indicativo. Para que fosse possível obter projeções de PLD para um horizonte de 21 anos a partir de 2021 (período de projeção dos fluxos de caixa do projeto avaliado), adotou-se como premissa a replicação dos dados do $15^{\circ}$ ano (2033) até 2047.

Para a obtenção dos cenários de preço em base horária, a estratégia adotada foi a mesma descrita para os cenários sintéticos de produção de eletricidade, i.e., a desagregação dos cenários mensais de preço por meio da aplicação de Fatores de Desagregação Horários sobre as séries mensais.

Tais Fatores de Desagregação também foram obtidos através de uma análise exploratória dos dados históricos de preço horário, disponibilizados pela CCEE. O cálculo dos Fatores de Desagregação do preço se encontra detalhado no capítulo 6 (Geração de Cenários para o Preço da Energia Elétrica no Mercado de Curto Prazo).

\section{4}

\section{Análises Econômico-Financeiras}

Para realizar as análises econômicas foi utilizada a versão 5.4.2 do modelo ANAFIN (BATISTA et al., 2016, MELO et al., 2018, BATISTA et al., 2012, MELO et al., 1998), adaptado para considerar a abordagem metodológica desenvolvida nesta dissertação. Este modelo é desenvolvido pelo CEPEL com a finalidade de determinar a viabilidade econômico-financeira e de risco de empreendimentos de geração e transmissão de energia elétrica.

O modelo ANAFIN permite que a viabilidade econômica de um projeto de geração de energia elétrica seja analisada sob a ótica determinística, na qual apenas um único cenário de fluxo de caixa é considerado, e/ou sob a ótica probabilística, 
também chamada de análise de risco, na qual diferentes cenários de fluxo de caixa são considerados em função da realização das incertezas consideradas.

Neste trabalho, o enfoque principal é na realização de análises de risco acerca da viabilidade do empreendimento híbrido. Assim, a partir das distribuições de frequências de indicadores de viabilidade do projeto, tais como o Valor Presente Líquido (VPL) e da Taxa Interna de Retorno (TIR), são obtidas estatísticas como a média, mediana, desvio padrão, valores mínimo e máximo, além do valor em risco VaR e valor condicional em risco - CVaR (JORION, 1999).

O modelo ANAFIN pertence à cadeia de modelos energéticos desenvolvida pelo CEPEL para o planejamento da Expansão e da Operação Energética de sistemas elétricos (Figura 8). O modelo ANAFIN é integrado aos modelos NEWAVE e SUISHI (MACEIRA et al, 2018b), o que o permite receber cenários de Custos Marginais de Operação e de produção de energia, em base mensal, para a realização de análises probabilísticas. A integração do ANAFIN aos modelos da cadeia energética também é apresentada na Figura 8, e o ANAFIN está identificado por uma elipse pontilhada.

Cabe destacar que o modelo ANAFIN é desenvolvido à luz da legislação vigente no setor elétrico brasileiro, tanto comercial quanto tributária, considerando, detalhadamente, todas as parcelas do fluxo de caixa de um projeto de geração desenvolvido no Brasil.

Nas análises de risco realizadas neste trabalho, considerou-se 2.000 cenários fluxos de caixa, obtidos a partir de 2.000 cenários gerados para cada fator de risco, ou seja, produção de energia e preço. Para tanto, utiliza-se o método de simulação Monte Carlo (SMC) para construir um cenário de fluxo de caixa, sorteando-se 1 entre os 2.000 cenários sintéticos de produção, e 1 entre os 2.000 cenários sintéticos de preço. A Figura 9 ilustra este processo.

Note que isto implica em considerar que as séries de produção de energia eólica e solar são estatisticamente independentes das séries de preço. Esta hipótese é razoável porque, dado o porte do SIN, a produção de energia pelo projeto eólico, solar ou híbrido pode ser considerada como marginal, i.e., não impacta o preço do submercado onde o projeto está localizado. 


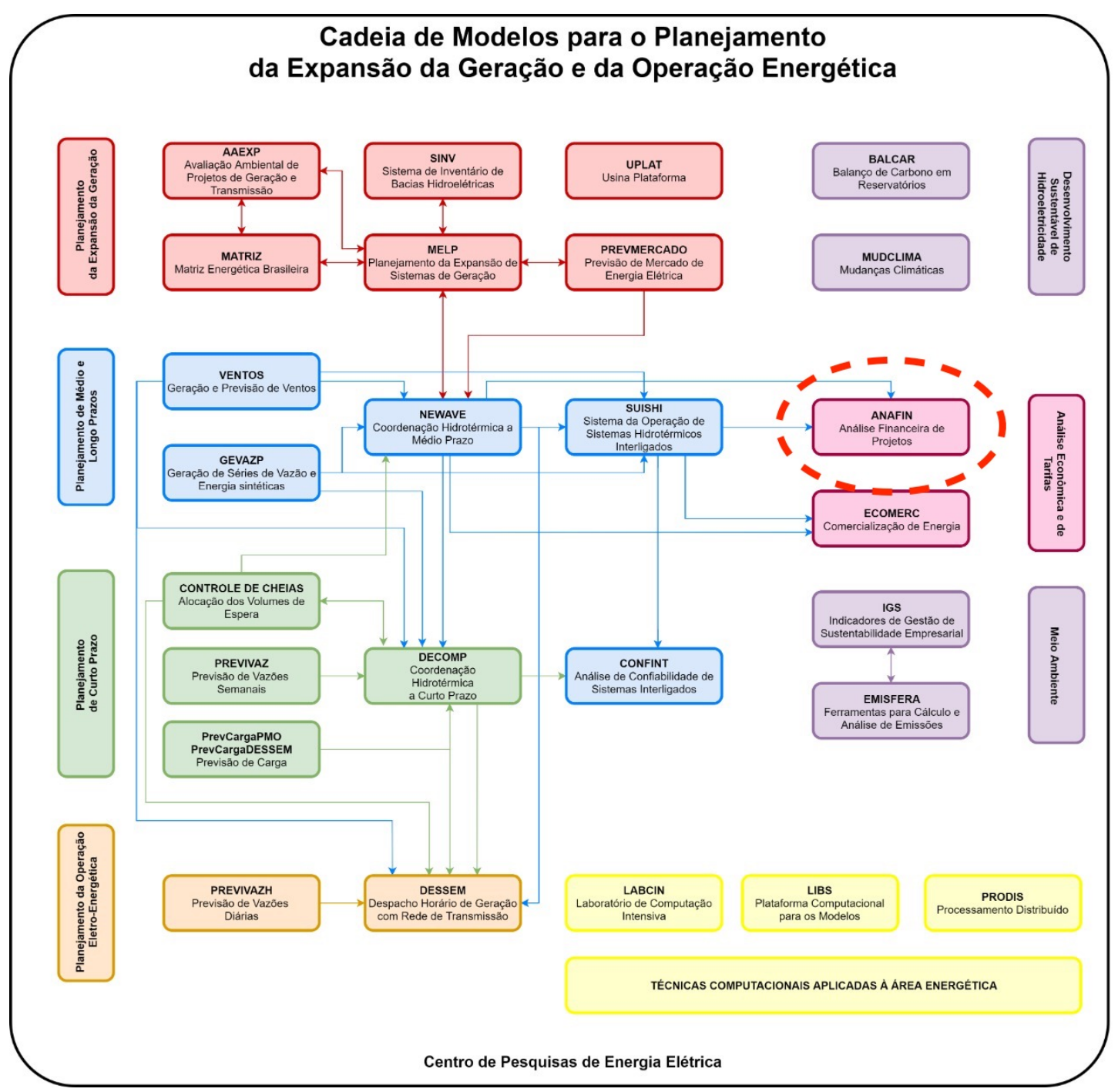

Fonte: CEPEL (adaptado)

Figura 8 - Cadeia de Modelos para o Planejamento da Expansão e da Operação Energética de Sistemas Elétricos

N-ésimo Cenário da Análise Probabilística
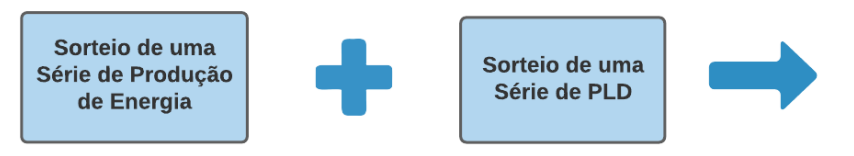

Par

(Série de Produção de Energia / Série de PLD) para Análise Probabilística

Fonte: Elaboração Própria

Figura 9 - Exemplificação de Sorteio em cada Cenário da Análise Probabilística

Como se está utilizando um processo de simulação estocástica (SMC), é recomendável a adoção de um critério de parada, em adição ao número máximo de simulações, que reflita a precisão das estimativas ao longo dos sorteios realizados. 
Esta dissertação utilizou como critério o coeficiente de variação do estimador da média amostral do VPL. Aplicação deste critério em outras áreas sugerem que esta medida de dispersão se estabilize em valores abaixo de 5\% ou 1\% (MELO et al., 1992).

Finalmente, cabe destacar que a versão 5.4.2 do modelo ANAFIN teve que ser adaptada para que as análises em base horária pudessem ser realizadas.

\section{5}

\section{Análise dos Resultados}

Os resultados das análises econômicas foram analisados sob as seguintes óticas:

○ Discretização mensal e horária - de forma a se mensurar os eventuais ganhos, em uma análise econômica de projetos de geração, com a utilização da base horária, a qual passou a ser utilizada para a determinação do PLD no Brasil;

- Tecnologias de geração individuais e arranjo híbrido - de forma a avaliar o ganho de se implementar um projeto híbrido em comparação aos arranjos individuais; além de verificar os ganhos de escala nos investimentos e nos custos operacionais;

- Intensidade do curtailment - através da realização de uma análise de sensibilidade, avalia-se a possibilidade de se contratar diferentes valores para o Montante de Uso do Sistema de Transmissão (MUST), que por sua vez reduz investimentos e custos, porém não garante que toda a energia produzida poderá ser escoada, levando ao curtailment.

A Figura 10 traz um resumo da abordagem metodológica proposta nesta dissertação. 


\section{Fluxograma da Abordagem Metodológica}
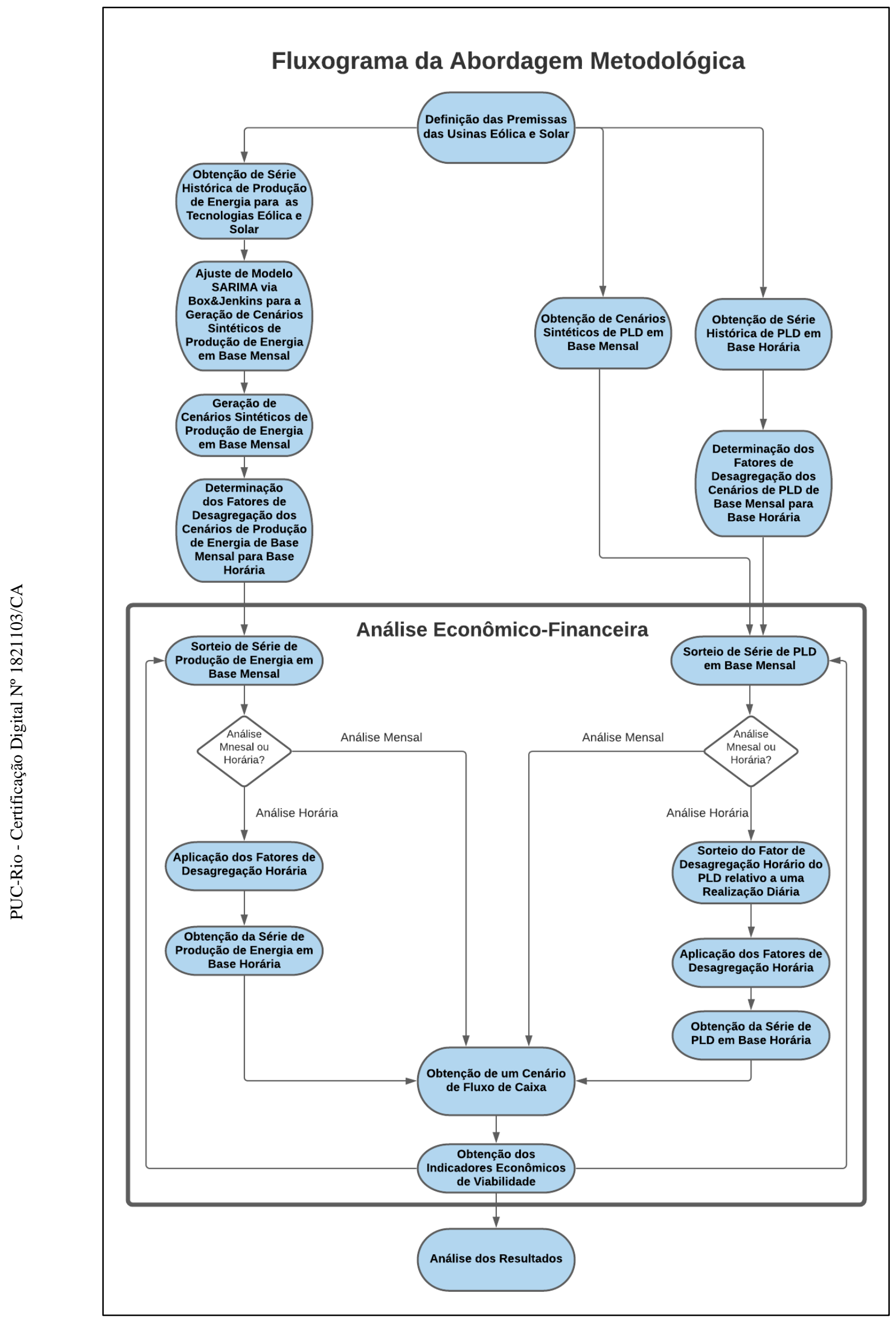

Fonte: Elaboração Própria

Figura 10 - Fluxograma da Abordagem Metodológica Proposta - Etapas da Dissertação 


\section{5 \\ Geração de Cenários de Produção de Energia Eólica e Solar}

Conforme descrito no capítulo 4, um dos fatores de risco considerados nesta dissertação, para a análise econômica de usinas híbridas, é a incerteza associada à sua produção de energia elétrica. O objetivo deste capítulo é apresentar o procedimento desenvolvido para a obtenção dos cenários sintéticos de produção de energia para as tecnologias aqui analisadas, ou seja, as tecnologias eólica e solar fotovoltaica, tanto separadamente quanto em um arranjo híbrido que combine estas duas tecnologias.

Inicialmente será abordado o conceito de séries temporais, fundamental para geração de cenários. Em seguida, será apresentada a série temporal, denominada de série "histórica", que será a base para a geração de cenários sintéticos e como esta série foi obtida. Logo após, será discutido como ajustar um modelo para gerar cenários de produção de energia, por meio da metodologia BOX \& JENKINS. Posteriormente, como verificar se os valores sintéticos obtidos estão aderentes aos da série histórica, por meio de análise exploratória de dados. Por fim, será expressa a metodologia para se obter os valores de produção de energia em base horária.

\section{1}

\section{Séries Temporais}

Um processo estocástico pode ser entendido como um modelo que descreve a estrutura de probabilidade de uma sequência de observações ao longo do tempo. Por sua vez, uma série temporal é uma realização amostral do processo estocástico, i.e., é uma amostra finita do conjunto de todas as trajetórias possíveis que podem ser geradas pelo processo estocástico (BOX e JENKINS, 1970). Assim, uma série temporal pode ser caracterizada como um conjunto de observações de uma determinada variável, medidas sequencialmente no tempo, e.g., em horas, dias, meses ou anos (MORETTIN e TOLOI, 2006). 
O problema tratado neste capítulo é, dada uma série temporal produção de energia elétrica (aqui denominada de série observada ou histórica), identificar o processo estocástico gerador da série e, a partir dele, elaborar cenários sintéticos. Uma solução para este problema pode ser dada pela modelagem proposta por BOX e JENKINS (1970), onde uma família de modelos podem ser ajustada, de acordo com as características da série temporal sob estudo.

\section{2}

\section{Série "Histórica"}

Uma questão importante no desenvolvimento e testes de metodologias que considerem a incerteza na produção de energia por fontes eólicas e solares diz respeito à disponibilização de dados verificados (medidos). Por exemplo, no caso da tecnologia eólica, idealmente seria relevante que se tivesse acesso às séries horárias consistidas e pareadas de velocidades de ventos e produções eólicas, para todos os parques existentes, ou pelo menos para aqueles vencedores nos leilões públicos de compra de energia elétrica (MACEIRA et al., 2020). No entanto, como não está disponível no Brasil uma base de dados com séries horárias consistidas e pareadas de velocidades de ventos e produções eólicas, tornou-se necessária a utilização de dados oriundos de reanálises.

Assim, os valores utilizados como série "histórica" para a geração de cenários sintéticos das tecnologias eólica e solar fotovoltaica foram obtidos através do sistema Renewables Ninja ${ }^{14}$, que disponibiliza dados de potência a partir de dados climáticos de reanálise. Trata-se de dados meteorológicos de modelos de reanálise global e de observações de satélite. Os dados são oriundos do conjunto de dados da NASA Modern-Era Retrospective Analysis for Research and Applications, Version 2 (MERRA-2) ${ }^{15}$.

Os dados de irradiância solar são convertidos em potência utilizando o modelo Global Solar Energy Estimator (GSEE), (PFENNINGER, 2016). Já os dados de velocidade de vento são convertidos em potência através do modelo Virtual Wind

\footnotetext{
${ }^{14}$ Sistema Renewables Ninja pode ser acessado pelo sítio: renewables.ninja

${ }^{15}$ Mais informações sobre o MERRA em https:/gmao.gsfc.nasa.gov/reanalysis/MERRA/
} 
Farm (VWF), (STAFFELL, 2016). Todos estes dados são exibidos pelo sistema Renewables Ninja.

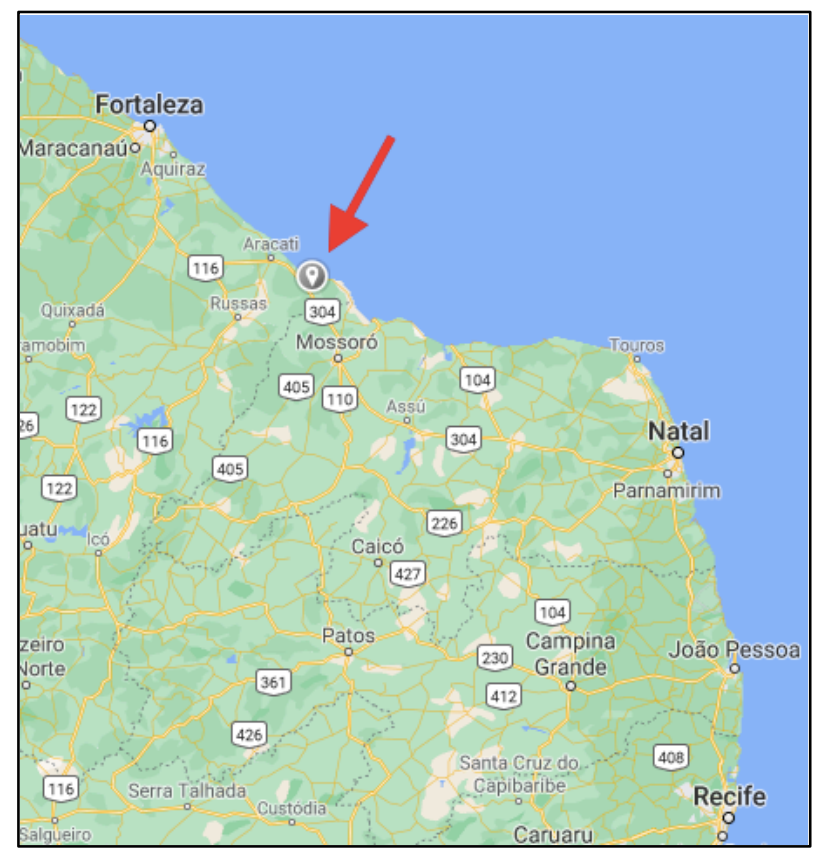

Figura 11 - Localidade Escolhida para Obtenção dos Dados de Reanálise: Icapuí/CE

Os valores da série de dados de reanálise foram obtidos para o município de Icapuí, no estado do Ceará (Figura 11), que possui coordenadas geográficas latitude e longitude iguais a $-4,661^{\circ}$ e $-37,505^{\circ}$, respectivamente. Para esta dissertação, buscouse uma localidade que apresentasse alguma complementaridade intra-diária entre as tecnologias de geração de modo a obter sinergias operativas.

O sistema Renewables Ninja disponibiliza dados de produção de energia para o período de 1980 a 2019 para as tecnologias eólica e solar fotovoltaica. Desta forma, foram coletados estes 40 anos disponíveis, formando a série temporal estudada e utilizada nesta dissertação.

Uma opção seria coletar os dados primários, ou seja, relativos às variáveis naturais (velocidade de vento e irradiância solar), e utilizá-los para a geração de cenários sintéticos dos mesmos, os quais seriam posteriormente transformados em cenários de geração de energia elétrica. Para o caso da velocidade do vento, tem-se uma relação não linear entre a velocidade de vento e a produção de potência de energia, dada pela Equação 4. Através desta equação, a conversão de energia eólica em energia elétrica ocorre a partir da velocidade de partida, também chamada de velocidade de cut-in. Caso a velocidade do vento esteja abaixo da velocidade de cut- 
in, a potência é nula. Para velocidades de vento superiores a cut-in e inferiores à velocidade de corte (cut-out), a velocidade é convertida em potência de acordo com a Equação 4. Caso a velocidade do vento atinja velocidades superiores a cut-out, a operação da turbina é interrompida com a finalidade de preservá-la de excessivos esforços mecânicos. Consequentemente, a potência associada a velocidades superiores a velocidade de cut-out é nula.

$$
P=\frac{1}{2} \cdot \rho \cdot v^{3} \cdot A \cdot \eta \cdot C_{P}
$$

onde:

P: Produção (potência) de Energia Elétrica

$\rho$ : densidade do ar

$v$ : velocidade do vento

A: Área varrida pelas pás do rotor do aerogerador

$\eta$ : Eficiências mecânicas e elétricas do sistema

$C_{P}$ : Coeficiente de desempenho aerodinâmico

A abordagem de se utilizar dados de velocidade de vento para a geração de cenários sintéticos tem como vantagem de se obter uma série temporal de produção de energia a partir de uma série temporal que representa o processo estocástico original associado.

Por outro lado, esta dissertação envolve não apenas discretização horária, mas também mensal; e a Equação 4 é utilizada somente para valores horários. Assim, caso fosse realizada a geração de cenários sintéticos de velocidades mensais dos ventos, seria necessário construir uma Função de Transferência Mensal para se obter as produções de energia em base mensal, como realizado em MACEIRA (2020) para a incorporação das incertezas relacionadas à velocidade dos ventos no modelo NEWAVE. No entanto, a construção de uma Função de Transferência Mensal está fora do escopo desta dissertação.

Desta forma, optou-se por utilizar a própria série histórica de produção de energia para geração de cenários sintéticos, estratégia também utilizada em outras aplicações (PESSANHA et al., 2014; HOELTGEBAUM et al., 2018). Para isso, este trabalho coletou a série de produção de energia disponibilizada pelo Renewables Ninja, a qual é originalmente disponibilizada em base horária. Os valores horários 
foram então agregados em valores médios mensais, que por sua vez foram utilizados para a geração de cenários sintéticos de produção de energia, também em base mensal. A série histórica de produção horária ainda foi utilizada para a obtenção de Fatores de Desagregação, os quais são aplicados sobre os cenários sintéticos mensais para desagregá-los em valores horários, como será mostrado na seção 5.5.

Cabe ainda destacar que os cenários sintéticos de produção eólica e solar fotovoltaica foram gerados de forma independente entre si e independente da geração de cenários de PLD. Isto pressupõe, conforme discutido anteriormente, que a produção da usina híbrida é marginal frente à produção de energia de todo o SIN, não impactando significativamente a formação do PLD.

Os dados de entrada requisitados pelo sistema Renewables Ninja para a obtenção dos valores de potência elétrica $(\mathrm{kW})$, em cada hora, são apresentados na Tabela 2.

Tabela 2 - Dados de Entrada para o Sistema Renewables Ninja

\begin{tabular}{|c|c|c|c|}
\hline \multicolumn{2}{|c|}{ Eólica } & \multicolumn{2}{c|}{ Solar } \\
\hline Potência Nominal (MW) & 160 & Potência Nominal (MW) & 40 \\
\hline Conjunto de Dados & MERRA - 2 & Conjunto de Dados & MERRA - 2 \\
\hline Período do Dados & $1980-2019$ & Período do Dados & $1980-2019$ \\
\hline Modelo da Turbina Eólica & GAMESA G90 2000W & Rastreamento & Em 1 eixo (Azimute) \\
\hline- & - & Inclinação & 350 \\
\hline- & - & Azimute & 1800 \\
\hline
\end{tabular}

Fonte: Elaboração Própria

O modelo GAMESA G90 2000W de turbina eólica, apresentado na Tabela 2, possui a curva de potência ilustrada na Figura 12 (GAMESA, 2007). Este aerogerador possui velocidade de cut-in de $3 \mathrm{~m} / \mathrm{s}$ e velocidade de cut-out de $21 \mathrm{~m} / \mathrm{s}$. Conforme já mencionado, a velocidade de cut-in consiste na velocidade mínima para que o aerogerador gire no próprio eixo e gere energia; já a velocidade de cut-out consiste na velocidade de corte da turbina, e velocidades superiores a este valor podem gerar danos à turbina.

A Figura 13 apresenta as séries de dados obtidas pelo sistema Renewables Ninja relativas à produção de energia eólica e solar fotovoltaica, já agregadas em base mensal. Para o caso da produção de energia para o arranjo híbrido, considerou-se a 
soma da produção de energia eólica com a produção de energia solar fotovoltaica, desconsiderando as eventuais interferências relativas a um possível sombreamento dos aerogeradores nos painéis solares fotovoltaicos, ou possível aumento de rugosidade do terreno devido à instalação destes painéis. Assim, a série temporal para produção de energia para o arranjo híbrido é apresentada na Figura 14.

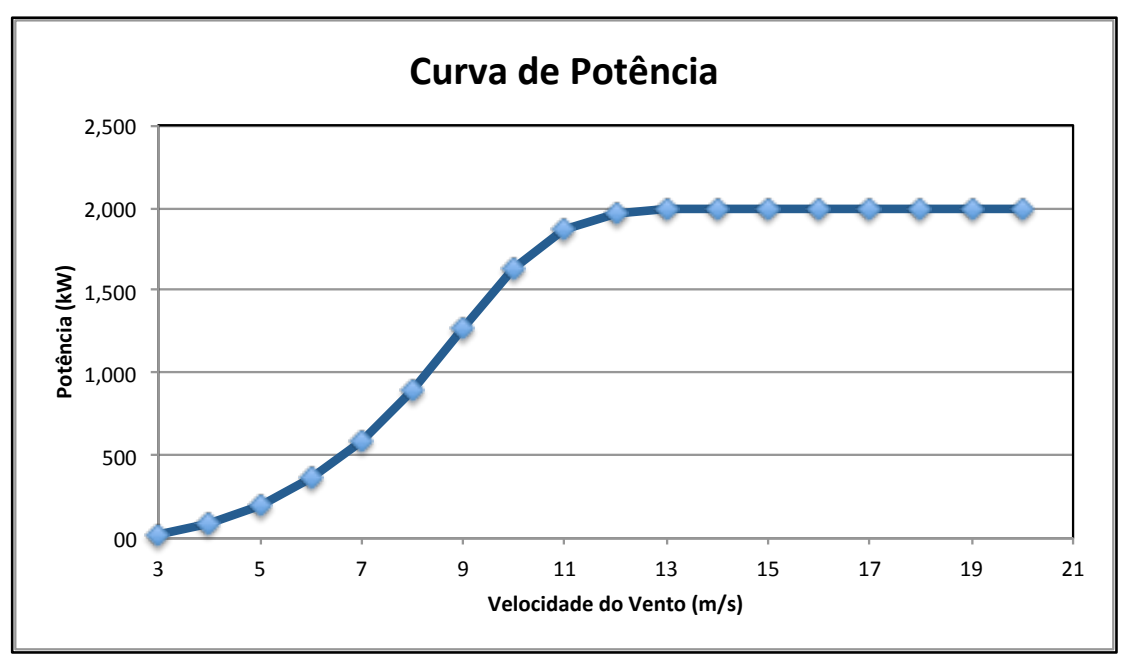

Fonte: Elaboração Própria

Figura 12 - Curva de Potência GAMESA G90 2000W

Tabela 3 - Dados da Curva de Potência GAMESA G90 2000W

\begin{tabular}{|c|c|c|c|}
\hline $\begin{array}{c}\text { Velocidade do } \\
\text { Vento }(\mathrm{m} / \mathbf{s})\end{array}$ & Potência $(\mathbf{k W})$ & $\begin{array}{c}\text { Velocidade do } \\
\text { Vento }(\mathrm{m} / \mathbf{s})\end{array}$ & Potência $(\mathbf{k W})$ \\
\hline 3 & 21,3 & 11 & 1863,0 \\
\hline 4 & 84,9 & 12 & 1960,4 \\
\hline 5 & 197,3 & 13 & 1990,4 \\
\hline 6 & 363,8 & 14 & 1997,9 \\
\hline 7 & 594,9 & 15 & 1999,6 \\
\hline 8 & 900,8 & 16 & 1999,9 \\
\hline 9 & 1274,4 & 17 & 2000,0 \\
\hline 10 & 1633,0 & $18-21$ & 2000,0 \\
\hline
\end{tabular}


Fonte: Elaboração Própria. Dados: GAMESA (2007)
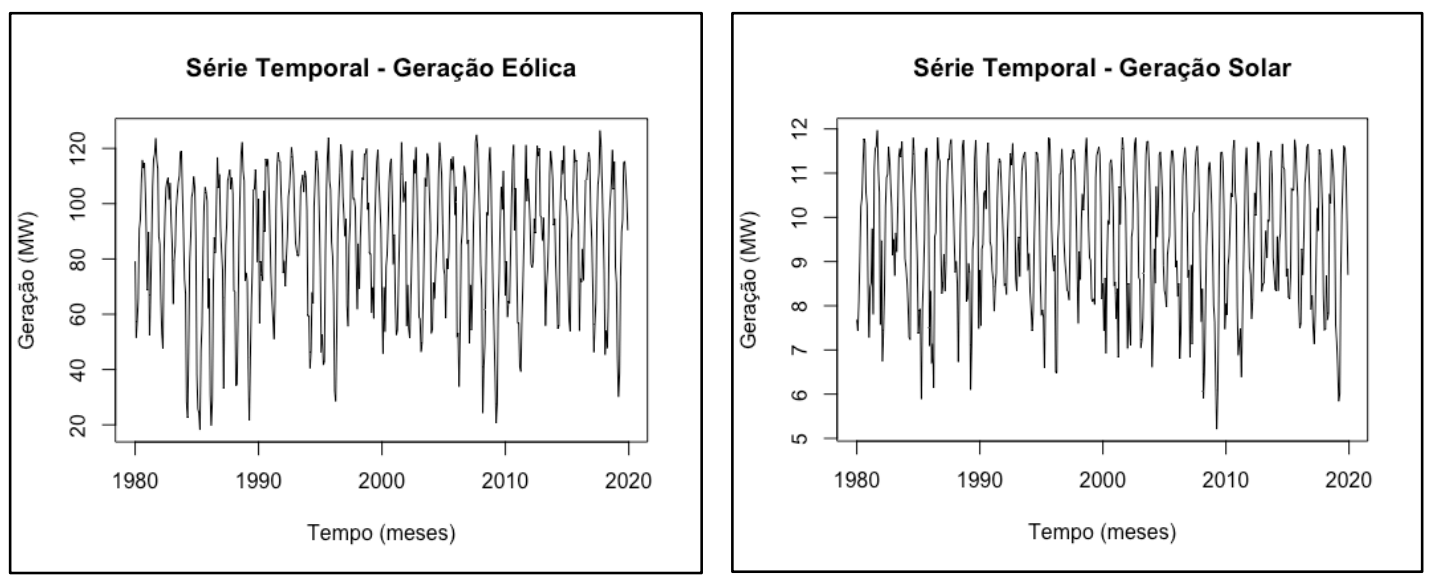

Fonte: Elaboração Própria

Figura 13 - Séries Temporais de Produção de Energia Eólica e Solar Obtida por Reanálise em Base Mensal

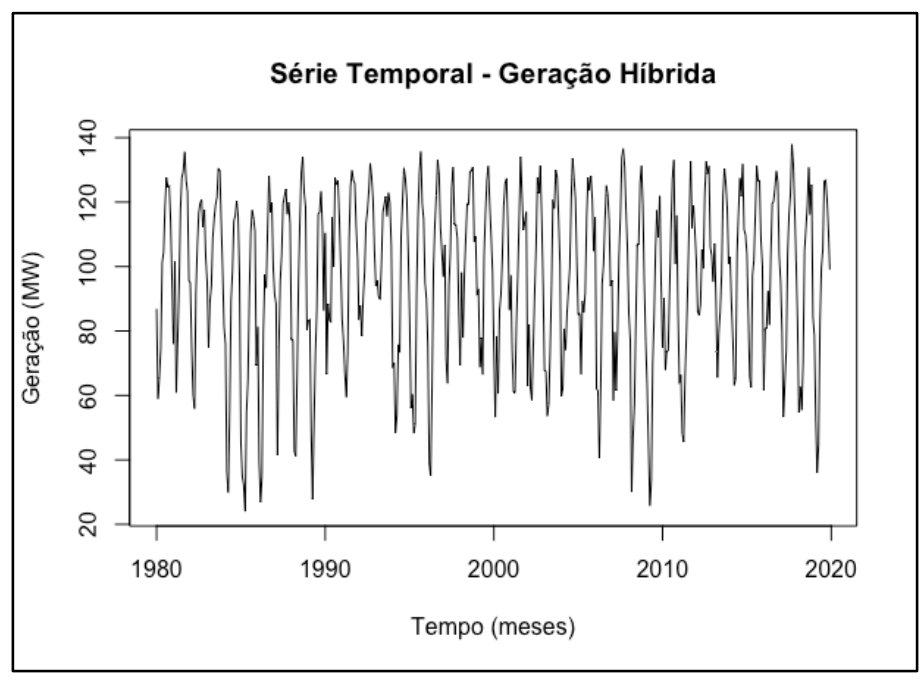

Fonte: Elaboração Própria

Figura 14 - Produção Mensal de Energia do Arranjo Híbrido, Obtida pela Soma das Produções Eólica e Solar Fotovoltaica

Com o objetivo de analisar a dispersão dos dados de produção de energia mensal, obtidos para cada mês do ano a partir da série de dados de reanálise (40 anos), assim como a sazonalidade destes dados ao longo do ano, foram construídos boxplots com os dados históricos de cada mês. Dessa forma, cada boxplot representa o conjunto de 40 valores, um valor para cada ano da série utilizada. Por exemplo, para o mês de janeiro, o boxplot obtido considera os valores de geração observados nos meses de janeiro dos 40 anos analisados. Estes boxplots podem ser vistos na Figura 15. 

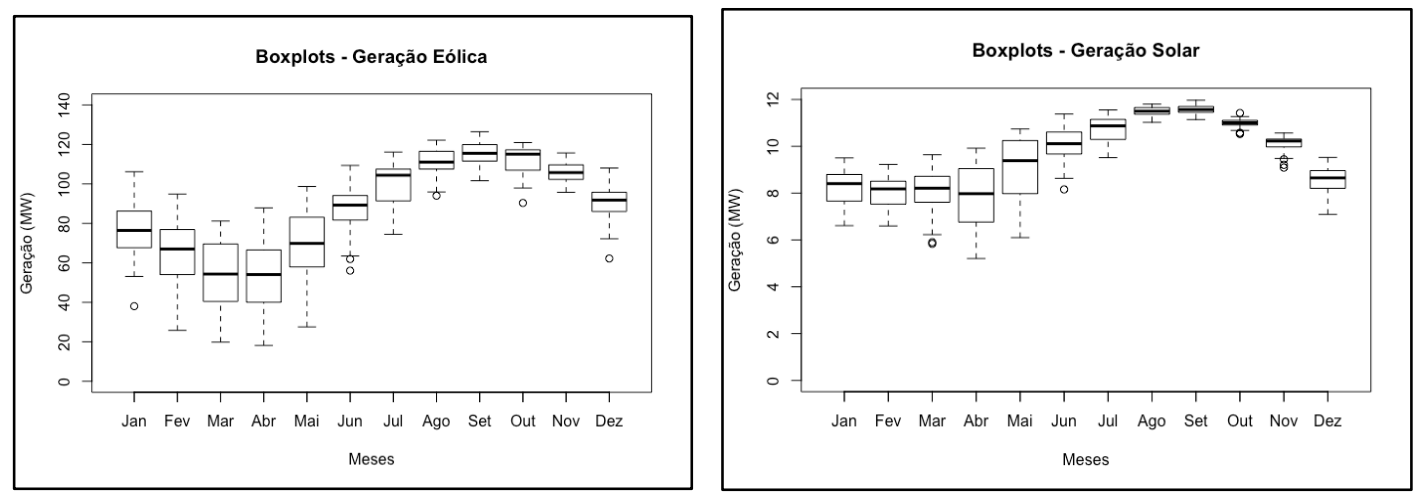

Fonte: Elaboração Própria

Figura 15 - Boxplots dos Valores de Produção de Energia em Cada Mês para as Tecnologias Eólica e Solar Fotovoltaica

Observa-se a existência de sazonalidade na produção de energia de ambas as tecnologias ao longo do ano, com ambas as fontes apresentando maior nível de geração ao longo dos meses do segundo semestre. Para o caso da produção de energia solar, a dispersão dos dados é menor nos meses em que a produção de energia é maior. Situação semelhante ocorre no caso da tecnologia eólica.

A Figura 16 apresenta o comportamento da produção de energia para o arranjo híbrido, obtida somando-se a série de produção de energia eólica com a solar fotovoltaica. Observa-se que as características de sazonalidade e de dispersão são mantidas em relação aos arranjos individuais.

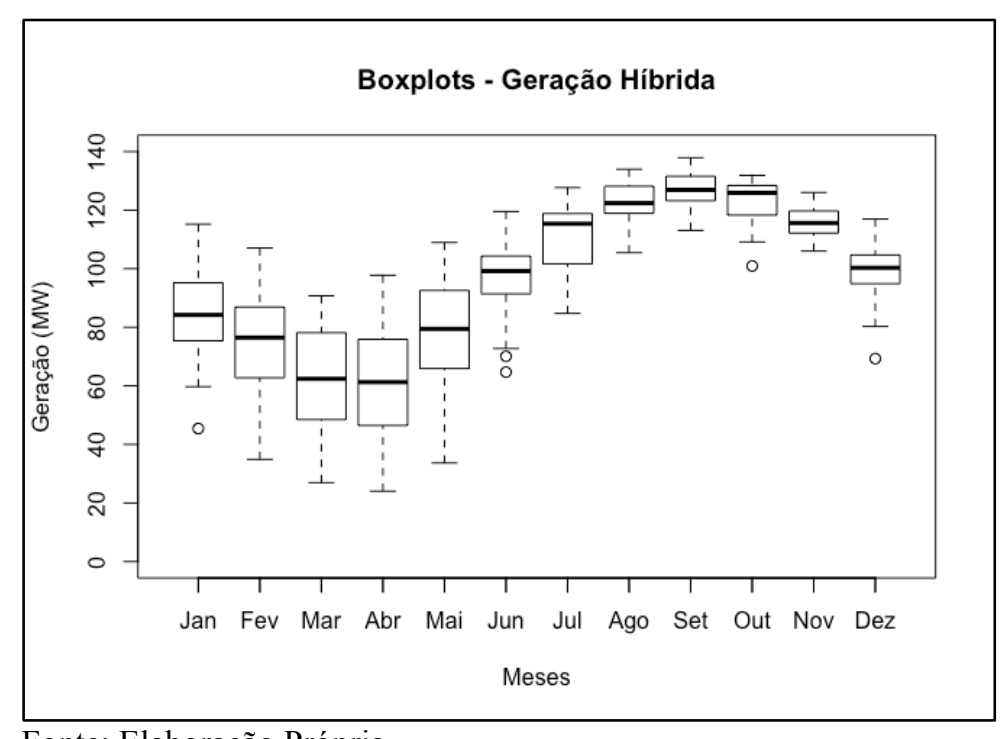

Figura 16 - Boxplots da Média de Produção de Energia de Cada Mês para o Arranjo Híbrido 
Cabe ressaltar que as séries de produção de energia apresentadas na Figura 13 possuem algum nível de complementaridade intradiária. De forma a ilustrar a presença de complementaridade durante um dia, apresenta-se na Figura 17 um exemplo de um dia da série histórica. Percebe-se que a fonte de geração eólica possui a produção mínima no momento em que a geração solar fotovoltaica apresenta a produção próxima do ponto máximo. Entre outras aplicações, o capítulo 7 (Aplicação da Abordagem Metodológica) mostra que a presença de complementaridade pode trazer benefícios caso o empreendimento híbrido possa contratar um Montante de Uso do Sistema de Transmissão (MUST) inferior à potência nominal.

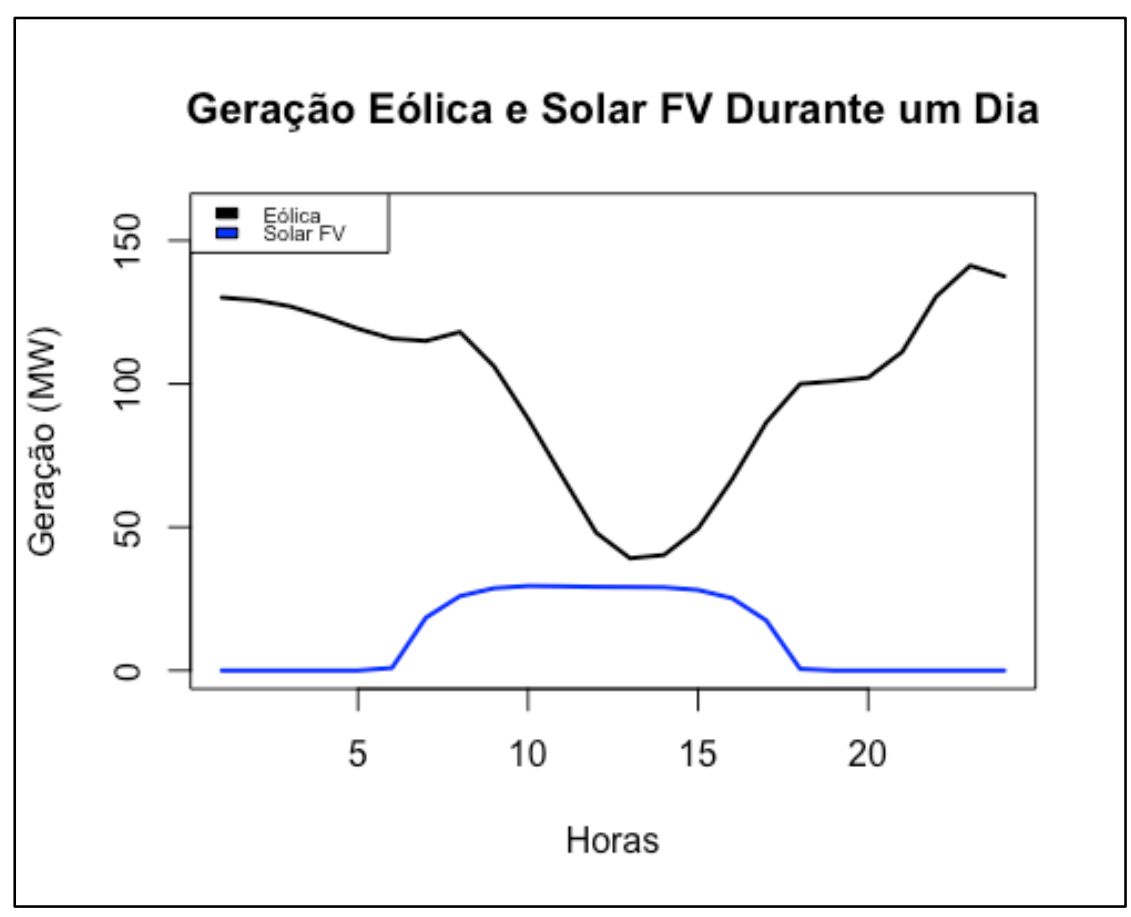

Figura 17 - Exemplo de Complementaridade entre as Fontes de Geração Eólica e Solar

Conforme será mostrado na próxima seção, neste trabalho será ajustado um modelo de séries temporais para a geração de cenários sintéticos de produção de energia elétrica. Espera-se que as características de sazonalidade ao longo do ano e dispersão dos dados em cada mês observadas na série histórica de dados possam ser reproduzidas nos cenários sintéticos. Além da análise visual, também serão analisadas determinadas estatísticas dos resultados, tais como a média, mediana, desvio padrão, coeficiente de variação, valores máximo e mínimo, e percentis extremos da distribuição de valores. 
Novamente se enfatiza que esta dissertação está utilizando como dados históricos os dados oriundos de reanálises e disponibilizados pelo MERRA-2.

\section{3}

\section{Ajuste do Modelo BOX \& JENKINS}

Uma das etapas mais importantes na aplicação de séries temporais diz respeito à identificação do modelo mais adequado, dentre uma família de modelos. De igual importância é a determinação da ordem de cada modelo selecionado, onde se deve usar de parcimônia para se evitar sobreparametrização. Uma vez identificado o modelo e determinada a sua ordem, realiza-se a estimação de seus parâmetros. Nesta dissertação foi utilizada a metodologia BOX \& JENKINS (BOX e JENKINS, 1970; MORETTIN e TOLOI, 2006).

Seja $\left\{y_{t}\right\}_{t=1}^{T}$ uma realização do processo estocástico $\left\{Y_{t}\right\}_{t=1}^{T}$, correspondendo a uma série temporal estacionária de segunda ordem, i.e., com média, variância e covariâncias invariantes no tempo. O modelo de BOX \& JENKINS para $\left\{y_{t}\right\}_{t=1}^{T}$ é especificado pela Equação 5.

$$
y_{t}=\varphi y_{t-1}+\cdots+\varphi_{p} y_{p-1}+\varepsilon_{t}-\theta_{1} \varepsilon_{t-1}-\cdots-\theta_{q} \varepsilon_{t-q}
$$

Os coeficientes $\varphi_{k}$ e $\theta_{j}$ denotam os parâmetros do modelo de BOX \& JENKINS e a componente estocástica $\varepsilon_{t}$, o ruído branco. A Equação 5 pode ser representada em termos de dois polinômios, conforme apresentado na Equação 6, dando origem à classe de modelos denominados $\operatorname{ARMA}(\mathrm{p}, \mathrm{q})$, onde $\mathrm{p}$ representa a ordem de defasagem do termo autorregressivo e q a ordem de defasagem do termo de média móvel.

$$
\left(1-\varphi_{1} B-\cdots-\varphi_{p} B^{p}\right) y_{t}=\left(1-\theta_{1} B-\cdots-\theta_{q} B^{q}\right) \varepsilon_{t}
$$

onde:

B : Operador defasagem definido por $B^{d} y_{t}=y_{t-d}$.

No caso de uma série temporal $\left\{y_{t}\right\}_{t=1}^{T}$ com tendência (ou seja, não estacionariedade na média), deve-se diferenciá-la $d$ vezes, a fim de se encontrar uma 
série temporal (transformada) que seja estacionária de segunda ordem. Assim, se a série temporal $\left\{y_{t}\right\}_{t=1}^{T}$ apresenta não estacionariedade na média, o modelo de BOX \& JENKINS para representar o processo estocástico que gerou $\left\{y_{t}\right\}_{t=1}^{T}$ é especificado pela Equação 7. O modelo resultante é denominado autorregressivo-média móvelintegrado ou ARIMA (p,d,q), onde $d$ representa a ordem das diferenças simples.

$$
\left(1-\varphi_{1} B-\cdots-\varphi_{p} B^{p}\right)(1-B)^{d} y_{t}=\left(1-\theta_{1} B-\cdots-\theta_{q} B^{q}\right) \varepsilon_{t}
$$

A modelagem BOX \& JENKINS ainda pode ser aplicada para séries temporais com componentes sazonais e não sazonais. Neste caso, o processo estocástico pode ser descrito pelo modelo $\operatorname{SARIMA}(\mathrm{p}, \mathrm{d}, \mathrm{q})(\mathrm{P}, \mathrm{D}, \mathrm{Q})_{\mathrm{s}}$ expresso pela Equação 8:

$$
\varphi(B)\left(1-\Phi_{1} B-\cdots-\Phi_{p} B^{P S}\right) \nabla^{d}\left(1-B^{S}\right)^{D} y_{t}=\theta(B)\left(1-\Theta_{1} B-\cdots-\Theta_{Q} B^{Q S}\right) \varepsilon_{t}
$$

onde $\varphi(B)=\left(1-\varphi_{1} B-\cdots-\varphi_{p} B^{p}\right), \theta(\mathrm{B})=\left(1-\theta_{1} B-\cdots-\theta_{q} B^{q}\right), d$ é a ordem das diferenças simples, $D$ é a ordem das diferenças sazonais, $S$ é o período sazonal, $\varphi_{k}$ e $\theta_{j}$ são os coeficientes dos polinômios não sazonais e $\Phi_{m}$ e $\Theta_{n}$ são os coeficientes dos polinômios sazonais.

A inspeção visual da Figura 13, Figura 14, Figura 15 e Figura 16, construídas com dados de reanálise, aponta para a presença de sazonalidade nas séries. Assim, há a indicação de se ajustar incialmente um modelo SARIMA, ou seja, um modelo sazonal-autorregressivo móvel-integrado, $\operatorname{com} S=12$.

Conforme indicado na Equação 8, a sazonalidade presente na série deve ser tratada para se preservar a hipótese de estacionariedade, envolvendo uma diferenciação sazonal de tamanho 12 .

Após o ajuste do modelo selecionado, ou seja, identificação do modelo, determinação da sua ordem e estimação de seus parâmetros, é importante verificar se modelo ajustado apresenta uma diferença não-significativa em relação à série original. Em geral, as métricas de avaliação do desempenho são dadas em função dos erros calculados em relação à previsão dada pelo modelo ajustado. Assim, ao se comparar possíveis modelos, o modelo com menores valores em relação a essas métricas é 
considerado um modelo que representa melhor a série histórica. Neste trabalho, utilizou-se os seguintes critérios de avaliação (SOUZA e OLIVEIRA, 2015):

○ Erro Médio Absoluto Percentual $\left(M A P E^{16}\right)$;

- Raiz Quadrada do Erro Quadrático Médio $\left(R M S E^{17}\right)$;

○ Critérios de Informação de Akaike $\left(A I C^{18}\right)$;

○ Critério de Informação Bayseiano $\left(B I C^{19}\right)$.

Ainda, a partir de um modelo selecionado inicialmente, realizou-se o teste de sobrefixação (SOUZA e CAMARGO, 2004) para encontrar o modelo mais adequado. Além de evitar a sobreparametrização, o teste de sobrefixação permite variar a ordem do modelo inicial, de forma a melhorá-lo com base nos critérios de avaliação.

Utilizando o pacote auto.arima do ambiente R (R Core Team, 2019), ajustouse inicialmente o modelo $\operatorname{SARIMA}(1,0,0) \times(2,1,0){ }_{12}$ para a série de produção mensal de energia eólica considerada. A partir deste modelo inicial foi realizado o teste de sobrefixação, conforme apresentado na Tabela 4.

Tabela 4 - Teste de Sobrefixação para a Série de Produção de Energia Eólica

\begin{tabular}{|c|c|c|c|c|c|c|}
\hline \multicolumn{7}{|c|}{ Eólica } \\
\hline Modelo & Não Sazonal & Sazonal & AIC & BIC & $\begin{array}{l}\text { Erro Quadrático } \\
\text { Médio (RMSE) }\end{array}$ & MAPE \\
\hline 1 & $(1,0,0)$ & $(2,1,0)$ & 2841.46 & 2857.73 & 6.29 & 13.88 \\
\hline 2 & $(1,0,1)$ & $(2,1,0)$ & 2825.69 & 2846.03 & 6.16 & 13.66 \\
\hline 3 & $(1,0,1)$ & $(2,1,1)$ & 2726.56 & 2750.97 & 5.31 & 12.25 \\
\hline 4 & $(1,0,1)$ & $(0,1,1)$ & 2725.01 & 2741.28 & 5.32 & 12.27 \\
\hline 5 & $(1,0,1)$ & $(1,1,1)$ & 2726.31 & 2746.65 & 5.26 & 12.14 \\
\hline 6 & $(1,0,2)$ & $(1,1,1)$ & 2726.08 & 2750.49 & 5.29 & 12.20 \\
\hline 7 & $(2,0,2)$ & $(1,1,1)$ & 2727.75 & 2756.23 & 5.29 & 12.21 \\
\hline 8 & $(1,0,2)$ & $(2,1,1)$ & 2726.83 & 2755.31 & 5.31 & 12.22 \\
\hline 9 & $(1,0,2)$ & $(2,1,0)$ & 2825.93 & 2850.34 & 6.15 & 13.69 \\
\hline 10 & $(1,0,0)$ & $(1,1,1)$ & 2741.15 & 2757.42 & 5.37 & 12.36 \\
\hline 11 & $(0,0,0)$ & $(0,1,1)$ & 2885.06 & 2893.2 & 6.37 & 15.14 \\
\hline 12 & $(1,0,0)$ & $(0,1,1)$ & 2739.75 & 2751.95 & 5.37 & 12.37 \\
\hline 13 & $(1,1,1)$ & $(0,1,1)$ & 2739.34 & 2755.6 & 5.37 & 12.00 \\
\hline
\end{tabular}

Fonte: Elaboração Própria

\footnotetext{
${ }_{17}^{16}$ Sigla do inglês Mean Absolute Percentage Error

${ }^{17}$ Sigla do inglês Root Mean Square Error

${ }^{18}$ Sigla do inglês Akaike Information Criterion

${ }^{19}$ Sigla do inglês Bayesian Information Criterion
} 
O quinto modelo na Tabela 4, ou seja, o modelo $\operatorname{SARIMA}(1,0,1) \times(1,1,1)_{12}$ poderia ser uma opção por apresentar bom desempenho nos critérios RMSE e MAPE. Todavia, verificou-se que, ao se realizar testes de hipótese nos coeficientes deste modelo, alguns coeficientes se apresentaram estatisticamente não-significativos, ou seja, com alta probabilidade de serem iguais a zero.

Ao final selecionou-se o modelo $\operatorname{SARIMA}(1,0,1) \times(0,1,1)_{12}$, pois apresentou $\mathrm{o}$ melhor desempenho nos critérios $A I C$ e $B I C$, além de bons desempenhos nos critérios RMSE e MAPE.

Também se obteve o modelo $\operatorname{SARIMA}(1,0,1) \times(0,1,1)_{12}$ ao se realizar o mesmo procedimento para a série de produção de energia solar. Seguiu-se o procedimento similar ao realizado para produção de energia eólica, escolhendo-se o modelo com os menores critérios de avaliação e com coeficientes estatisticamente significativos. O teste de sobrefixação para o ajuste do modelo para série de produção de energia solar é aprestando na Tabela 5. Destaca-se nesta tabela que os modelos 6, 7 e 8 apresentam alguns valores das métricas inferiores ao modelo escolhido (modelo 4). Entretanto, verificou-se que alguns dos coeficientes dos modelos 6,7 e 8 se mostraram estatisticamente não-significativos.

Os coeficientes e os respectivos erros padrões de cada coeficiente do modelo SARIMA ajustado são apresentados, por tecnologia, na Tabela 6.

Tabela 5 - Teste de Sobrefixação para a Série de Produção de Energia Solar

\begin{tabular}{|c|c|c|c|c|c|c|}
\hline \multicolumn{7}{|c|}{ Solar } \\
\hline Modelo & Não Sazonal & Sazonal & AIC & BIC & $\begin{array}{c}\text { Erro Quadrático } \\
\text { Médio (RMSE) }\end{array}$ & MAPE \\
\hline 1 & $(1,0,0)$ & $(2,1,0)$ & 417.14 & 433.41 & 0.38 & $6.35 \%$ \\
\hline 2 & $(1,0,1)$ & $(2,1,0)$ & 413.26 & 433.60 & 0.38 & $6.31 \%$ \\
\hline 3 & $(1,0,1)$ & $(2,1,1)$ & 328.41 & 352.82 & 0.33 & 5.41 \\
\hline 4 & $(1,0,1)$ & $(0,1,1)$ & 328.36 & 344.63 & 0.33 & 5.46 \\
\hline 5 & $(1,0,1)$ & $(1,1,1)$ & 330.35 & 350.69 & 0.33 & 5.47 \\
\hline 6 & $(1,0,2)$ & $(1,1,1)$ & 326.72 & 351.13 & 0.33 & 5.43 \\
\hline 7 & $(2,0,2)$ & $(1,1,1)$ & 328.71 & 357.19 & 0.33 & 5.43 \\
\hline 8 & $(1,0,2)$ & $(2,1,1)$ & 325.70 & 354.18 & 0.32 & 5.37 \\
\hline 9 & $(1,0,2)$ & $(2,1,0)$ & 412.10 & 436.51 & 0.38 & 6.29 \\
\hline 10 & $(1,0,0)$ & $(1,1,1)$ & 334.07 & 350.34 & 0.33 & 5.49 \\
\hline 11 & $(0,0,0)$ & $(0,1,1)$ & 408.14 & 416.27 & 0.36 & 5.97 \\
\hline 12 & $(1,0,0)$ & $(0,1,1)$ & 332.09 & 344.29 & 0.33 & 5.49 \\
\hline 13 & $(1,1,1)$ & $(0,1,1)$ & 343.33 & 359.59 & 0.33 & 5.49 \\
\hline
\end{tabular}


Tabela 6 - Coeficientes dos Modelos Ajustados via Box \& Jenkins

\begin{tabular}{|c|c|c|c|c|}
\hline Modelo SARIMA(1,0,1)x(0,1,1)12 & \multicolumn{2}{|c|}{ Eólica } & \multicolumn{2}{c|}{ Solar } \\
\hline Termo & Valor & Erro Padrão & Valor & Erro Padrão \\
\hline 1o coeficiente autorregressivo não-sazonal $\varphi_{1}$ & 0,7613 & 0,0512 & 0,5972 & 0,0780 \\
\cline { 2 - 5 } 10 coeficiente média-móvel não-sazonal $\theta_{1}$ & $-0,3208$ & 0,0726 & $-0,2259$ & 0,0913 \\
\cline { 2 - 5 } 1o coeficiente média-móvel sazonal $\Theta_{1}$ & $-0,9754$ & 0,0544 & $-1,000$ & 0,0442 \\
\hline
\end{tabular}

Fonte: Elaboração Própria

A partir dos modelos de séries temporais ajustados, foram gerados 2.000 cenários sintéticos de produção de energia eólica e solar fotovoltaica em base mensal. Os cenários de produção de energia relativos ao arranjo híbrido foram obtidos a partir da soma entre os cenários de produção de energia eólica e solar fotovoltaica, em cada mês e em cada série sintética simulada.

A Figura 18, a Figura 19 e a Figura 20 ilustram as 100 primeiras das 2.000 séries sintéticas para as tecnologias eólica, solar fotovoltaica e arranjo híbrido, respectivamente.

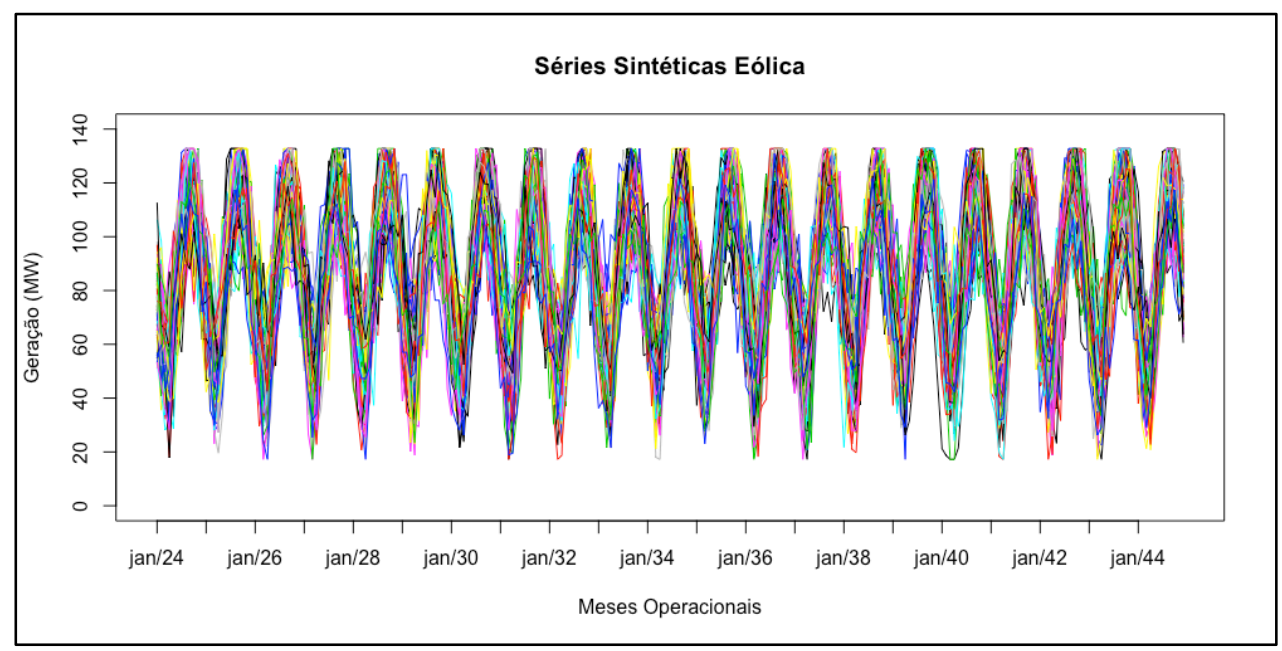

Figura 18 - 100 Séries Sintéticas - Eólica 


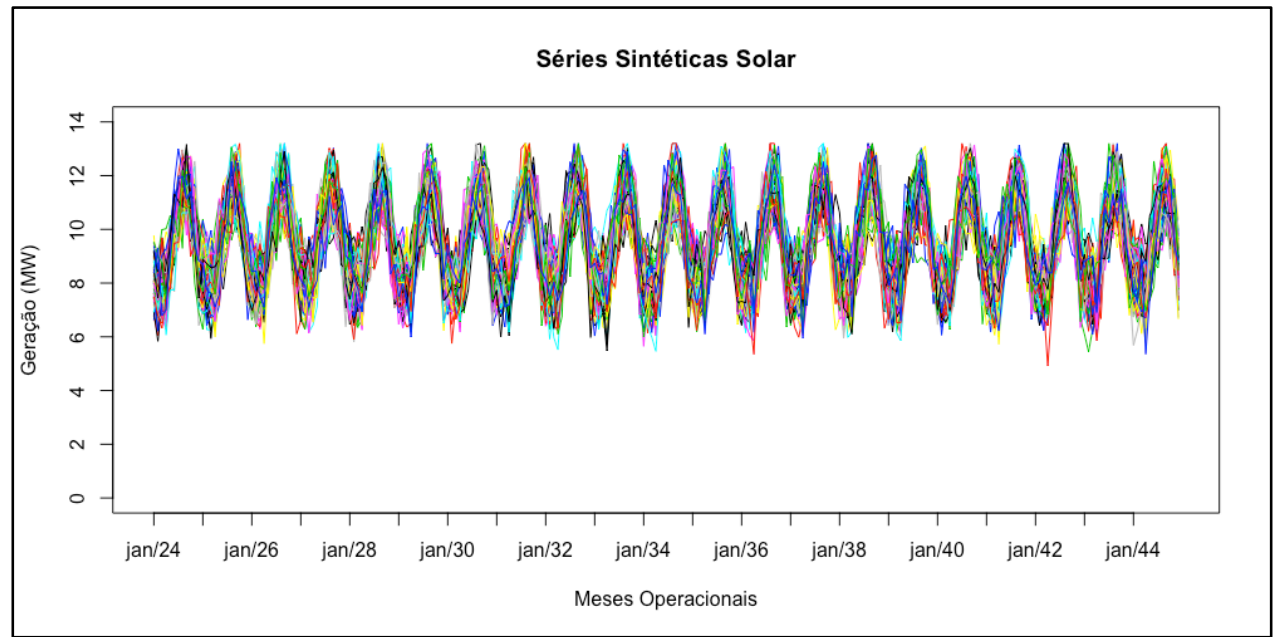

Figura 19 - 100 Séries Sintéticas - Solar

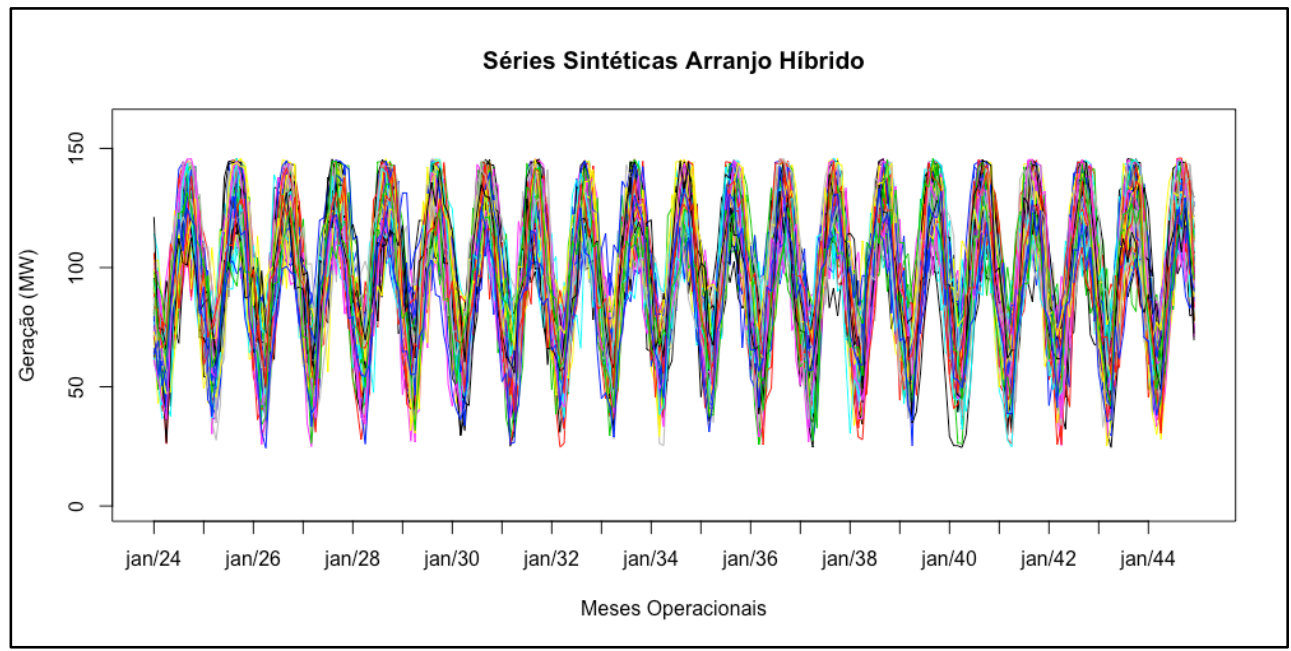

Figura 20 - 100 Séries Sintéticas - Arranjo Híbrido

5.4

Análise dos Cenários Sintéticos de Produção de Energia

Após a obtenção dos cenários sintéticos de produção de eletricidade para cada uma das tecnologias, os mesmos foram comparados com os respectivos dados históricos associados, utilizando algumas estatísticas, conforme apresentado a seguir. 


\section{4 .1}

\section{Tecnologia Eólica}

A Tabela 7 apresenta algumas estatísticas calculadas para as séries históricas e sintéticas de produção de energia eólica, e também os respectivos fatores de capacidade ${ }^{20}$.

Analisando os valores da Tabela 7 nota-se que, estatísticas de posição e dispersão das séries histórica e sintética são próxima ,e.g., percentis de $25 \%$ e $75 \%$ (e, por conseguinte, a distância interquartílica), mediana, média, desvio padrão e, também, o coeficiente de variação; indicando que a série sintética gerada reproduz adequadamente, de forma geral, as características da série histórica. Isto também fica evidenciado quando se compara as distribuições de frequências acumulada das séries histórica sintética, conforme apresentado na Figura 21.

Tabela 7 - Comparação entre as Séries Histórica e Sintética - Principais Estatísticas em Base Mensal - Tecnologia Eólica

\begin{tabular}{|c|c|c|c|c|}
\hline \multirow{2}{*}{ Base Mensal } & \multicolumn{4}{|c|}{ Tecnologia Eólica (Usina de 160 MW) } \\
\cline { 2 - 5 } & $\begin{array}{c}\text { Série Histórica } \\
\text { (MWmês) }\end{array}$ & $\begin{array}{c}\text { Fator de } \\
\text { Capacidade (\%) }\end{array}$ & $\begin{array}{c}\text { Série Sintética } \\
\text { (MWmês) }\end{array}$ & $\begin{array}{c}\text { Fator de } \\
\text { Capacidade (\%) }\end{array}$ \\
\hline Mínimo & 18,15 & 11,34 & $-14,39$ & $-8,99$ \\
\hline Percentil 25\% & 69,23 & 43,27 & 66,77 & 41,73 \\
\hline Mediana & 90,77 & 56,73 & 87,92 & 54,95 \\
\hline Média & 86,67 & 54,17 & 86,70 & 54,19 \\
\hline Percentil 75\% & 107,78 & 67,36 & 106,78 & 66,74 \\
\hline Máximo & 126,45 & 79,03 & 187,39 & 117,12 \\
\hline Desvio Padrão & 25,10 & - & 25,68 & - \\
\hline Coef. de Variação & $28,96 \%$ & - & $29,62 \%$ & - \\
\hline
\end{tabular}

Fonte: Elaboração Própria

\footnotetext{
${ }^{20}$ Fator de Capacidade: razão entre a produção de energia de uma usina em um determinado período de tempo e a respectiva potência nominal. Ou seja, representa um percentual de energia em relação à máxima capacidade da usina.
} 


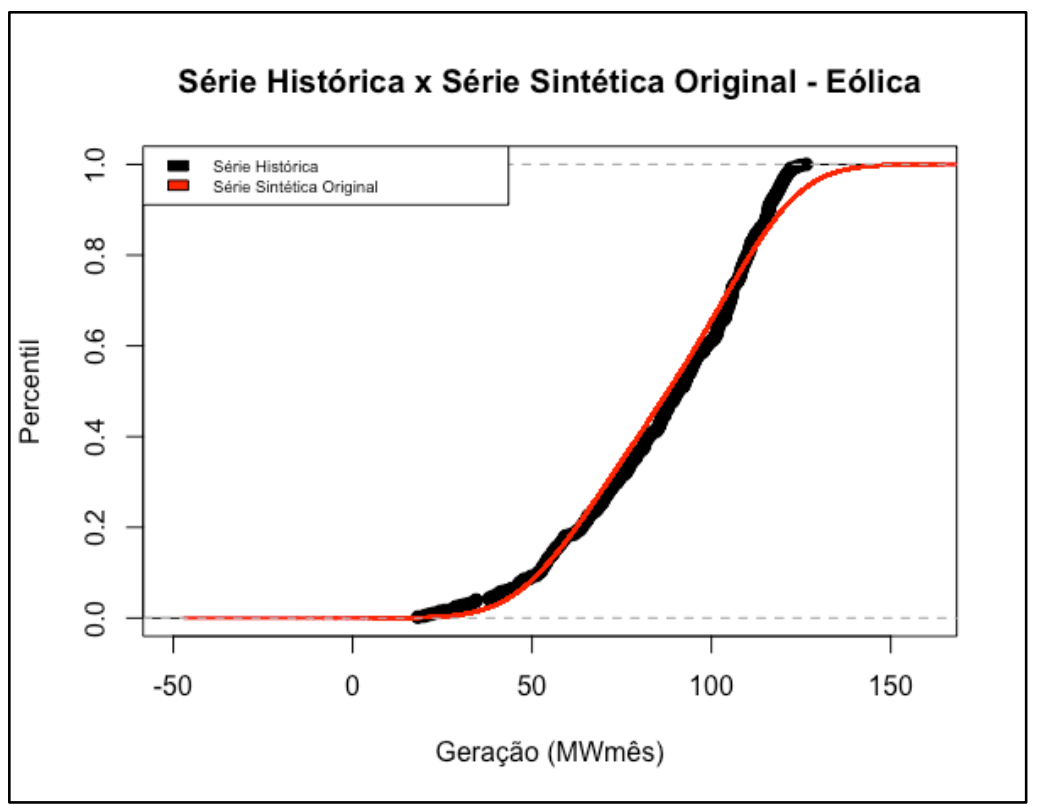

Figura 21 - Comparação entre as Distribuições de Frequências Acumuladas da Série Histórica e da Série Sintética Original de Produção Eólica

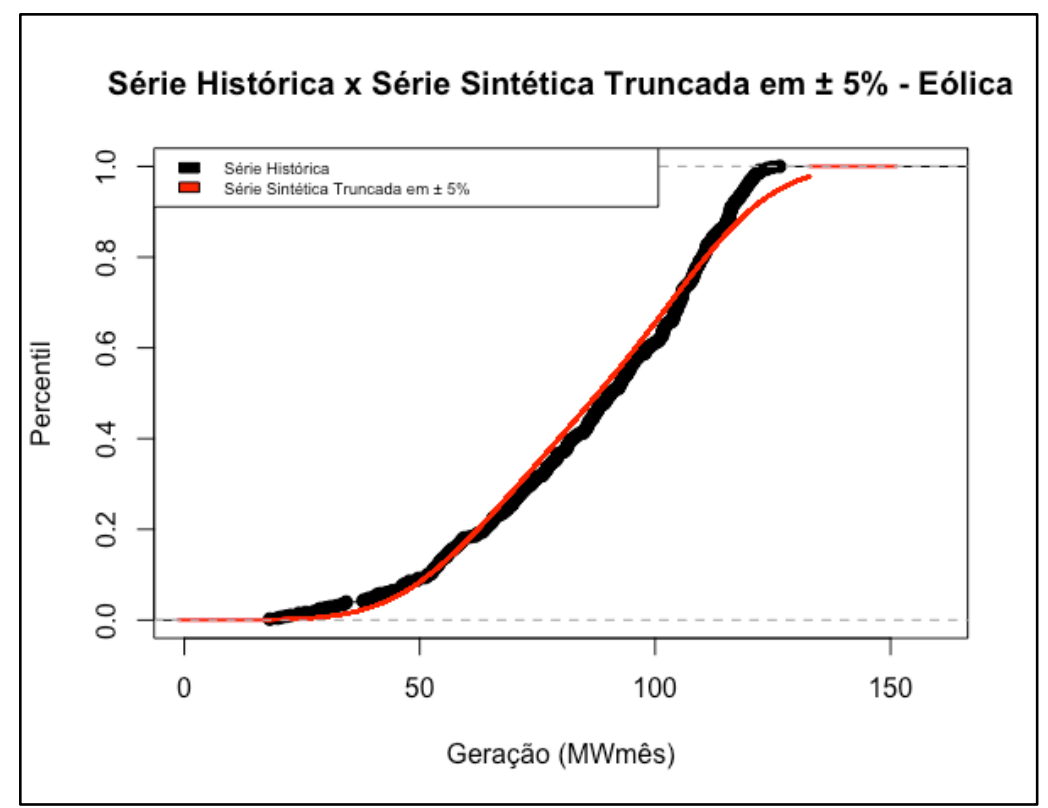

Figura 22 - Comparação entre as Distribuições de Frequências Acumuladas da Série Histórica e da Série Sintética de Produção Eólica Truncada em $\pm 5 \%$

Por outro lado, verifica-se também na Tabela 7 que os valores mínimo e máximo obtidos com a série sintética transpõem os limites físicos da usina eólica em análise: o valor mínimo de produção de energia foi negativo (fator de capacidade igual a $-8.99 \%$ ) e o valor máximo (fator de capacidade igual a 117,12\%) ultrapassou a potência nominal de $160 \mathrm{MW}$ da usina eólica. Examinando outros percentis das 
distribuições de frequências de ambas as séries, conforme exibidos na Tabela 8, constata-se que as maiores diferenças estão associadas aos valores extremos das distribuições. Por exemplo, os percentis de 1\%, 5\%, 90\%, 95\% e 99\% da distribuição de frequências da série sintética são, respectivamente, 33\%, 10\%, 3\%, 6\% e 13\% superiores aos correspondentes valores da série histórica. Estes resultados estão em sintonia com a Figura 21, onde se percebe que as distribuições acumuladas se distanciam em valores altos de produção de energia, a partir de percentis próximos de $95 \%$.

Pode-se afirmar que diferenças nos valores extremos eram esperadas, pois como não se considerou de forma explícita o processo de conversão das velocidades dos ventos em produção de energia, não houve limitação aos possíveis valores gerados pelo modelo SARIMA ajustado. Assim, há a necessidade de se truncar alguns valores sintéticos de produção de energia de tal forma que os valores finais obtidos sejam fisicamente factíveis e também coerentes com o observado na realidade operativa deste tipo de usina, contudo modificando a série gerada o mínimo possível. Nesta dissertação se empregou um procedimento heurístico com esta finalidade, partindo de uma análise de sensibilidade, onde se limitou (i.e, truncou) os valores máximos e mínimos da série sintética em $\pm 5 \%, \pm 10 \%, \pm 15 \%$ e $\pm 20 \%$ dos correspondentes valores da série histórica. Os boxplots resultantes desta análise de sensibilidade podem ser visualizados na Figura 23.

Tabela 8 - Comparação entre as Séries Histórica e Sintética - Percentis em Base Mensal Tecnologia Eólica

\begin{tabular}{|c|c|c|c|c|}
\hline \multirow{2}{*}{ Base Mensal } & \multicolumn{4}{|c|}{ Tecnologia Eólica (Usina de 160 MW) } \\
\cline { 2 - 5 } & $\begin{array}{c}\text { Série Histórica } \\
\text { (MWmês) }\end{array}$ & $\begin{array}{c}\text { Fator de } \\
\text { Capacidade (\%) }\end{array}$ & $\begin{array}{c}\text { Série Sintética } \\
\text { (MWmês) }\end{array}$ & $\begin{array}{c}\text { Fator de } \\
\text { Capacidade (\%) }\end{array}$ \\
\hline Percentil 1\% & 23,94 & 14,96 & 31,81 & 19,88 \\
\hline Percentil 5\% & 40,52 & 25,33 & 44,54 & 27,84 \\
\hline Percentil 10\% & 52,35 & 32,72 & 51,97 & 32,48 \\
\hline Percentil 90\% & 115,97 & 72,48 & 119,59 & 74,74 \\
\hline Percentil 95\% & 119,14 & 74,46 & 126,3 & 78,94 \\
\hline Percentil 99\% & 122,17 & 76,36 & 138,03 & 86,27 \\
\hline
\end{tabular}

Fonte: Elaboração Própria

Inicialmente, verifica-se que a posição de todas as "caixas" e das medianas é praticamente a mesma, corroborando que as séries sintéticas geradas com o modelo 
SARIMA selecionado reproduzem adequadamente, de forma geral, as características da série histórica.

Ao se analisar o boxplot da série sintética original (i.e., sem aplicação de limites) verifica-se a existência de valores discrepantes superiores (acima da cerca superior (166,80 MWmês) e, principalmente, abaixo da cerca inferior (6,76 MWmês), indicando ser razoável a remoção destes valores discrepantes. Também, as próprias cercas superior e inferior da série sintética original estão respectivamente $32 \%$ acima e $62 \%$ abaixo daquelas da série histórica. Além disso o valor da cerca superior da série sintética original está acima da capacidade da usina eólica considerada (160 MW). Estes elementos sugerem a possibilidade de adoção de limites máximo e mínimo para a série sintética original, resultando em uma série sintética truncada.

Ao se aplicar os limites de $\pm 5 \%, \pm 10 \%, \pm 15 \%$ e $\pm 20 \%$ aos valores máximos e mínimos da série sintética em relação aos valores da série histórica, observa-se pelos boxplots da Figura 23 que deixam de existir valores discrepantes, e os valores das cercas superior e inferior correspondem aos limites aplicados. A questão que surge diz respeito à escolha do limite de truncamento a ser adotado nesta dissertação.

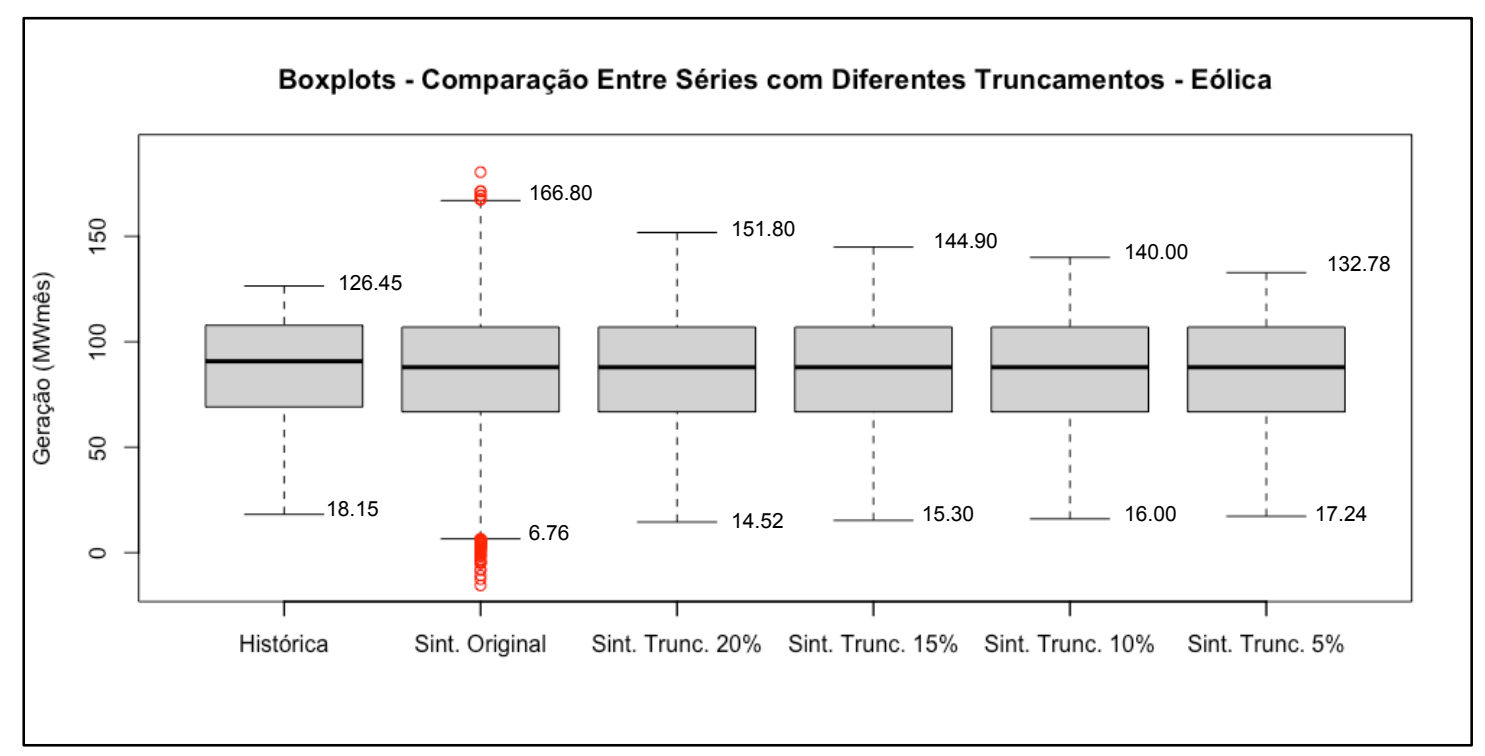

Figura 23 - Boxplots da Série Histórica e da Série Sintética com Diferentes Truncamentos Eólica

Para se obter um balizamento, recorreu-se aos fatores de capacidades disponibilizados nos boletins mensais de geração eólica do ONS (2021b), para usinas em operação na região Nordeste e no estado do Ceará, especialmente nos meses com 
maiores valores de produção de energia (agosto, setembro e outubro, conforme a Figura 15). Desta análise, concluiu-se que era razoável a adoção de um limite de truncamento para a série sintética de produção de energia eólica igual a $\pm 5 \%$ dos valores máximo e mínimo observados na série histórica. Com isso, como pode ser visto na Tabela 9, o limite inferior considerado para tecnologia eólica foi fixado em 17,24 MW (o que corresponde a um fator de capacidade igual a 10,78\%) e o limite superior em 132,78 MW (o que corresponde a um fator de capacidade igual a $82,99 \%)$.

A Tabela 10 apresenta estatísticas da série histórica de produção de energia eólica e da série sintética truncada em $\pm 5 \%$. Observa-se que, exceto pelos valores mínimo e máximo, as demais estatísticas da série sintética truncada não sofreram alterações significativas em relação à serie sintética original (vide Tabela 7). Comparando com a série histórica, a amplitude dos dados da série sintética truncada em $\pm 5 \%$ passou a ficar mais aderente agora, e também a distribuição de frequências, conforme apresentado na Figura 22. Assim, esta série sintética passou a ser adotada.

Tabela 9 - Limites Estabelecidos para as Tecnologias Eólica e Solar Fotovoltaica em Base Mensal

\begin{tabular}{|c|c|c|c|c|}
\hline \multirow{2}{*}{ Limites } & \multicolumn{2}{|c|}{ Tecnologia Eólica (160 MW) } & \multicolumn{2}{c|}{ Tecnologia Solar (40 MW) } \\
\cline { 2 - 5 } & Potência (MW) & $\begin{array}{c}\text { Fator de } \\
\text { Capacidade (\%) }\end{array}$ & Potência (MW) & $\begin{array}{c}\text { Fator de } \\
\text { Capacidade (\%) }\end{array}$ \\
\hline Limite Inferior & 17,24 & 10,78 & 4,68 & 11,70 \\
\hline Limite Superior & 132,78 & 82,99 & 13,20 & 33,00 \\
\hline
\end{tabular}

Tabela 10 - Comparação entre Estatísticas em Base Mensal da Série Histórica e da Série Sintética Truncada em $\pm 5 \%$-Tecnologia Eólica

\begin{tabular}{|c|c|c|c|c|}
\hline \multirow{2}{*}{ Base Mensal } & \multicolumn{3}{|c|}{ Tecnologia Eólica (Usina de 160 MW) - Série Sintética com Limites } \\
\cline { 2 - 5 } & $\begin{array}{c}\text { Série Histórica } \\
\text { (MWmês) }\end{array}$ & $\begin{array}{c}\text { Fator de } \\
\text { Capacidade (\%) }\end{array}$ & $\begin{array}{c}\text { Série Sintética } \\
\text { (MWmês) }\end{array}$ & $\begin{array}{c}\text { Fator de } \\
\text { Capacidade (\%) }\end{array}$ \\
\hline Mínimo & 18,15 & 11,34 & 17,24 & 10,78 \\
\hline Percentil 25\% & 69,23 & 43,27 & 66,78 & 41,74 \\
\hline Mediana & 90,77 & 56,73 & 87,92 & 54,95 \\
\hline Média & 86,67 & 54,17 & 86,95 & 54,34 \\
\hline Percentil 75\% & 107,78 & 67,36 & 106,95 & 66,84 \\
\hline Máximo & 126,45 & 79,03 & 132,78 & 82,99 \\
\hline Desvio Padrão & 25,10 & - & 25,68 & - \\
\hline Coef. de Variação & $28,96 \%$ & - & $29,54 \%$ & - \\
\hline
\end{tabular}




\section{4 .2}

\section{Tecnologia Solar Fotovoltaica}

Com relação à tecnologia solar fotovoltaica, o mesmo procedimento descrito na seção 5.4.1 para a tecnologia eólica foi realizado, com conclusões também análogas. Entretanto, não se observou valores infactíveis de ocorrer, ou seja, todos os valores foram positivos e inferiores a potência nominal de 40 MW da usina solar fotovoltaica. A Tabela 11 e a Tabela 12 apresentam os resultados. Observa-se que, embora de menores magnitudes que no caso eólico, ainda há diferenças nas estatísticas associadas a valores extremos entre a série histórica e a série sintética, também indicado nas distribuições de frequências acumuladas das duas séries, conforme Figura 24.

Tabela 11 - Comparação entre as Séries Histórica e Sintética - Principais Estatísticas em Base Mensal - Tecnologia Solar

\begin{tabular}{|c|c|c|c|c|}
\hline \multirow{2}{*}{ Base Mensal } & \multicolumn{4}{|c|}{ Tecnologia Solar Fotovoltaica (Usina de 40 MW) } \\
\cline { 2 - 5 } & $\begin{array}{c}\text { Série Histórica } \\
\text { (MWmês) }\end{array}$ & $\begin{array}{c}\text { Fator de } \\
\text { Capacidade (\%) }\end{array}$ & $\begin{array}{c}\text { Série Sintética } \\
\text { (MWmês) }\end{array}$ & $\begin{array}{c}\text { Fator de } \\
\text { Capacidade (\%) }\end{array}$ \\
\hline Mínimo & 5,21 & 13,02 & 4,54 & 11,35 \\
\hline Percentil 25\% & 8,38 & 20,95 & 8,31 & 20,78 \\
\hline Mediana & 9,69 & 24,23 & 9,52 & 23,81 \\
\hline Média & 9,58 & 23,95 & 9,59 & 23,96 \\
\hline Percentil 75\% & 11,00 & 27,50 & 10,85 & 27,12 \\
\hline Máximo & 11,97 & 29,93 & 15,01 & 37,53 \\
\hline Desvio Padrão & 1,53 & - & 1,56 & - \\
\hline Coef. de Variação & $15,97 \%$ & - & $16,25 \%$ & - \\
\hline
\end{tabular}

Fonte: Elaboração Própria 
Tabela 12 - Comparação entre as Séries Histórica e Sintética - Percentis em Base Mensal Tecnologia Solar

\begin{tabular}{|c|c|c|c|c|}
\hline \multirow{2}{*}{ Base Mensal } & \multicolumn{4}{|c|}{ Tecnologia Solar Fotovoltaica (Usina de 40 MW) } \\
\cline { 2 - 5 } & $\begin{array}{c}\text { Série Histórica } \\
\text { (MWmês) }\end{array}$ & $\begin{array}{c}\text { Fator de } \\
\text { Capacidade (\%) }\end{array}$ & $\begin{array}{c}\text { Série Sintética } \\
\text { (MWmês) }\end{array}$ & $\begin{array}{c}\text { Fator de } \\
\text { Capacidade (\%) }\end{array}$ \\
\hline Percentil 1\% & 6,08 & $15,20 \%$ & 6,58 & 16,45 \\
\hline Percentil 5\% & 7,03 & $17,6 \%$ & 7,22 & 18,05 \\
\hline Percentil 10\% & 7,48 & $18,7 \%$ & 7,59 & 18,98 \\
\hline Percentil 90\% & 11,5 & $28,8 \%$ & 11,68 & 29,20 \\
\hline Percentil 95\% & 11,65 & $29,1 \%$ & 12,09 & 30,23 \\
\hline Percentil 99\% & 11,79 & $29,5 \%$ & 12,8 & 32,00 \\
\hline
\end{tabular}

Fonte: Elaboração Própria

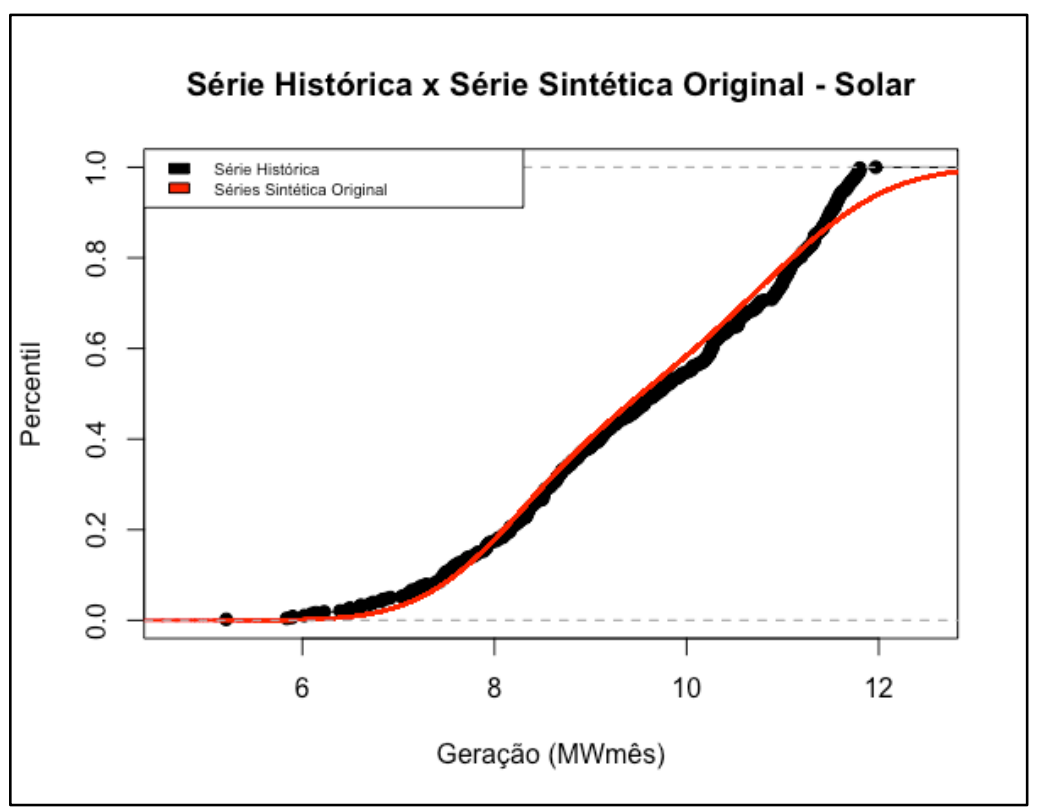

Figura 24 - Comparação entre as Distribuições de Frequências Acumuladas da Série Histórica e da Série Sintética Original de Produção Solar 


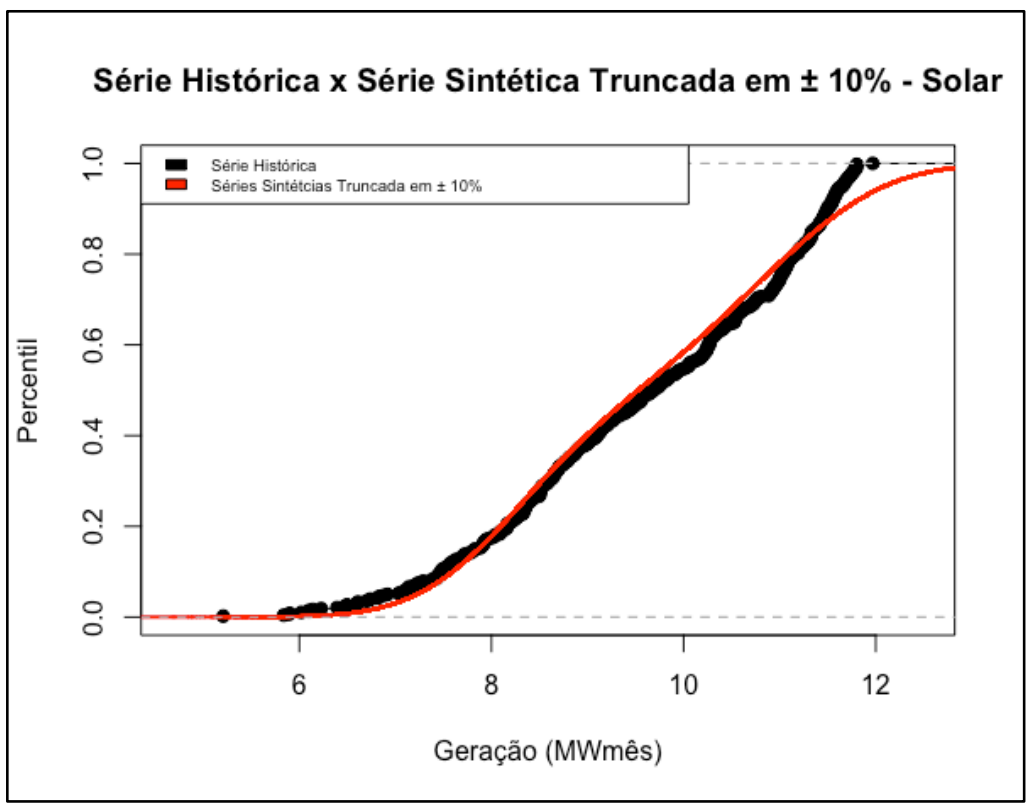

Figura 25 - Comparação entre as Distribuições de Frequências Acumuladas da Série Histórica e da Série Sintética de Produção Solar Truncada em $\pm 10 \%$

Também foi realizada uma análise de sensibilidade com o truncamento da série sintética em $\pm 5 \%, \pm 10 \%, \pm 15 \%$ e $\pm 20 \%$ dos correspondentes valores máximos e mínimos da série histórica. Os boxplots resultantes desta análise de sensibilidade podem ser visualizados na Figura 26.

Ao se analisar o boxplot da série sintética original (i.e., sem aplicação de limites) verifica-se a existência de valores discrepantes superiores. Também, as próprias cercas superior e inferior da série sintética original estão respectivamente acima e abaixo daquelas da série histórica, sugerindo a possibilidade de truncamento da série sintética original. Ao se aplicar os limites de $\pm 5 \%, \pm 10 \%, \pm 15 \%$ e $\pm 20 \%$ aos valores máximos e mínimos da série sintética em relação aos valores da série histórica, observa-se pelos boxplots da Figura 26 que deixam de existir valores discrepantes, e os valores das cercas superior e inferior correspondem aos limites aplicados. 


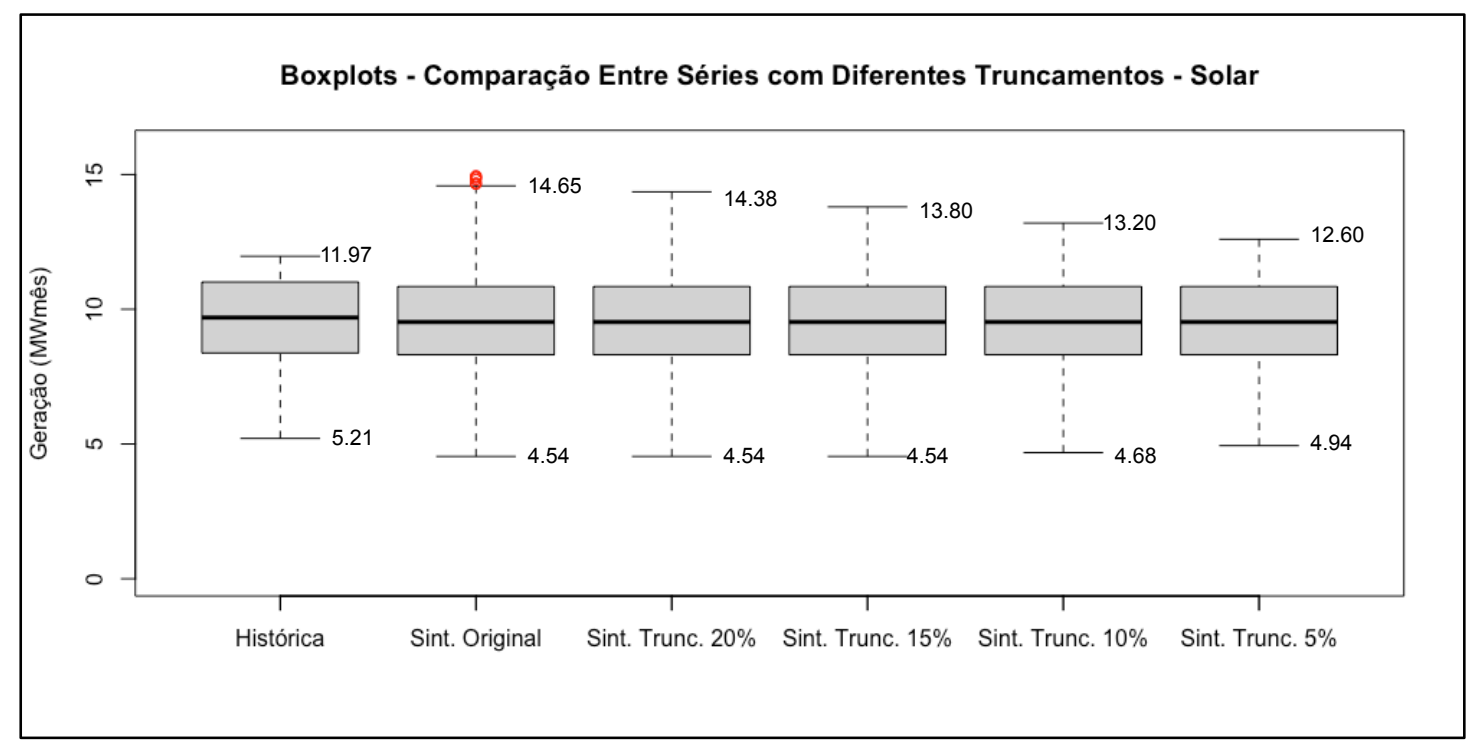

Figura 26 - Boxplots da Série Histórica e da Série Sintética sob Diferentes Truncamentos Solar

Novamente, para apoiar a decisão com relação à escolha do limite de truncamento a ser adotado, analisaram-se os fatores de capacidades disponibilizados nos boletins mensais de geração solar fotovoltaica do ONS (2021), para usinas em operação na região Nordeste e no estado do Ceará.

Desta análise, concluiu-se que era razoável a adoção de um limite de truncamento para a série sintética de produção de energia solar igual a $\pm 10 \%$ dos valores máximo e mínimo observados na série histórica. Assim, o limite inferior considerado para os cenários sintéticos da tecnologia solar fotovoltaica foi fixado em 4,68 MWmês (o que corresponde a 11,70\% de fator de capacidade) e o limite superior em 13,20 MWmês (o que corresponde a 33,00\% de fator de capacidade).

A Tabela 13 apresenta a comparação das estatísticas dos dados da série histórica de produção de energia solar fotovoltaica com as estatísticas da série sintética com valores extremos limitados, adotada nesta dissertação.

Finalmente, tanto a série histórica quanto a série sintética do arranjo híbrido são obtidas, respectivamente, pela soma dos valores correspondentes das séries históricas e sintéticas truncadas das tecnologias eólica e solar. A Tabela 14 apresenta, para o arranjo híbrido, estatísticas da série histórica e da série sintética de produção de energia. Percebe-se que o valor máximo de produção de energia pelo arranjo híbrido nas 2.000 séries sintéticas foi $73 \%$ da capacidade instalada de $200 \mathrm{MW}$, ao passo que com a série histórica este valor atingiu $69 \%$. 
Tabela 13 - Comparação entre Estatísticas em Base Mensal da Série Histórica e da Série Sintética Truncada em $\pm 10 \%$ - Tecnologia Solar

\begin{tabular}{|c|c|c|c|c|}
\hline \multirow{2}{*}{ Base Mensal } & \multicolumn{2}{|c|}{ Tecnologia Solar Fotovoltaica (Usina de $\mathbf{4 0}$ MW) - Série Sintética Com Limites } \\
\cline { 2 - 5 } & $\begin{array}{c}\text { Série Histórica } \\
\text { (MWmês) }\end{array}$ & $\begin{array}{c}\text { Fator de } \\
\text { Capacidade (\%) }\end{array}$ & $\begin{array}{c}\text { Série Sintética } \\
\text { (MWmês) }\end{array}$ & $\begin{array}{c}\text { Fator de } \\
\text { Capacidade (\%) }\end{array}$ \\
\hline Mínimo & 5,21 & 13,02 & 4,68 & 11,70 \\
\hline Percentil 25\% & 8,38 & 20,95 & 8,31 & 20,78 \\
\hline Mediana & 9,69 & 24,23 & 9,53 & 23,82 \\
\hline Média & 9,58 & 23,95 & 9,59 & 23,97 \\
\hline Percentil 75\% & 11,00 & 27,50 & 10,85 & 27,11 \\
\hline Máximo & 11,97 & 29,93 & 13,20 & 33,00 \\
\hline Desvio Padrão & 1,53 & - & 1,56 & - \\
\hline Coef. de Variação & $15,97 \%$ & - & $16,25 \%$ & - \\
\hline
\end{tabular}

Tabela 14 - Comparação entre Estatísticas em Base Mensal da Série Histórica e da Série Sintética com Limitesde $\pm 10 \%$ - Arranjo Híbrido com Tecnologias Eólica e Solar

\begin{tabular}{|c|c|c|c|c|}
\hline \multirow{2}{*}{ Base Mensal } & \multicolumn{3}{|c|}{ Arranjo Híbrido (Usina de 200 MW) - Série Sintética Com Limites } \\
\cline { 2 - 5 } & $\begin{array}{c}\text { Série Histórica } \\
\text { Eólica + Série } \\
\text { Histórica Solar } \\
\text { (MWmês) }\end{array}$ & $\begin{array}{c}\text { Fator de } \\
\text { Capacidade (\%) }\end{array}$ & $\begin{array}{c}\text { Série Sintética } \\
\text { Eólica + Série } \\
\text { Histórica Solar } \\
\text { (MWmês) }\end{array}$ & $\begin{array}{c}\text { Fator de } \\
\text { Capacidade (\%) }\end{array}$ \\
\hline Mínimo & 24,04 & 12,02 & 22,84 & 11,42 \\
\hline Percentil 25\% & 77,79 & 38,90 & 75,26 & 37,63 \\
\hline Mediana & 100,60 & 50,30 & 97,45 & 48,73 \\
\hline Média & 96,41 & 48,21 & 96,17 & 48,09 \\
\hline Percentil 75\% & 118,47 & 59,24 & 117,56 & 58,78 \\
\hline Máximo & 137,89 & 68,95 & 145,98 & 72,99 \\
\hline Desvio Padrão & 26,33 & - & 23,54 & - \\
\hline Coef. de Variação & $27,31 \%$ & - & $24,47 \%$ & - \\
\hline
\end{tabular}

\section{5}

\section{Desagregação da Produção de Energia em Base Mensal para Base} Horária

Reconhecendo a relevância de se estudar os ganhos potenciais da realização de estudos de viabilidade econômica de usinas híbridas em base horária, os cenários sintéticos de produção de energia, originalmente obtidos em base mensal, necessitam 
ser desagregados em base horária, ou seja, cada valor de geração mensal necessita ser desagregado em 730 valores ${ }^{21}$ horários.

Para tanto, utilizou-se os dados da série histórica para se determinar o que aqui foi denominado "Fatores de Desagregação". Procurou-se obter, para cada tecnologia de geração (eólica e solar fotovoltaica) e para cada hora do dia de cada mês do ano, um fator que representa a variação média, em p.u., da produção de energia da usina, naquela hora, em relação à produção horária média do respectivo mês. As equações 9 , 10 e 11 apresentam a forma de cálculo do Fator de Desagregação para um determinado mês $m$.

$$
\begin{gathered}
\mathrm{FD}_{-} \mathrm{PE}_{h, m}^{f}=\frac{1}{40 * \operatorname{dias}_{m}} * \sum_{a=1}^{40} \sum_{d=1}^{\text {dias }_{m}} \Gamma_{h, d, m, a}^{f} \\
\Gamma_{h, d, m, a}^{f}=\frac{P E_{-} H_{h, d, m, a}^{f}-P E_{-} H M_{m, a}^{f}}{P E_{-} H M_{m, a}^{f}} \\
P E_{-} H M_{m, a}^{f}=\frac{1}{24 * \text { dias }_{m}} * \sum_{h=1}^{24} \sum_{d=1}^{\text {dias }_{m}} P E_{-} H_{h, d, m, a}^{f}
\end{gathered}
$$

onde:

FD_P $E_{h, m}^{f}$ : Fator de Desagregação referente à Produção de Energia da tecnologia $f$, para hora $h$ e para o mês $m$;

$P E_{-} H_{h, d, m, a}^{f}$ : Produção de Energia em Base Horária referente a tecnologia $f$, à hora $h$, ao dia $d$, ao mês $m$ e ano $a$;

$P E_{-} H M_{m, a}^{f}$ : Média da Produção Horária de Energia referente a tecnologia $f$, no mês $m$ e ano $a$;

$\operatorname{dias}_{m} \quad$ : Número de dias no mês $m$;

: Número de horas no dia;

40

: Número de anos com valores "históricos" (reanálise).

Por exemplo, se um Fator de Desagregação igual a 1,25 foi obtido para a hora 1 do mês de Janeiro, isto significa que, ao longo dos 40 meses de janeiro da série

${ }^{21}$ Considerou-se que um mês possui 730 horas. 
histórica, a produção de energia da hora 1 esteve, em média, 25\% acima da geração horária média de todos os meses de janeiro da série histórica.

Após obtidos todos os fatores, ter-se-á 12 conjuntos de 24 valores, cada conjunto representando um mês e cada valor representando uma hora do dia daquele mês. A Tabela 15 e a Tabela 16 apresentam os valores dos Fatores de Desagregação para a tecnologia Eólica distribuídos ao longo das horas do dia de cada mês do ano. Já a Tabela 17 e a Tabela 18 apresentam os Fatores de Desagregação de produção de energia para a tecnologia solar fotovoltaica.

A Figura 27 e a Figura 28 apresentam estes valores de forma gráfica.

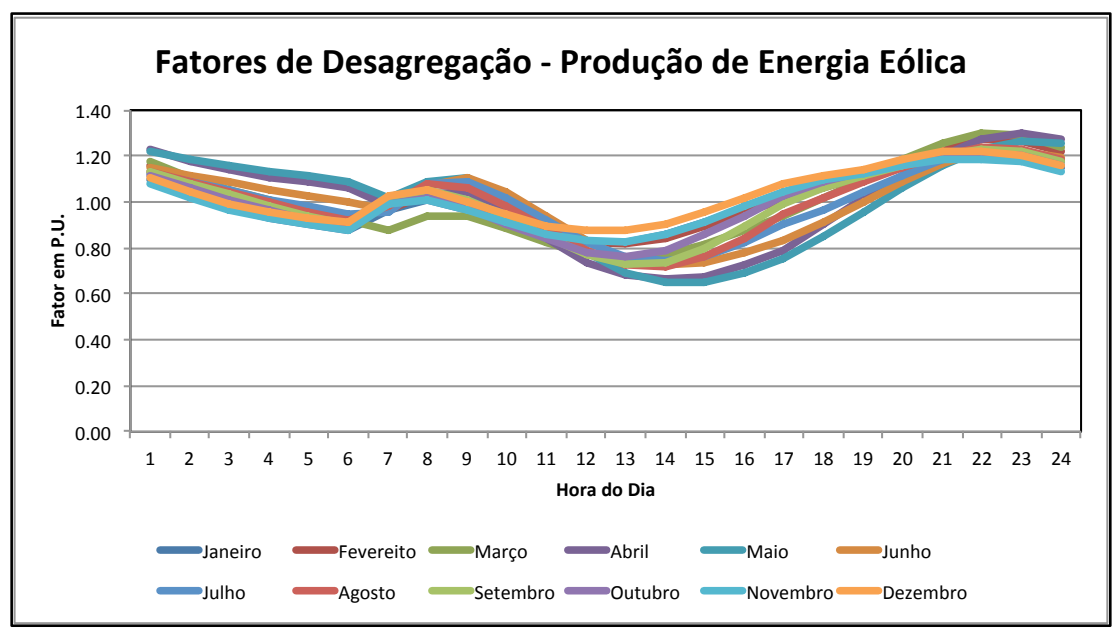

Figura 27 - Fatores de Desagregação para cada Mês do Ano - Solar

Tabela 15 - Fatores de Desagregação para a Tecnologia Eólica - Horas de 1 a 12

\begin{tabular}{|c|c|c|c|c|c|c|c|c|c|c|c|c|c|}
\hline \multirow{2}{*}{\multicolumn{2}{|c|}{$\begin{array}{c}\text { Fatores de Desagregação } \\
\text { Eólica }\end{array}$}} & \multicolumn{12}{|c|}{ Hora do Dia } \\
\hline & & 1 & 2 & 3 & 4 & 5 & 6 & 7 & 8 & 9 & 10 & 11 & 12 \\
\hline \multirow{12}{*}{ Meses } & Janeiro & 1,09 & 1,03 & 0,97 & 0,93 & 0,90 & 0,88 & 0,97 & 1,01 & 0,96 & 0,90 & 0,85 & 0,82 \\
\hline & Fevereito & 1,16 & 1,09 & 1,03 & 0,99 & 0,96 & 0,93 & 0,96 & 1,04 & 1,00 & 0,93 & 0,87 & 0,83 \\
\hline & Março & 1,17 & 1,11 & 1,05 & 1,01 & 0,96 & 0,92 & 0,88 & 0,94 & 0,94 & 0,88 & 0,82 & 0,77 \\
\hline & Abril & 1,23 & 1,18 & 1,14 & 1,11 & 1,08 & 1,06 & 0,98 & 1,04 & 1,04 & 0,96 & 0,84 & 0,74 \\
\hline & Maio & 1,22 & 1,18 & 1,16 & 1,14 & 1,11 & 1,09 & 1,02 & 1,09 & 1,10 & 1,02 & 0,90 & 0,78 \\
\hline & Junho & 1,15 & 1,12 & 1,09 & 1,06 & 1,03 & 1,00 & 0,96 & 1,07 & 1,11 & 1,04 & 0,94 & 0,83 \\
\hline & Julho & 1,13 & 1,09 & 1,05 & 1,01 & 0,98 & 0,95 & 0,96 & 1,08 & 1,08 & 1,02 & 0,92 & 0,83 \\
\hline & Agosto & 1,14 & 1,09 & 1,04 & 1,00 & 0,95 & 0,92 & 0,98 & 1,08 & 1,06 & 0,98 & 0,88 & 0,79 \\
\hline & Setembro & 1,13 & 1,08 & 1,03 & 0,98 & 0,94 & 0,90 & 0,99 & 1,05 & 1,01 & 0,94 & 0,85 & 0,77 \\
\hline & Outubro & 1,11 & 1,06 & 1,01 & 0,96 & 0,92 & 0,89 & 0,99 & 1,02 & 0,97 & 0,90 & 0,84 & 0,78 \\
\hline & Novembro & 1,08 & 1,02 & 0,97 & 0,93 & 0,90 & 0,88 & 0,99 & 1,01 & 0,96 & 0,91 & 0,86 & 0,83 \\
\hline & Dezembro & 1,11 & 1,05 & 0,99 & 0,95 & 0,93 & 0,91 & 1,03 & 1,05 & 1,00 & 0,94 & 0,90 & 0,87 \\
\hline
\end{tabular}


Tabela 16 - Fatores de Desagregação para a Tecnologia Eólica - Horas de 13 a 24

\begin{tabular}{|c|c|c|c|c|c|c|c|c|c|c|c|c|c|}
\hline \multirow{2}{*}{\multicolumn{2}{|c|}{$\begin{array}{c}\text { Fatores de Desagregação } \\
\text { Eólica }\end{array}$}} & \multicolumn{12}{|c|}{ Hora do Dia } \\
\hline & & 13 & 14 & 15 & 16 & 17 & 18 & 19 & 20 & 21 & 22 & 23 & 24 \\
\hline \multirow{12}{*}{ Meses } & Janeiro & 0,83 & 0,86 & 0,91 & 0,97 & 1,03 & 1,07 & 1,10 & 1,15 & 1,19 & 1,21 & 1,20 & 1,15 \\
\hline & Fevereito & 0,82 & 0,85 & 0,89 & 0,95 & 1,01 & 1,06 & 1,11 & 1,18 & 1,24 & 1,27 & 1,27 & 1,22 \\
\hline & Março & 0,75 & 0,77 & 0,82 & 0,88 & 0,94 & 1,02 & 1,10 & 1,18 & 1,25 & 1,30 & 1,29 & 1,24 \\
\hline & Abril & 0,68 & 0,66 & 0,68 & 0,72 & 0,79 & 0,90 & 1,01 & 1,11 & 1,20 & 1,27 & 1,30 & 1,27 \\
\hline & Maio & 0,69 & 0,65 & 0,65 & 0,69 & 0,75 & 0,85 & 0,96 & 1,06 & 1,16 & 1,23 & 1,26 & 1,26 \\
\hline & Junho & 0,76 & 0,72 & 0,73 & 0,78 & 0,84 & 0,91 & 1,00 & 1,09 & 1,17 & 1,22 & 1,22 & 1,20 \\
\hline & Julho & 0,76 & 0,74 & 0,77 & 0,83 & 0,90 & 0,97 & 1,04 & 1,11 & 1,18 & 1,22 & 1,21 & 1,17 \\
\hline & Agosto & 0,73 & 0,72 & 0,76 & 0,84 & 0,94 & 1,02 & 1,09 & 1,15 & 1,20 & 1,24 & 1,23 & 1,19 \\
\hline & Setembro & 0,73 & 0,74 & 0,80 & 0,89 & 0,99 & 1,06 & 1,11 & 1,16 & 1,20 & 1,22 & 1,22 & 1,18 \\
\hline & Outubro & 0,76 & 0,79 & 0,85 & 0,94 & 1,03 & 1,09 & 1,13 & 1,17 & 1,20 & 1,21 & 1,20 & 1,16 \\
\hline & Novembro & 0,83 & 0,86 & 0,91 & 0,98 & 1,05 & 1,09 & 1,13 & 1,16 & 1,18 & 1,19 & 1,17 & 1,13 \\
\hline & Dezembro & 0,88 & 0,91 & 0,96 & 1,02 & 1,08 & 1,12 & 1,14 & 1,19 & 1,22 & 1,22 & 1,20 & 1,16 \\
\hline
\end{tabular}

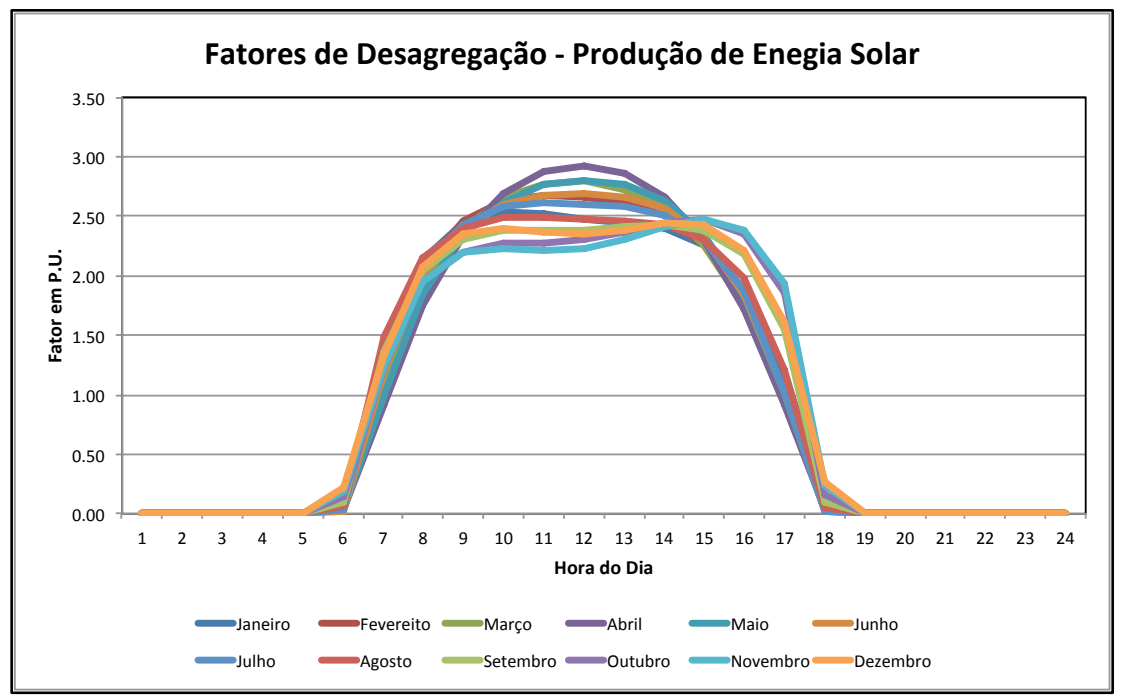

Figura 28 - Fatores de Desagregação para cada Mês do Ano - Solar

Tabela 17 - Fatores de Desagregação para a Tecnologia Solar Fotovoltaica - Horas de 1 a 12

\begin{tabular}{|c|c|c|c|c|c|c|c|c|c|c|c|c|c|}
\hline \multirow{2}{*}{\multicolumn{2}{|c|}{$\begin{array}{c}\text { Fatores de Desagregação } \\
\text { Solar }\end{array}$}} & \multicolumn{12}{|c|}{ Hora do Dia } \\
\hline & & 1 & 2 & 3 & 4 & 5 & 6 & 7 & 8 & 9 & 10 & 11 & 12 \\
\hline \multirow{12}{*}{ Meses } & Janeiro & 0,00 & 0,00 & 0,00 & 0,00 & 0,00 & 0,16 & 1,39 & 2,13 & 2,44 & 2,53 & 2,52 & 2,48 \\
\hline & Fevereito & 0,00 & 0,00 & 0,00 & 0,00 & 0,00 & 0,14 & 1,32 & 2,05 & 2,45 & 2,63 & 2,67 & 2,66 \\
\hline & Março & 0,00 & 0,00 & 0,00 & 0,00 & 0,00 & 0,06 & 1,10 & 1,89 & 2,39 & 2,66 & 2,78 & 2,79 \\
\hline & Abril & 0,00 & 0,00 & 0,00 & 0,00 & 0,00 & 0,03 & 0,91 & 1,76 & 2,34 & 2,69 & 2,87 & 2,92 \\
\hline & Maio & 0,00 & 0,00 & 0,00 & 0,00 & 0,00 & 0,03 & 0,99 & 1,84 & 2,35 & 2,62 & 2,76 & 2,81 \\
\hline & Junho & 0,00 & 0,00 & 0,00 & 0,00 & 0,00 & 0,03 & 1,19 & 1,99 & 2,40 & 2,60 & 2,67 & 2,68 \\
\hline & Julho & 0,00 & 0,00 & 0,00 & 0,00 & 0,00 & 0,04 & 1,35 & 2,08 & 2,43 & 2,58 & 2,62 & 2,61 \\
\hline & Agosto & 0,00 & 0,00 & 0,00 & 0,00 & 0,00 & 0,07 & 1,49 & 2,15 & 2,41 & 2,49 & 2,50 & 2,48 \\
\hline & Setembro & 0,00 & 0,00 & 0,00 & 0,00 & 0,00 & 0,10 & 1,36 & 2,05 & 2,30 & 2,38 & 2,38 & 2,38 \\
\hline & Outubro & 0,00 & 0,00 & 0,00 & 0,00 & 0,00 & 0,14 & 1,22 & 1,94 & 2,20 & 2,27 & 2,28 & 2,30 \\
\hline & Novembro & 0,00 & 0,00 & 0,00 & 0,00 & 0,00 & 0,18 & 1,24 & 1,95 & 2,19 & 2,23 & 2,21 & 2,23 \\
\hline & Dezembro & 0,00 & 0,00 & 0,00 & 0,00 & 0,00 & 0,22 & 1,33 & 2,07 & 2,35 & 2,40 & 2,36 & 2,35 \\
\hline
\end{tabular}


Tabela 18 - Fatores de Desagregação para a Tecnologia Solar Fotovoltaica - Horas de 13 a 24

\begin{tabular}{|c|c|c|c|c|c|c|c|c|c|c|c|c|c|}
\hline \multirow{2}{*}{\multicolumn{2}{|c|}{\begin{tabular}{|c|} 
Fatores de Desagregação \\
Solar
\end{tabular}}} & \multicolumn{12}{|c|}{ Hora do Dia } \\
\hline & & 13 & 14 & 15 & 16 & 17 & 18 & 19 & 20 & 21 & 22 & 23 & 24 \\
\hline \multirow{12}{*}{ Meses } & Janeiro & 2,45 & 2,40 & 2,26 & 1,89 & 1,17 & 0,17 & 0,00 & 0,00 & 0,00 & 0,00 & 0,00 & 0,00 \\
\hline & Fevereito & 2,61 & 2,50 & 2,26 & 1,80 & 1,03 & 0,14 & 0,00 & 0,00 & 0,00 & 0,00 & 0,00 & 0,00 \\
\hline & Março & 2,73 & 2,57 & 2,26 & 1,74 & 0,96 & 0,07 & 0,00 & 0,00 & 0,00 & 0,00 & 0,00 & 0,00 \\
\hline & Abril & 2,86 & 2,66 & 2,30 & 1,73 & 0,91 & 0,03 & 0,00 & 0,00 & 0,00 & 0,00 & 0,00 & 0,00 \\
\hline & Maio & 2,77 & 2,64 & 2,35 & 1,82 & 1,00 & 0,02 & 0,00 & 0,00 & 0,00 & 0,00 & 0,00 & 0,00 \\
\hline & Junho & 2,66 & 2,56 & 2,32 & 1,85 & 1,02 & 0,02 & 0,00 & 0,00 & 0,00 & 0,00 & 0,00 & 0,00 \\
\hline & Julho & 2,58 & 2,50 & 2,30 & 1,87 & 1,03 & 0,02 & 0,00 & 0,00 & 0,00 & 0,00 & 0,00 & 0,00 \\
\hline & Agosto & 2,46 & 2,43 & 2,30 & 1,98 & 1,21 & 0,05 & 0,00 & 0,00 & 0,00 & 0,00 & 0,00 & 0,00 \\
\hline & Setembro & 2,41 & 2,43 & 2,39 & 2,18 & 1,55 & 0,10 & 0,00 & 0,00 & 0,00 & 0,00 & 0,00 & 0,00 \\
\hline & Outubro & 2,36 & 2,44 & 2,47 & 2,35 & 1,85 & 0,16 & 0,00 & 0,00 & 0,00 & 0,00 & 0,00 & 0,00 \\
\hline & Novembro & 2,31 & 2,42 & 2,48 & 2,38 & 1,94 & 0,24 & 0,00 & 0,00 & 0,00 & 0,00 & 0,00 & 0,00 \\
\hline & Dezembro & 2,39 & 2,45 & 2,43 & 2,21 & 1,61 & 0,26 & 0,00 & 0,00 & 0,00 & 0,00 & 0,00 & 0,00 \\
\hline
\end{tabular}




\section{6 \\ Geração de Cenários para o Preço da Energia Elétrica no Mercado de Curto Prazo}

O preço futuro da energia elétrica negociada no mercado à vista, no Brasil chamado de Preço de Liquidação das Diferenças (PLD), usualmente é considerado um dos principais fatores de risco nas análises de viabilidade econômica de usinas de produção de energia. Assim, é necessário definir e utilizar cenários como forma de representar as possíveis realizações desta variável ao longo do tempo.

Adicionalmente, as análises desta dissertação consideram as análises de viabilidade realizadas em duas bases temporais: mensal e horária. Assim, neste capítulo, será descrita a metodologia empregada para a obtenção dos cenários de PLD nestas duas bases temporais.

Conforme discutido na seção 3.2, a operação do sistema interligado brasileiro baseia-se em um esquema centralizado de otimização, programação e despacho do sistema, realizado pelo ONS. Os modelos de otimização utilizados (NEWAVE, DECOMP e DESSEM), também fornecem, como subproduto do processo de otimização, os custos marginais de operação associados aos diversos estágios de discretização temporal - mensal, semanal e horário. Por sua vez, os custos marginais de operação formam a base de cômputo dos preços no mercado de curto prazo (PLD), calculados pela Câmara de Comercialização de Energia Elétrica (CCEE).

Assim, de forma aderente ao marco regulatório do setor elétrico brasileiro, a abordagem empregada para a geração de cenários de PLD, nas bases mensal e horária, considerará a utilização dos modelos NEWAVE, DECOMP e DESSEM.

\section{1}

\section{Geração de Cenários de PLD em Base Mensal}

Conforme mencionado na seção 3.1, o modelo NEWAVE possui horizonte de planejamento de até 30 anos, com discretização temporal mensal. Após o cálculo da estratégia de operação, é realizada uma simulação final do sistema, adotando 2.000 cenários sintéticos de energias afluentes aos reservatórios, ou considerando 
sequências de registros históricos de vazões. A partir dos resultados desta simulação final são produzidas diversas estatísticas associadas ao desempenho do sistema, entre as quais, os custos marginais de operação (CMOs). Como os custos marginais de operação formam a base do PLD, nesta dissertação os CMOs mensais calculados pelo NEWAVE, limitados aos valores máximo e mínimo regulatório do PLD, serão utilizados como proxies dos PLDs mensais.

Os cenários de PLD em base mensal foram obtidos através da execução do modelo NEWAVE, versão 27, considerando os dados do Plano Decenal de Expansão de Energia 2020-2029 (PDE 2029). Esta plataforma de dados foi estendida repetindose a configuração do sistema relativa ao último ano do PDE 2029. Esta extensão se mostrou necessária uma vez que a plataforma de dados original possui horizonte de 15 anos e as análises de viabilidade que serão realizadas neste trabalho possuem horizonte de estudo de 24 anos, sendo 3 anos o tempo de construção e 21 anos o tempo de operação, ou seja, a vida útil econômica da usina. Em outras palavras, são necessários 21 anos de dados para a execução do planejamento da operação do SIN.

O modelo NEWAVE foi executado considerando séries sintéticas de energias naturais afluentes, obtendo-se 2.000 séries de PLDs mensais, cada qual iniciando em 05/2019 e se estendendo até 12/2047. A média dos cenários de PLD obtidos para o submercado Nordeste, local onde será considerado o desenvolvimento de uma usina híbrida, pode ser vista na Figura 29.

De forma a ilustrar a variabilidade destas séries de PLD, apresenta-se na Figura 30 uma comparação da média das 2.000 séries (linha mais espessa) com as 100 primeiras séries de PLDs geradas a partir da plataforma de dados estendida do PDE 2029.

Percebe-se nesta figura que, após o $15^{\circ}$ ano ( $180^{\circ}$ mês), os dados perdem a tendência de elevação verificada até então. Este comportamento era esperado, tendo em vista após o $15^{\circ}$ ano a configuração adotada se torna estática, ou seja, inalterada, com as variações do PLD médio devendo-se apenas ao comportamento hidrológico sazonal ao longo do ano. 


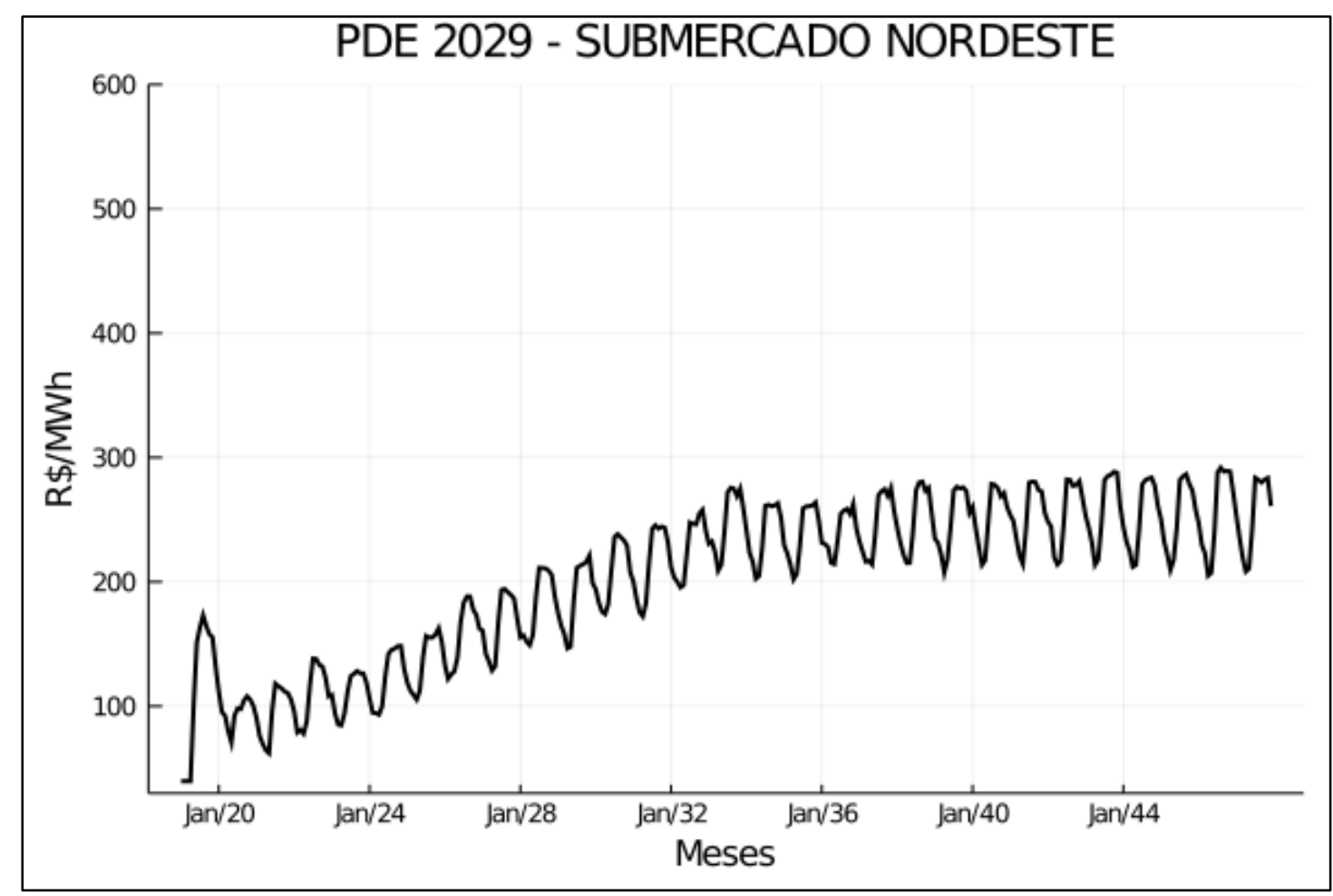

Figura 29 - Média das 2.000 Séries de PLDs Mensais Geradas a partir da Plataforma de Dados Estendida do PDE 2029

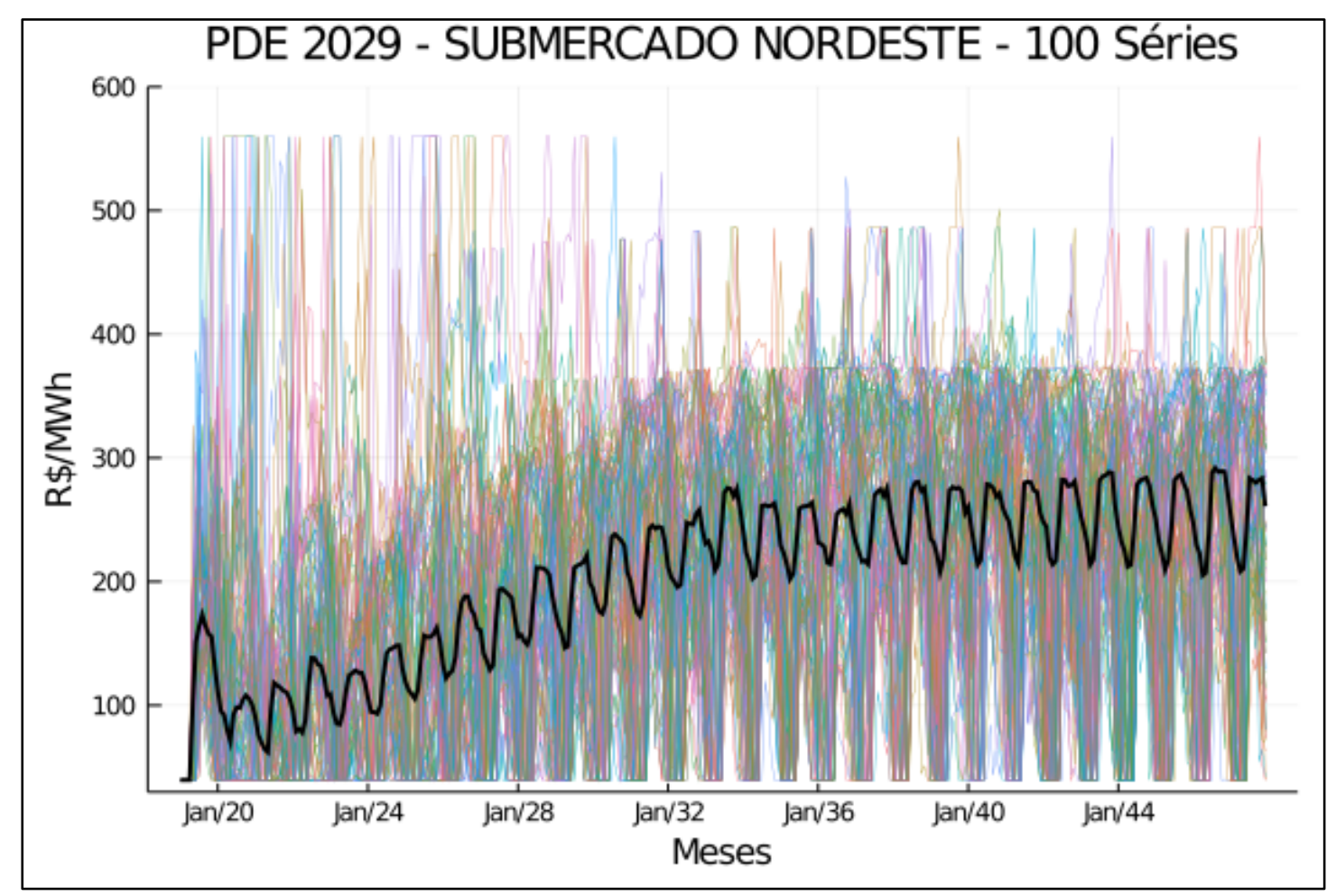

Figura 30 - Comparação da Média das 2.000 Séries de PLDs Mensais com as Primeiras 100 Séries - PDE 2029 Estendido 


\section{2}

\section{Geração de Cenários de PLD em Base Horária}

No Brasil, desde 01/01/2021 o modelo DESSEM é oficialmente empregado na determinação do PLD horário da energia elétrica. Entretanto, o seu horizonte máximo de análise é de duas semanas, ou seja, insuficiente para uma análise de longo prazo.

Por outro lado, conforme discutido na seção 3.2, o DESSEM não é executado de maneira isolada, mas de forma integrada, acoplando-se ao final de seu horizonte à função de custo futuro fornecida pelo modelo DECOMP, que por sua vez também se acopla, ao final de seu horizonte, à uma função de custo futuro fornecida pelo modelo NEWAVE. Em outras palavras, o PLD horário recebe influência das decisões operativas tomadas pelos modelos de longo/médio e de curto prazos.

Para se obter cenários de PLDs horários para horizontes com vários anos a frente, necessários para as análises desta dissertação, a estratégia adotada foi desagregar os cenários de PLDs (i.e., CMOs) mensais calculados pelo NEWAVE em valores horários. Para tanto foram determinados Fatores de Desagregação do PLD, obtidos através de uma análise exploratória dos dados históricos de PLD Horário publicados pela CCEE. Tais Fatores de Desagregação são aplicados a cada valor dos cenários de PLDs mensais, os quais são desagregados em 24 valores válidos para as horas de cada dia do mês em questão. As análises realizadas para se chegar aos Fatores de Desagregação do PLD estão descritas nas próximas seções deste capítulo.

\section{2 .1}

\section{Série Histórica de PLD Horário}

Os dados para a realização desta análise foram coletados junto a CCEE, que disponibiliza os dados do PLD em base horária em seu sítio eletrônico (CCEE, 2020). Apesar da precificação horária ter sido oficialmente iniciada somente a partir de 01/01/2021, houve um período anterior em que o modelo DESSEM foi utilizado em fase de testes (em "operação sombra"), e estes dados estão disponíveis desde de Abril de 2018.

Quando da coleta e análise dos PLDs horários, no desenvolvimento da pesquisa desta dissertação, os dados disponibilizados pela CCEE cobriam o período de 17/04/18 a 10/08/20. Assim, optou-se por descartar o período posterior a fevereiro 
de 2020, uma vez que o início da pandemia do COVID-19 reduziu fortemente a demanda de energia e, consequentemente, os PLDs. Ponderou-se que a consideração deste efeito conjuntural, diante de uma janela amostral reduzida, poderia prejudicar a geração de cenários de PLDs para o longo prazo. Desta forma, o período de dados coletados abrangeu o período de 17/04/18 a 29/02/20. Chama-se a atenção, todavia, que o ideal seria a disponibilidade de um período mais abrangente. Na Figura 31, pode-se observar a série temporal em base horária para o submercado Nordeste, região escolhida para os estudos de caso desta pesquisa.

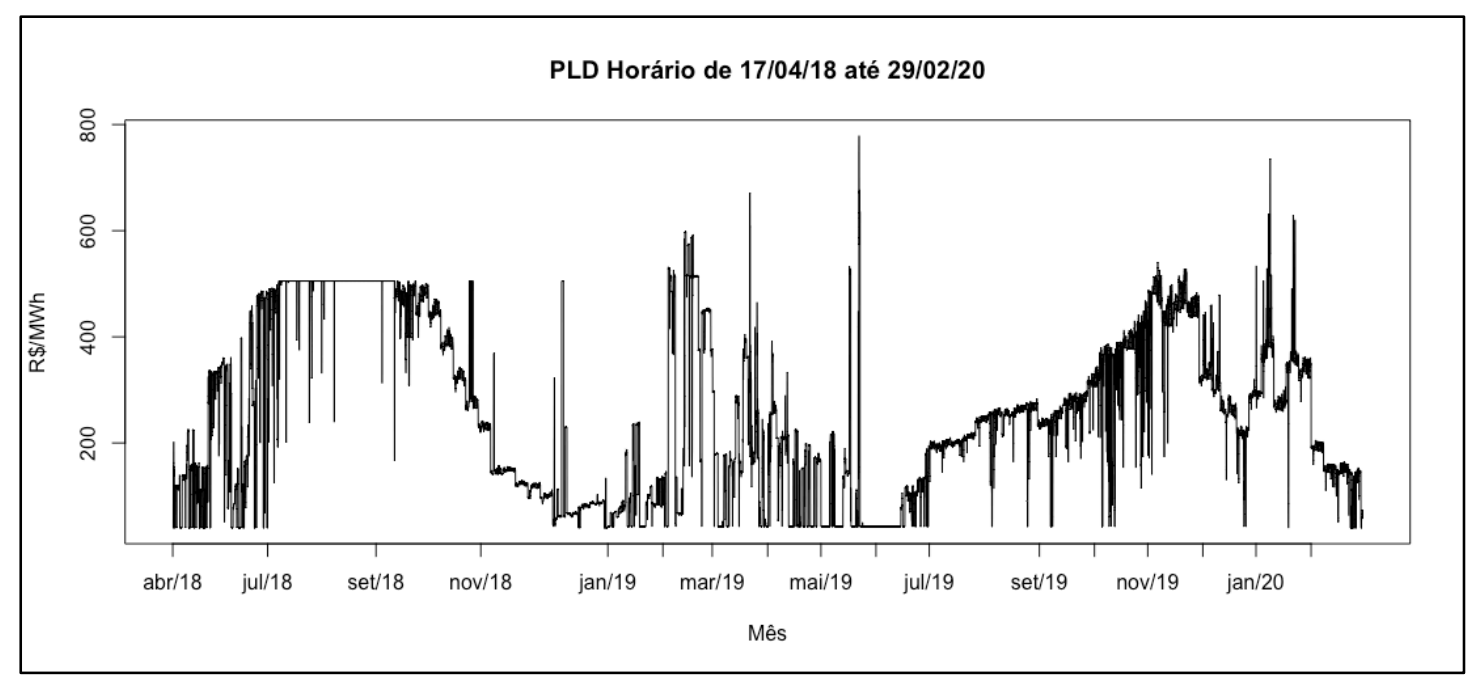

Figura 31 - Série Temporal PLD Horário Nordeste

É possível observar que durante 2018 os dados divulgados estavam limitados a um PLD máximo, igual a 505,18 R\$/MWh. A partir de 2019, os dados divulgados não tiveram mais esta limitação. Para as análises desta pesquisa, utilizou-se os valores históricos de PLDs limitados ao máximo regulatório ${ }^{22}$. Tais valores, conforme estabelecidos na Resolução Homologatória 2498 ANEEL (2018) e na Resolução Normativas ANEEL 858 (2019), são apresentados na Tabela 19.

\footnotetext{
${ }^{22}$ Limites para o PLD: Estes limites são estabelecidos anualmente pela ANEEL. Para estabelecer esses limites, verifica-se qual a usina térmica movida a gás natural de maior custo com contrato regulado para determinação do limite máximo. O limite mínimo é estabelecido pelo maior valor entre a receita recebida pelas usinas que tiveram concessões renovadas ou relicitadas e o custo de operação da usina de Itaipu.
} 
Tabela 19 - Limites para formação do PLD

\begin{tabular}{|r|c|c|}
\hline Ano & 2019 & 2020 \\
\hline Piso PLD (R\$⿳MWh) & 42,35 & 39,68 \\
\cline { 2 - 3 } Teto PLD (R\$⿳MWh) & 513,89 & 559,75 \\
\hline
\end{tabular}

\section{2 .2}

\section{Estratégia de Cálculo dos Fatores de Desagregação}

Algumas alternativas foram exploradas neste trabalho para realizar a desagregação dos cenários de PLDs mensais em valores horários. Em todas as análises, o objetivo foi determinar um conjunto de 24 valores, em p.u., um para cada hora do dia, que pudesse representar adequadamente as variações percentuais do PLD em cada uma destas horas, quando comparado a um determinado valor mensal. $\mathrm{Na}$ Figura 32 é mostrado um conjunto hipotético de valores para um determinado mês do ano.

As primeiras alternativas exploradas foram baseadas na comparação dos PLDs horários da série histórica com o PLD horário médio do respectivo mês, determinando-se assim as variações percentuais médias para cada hora do dia. Entretanto, esta abordagem não capturou adequadamente a variação intradiária do PLD presente na série histórica. Por este motivo, optou-se por outra abordagem, descrita a seguir.

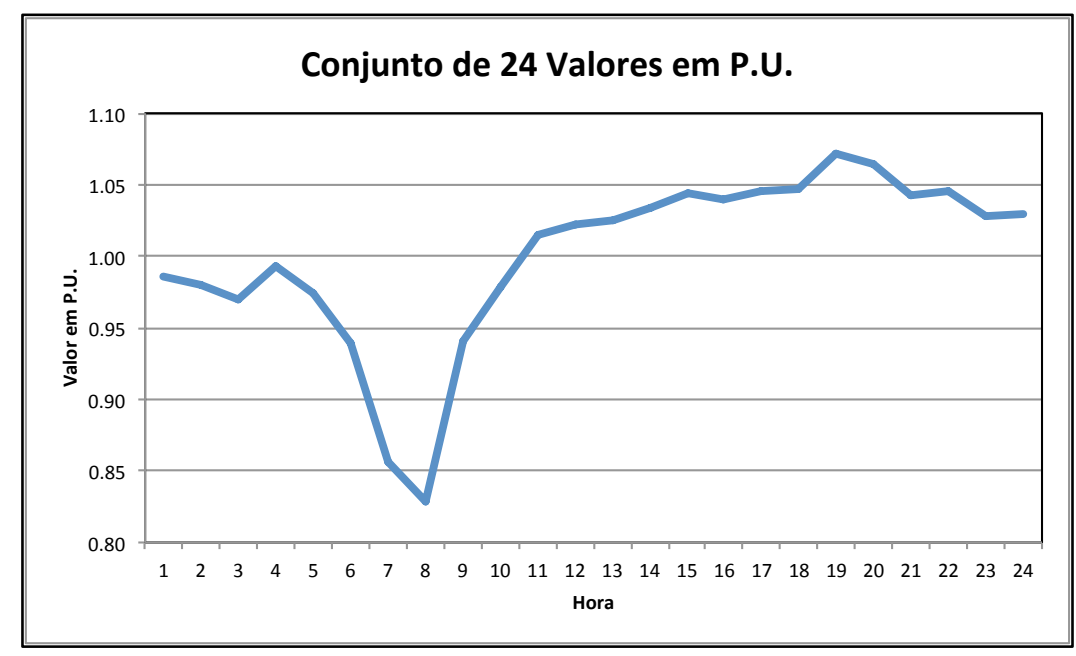

Figura 32 - Conjunto Hipotético de 24 Valores em P.U. 
A estratégia utilizada neste trabalho para a determinação dos Fatores de Desagregação dos PLDs foi a utilização de dados e modelos oficiais. Assim, incialmente, foram empregados: (i) o modelo DECOMP, que até dezembro de 2020, oficialmente fornecia o PLD semanal, calculado para cada um dos três patamares de carga (pesada, média e leve) utilizados nos estudos oficiais de planejamento da expansão e operação (MELO et al., 2018); e (ii) o modelo DESSEM, que desde abril de 2018 foi utilizado em operação sombra para fornecer o PLD horário, e de forma oficial a partir de janeiro de 2021.

Assim, o Fator de Desagregação do PLD foi definido como a variação percentual do PLD de cada hora de cada mês da série histórica, fornecida pelo modelo DESSEM, em relação ao correspondente valor do PLD semanal, em patamares, calculado pelo modelo DECOMP.

A Figura 33 apresenta no mesmo gráfico, para o período estudado, os PLDs calculados pelos modelos DESSEM e DECOMP. Nota-se que há vários períodos em que os resultados dos modelos são bastante diferentes, sobretudo no segundo semestre de 2019. Cabe destacar que a representação do sistema elétrico brasileiro é mais detalhada no modelo DESSEM quando comparada ao modelo DECOMP, e.g., levando em consideração restrições não consideradas neste modelo e a representação $\mathrm{CC}$ da rede de transmissão. Isto contribui para que os PLDs calculados em base horária tendam a ser superiores aos PLDs calculados em base semanal.

Uma vez obtidos os Fatores de Desagregação de PLDs do DECOMP (semanais) para o DESSEM (horários), resta ainda a questão de obtenção de cenários de PLDs semanais futuros, em horizonte compatível com as análises de viabilidade econômico-financeiras, i.e., 21 anos (vide seção 6.1). Para isso, seria necessário processar o modelo DECOMP com os dados do PDE 2029 modificado, o que não é factível visto que se trata de um modelo de planejamento da operação de curto prazo, cujo horizonte é dois meses.

Conforme já visto, o modelo que consegue lidar com horizonte de planejamento de até 30 anos, é o modelo NEWAVE. Assim, uma alternativa seria calcular os fatores de desagregação de PLDs mensais fornecidos pelo NEWAVE em relação aos PLDs horários fornecidos pelo DESSEM. Entretanto, isto não foi possível pois, para cada mês, o NEWAVE não fornece um único valor de PLD mensal, mas um conjunto de 2.000 valores, um para cada cenário hidrológico considerado. Ademais, a opção de se utilizar a média dos 2.000 valores de PLDs para cada mês não 
é interessante, dada a grande variabilidade destas séries de PLD, conforme já ilustrada na Figura 30.

Sendo assim, optou-se nessa dissertação por calcular Fatores de Desagregação determinando a variação percentual dos PLDs horários, obtidos pelo DESSEM, em relação aos valores dos PLDs semanais por patamares determinados pelo DECOMP.

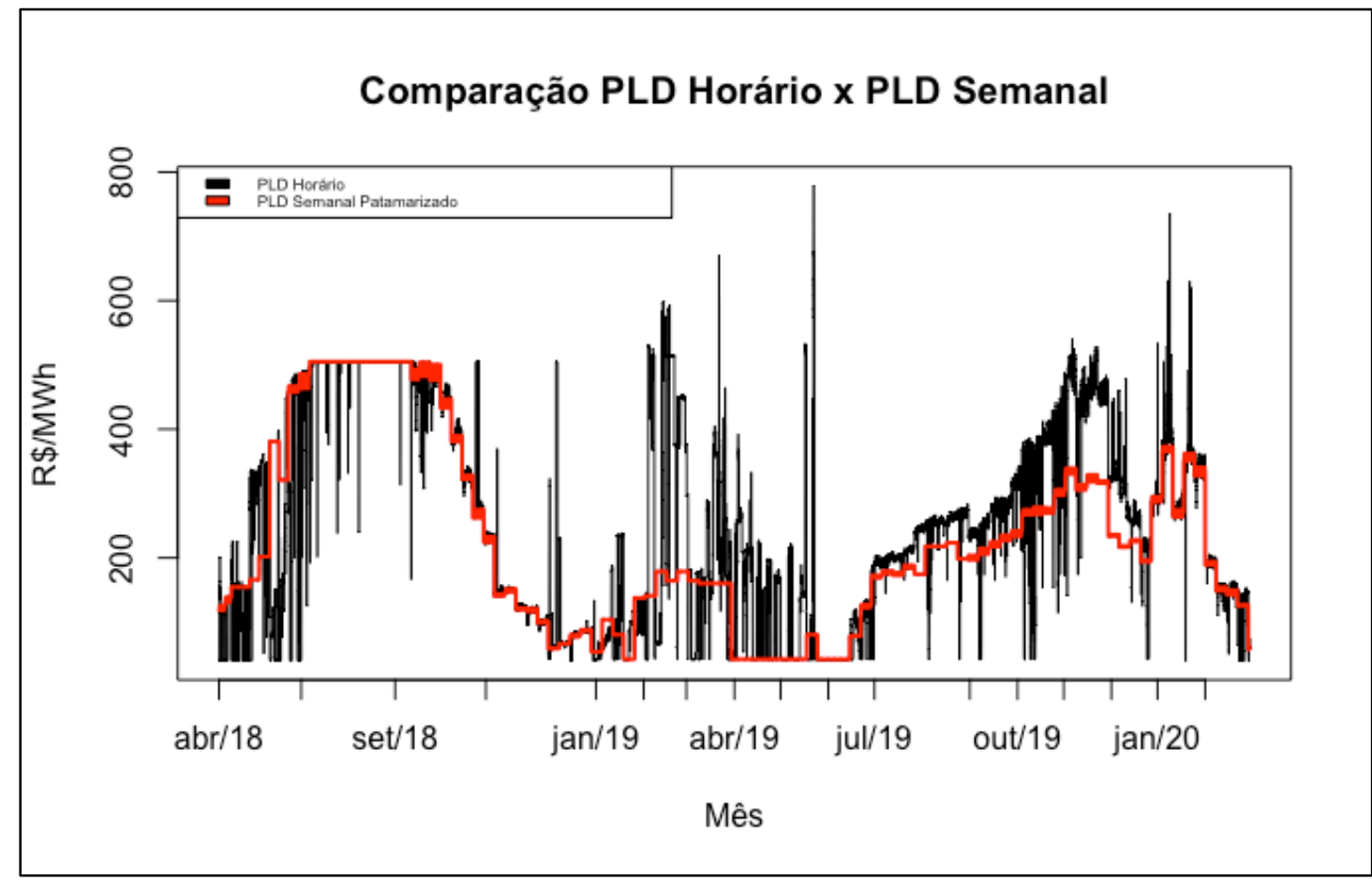

Figura 33 - Comparação do PLD Horário com o PLD Semanal em Patamares

Tratamento similar foi realizado por ZAMBELLI et al. (2019). Com dados disponíveis até Janeiro/19, ZAMBELLI et al. (2019) propuseram um modelo para analisar o risco associado ao PLD Horário, baseado na aplicação de fatores horários sobre a série de PLDs mensais, divididos por patamares de carga, que foram obtidos através do NEWAVE. Os autores obtiveram fatores de modulação para representar os desvios do valor do PLD horário em relação ao PLD Semanal, por patamar de carga, dado pelo modelo DECOMP. No estudo de ZAMBELLI et al. (2019), os autores separaram os meses do ano em três grupos para a realização das análises: Verão (Novembro a Março), Inverno (Maio a Agosto) e Transição (Abril, Setembro e Outubro). Estes fatores de modulação do trabalho de ZAMBELLI et al. (2019) equivalem aos Fatores de Desagregação da presente dissertação. 
A presente dissertação realizou uma análise semelhante à realizada por ZAMBELLI, entretanto, os desvios do valor do PLD horário em relação ao PLD semanal foram calculados para todos os meses do ano e por patamar de carga, conforme descrito na Equação 12.

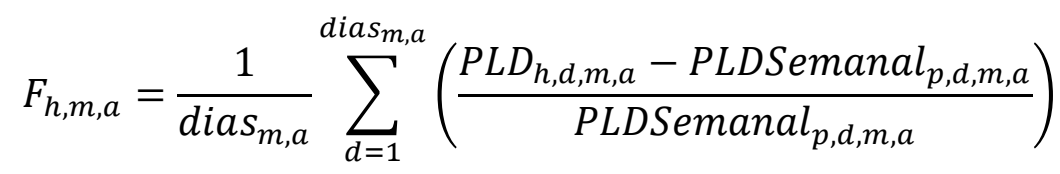

onde:

$F_{h, m, a} \quad:$ Fator de Desagregação referente à hora $h$, do mês $m$, do ano $a$;

$P L D_{h, d, m, a} \quad:$ PLD Horário da hora $h$, dia $d$, mês $m$, do ano $a$;

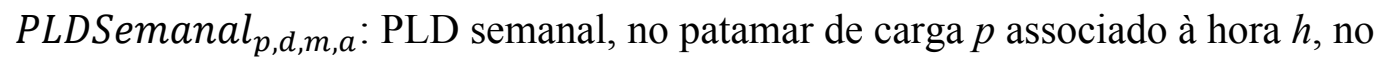
dia $d$, mês $m$, do ano $a$ obtido pelo modelo DECOMP;

$\operatorname{dias}_{m, a} \quad$ : número de dias no mês $m$, do ano $a$;

$m$

: Mês pertencente ao conjunto de meses de Janeiro a Dezembro;

$a$

: Ano pertencente à série histórica de PLDs horários, ou seja, de 2018 a 2020.

A série de valores de PLDs semanais foram obtidos no website da CCEE (CCEE, 2020). Para a comparação mostrada na Figura 33, a associação entre a hora do dia e o patamar de carga foi feita conforme descrito nas Tabela 20 (colunas $2^{\mathrm{a}}$ a $6^{\mathrm{a}}$ feira) e Tabela 21 (MELO et al., 2018).

Tabela 20 - Intervalos Horários dos Patamares de Carga considerando 3 Perfis Típicos para o Ano

\begin{tabular}{|c|c|c|c|c|c|c|}
\hline \multirow{2}{*}{$\begin{array}{c}\text { Patamar de } \\
\text { Carga }\end{array}$} & \multicolumn{2}{|c|}{ Inverno } & \multicolumn{2}{c|}{ Intermediário } & \multicolumn{2}{c|}{ Verão } \\
\cline { 2 - 7 } & 2 a feira & $\begin{array}{c}\text { Sábado, Domingo } \\
\text { e Feriado }\end{array}$ & 2 a a 6 feira & $\begin{array}{c}\text { Sábado, Domingo } \\
\text { e Feriado }\end{array}$ & 2 a a 6a feira & $\begin{array}{c}\text { Sábado, Domingo } \\
\text { e Feriado }\end{array}$ \\
\hline Pesada & $10 h 00-22 h 00$ & & $10 h 00-20 h 00$ & & $10 h 00-18 \mathrm{~h} 00$ & \\
\hline Média & $\begin{array}{c}07 \mathrm{~h} 00-10 \mathrm{~h} 00 \\
22 \mathrm{~h} 00-24 \mathrm{~h} 00\end{array}$ & $18 \mathrm{~h} 00-22 \mathrm{~h} 00$ & $\begin{array}{c}08 \mathrm{~h} 00-10 \mathrm{~h} 00 \\
20 \mathrm{~h} 00-24 \mathrm{~h} 00\end{array}$ & $18 \mathrm{~h} 00-22 \mathrm{~h} 00$ & $\begin{array}{c}08 \mathrm{~h} 00-10 \mathrm{~h} 00 \\
18 \mathrm{~h} 00-24 \mathrm{~h} 00\end{array}$ & $20 \mathrm{~h} 00-23 \mathrm{~h} 00$ \\
\hline Leve & $00 \mathrm{~h} 00-07 \mathrm{~h} 00$ & $\begin{array}{c}00 \mathrm{~h}: 00-18 \mathrm{~h} 00 \\
22 \mathrm{~h} 00-24 \mathrm{~h} 00\end{array}$ & $00 \mathrm{~h} 00-08 \mathrm{~h} 00$ & $\begin{array}{c}00 \mathrm{~h}: 00-18 \mathrm{~h} 00 \\
22 \mathrm{~h} 00-24 \mathrm{~h} 00\end{array}$ & $00 \mathrm{~h} 00-08 \mathrm{~h} 00$ & $\begin{array}{c}00 \mathrm{~h}: 00-20 \mathrm{~h} 00 \\
23 \mathrm{~h} 00-24 \mathrm{~h} 00\end{array}$ \\
\hline
\end{tabular}


Tabela 21 - Agregação dos Meses nos Períodos de Definição dos Intervalos Horários dos Patamares de Carga

\begin{tabular}{|c|c|c|}
\hline Inverno & Intermediário & Verão \\
\hline Maio & Abril & Janeiro \\
\hline Junho & Setembro & Fevereiro \\
\hline Julho & Outubro & Março \\
\hline Agosto & - & Novembro \\
\hline- & - & Dezembro \\
\hline
\end{tabular}

Com o intuito de comparar os PLDs horários e os semanais em uma mesma base temporal, agrupou-se os PLDs horários em patamares de carga, os mesmos patamares de carga considerados pelo modelo DECOMP. A Figura 34 exibe os resultados, ratificando as diferenças entre o PLD horário, calculado pelo DESSEM, e o PLD Semanal calculado pelo DECOMP.

Com intuito de capturar as diferenças observadas na Figura 33, calculou-se os Fatores de Desagregação considerando a variação percentual do PLD horário em relação ao PLD semanal do DECOMP, conforme a Equação 12.

A Figura 35 mostra os Fatores de Desagregação calculados para os meses da série histórica.

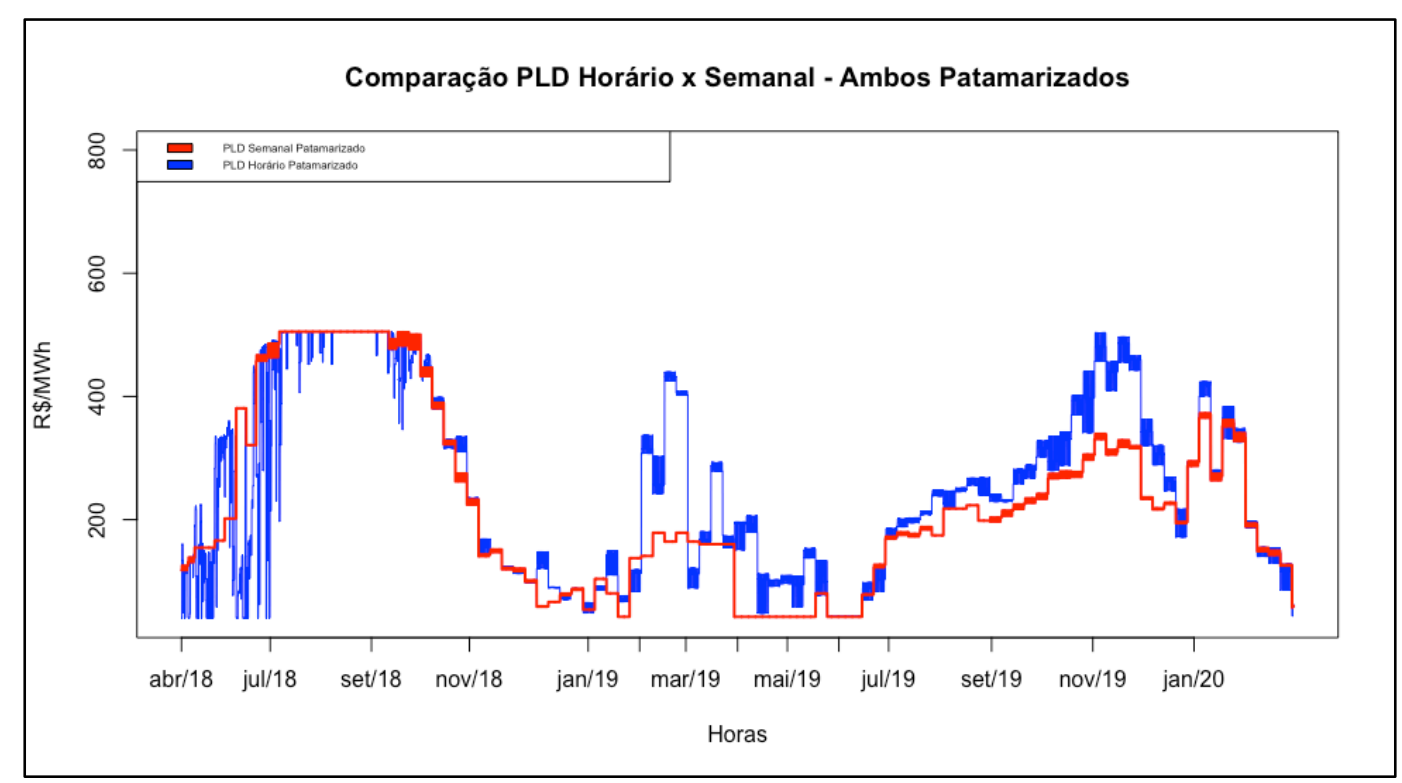

Figura 34 - Comparação do PLD Horário com PLD Semanal na mesma Base Temporal 


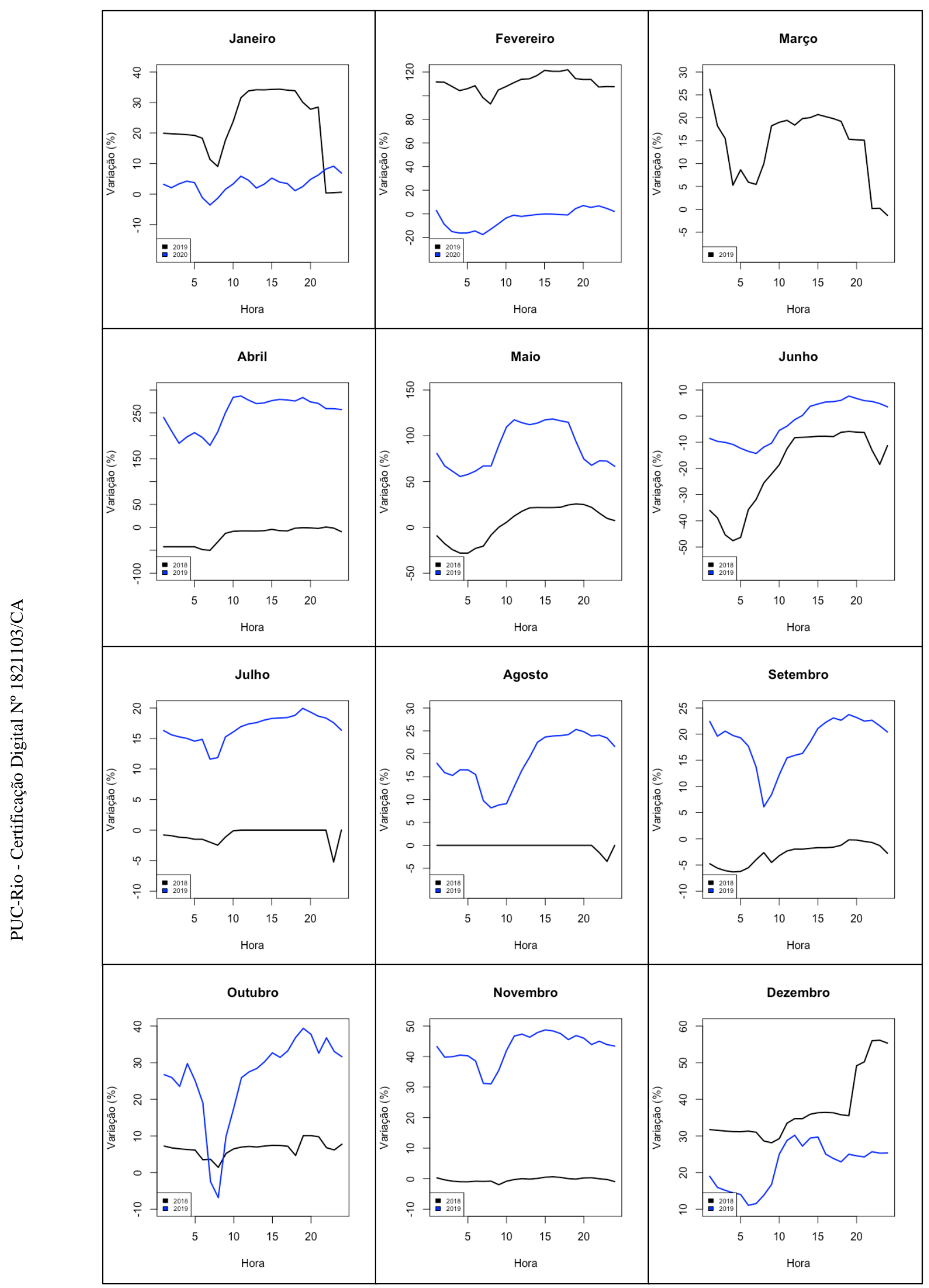

Figura 35 - Fatores de Desagregação Calculados para os Meses da Série Histórica 


\section{2 .3}

\section{Distinção entre Dias Úteis e Não Úteis}

Quando da agregação da curva de carga em patamares, para estudos do setor elétrico, incluindo a sua recente revisão em MELO et al. (2018), houve a separação dos dias úteis ( $2^{\mathrm{a}}$ a $6^{\mathrm{a}}$ feira) dos dias não úteis, conforme consta Tabela 20 (colunas Sábado, Domingo e Feriado), não existindo patamar de carga pesada para os dias não úteis. Por apresentarem menor demanda por energia, os dias não úteis costumam ter PLDs inferiores em relação aos PLDs dos dias úteis. Assim, torna-se relevante analisar o impacto da consideração de Fatores de Desagregação distintos para os dias úteis e os dias não úteis, como também foi feito por ZAMBELLI et al. (2019). Para esta análise, denominou-se os dias úteis como dias Tipo 1 e os dias não uteis como dias Tipo 2. A equação de cálculo destes fatores é apresentada na Equação 13.

$$
F_{h, m, a}^{t}=\frac{1}{\operatorname{dias}_{m, a}^{t}} * \sum_{d=1}^{\text {dias }_{m, a}^{t}} \frac{\left(P L D_{h, d, m, a}^{t}-P L D \text { Semanal }_{p . d . m, a}\right)}{P L D \text { Semanal }_{p, d, m, a}}
$$

onde:

$F_{h, m, a}^{t} \quad:$ Fator de desagregação para os dias tipo $t$, referente a hora $h$, do mês $m$, do ano $a$;

dias $_{m, a}^{t} \quad$ : Número de dias de Tipo $t$ que o mês m possui no ano $a$;

$P L D_{h, d, m, a}^{t} \quad:$ PLD referente à hora $h$, do dia $d$, do tipo $t$ ocorrido no mês $m$, do ano $a$ obtido pelo modelo DESSEM;

PLDSemanal $_{p, d, m, a}$ : PLD referente ao patamar $p$ da hora $h$, do dia $d$ ocorrido no mês $m$, do ano $a$ obtido pelo modelo DECOMP;

$m$

: Mês pertencente ao conjunto de meses de Janeiro a Dezembro;

$a$

: Ano pertencente à série histórica de PLDs horários, ou seja, de 2018 a 2020.

A Figura 36 e a Figura 37 apresentam, de forma exemplificativa, Fatores de Desagregação calculados sem e com a distinção entre os dias úteis e não úteis para os meses de janeiro e fevereiro. Nestas figuras, apresentam-se três curvas, todas calculadas com base nos valores semanais em patamares dados pelo DECOMP, sendo que a curva em vermelho (representada pela legenda "Tipo 1") foi calculada 
considerando os dias úteis e a curva em verde (representada pela legenda "Tipo 2") levou em conta os dias não-úteis. Já a curva em azul (representada pela legenda "PLD Semanal Patamarizado") são os fatores calculados sem a distinção dos dias da semana. De maneira geral, os dias úteis (“Tipo 1") possuem valores de PLD superiores aos dias não-úteis (“Tipo 2") ”), consequentemente, a sua variação em relação ao PLD Semanal é maior. Assim, a curva de dias úteis (“Tipo 1") aparece acima das outras duas curvas, enquanto a curva de dias não úteis (“Tipo 2") se posiciona inferiormente em relação às outras duas curvas.

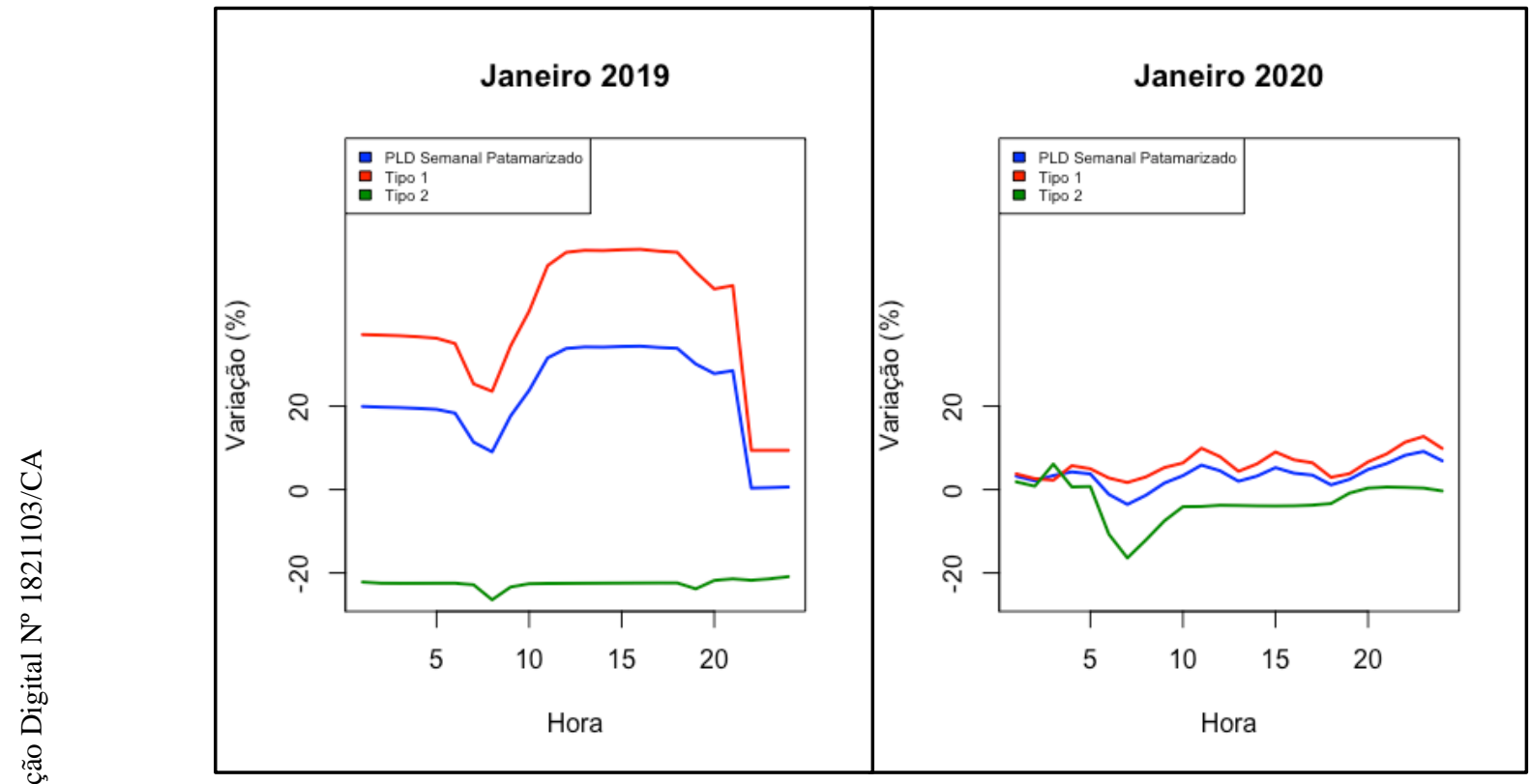

Figura 36 - Fatores de Desagregação com relação ao PLD Semanal em Patamares com a Distinção de Dias Úteis para o Mês de Fevereiro

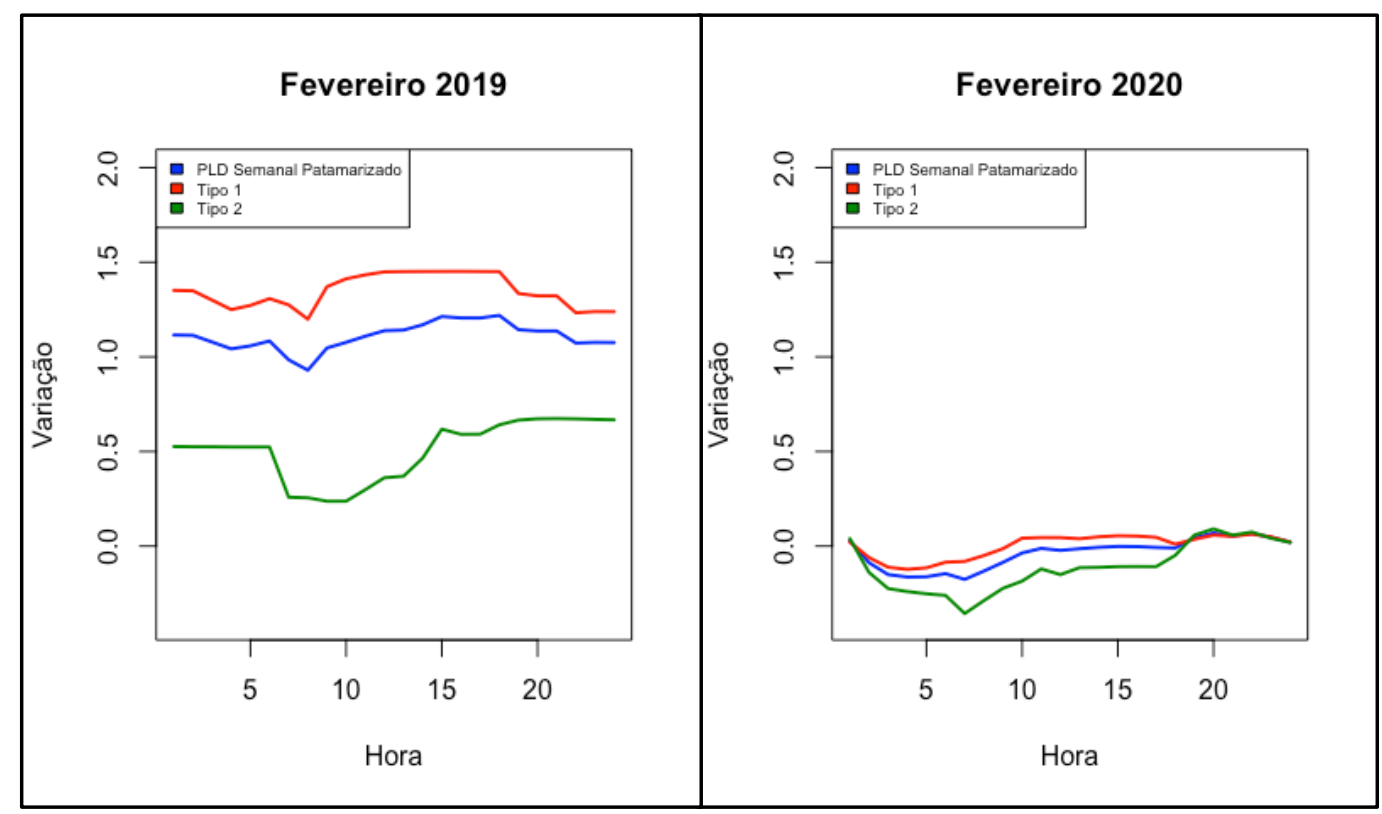

Figura 37 - Fatores de Desagregação com relação ao PLD Semanal em Patamares com a Distinção de Dias Úteis para o Mês de Fevereiro 


\section{2 .4}

\section{Obtenção de Fatores de Desagregação para Cada Dia da Série Histórica}

Tendo em vista a recente implantação do PLD horário no Brasil, a partir de janeiro de 2021, e a curta série histórica disponível, incluindo o período em que foram divulgados valores "sombra" para o PLD horário, ponderou-se que a determinação de um único Fator de Desagregação para cada mês da série histórica, mesmo com a distinção entre os dias úteis e não úteis, poderia não ser suficiente para representar as possibilidades futuras de realização desta variável. Por este motivo, optou-se por definir Fatores de Desagregação para cada dia da série histórica de PLDs horários, ou seja, 30 fatores de desagregação para o mês de abril de 2018, 31 para maio de 2018 e assim sucessivamente.

Na Figura 38 são apresentadas, para cada mês, as ocorrências diárias do PLD horário com a distinção do ano de ocorrência por cores. Estas cores se diferenciam por ano de ocorrência, conforme apresentado na Tabela 22. A linha com maior espessura se refere à média de todas as ocorrências para os meses a que se referem. Na comparação de um mês de um ano com este mesmo mês em outro ano, percebe-se que cada ano possui um comportamento distinto. Como, por exemplo, ao compararmos os meses de janeiro e fevereiro, meses em que os dados correspondem aos anos 2019 e 2020, percebe-se que de Janeiro/19 para Fevereiro/19 houve um aumento no PLD. Já no ano seguinte, de Janeiro/20 para Fevereiro/20, o efeito foi inverso, houve uma redução de um mês para o outro.

Outra forma para visualizar a dispersão dos dados consiste na exposição destes dados através de boxplots. Um exemplo disto pode ser visualizado na Figura $39 \mathrm{em}$ que há um boxplot para cada hora do dia dos meses Janeiro/19 e Janeiro/20. Através da Figura 39, pode-se ver o que foi constatado na Figura 38: a média de Janeiro/20 apresenta um valor superior à media de Janeiro/19. A presença de outliers se destaca na Figura 39. Os boxplots referentes aos outros meses estão presentes no Apêndice A (seção 11.1).

A Figura 40 traz a representação dos Fatores de Desagregação para cada dia da série histórica, também seguindo o código de cores da Tabela 22. A partir dos resultados da Figura 40, nota-se que a utilização de apenas dois possíveis Fatores de Desagregação para cada mês do ano, implica em uma perda relevante de informação 
acerca das possíveis realizações futuras do PLD horário, tendo em vista a pequena sequência histórica disponível.

Desta forma, optou-se neste trabalho por se utilizar um conjunto maior de Fatores de Desagregação, calculado a partir de todos os dias da série histórica, conforme mostrado na Figura 40.

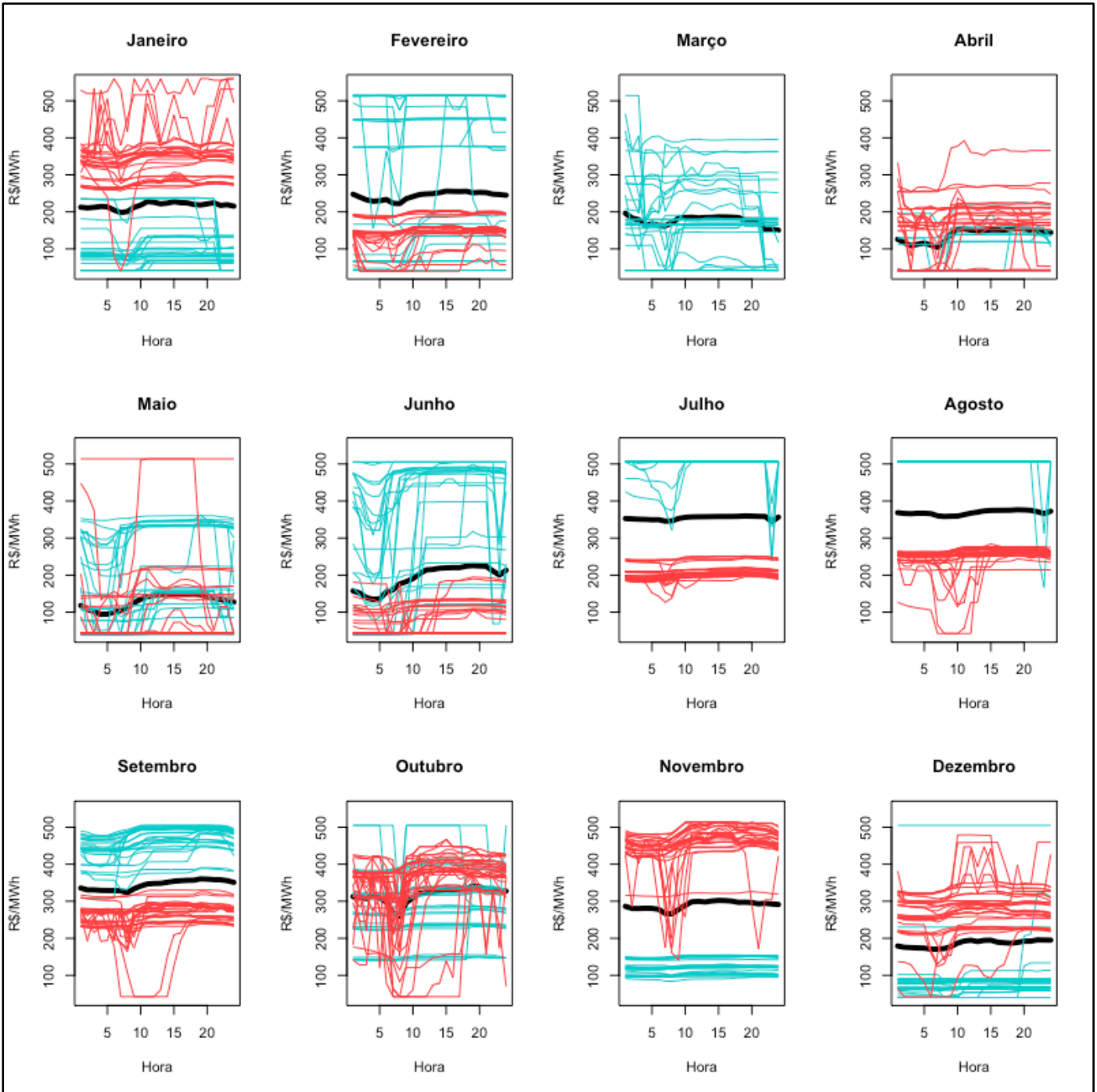

Figura 38 - Séries Históricas Diárias de PLDs Horários 
Tabela 22 - Referências de Cores para os Resultados

\begin{tabular}{|c|c|c|}
\hline & Azul & Vermelho \\
\hline Janeiro & 2019 & 2020 \\
\hline Fevereiro & 2019 & 2020 \\
\hline Março & 2019 & - \\
\hline Abril & 2018 & 2019 \\
\hline Maio & 2018 & 2019 \\
\hline Junho & 2018 & 2019 \\
\hline Julho & 2018 & 2019 \\
\hline Agosto & 2018 & 2019 \\
\hline Setembro & 2018 & 2019 \\
\hline Outubro & 2018 & 2019 \\
\hline Novembro & 2018 & 2019 \\
\hline Dezembro & 2018 & 2019 \\
\hline
\end{tabular}

Janeiro 2019

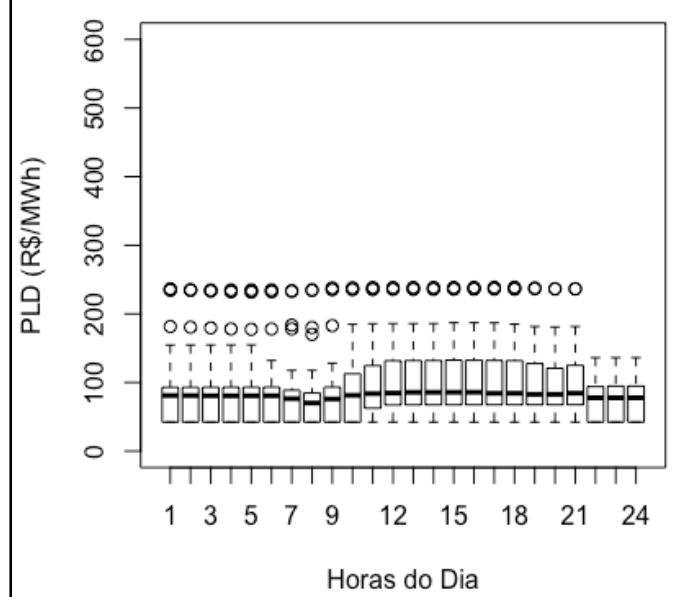

Janeiro 2020

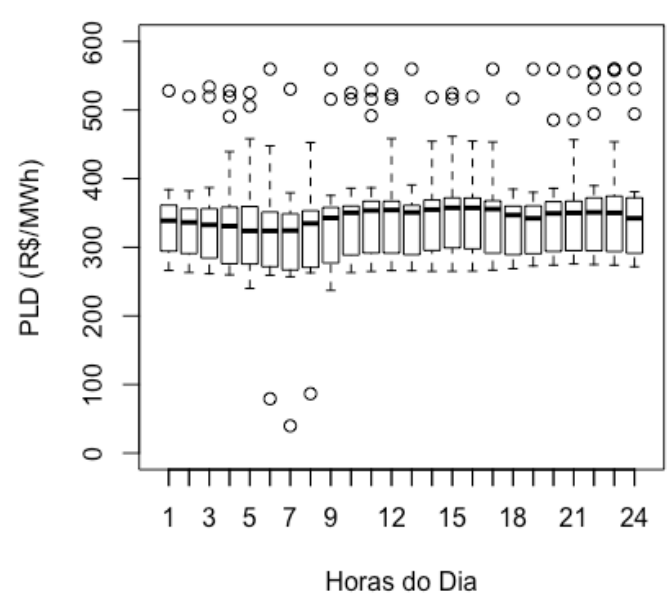

Figura 39 - Boxplots com PLDs das Horas de Janeiro 


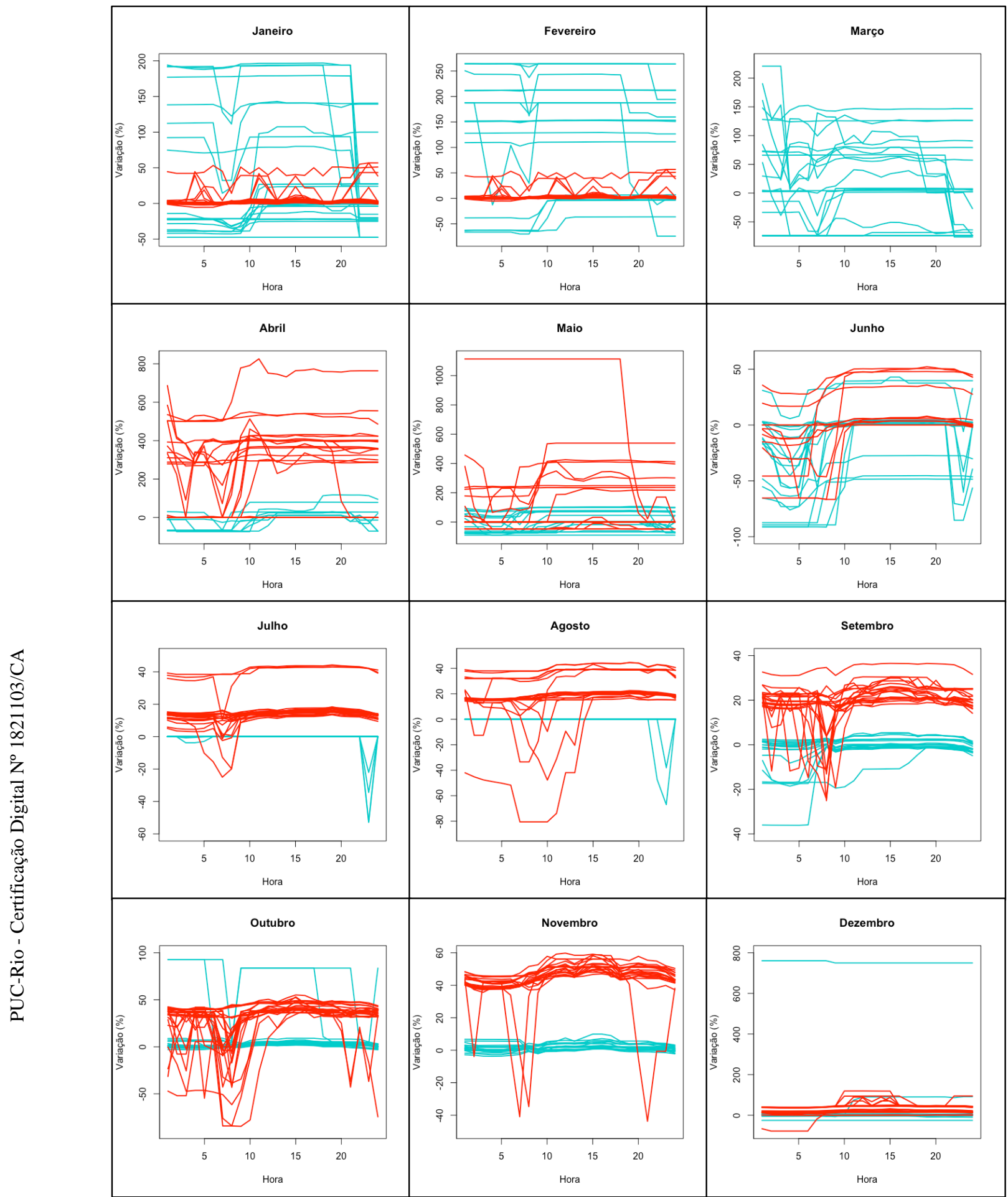

Figura 40 - Perfis Diários em Termos de Variação do PLD Horário em Relação ao PLD Semanal por Patamar de Carga 


\section{2 .5}

\section{Estratégia de Desagregação de PLDs Mensais em Horários}

As análises realizadas nas seções 6.2.1 a 6.2 .4 conduziram às seguintes conclusões:

○ os perfis diários de PLDs horários apresentam grande variação dentro de um mesmo mês, e com relação ao mesmo mês em anos distintos;

- o uso de Fatores de Desagregação médios para cada mês pode não ser adequado, pois tais médias não seriam representativas, tendo em vista a pequena janela de dados históricos;

○ o uso de Fatores de Desagregação médios tende a suavizar as oscilações do PLD intradiário;

○ os Fatores de Desagregação calculados para os dias úteis são distintos daqueles calculados para os dias não úteis;

○ os Fatores de Desagregação calculados para cada dia dentro do mês se mostraram bastante distintos uns dos outros; logo, o seu uso tende a proporcionar uma melhor representação do comportamento do PLD horário dentro dos diferentes cenários a serem construídos para a realização da análise de viabilidade econômica.

Desta forma, a estratégia de desagregação a ser adotada para a obtenção de PLDs horários a partir de cenários de PLDs mensais será a seguinte:

- geração de cenários de CMOs mensais como proxies dos PLDs mensais por meio do modelo NEWAVE;

- para o mês e o cenário em questão sorteia-se, entre os fatores de desagregação diários calculados para todos os anos do histórico de dados, um perfil para os dias úteis e outro perfil para representar os dias não úteis;

○ todos os dias úteis deste mês terão o seu PLD horário determinado pela multiplicação do fator de desagregação de cada hora do dia pelo PLD mensal. O mesmo é feito para os dias não úteis (final de semana e feriados).

Este perfil citado anteriormente é representado através dos fatores de desagregação obtidos pela Equação 14. 


$$
F_{d, h, m, a}^{t}=\frac{\left(P L D_{h, d, m, a}^{t}-P L D \text { Semanal }_{p, d, m, a}\right)}{P L D \text { Semanal }}
$$

onde:

$$
\begin{array}{ll}
F_{d, h, m, a}^{t} & : \text { Fator de desagregação para os dias } d \text { de tipo } t \text {, referente a hora } \\
& h, \text { do mês } m, \text { do ano } a ; \\
P L D_{h, d, m, a}^{t} & : \text { PLD referente a hora } h, \text { do dia } d \text { do tipo } t \text { ocorridos no mês } m \\
& \text { obtido pelo modelo DESSEM; } \\
P L D S e m a n a l_{p, d, m, a}: & \text { PLD referente ao patamar } p, \text { referente à hora } h \text {, do dia } d \\
& \text { ocorrido no mês } m \text { obtido pelo modelo DECOMP; } \\
m & : \text { mês pertencente ao conjunto de meses de Janeiro a Dezembro; } \\
a & : \text { Ano pertencente à série histórica de PLDs horários, ou seja, de } \\
& 2018 \text { a } 2020 .
\end{array}
$$

Os fatores obtidos formarão 24 conjuntos de Fatores de Desagregação, um para cada mês da série histórica. Em cada mês serão calculados Fatores de Desagregação para dia úteis e dias não úteis. Cada conjunto terá o número de Fatores de Desagregação igual ao número de dias que o respectivo tipo de dia possui na amostra histórica. Por exemplo, há 62 dias para o mês de janeiro, uma vez que há dois “Janeiros” na série histórica. Estes 62 dias geram 62 Fatores de Desagregação, cada um com 24 valores, um para cada hora do dia. Estes 62 grupos são divididos em dois conjuntos de dias: dias tipo 1 (dias úteis) e dias tipo 2 (dias não úteis). Este procedimento é realizado para cada mês, i.e., de Janeiro a Dezembro.

De forma ilustrativa, apresenta-se o seguinte exemplo:

○ sendo $m$ pertencente ao conjunto de meses de Janeiro a Dezembro e $t$ um valor para representar dias Tipo 1 ou Tipo 2, supõe-se que os Fatores de Desagregação apresentados na Tabela 23 foram obtidos com os dados do mês $m$ (qualquer mês de Janeiro a Dezembro) e para dias do Tipo t. Cada linha desta tabela representa um conjunto de fatores obtidos com dados de 24 horas de um dia da amostra referente ao mês $m$ para dias do Tipo $t$;

- durante o estudo de viabilidade econômica, para o mês $m$ de um dos anos da análise, supõe-se que se sorteou a primeira linha a Tabela 23; 
o para este mês $m$, supõe-se, hipoteticamente, que o valor de PLD mensal dado pelo NEWAVE correspondeu a R\$100/MWh.

Assim, após realizar os cálculos, obtém-se valores de PLD para as 24 horas dos dias Tipo t. Estes serão iguais aos valores apresentados na Tabela 24.

Tabela 23 - Exemplo de Fatores de Desagregação

\begin{tabular}{|c|c|c|c|c|c|c|c|c|c|}
\hline Hora & $\mathbf{1}$ & $\mathbf{2}$ & $\mathbf{3}$ & $\mathbf{4}$ & $\ldots$ & $\mathbf{2 1}$ & $\mathbf{2 2}$ & $\mathbf{2 3}$ & $\mathbf{2 4}$ \\
\hline \multirow{5}{*}{$\begin{array}{c}\text { Fator de } \\
\text { Desagregação }\end{array}$} & 1,3043 & 1,2943 & 1,2601 & 0,8680 & $\ldots$ & 1,7894 & 1,5858 & 1,2521 & 1,1919 \\
\cline { 2 - 11 } & 0,9135 & 0,9139 & 0,9144 & 0,9148 & $\ldots$ & 0,7853 & 1,1138 & 0,8046 & 0,2895 \\
\cline { 2 - 10 } & $\ldots$ & $\ldots$ & $\ldots$ & $\ldots$ & $\ldots$ & $\ldots$ & $\ldots$ & $\ldots$ & $\ldots$ \\
\cline { 2 - 10 } & 1,074 & 0,2599 & 0,2599 & 0,2599 & $\ldots$ & 2,1671 & 2,1676 & 2,1345 & 1,9435 \\
\cline { 2 - 10 } & 3,881 & 3,881 & 3,881 & 3,8656 & $\ldots$ & 4,2326 & 4,2468 & 4,2427 & 4,2409 \\
\hline
\end{tabular}

Tabela 24 - PLD Horário

\begin{tabular}{|c|c|c|c|c|c|c|c|c|c|}
\hline Hora & $\mathbf{1}$ & $\mathbf{2}$ & $\mathbf{3}$ & $\mathbf{4}$ & $\ldots$ & $\mathbf{2 1}$ & $\mathbf{2 2}$ & $\mathbf{2 3}$ & $\mathbf{2 4}$ \\
\hline PLD Horário & 130,43 & 129,43 & 126,01 & 86,80 & $\ldots$ & 178,94 & 158,58 & 125,21 & 119,19 \\
\hline
\end{tabular}

Este procedimento é realizado para cada mês da análise para dias Tipo 1 e dias Tipo 2. Em seguida, os valores são distribuídos ao longo das 730 horas do mês conforme a Figura 41, ou seja, as semanas (168 horas) são divididas em 5 dias Tipo 1 e 2 dias Tipo 2.

Após isso, tem-se o PLD horário para todas as horas da análise para o mês $m$. Esse procedimento se repete até o final do horizonte de estudo da análise.

\begin{tabular}{|c|c|c|c|c|c|c|}
\hline $120 \mathrm{~h}$ & 48h & $120 \mathrm{~h}$ & $48 \mathrm{~h}$ & $120 \mathrm{~h}$ & $\stackrel{48 \mathrm{~h}}{1}$ & \\
\hline \multicolumn{7}{|c|}{$r$} \\
\hline Tipo 1 & Tipo 2 & Tipo 1 & Tipo 2 & Tipo 1 & Tipo 2 & $\ldots$ \\
\hline \multicolumn{7}{|c|}{1} \\
\hline \multirow{2}{*}{\multicolumn{2}{|c|}{$168 \mathrm{~h}$}} & \multicolumn{2}{|l|}{$T$} & \multicolumn{2}{|c|}{$\nabla$} & \\
\hline & & $168 \mathrm{~h}$ & & \multicolumn{2}{|c|}{$168 \mathrm{~h}$} & \\
\hline & & & $730 \mathrm{~h}$ & & & \\
\hline
\end{tabular}

Figura 41 - Distribuição do PLD Horário ao Longo do Mês 


\section{7 \\ Aplicação da Abordagem Metodológica Proposta}

A metodologia descrita nos capítulos anteriores será utilizada para avaliar a viabilidade econômica de uma usina de geração híbrida hipotética, localizada no litoral do Nordeste Brasileiro, na cidade de Icapuí-CE. A usina híbrida considerada combina as tecnologias de geração eólica e solar fotovoltaica, logo, para efeito de comparação e melhor entendimento dos resultados obtidos estas tecnologias também serão analisadas individualmente.

Para realizar a análise proposta, primeiramente serão apresentadas as principais premissas do estudo de caso. Em seguida, resultados de análises determinísticas, ou seja, considerando apenas um único cenário para os fluxos de caixa do projeto, e de análises probabilísticas, considerando diversos cenários para a realização das principais variáveis de risco do projeto, serão produzidos para cada arranjo, ou seja, para o arranjo híbrido e para as duas tecnologias avaliadas individualmente. Logo após será apresentada uma análise de sensibilidade da viabilidade do empreendimento em relação Montante de Uso do Sistema de Transmissão (MUST) e uma análise relativa ao curtailment, ou seja, com relação à quantidade de energia que se deixaria de injetar na rede em função do MUST contratado ser inferior à potência total do empreendimento.

\section{1}

\section{Estudo de Caso}

As principais premissas para a avaliação econômico financeira do estudo de caso consideradas neste trabalho se encontram apresentadas na Tabela 25, por arranjo tecnológico, e serão detalhadas ao longo deste capítulo. 
Tabela 25 - Premissas do Estudo de Caso

\begin{tabular}{|c|c|c|c|}
\hline Parâmetro & $\begin{array}{c}\text { Valor } \\
\text { Usina Eólica }\end{array}$ & $\begin{array}{c}\text { Valor } \\
\text { Usina Solar }\end{array}$ & $\begin{array}{c}\text { Valor } \\
\text { Usina Híbrida }\end{array}$ \\
\hline Data de Início do Investimento & \multicolumn{3}{|c|}{$\operatorname{Jan} / 21$} \\
\hline Data de Início da Operação & \multicolumn{3}{|c|}{$\mathrm{Jan} / 24$} \\
\hline Data de Início dos Contratos ACR e ACL 1 & \multicolumn{3}{|c|}{$\mathrm{Jan} / 25$} \\
\hline Data de Início dos Contratos ACL 2 & \multicolumn{3}{|c|}{ Jan/24 } \\
\hline Duração do Contrato ACR e ACL 1 & \multicolumn{3}{|c|}{20 anos } \\
\hline Duração do Contrato ACL 2 & \multicolumn{3}{|c|}{1 ano } \\
\hline Potência Total (MW) & 160,00 & 40,00 & 200,00 \\
\hline Investimento Total (Milhões R\$) & 720,00 & 120,00 & 840,00 \\
\hline Investimento Total (R\$/kW) & $4.500,00$ & $3.000,00$ & $4.137,00$ \\
\hline Fator de Capacidade da GF (\%) & 54,17 & 23,95 & 48,12 \\
\hline Garantia Física (MW médio) & 86,67 & 9,58 & 96,24 \\
\hline Geração (MW médio) & 86,67 & 9,58 & 96,24 \\
\hline Preço do Contrato ACR (R\$/MWh) & 101,72 & 125,00 & 106,38 \\
\hline Preço dos Contratos ACL 1 e ACL 2 (R\$/MWh) & \multicolumn{3}{|c|}{203,66} \\
\hline Arrendamento da Terra (\%ROL) & $1,00 \%$ & $1,00 \%$ & $1,00 \%$ \\
\hline Arrendamento da Terra (Milhões R\$) & 1,200 & 0,144 & 1,344 \\
\hline Seguros (\% Investimento - Depreciação) & \multicolumn{3}{|c|}{$0,50 \%$} \\
\hline TUST 50\% (R\$/kW.mês) & 3,27 & 3,27 & 3,27 \\
\hline O\&M (R\$/kW/ano) & 90,00 & 35,00 & 79,00 \\
\hline Taxas de Juros do Financiamento (\% a.a. real) & 4,35 & 3,94 & 4,27 \\
\hline TLP (\% a.a.) & \multicolumn{3}{|c|}{1,49} \\
\hline Remuneração BNDES (\% a.a.) & 1,30 & 0,90 & 1,22 \\
\hline Risco de Crédito (\%) & \multicolumn{3}{|c|}{1,50} \\
\hline Prazo do Financimento (anos) & \multicolumn{3}{|c|}{15} \\
\hline Carência (meses) & \multicolumn{3}{|c|}{6} \\
\hline Custo de Capital Próprio (\% a.a.) & \multicolumn{3}{|c|}{7,90} \\
\hline Estrutura de Capital (\% Próprio / \% Terceiros) & \multicolumn{3}{|c|}{$30 / 70$} \\
\hline Depreciação (\% a.a.) & 5,00 & 4,00 & $\begin{array}{c}\text { 5,00 (Ativos Usina } \\
\text { Eólica) }\end{array}$ \\
\hline Percentual de Contratação (\% ACR / \% ACL) & \multicolumn{3}{|c|}{$30 / 70$} \\
\hline
\end{tabular}




\subsection{1}

\section{Marcos Temporais}

Considerou-se janeiro de 2021 a data do primeiro aporte de recursos financeiros para construção do projeto. Considerou-se o período de construção igual a três anos, ou seja, o início operacional do empreendimento ocorre em janeiro de 2024. Entende-se que três anos de construção é um extenso período para uma usina solar fotovoltaica do porte da analisada nesta dissertação; entretanto, considerando a construção do arranjo híbrido, que também inclui a tecnologia eólica, optou-se por uniformizar os períodos de construção.

Com relação à contratação de longo prazo do empreendimento, considerou-se um CCEAR (Contrato de Comercialização de Energia no Ambiente Regulado) celebrado em um Leilão de Energia Nova ${ }^{23}$ "A - 4", ou seja, a vigência do contrato se inicia quatro anos após a realização do leilão. Assim, o contrato no Ambiente de Comercialização Regulado (ACR) se inicia em janeiro de 2025.

Percebe-se a existência de um hiato de 12 meses entre o início operacional da usina e o início da vigência do contrato no ACR. Neste período, considerou-se a celebração de um contrato no Ambiente de Comercialização Livre (ACL) relativa à totalidade da Garantia Física da usina. Ressalta-se que estas premissas são válidas tanto para a análise do empreendimento híbrido, quanto para as tecnologias avaliadas individualmente. Os preços dos contratos no ACR e ACL serão descritos na seção 7.1.6.

\subsection{2}

\section{Potência Total}

Tendo em vista o levantamento bibliográfico realizado, vide WINDEUROPE (2019), AGRAWAL et al. (2017), CARVALHO (2018), CAMPOS (2020), verificouse que não há um padrão estabelecido para se definir a proporção entre a capacidade instalada das tecnologias envolvidas em um empreendimento híbrido, que por sua vez depende das tecnologias combinadas, da complementaridade entre as fontes de

\footnotetext{
${ }^{23}$ Leilão de Energia Nova: 0 leilão de energia nova tem como finalidade atender ao aumento de carga das distribuidoras. Neste caso são vendidas e contratadas energia de usinas que ainda serão construídas. (CCEE,2021)
} 
geração no local de instalação do empreendimento, entre outros fatores. Os exemplos observados na literatura para as tecnologias eólica e solar fotovoltaica mostram empreendimentos com proporção desde 90\% Eólica e 10\% Solar até 40\% Eólica e $60 \%$ Solar. Sendo assim, neste trabalho foi considerado um empreendimento híbrido composto por $80 \%$ de capacidade eólica e $20 \%$ de solar fotovoltaica. Uma vez que a usina híbrida considerada neste trabalho possui 200 MW de capacidade instalada, a parte referente a usina eólica corresponde a $160 \mathrm{MW}$ e a parte solar a $40 \mathrm{MW}$.

\subsection{3}

\section{Investimento Total}

As premissas de investimento consideradas para as tecnologias em análise neste estudo de caso foram baseadas na faixa de valores de investimentos adotados nos estudos do Plano Decenal de Expansão de Energia 2021-2030 (PDE 2030), EPE (2021). Este valor de investimento inclui todos os custos diretos (obras civis, equipamentos, conexão e meio ambiente) e indiretos do empreendimento.

Para a tecnologia eólica adotou-se o valor de investimento igual a $\mathrm{R} \$ 4.500,00$ por $\mathrm{kW}$ instalado. Isto resulta em um investimento absoluto de R 720 milhões. Para a tecnologia solar fotovoltaica, com potência nominal de $40 \mathrm{MW}$, adotou-se o valor de investimento de $\mathrm{R} \$ 3.000,00$ por $\mathrm{kW}$. Isto resulta no valor de investimento absoluto igual a $\mathrm{R} \$ 120$ milhões.

O investimento total realizado no arranjo híbrido é igual à soma dos investimentos nas duas tecnologias. Considerou-se a contratação do MUST igual a $100 \%$ da potência nominal do empreendimento, em linha com a legislação atualmente vigente no setor elétrico brasileiro. A possibilidade de se contratar valores do MUST inferiores a $100 \%$ da potência nominal do empreendimento, tendo em vista a complementaridade das fontes de geração, será objeto de análise nesta dissertação.

\subsection{4}

\section{Fator de Capacidade}

O fator de capacidade das usinas em questão foi calculado com base na série histórica de produção de energia obtida por meio do sistema Renewables Ninja. Utilizou-se a Equação 15 para o cálculo mensal do fator de capacidade, ou seja, 
verificou-se a produção de energia ocorrida no mês $m$ e qual é a representatividade deste valor em relação a potência nominal da usina.

$$
F C_{m, a}=\frac{\sum_{h=1}^{H_{m}} g_{h, m, a}}{H_{m} * \text { Pot.Nom }}
$$

Onde:

$F C_{m, a} \quad$ : Fator de Capacidade da Usina para mês $m$ e ano $a$;

$H_{m} \quad$ : Horas no mês $m$;

$g_{h \prime m, a}$ : Produção de energia na hora $h$, mês $m$ e ano $a$;

Pot. Nom : Potência Nominal da Usina.

Ao realizar essa operação para os 40 anos disponíveis (480 meses), obteve-se as séries temporais de fator de capacidade para cada tecnologia (Caso eólico, Caso Solar e Arranjo Híbrido) apresentadas nas Figura 42, Figura 43 e Figura 44. Conforme citado no capítulo 5, a série de produção de energia para o Arranjo Híbrido foi obtido através da soma entre as séries de produção de energia eólica com as séries de produção de energia solar.

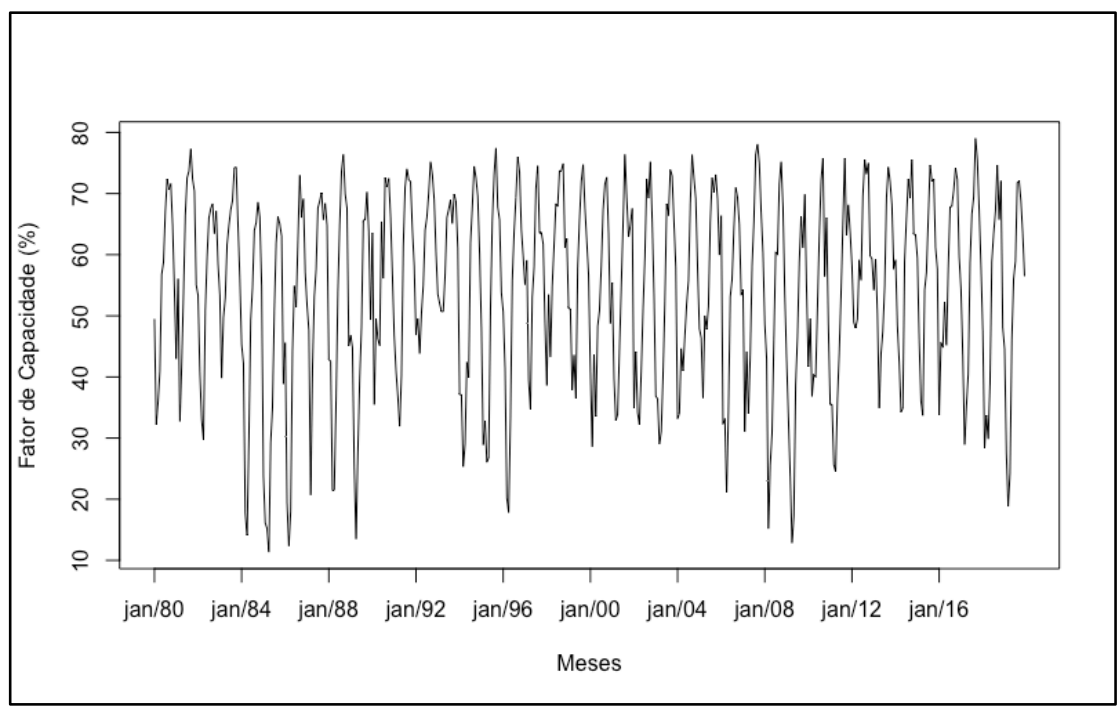

Figura 42 - Evolução dos Fatores de Capacidade Mensais para a Tecnologia Eólica 


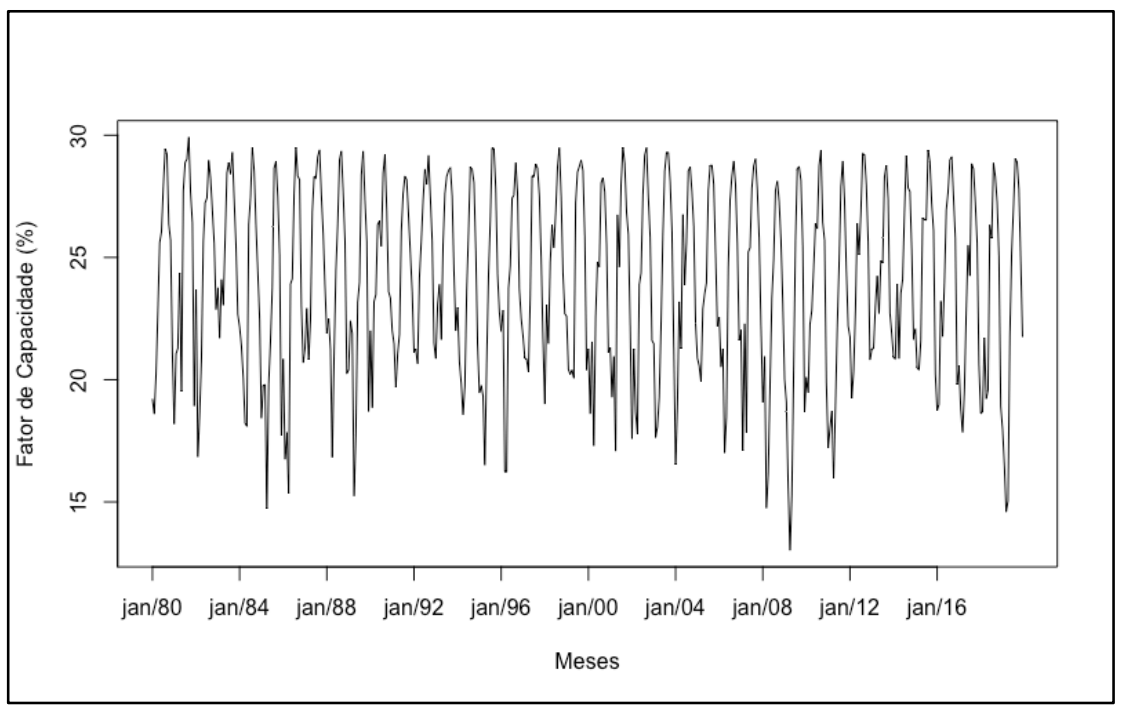

Figura 43 - Evolução dos Fatores de Capacidade Mensais para a Tecnologia Solar

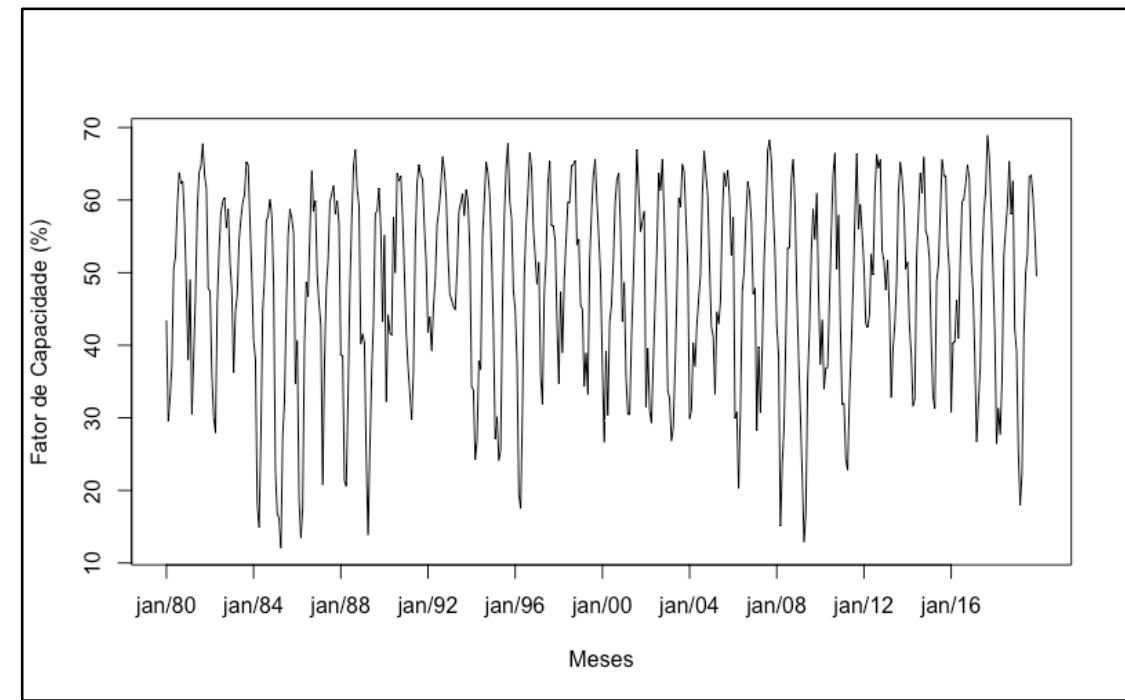

Figura 44 - Evolução dos Fatores de Capacidade Mensais para o Arranjo Híbrido

Destaca-se na Figura 42 que o fator de capacidade para a tecnologia eólica varia entre $11 \%$ e $80 \%$. Para tecnologia solar, o fator de capacidade varia no intervalo de $13 \%$ a $30 \%$. No caso do arranjo híbrido, o fator de capacidade se apresenta no intervalo de $12 \%$ a $70 \%$, aproximadamente.

Os valores médios de cada caso são respectivamente $54,17 \%, 23,95 \%$ e 48,12\% para as tecnologias eólica, solar e híbrida. Para o caso da tecnologia eólica, este valor de fator de capacidade é superior à média dos fatores de capacidade dos empreendimentos vencedores desta tecnologia no $30^{\circ}$ LEN ANEEL (2019), que foi de $46,14 \%$. Para a tecnologia solar fotovoltaica, o valor médio do fator de capacidade ao 
longo dos 40 anos da série histórica se mostrou inferior à 30,75\%, valor médio dos fatores de capacidade dos empreendimentos vencedores desta tecnologia solar fotovoltaica no $30^{\circ}$ LEN ANEEL (2019). Cabe destacar que os fatores de capacidade dos empreendimentos vencedores nos leilões de energia nova não foram obtidos pela Equação 15, mas aproximados pela divisão das suas respectivas garantias físicas de energia pela potência instalada do empreendimento.

Todavia, os valores de 54,17\% para tecnologia eólica e 23,95\% para tecnologia solar são valores coerentes para a região, de acordo com diversos empreendimentos verificados nos boletins mensais do ONS (2021).

\subsection{5}

\section{Garantia Física $^{24}$}

De acordo com a Portaria 101 do Ministério de Minas e Energia (MME), de 22 de março de 2016, o cálculo da garantia física de uma usina eólica é realizado com base no percentil 90\% (P90) da produção anual de energia certificada ${ }^{25}$, excluídas as indisponibilidades forçadas, as indisponibilidades programadas, o consumo interno e as perdas elétricas. Já a garantia física de uma usina solar fotovoltaica é calculada de forma análoga, porém com base no percentil 50\% (P50) da produção anual de energia certificada.

Tendo em vista a complexidade do cálculo da Garantia Física, os objetivos deste trabalho, e que ainda não há consenso sobre a forma de cálculo da Garantia Física de Energia de usinas híbridas, para o estudo de caso realizado neste trabalho a Garantia Física associada a cada tecnologia, em separado e em conjunto, foi aproximada multiplicando-se a sua potência instalada pelo respectivo Fator de Capacidade médio, obtido pela aplicação da Equação 15. Supondo a obrigação contratual do agente gerador igual à sua Garantia Física, tal aproximação tende a posicionar o agente gerador de forma neutra em relação às exposições no MCP. Os valores encontrados foram 86,67 MWmédios para a tecnologia eólica, 9,58 MWmédios para a tecnologia solar e 96,24 MWmédios para o arranjo híbrido.

\footnotetext{
${ }^{24}$ Garantia Física de uma usina: Montante, em MWmédios, correspondente à quantidade máxima de energia relativo à Usina que poderá ser utilizada para comprovação de atendimento de carga ou comercialização por meio de contratos (REN ANEEL 514/2012)

${ }^{25}$ A produção anual de energia certificada, em MWh, referente ao valor de energia anual com uma probabilidade de ocorrência igual ou maior a noventa por cento, constante da Certificação de Medições Anemométricas e de Produção Anual de Energia
} 


\subsection{6}

\section{Preços dos Contratos}

Considerou-se neste estudo de caso contratos celebrados no ACR e no ACL. No ACR o montante contratado foi igual a $30 \%$ da garantia física, vigente no período de janeiro de 2025 a dezembro 2044. Já no ACL, considerou-se dois contratos:

(i) montante contratado igual a $100 \%$ da garantia física, com período de vigência de janeiro de 2024 até dezembro de 2024 (ACL 2 na Tabela 25), período entre o início da operação comercial da usina e o início da vigência do CCEAR;

(ii) montante contratado (ACL 1) igual a 70\% da garantia física, com vigência de janeiro de 2025 a dezembro de 2044.

O preço de R\$203,66 por MWh para os contratos no ACL foi baseado na plataforma $\mathrm{DCIDE}^{26}$ para o produto "Energia Incentivada 50\% Longo Prazo". Esta plataforma divulga, semanalmente, um preço para cada produto. Este preço consiste na média dos preços divulgados pela DCIDE nas 16 primeiras semanas do ano de 2021. Por simplicidade, este preço foi considerado constante ao longo de todo o estudo, entretanto, sabe-se que os preços de contratos no ACL variam a depender do horizonte do contrato. Caso seja um contrato de curto prazo, o preço tende a ser fortemente influenciado pelo PLD. No caso de contratos de longo prazo, o preço tende a convergir para o Custo Marginal de Expansão $\left(\mathrm{CME}^{27}\right)$. (BATISTA et al., 2018)

Para a tecnologia eólica, o preço de venda de energia no ACR foi estimado com base na média dos preços dos empreendimentos vencedores do $30^{\circ}$ LEN (ANEEL, 2019), corrigida pelo IPCA. Este valor ficou em R\$101,72/MWh.

Para a tecnologia solar fotovoltaica considerou-se os valores desta fonte de geração ocorridos nos últimos leilões realizados pela ANEEL em que esta tecnologia participou. Assim, o preço de contrato no ACR para esta tecnologia resultou em $\mathrm{R} \$ 125,00 / \mathrm{MWh}$. No caso do projeto híbrido, chegou-se ao valor de $\mathrm{R} \$ 106,38 / \mathrm{MWh}$

\footnotetext{
${ }^{26}$ Plataforma DCIDE, acessível pelo sítio www.dcide.com.br

27 CME: Custo Marginal de Expansão é o custo associado ao atendimento de uma demanda adicional de energia no problema de expansão, que tem como objetivo otimizar a evolução do parque gerador. (EPE, 2020)
} 
ponderando os valores de preço de cada tecnologia pelos seus respectivos percentuais de participação no projeto híbrido.

\subsection{7}

\section{Percentual de Contratação no ACR/ACL}

Tendo em vista a prática adotada pelos desenvolvedores de projetos eólicos e solares fotovoltaicos ganhadores nos últimos leilões de Energia Nova, optou-se por contratar 30\% da Garantia Física do empreendimento híbrido no Ambiente de Contratação Regulado (ACR), o que equivale à contratação mínima obrigatória para a participação nos leilões. Considerou-se o restante contratado no ACL.

\subsection{8}

\section{Arrendamento da Terra e Seguros}

Para as despesas com o arrendamento da terra, adotou-se o valor de $1 \%$ da ROL (Receita Operacional Líquida) mensal do empreendimento, de acordo com o trabalho de LINDEMEYER (2018). Neste estudo de caso, a ROL do empreendimento é definia pela Receita Bruta subtraída dos tributos de PIS/COFINS.

Para a despesa com seguros, considerou-se que será pago $0,50 \%$ do valor do investimento imobilizado subtraído da depreciação acumulada em cada momento de pagamento desta despesa, o qual está em linha com a prática do Setor Elétrico Brasileiro.

\subsection{9}

\section{Tarifa de Uso de Sistema de Transmissão (TUST)}

O valor adotado para a TUST foi de 3,27 R \$/kW.mês, que equivale a 50\% da TUST de um empreendimento específico vencedor do 30 $0^{\circ}$ LEN (ANEEL, 2019), situado no Estado do Ceará, local de desenvolvimento da usina hipotética considerada nesta dissertação. Este desconto de 50\%, previsto na Lei Federal n ${ }^{0}$ 9.427/1996 e regulamentada pela Resolução Normativa da ANEEL nº 77 de 2004, surgiu como incentivo às fontes alternativas, com a justificativa de que estas fontes possuem impactos reduzidos ao meio ambiente quando comparadas às outras fontes de geração (e.g., usinas termelétricas com base em combustíveis poluentes). 


\subsubsection{0}

\section{Operação \& Manutenção (O\&M)}

Os valores para O\&M foram baseados nas premissas utilizadas pelo PDE 2030 (EPE, 2021), englobando a soma dos gastos (custos e despesas) fixos e variáveis. Para a tecnologia eólica o valor adotado foi de $\mathrm{R} \$ 90 / \mathrm{kW} /$ ano. Para a tecnologia solar fotovoltaica, considerou-se R \$35/kW/ano (EPE, 2021; NADLER, 2020).

O valor para o empreendimento híbrido consistiu na média ponderada em relação às potências nominais das usinas individuais. Este valor resultou em $\mathrm{R} \$ 79,00 / \mathrm{kW} / \mathrm{ano}$.

\subsubsection{1}

\section{Financiamento}

Em relação às condições de financiamento do projeto, baseou-se nas condições disponibilizadas no site do BNDES. Apesar do prazo máximo de amortização do empréstimo via BNDES ser igual a 24 anos, optou-se por se utilizar um prazo de 15 anos, valor mais coerente com a realidade dos projetos financiados pelo banco, com carência de juros igual a 6 meses após a entrada em operação da usina.

Considerou-se uma estrutura de capital com 30\% de capital próprio e $70 \%$ de capital de terceiros, também em linha com o informado no sítio ${ }^{28}$ do banco.

Com relação às taxas de financiamento, foi considerado um financiamento com o BNDES, cuja taxa é formada por 3 parcelas, conforme mostrado na Equação 16 :

Taxa de Juros $=$ TLP + Remuneração ${ }_{B N D E S}+$ Risco de Crédito

A taxa de longo prazo (TLP) para o mês de outubro de 2020 foi de 1,49\% a.a. A remuneração do BNDES é igual a 1,30\%a.a. para empreendimentos eólicos, 0,90\% para empreendimentos solares, sendo adotado neste trabalho $1,22 \%$ a.a. para o

\footnotetext{
${ }^{28}$ Sítio BNDES: https://www.bndes.gov.br/wps/portal/site/home/financiamento/produto/bndes-finemenergia
} 
empreendimento híbrido, ou seja, a média das taxas ponderada pela proporção de cada tecnologia no arranjo híbrido. Considerou-se o risco de crédito igual a 1,5\% a.a., ou seja, um valor intermediário entre os valores praticados para unidades federativas e municípios (entre $0,07 \%$ a.a. e 1,00\% a.a.) e o valor máximo de risco de crédito de $2,87 \%$ a.a., historicamente adotado pelo banco.

Desta forma, a taxa de juros do financiamento, em termos reais, ficou em 4,35\% a.a., 3,94\% a.a. e 4,27\% a.a. para as tecnologias eólica, solar fotovoltaica e para o arranjo híbrido, respectivamente.

\section{1 .12}

\section{Depreciação}

Para definir as taxas de depreciação, tomou-se por base o Manual de Controle Patrimonial do Setor Elétrico (MCPSE) (ANEEL, 2015). Para o empreendimento eólico, considerou-se que o principal ativo era constituído pelos aerogeradores, que possuem taxa de depreciação de 5\% a.a..

Para o empreendimento solar, considerando os módulos da unidade de geração fotovoltaica como principal ativo, considerou-se uma taxa de depreciação de $4 \%$ a.a. Para o projeto híbrido, considerou-se $5 \%$ a.a. aplicados à parcela do investimento associado à parte eólica, e 4\%a.a. aplicados à parte solar fotovoltaica.

\section{2}

\section{Resultados}

As seções a seguir apresentam os principais resultados obtidos com a aplicação da metodologia proposta, conforme o fluxograma apresentado na Figura 10 da seção 4.5. Estes resultados foram obtidos através de análises determinísticas, nas quais se estabelece o cenário base para o fluxo de caixa do projeto, e análises probabilísticas, nas quais são projetados diversos cenários de fluxos de caixa em função da realização das variáveis de risco consideradas no projeto. 


\subsection{1}

\section{Análises Determinísticas}

Para a realização da análise determinística em base mensal, foram consideradas as premissas citadas na seção 7.1 para um período de estudo de 21 anos. Estes 21 anos correspondem ao período de vigência do contrato no ACR, igual a 20 anos, acrescido de um contrato de ACL de um ano, em função da entrada em operação da usina ocorrer antes do início de vigência do CCEAR. Cabe salientar que, para o parâmetro produção de energia foi utilizado o valor da garantia física. Já para preço da energia no $\mathrm{MCP}$, foi estabelecido o valor médio de cada mês relativo às 2.000 série sintéticas em base mensal.

Os resultados foram obtidos através da versão 5.4.2 do modelo ANAFIN (BATISTA et al., 2016, MELO et al., 2018, BATISTA et al., 2012, MELO et al., 1998) e estão apresentados na Tabela 26.

Analisando os resultados da Tabela 26, verifica-se que os três casos apresentam viabilidade econômica (VPL $>0$ ). Percebe-se ainda que a soma do VPL do caso eólico com o VPL do caso Solar é inferior ao VPL do arranjo híbrido.

As Figura 45, Figura 46 e Figura 47 apresentam os fluxos de caixa anuais do arranjo hibrido, do caso eólico e caso solar fotovoltaico, respectivamente. Os indicadores econômicos da Tabela 26 foram obtidos através destes fluxos de caixa, nos quais ficam evidenciadas as fases de construção (fluxos negativos) e de operação (fluxos positivos) do empreendimento.

Tabela 26 - Resultados da Análise Determinística

\begin{tabular}{|c|c|c|c|}
\hline Mensal & $\begin{array}{c}\text { Arranjo } \\
\text { Híbrido }\end{array}$ & Emp. Eólico & Emp. Solar \\
\hline VPL (R\$ milhões) & 121,76 & 111,88 & 4,85 \\
\hline TIR (\% a.a.) & 12,87 & 13,59 & 9,12 \\
\hline
\end{tabular}




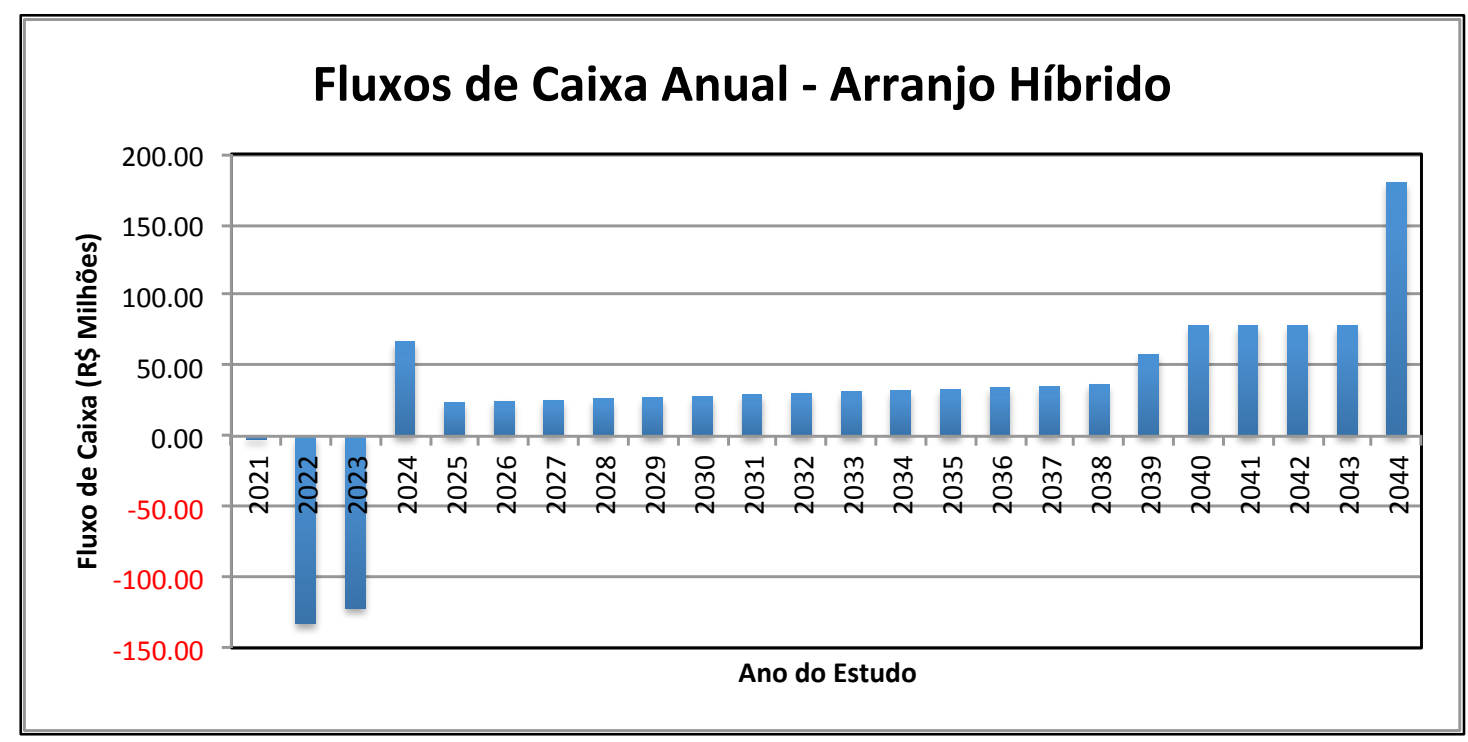

Figura 45 - Fluxos de Caixa Anual da Análise Determinística do Arranjo Híbrido

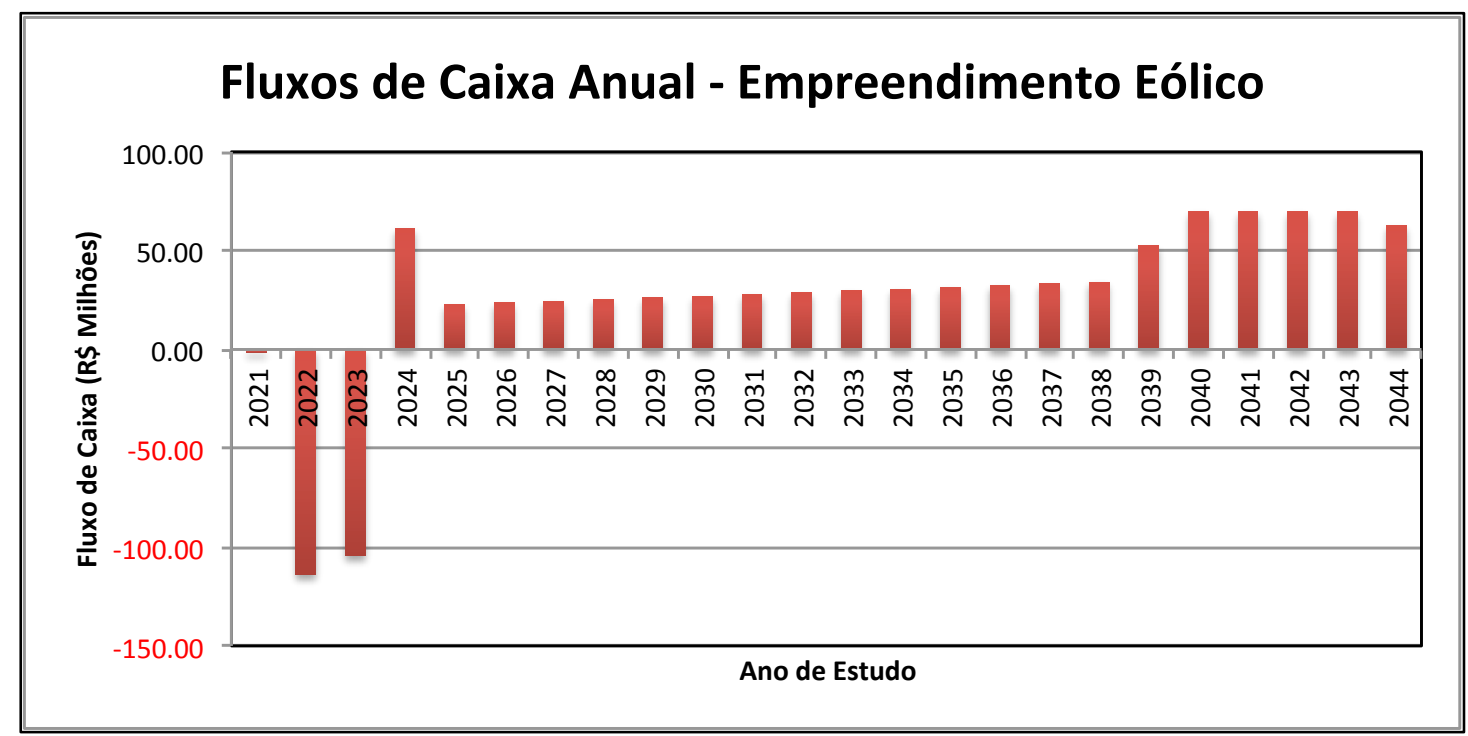

Figura 46 - Fluxos de Caixa Anual da Análise Determinística do Empreendimento Eólico 


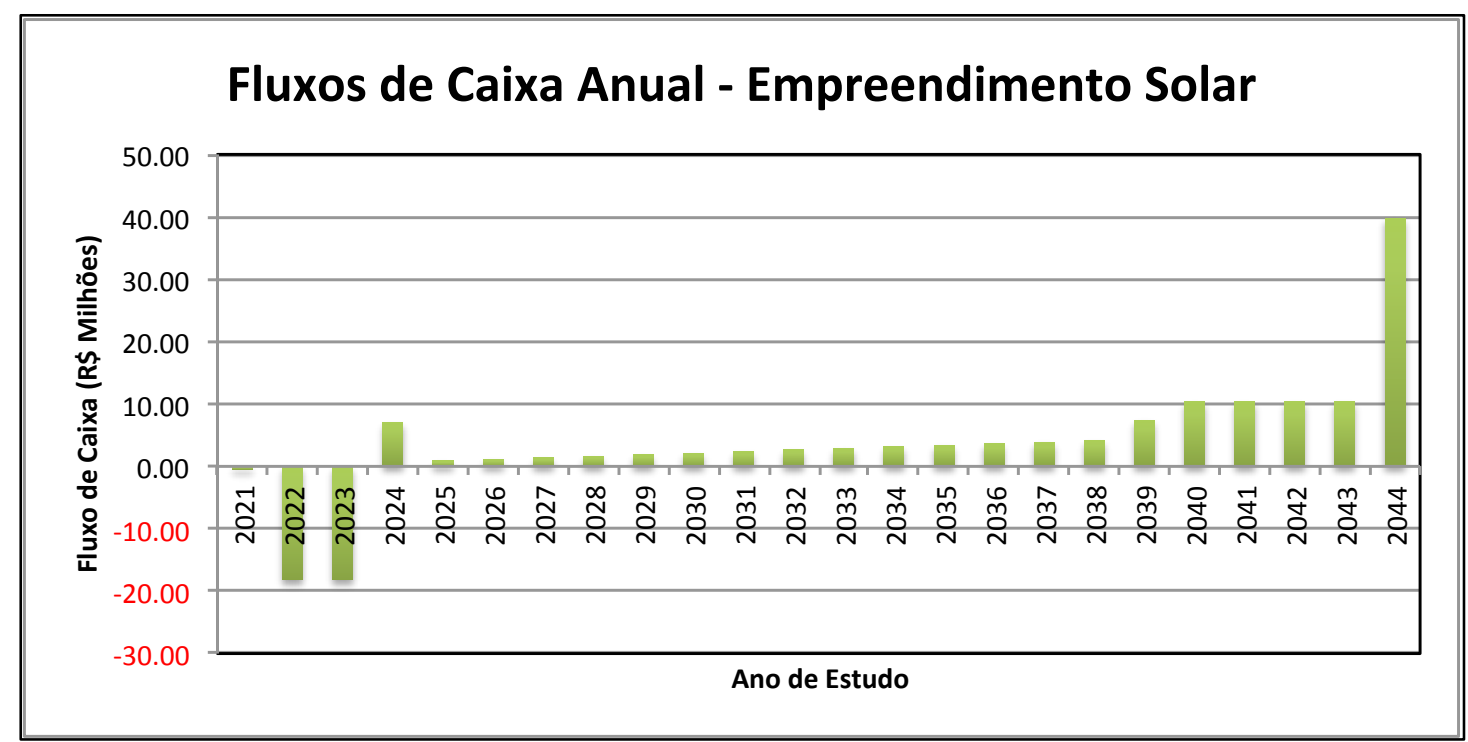

Figura 47 - Fluxos de Caixa Anual da Análise Determinística do Empreendimento Solar

\subsection{2}

\section{Análises Probabilísticas}

Análises econômicas que consideram diversos cenários para a realização de uma ou mais variáveis aleatórias que impactam nos fluxos de caixa do projeto são denominadas análises probabilísticas ou análises de risco.

Tal como mostrado no capítulo 5 (Geração de Cenários de Produção de Energia Eólica e Solar) e no capítulo 6 (Geração de Cenários para o Preço da Energia Elétrica no Mercado de Curto Prazo), as variáveis aleatórias consideradas na análise de risco do projeto híbrido são as produções de energia de cada tecnologia e os preços da energia no MCP (i.e., o PLD).

As análises foram realizadas em duas bases temporais: mensal e horária. A metodologia de aplicação dos cenários em cada base temporal também foi detalhada nos capítulos supracitados.

Nas análises probabilísticas foram consideradas 2.000 séries sintéticas de produção mensal de energia e de preço mensal, selecionadas por meio de um esquema de simulação Monte Carlo, tal conforme apresentado no capítulo 4. Utilizou-se como critério de monitoramento da convergência o coeficiente de variação da média amostral do VPL, tal como apresentado na Equação 17 e na Equação 18. Com 2.000 cenários, o coeficiente de variação obtido excursionou entre $0,64 \%$ e $0,93 \%$ para o arranjo híbrido, o caso eólico e o caso solar fotovoltaico, em ambas as bases 
temporais - mensal e horária. Estes valores atestam a convergência da simulação estocástica realizada.

$$
\begin{aligned}
& D P_{m a}(V P L)=\frac{D P(V P L)}{\sqrt{N}} \\
& C V_{m a}=\frac{D P_{m a}(V P L)}{\text { média }(V P L)}
\end{aligned}
$$

Os resultados da análise de risco para a estimativa do VPL, tanto em base mensal quanto horária, são apresentados na Tabela 27.

Os resultados mostram que os arranjos avaliados se mostraram viáveis economicamente, tal como a análise determinística havia apontado. O VPL médio também se mostrou próximo do VPL encontrado na análise determinística. Adicionalmente, comparando-se a análise em base mensal e horária, nota-se que os valores de média e mediana da distribuição de VPLs se mostram muito próximos para o arranjo híbrido e tecnologia eólica. Em relação aos valores máximo e mínimo do VPL, percebe-se que a análise horária levou a valores mais extremos. Também se observa que a base temporal horária conduz, nos casos híbrido e eólico a uma maior dispersão dos VPLs. Já no caso da tecnologia solar, apesar do VPL médio na base horária ser superior ao da base mensal, o desvio-padrão também o foi, levando ao mesmo coeficiente de variação.

Tabela 27 - Resultados da Análise Probabilística - VPL

\begin{tabular}{|c|c|c|c|c|c|c|}
\hline \multirow{2}{*}{$\begin{array}{c}\text { VPL } \\
\text { (R\$̣ milhões) }\end{array}$} & \multicolumn{2}{|c|}{ Arranjo Híbrido } & \multicolumn{2}{c|}{ Eólica } & \multicolumn{2}{c|}{ Solar } \\
\cline { 2 - 7 } & Base Mensal & Base Horária & Base Mensal & Base Horária & Base Mensal & Base Horária \\
\hline Média & 128,65 & 130,52 & 118,06 & 118,95 & 5,66 & 6,78 \\
\hline Mediana & 131,03 & 133,46 & 120,80 & 121,83 & 5,76 & 6,84 \\
\hline Mínimo & $-150,47$ & $-204,96$ & $-170,51$ & $-226,27$ & $-4,95$ & $-3,99$ \\
\hline Máximo & 296,08 & 335,17 & 286,00 & 324,58 & 16,11 & 19,84 \\
\hline Desvio Padrão & 36,80 & 44,52 & 36,79 & 44,68 & 2,35 & 2,81 \\
\hline Desvio Padrão MA* & 0,82 & 1,00 & 0,82 & 1,00 & 0,05 & 0,06 \\
\hline VaR 95\% & 68,23 & 58,61 & 58,63 & 47,32 & 1,93 & 2,19 \\
\hline CVaR 95\% & 38,12 & 20,97 & 27,26 & 8,42 & 0,47 & 0,73 \\
\hline Coef. De Variação & $28,60 \%$ & $34,11 \%$ & $31,17 \%$ & $37,56 \%$ & $41,54 \%$ & $41,41 \%$ \\
\hline Coef. De Variação MA* & $0,64 \%$ & $0,76 \%$ & $0,70 \%$ & $0,84 \%$ & $0,93 \%$ & $0,93 \%$ \\
\hline Prob VPL<0 (\%) & $0,35 \%$ & $1,00 \%$ & $0,85 \%$ & $1,65 \%$ & $1,20 \%$ & $1,15 \%$ \\
\hline
\end{tabular}

* Da Variável Aleatória: Média Amostral 
Em relação às métricas de risco, $\mathrm{VaR}$ (Value at Risk) e CVaR (Conditional Value at Risk), ambas ao nível de significância de 95\%, o arranjo híbrido e o empreendimento eólico possuem valores inferiores para base horária, ou seja, a simulação com discretização horária resultou em maior risco. No caso do empreendimento solar, os valores se mostraram muito próximos.

Ainda através da Tabela 27, percebe-se a ocorrência relativamente baixa de valores de VPL inferiores a zero, tendo em vista as baixas probabilidades associadas.

Apesar do critério mais adequado para se comparar projetos de mesmo horizonte econômico, e não replicáveis, ser o VPL, também são apresentados na Tabela 28 os resultados com relação à TIR do projeto. As conclusões são similares às descritas anteriormente, ratificando as análises efetuadas a partir da Tabela 27. Apesar de similares, com relação à medida de risco VaR, nota-se que diferenças consideradas significativas em termos de VPL não se mostraram tão significativas em termos de TIR, indicando uma maior equivalência desta métrica quando comparadas as análises em base mensal e horária.

Cabe destacar que o valor "zero" para o mínimo da distribuição se refere a um cenário que apresentou fluxos de caixa que necessitaria de um valor de TIR negativa para levar o VPL a zero. Este cenário específico está associado à série de produção de energia com menor média mensal entre todos os cenários simulados. Uma vez que a produção de energia se encontra constantemente abaixo do montante contratado, foi necessário comprar energia no MCP, o que impactou negativamente o fluxo de caixa.

Tabela 28 - Resultados da Análise Probabilística - TIR

\begin{tabular}{|c|c|c|c|c|c|c|}
\hline \multirow{2}{*}{ TIR (\% a.a.) } & \multicolumn{2}{|c|}{ Arranjo Híbrido } & \multicolumn{2}{|c|}{ Eólica } & \multicolumn{2}{|c|}{ Solar } \\
\hline & Base Mensal & Base Horária & Base Mensal & Base Horária & Base Mensal & Base Horária \\
\hline Média & 13,08 & 13,06 & 13,80 & 13,72 & 9,31 & 9,58 \\
\hline Mediana & 13,22 & 13,18 & 13,97 & 13,89 & 9,33 & 9,59 \\
\hline Mínimo & 0,00 & 0,00 & 0,00 & 0,00 & 6,54 & 6,81 \\
\hline Máximo & 18,80 & 19,92 & 20,49 & 21,76 & 11,72 & 12,49 \\
\hline Desvio Padrão & 1,45 & 1,73 & 1,76 & 2,12 & 0,59 & 0,70 \\
\hline Desvio Padrão MA* & 0,03 & 0,04 & 0,04 & 0,05 & 0,01 & 0,02 \\
\hline VaR 95\% & 10,74 & 10,29 & 11,00 & 10,27 & 8,38 & 8,45 \\
\hline CVaR 95\% & 9,46 & 8,74 & 9,33 & 8,33 & 8,02 & 8,08 \\
\hline Coef. De Variação & $11,05 \%$ & $13,24 \%$ & $12,73 \%$ & $15,43 \%$ & $6,29 \%$ & $7,26 \%$ \\
\hline Coef. De Variação MA* & $0,25 \%$ & $0,30 \%$ & $0,28 \%$ & $0,34 \%$ & $0,14 \%$ & $0,16 \%$ \\
\hline
\end{tabular}


Ressalta-se ainda que os resultados médios de VPL para o arranjo híbrido devem ser comparados com a soma dos resultados individuais de cada tecnologia, evidenciando os ganhos devido à complementaridade da geração, além dos ganhos de escala tanto no investimento quanto nos custos operacionais.

Nas Figura 48, Figura 49 e Figura 50 são apresentadas a comparação entre as distribuições de frequências dos VPLs obtidos com as duas bases temporais, para cada empreendimento. Em geral, as distribuições obtidas com cada uma das bases temporais estão bastante próximas. Para o caso solar há um ligeiro deslocamento entre as distribuições, o que justifica a diferença entre os VPLs apresentados na Tabela 27. Porém este deslocamento está amplificado na Figura 50 pois os valores de VPL são bem inferiores em relação aos casos híbrido e eólico, e a escala do gráfico teve que ser significativamente alterada.

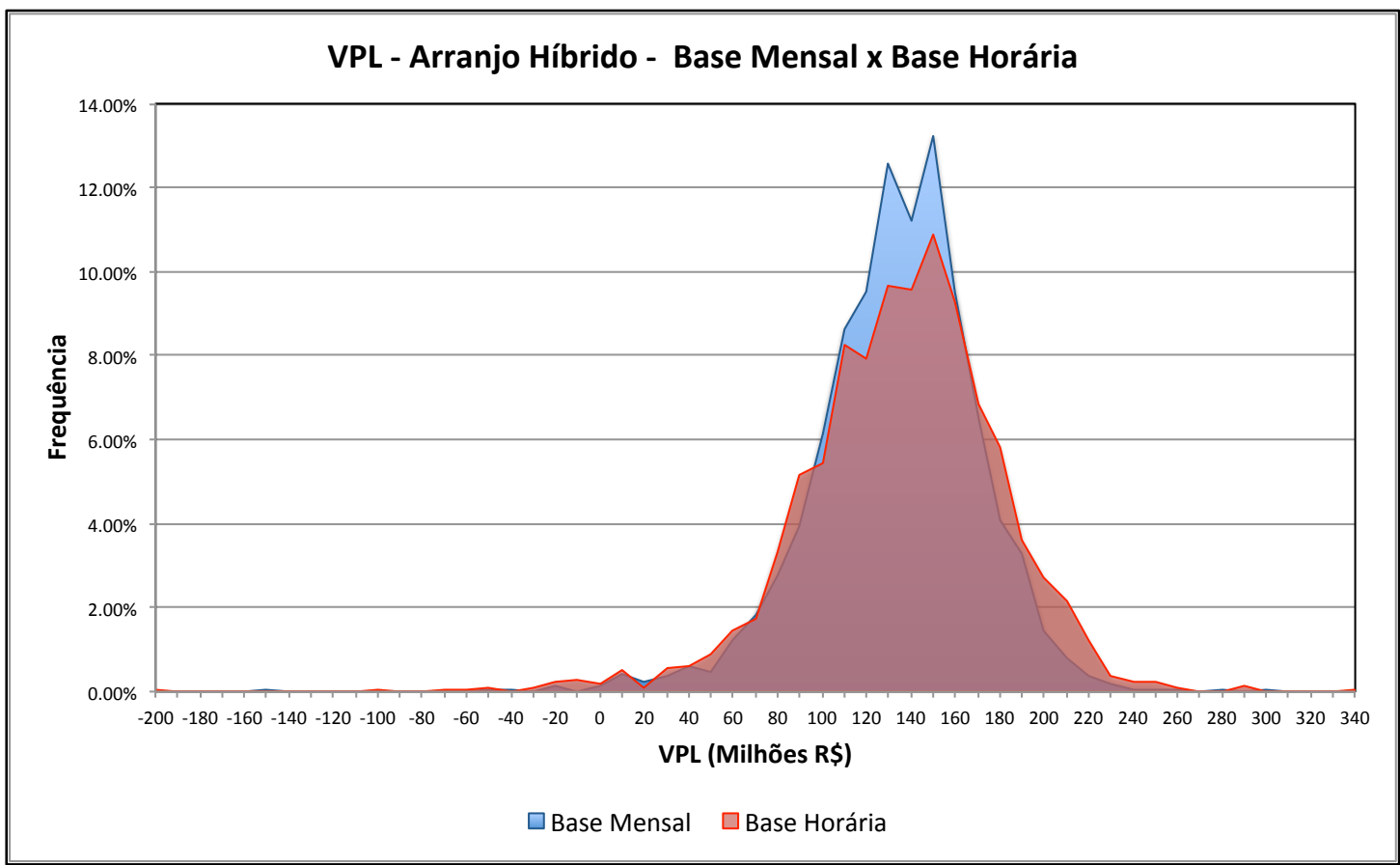

Figura 48 - Comparação entre as Distribuições de VPL da Análise em Base Mensal e em Base Horária - Arranjo Híbrido 


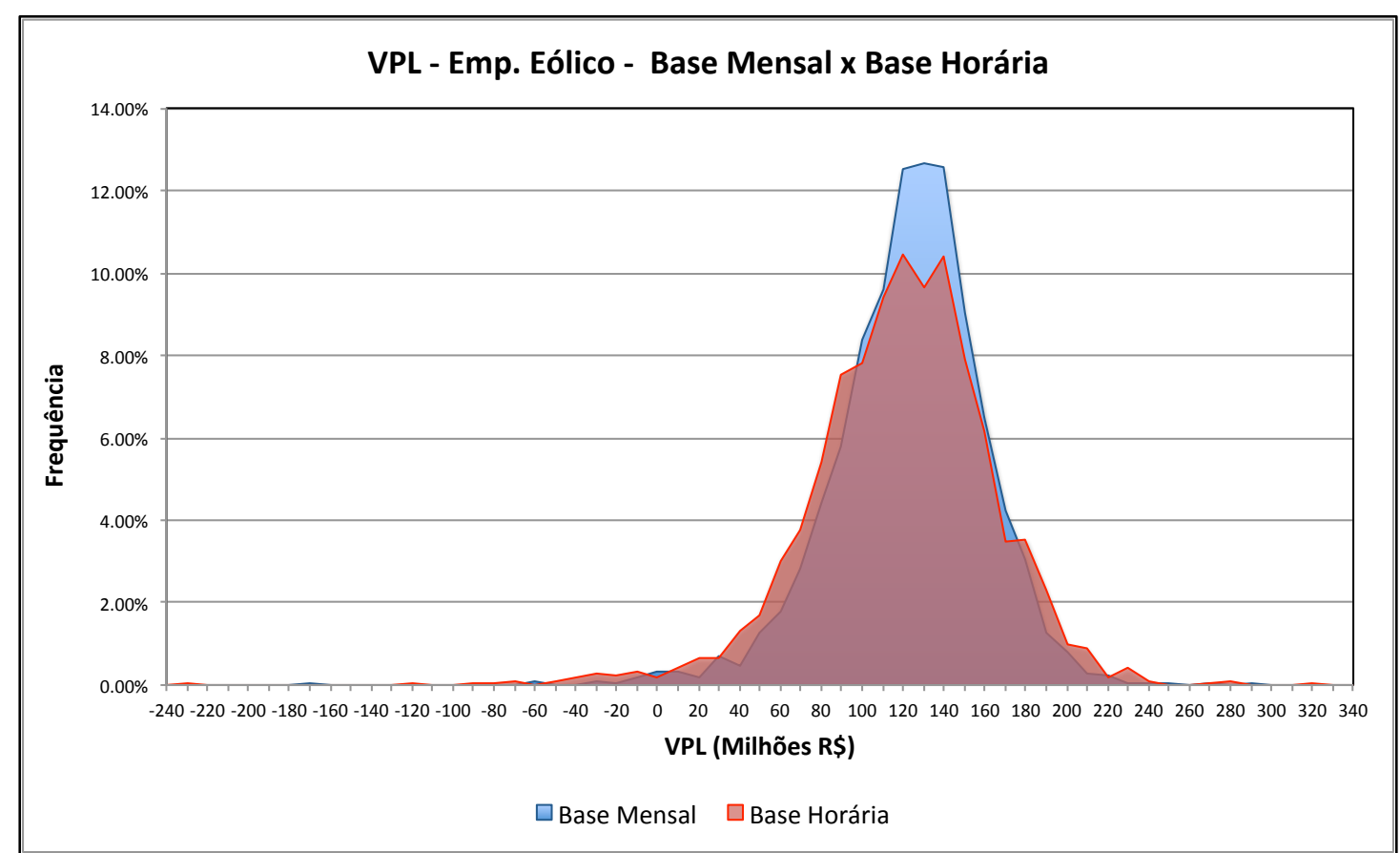

Figura 49 - Comparação entre as Distribuições de VPL da Análise em Base Mensal e em Base Horária - Empreendimento Eólico

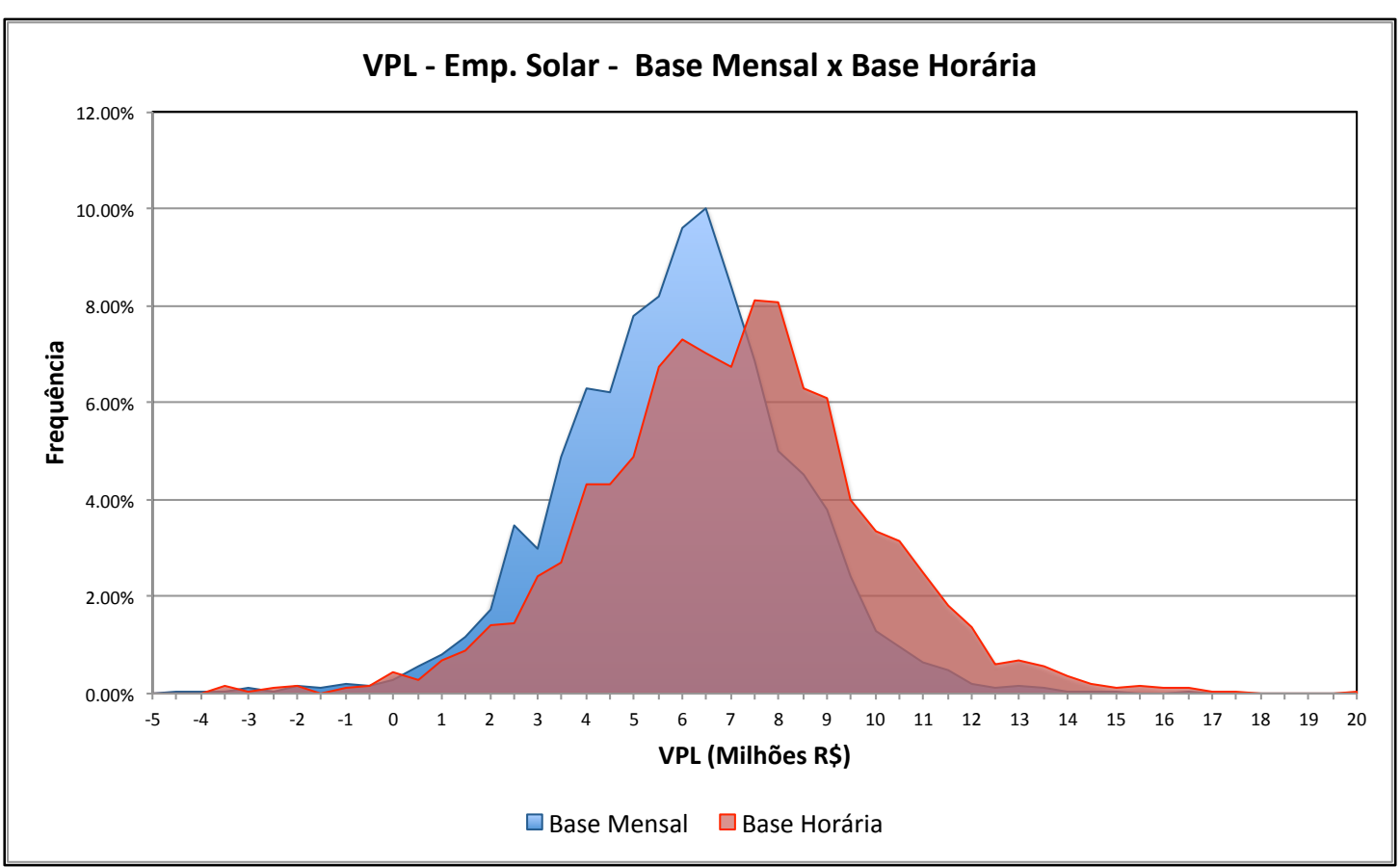

Figura 50 - Comparação entre as Distribuições de VPL da Análise em Base Mensal e em Base Horária - Empreendimento Solar

Já a Figura 51, a Figura 52 e a Figura 53 apresentam a comparação entre as distribuições de TIR entre as bases temporais para cada empreendimento. De forma semelhante ao visto nos gráficos de distribuição de VPL, percebe-se que as bases temporais possuem distribuições próximas. 


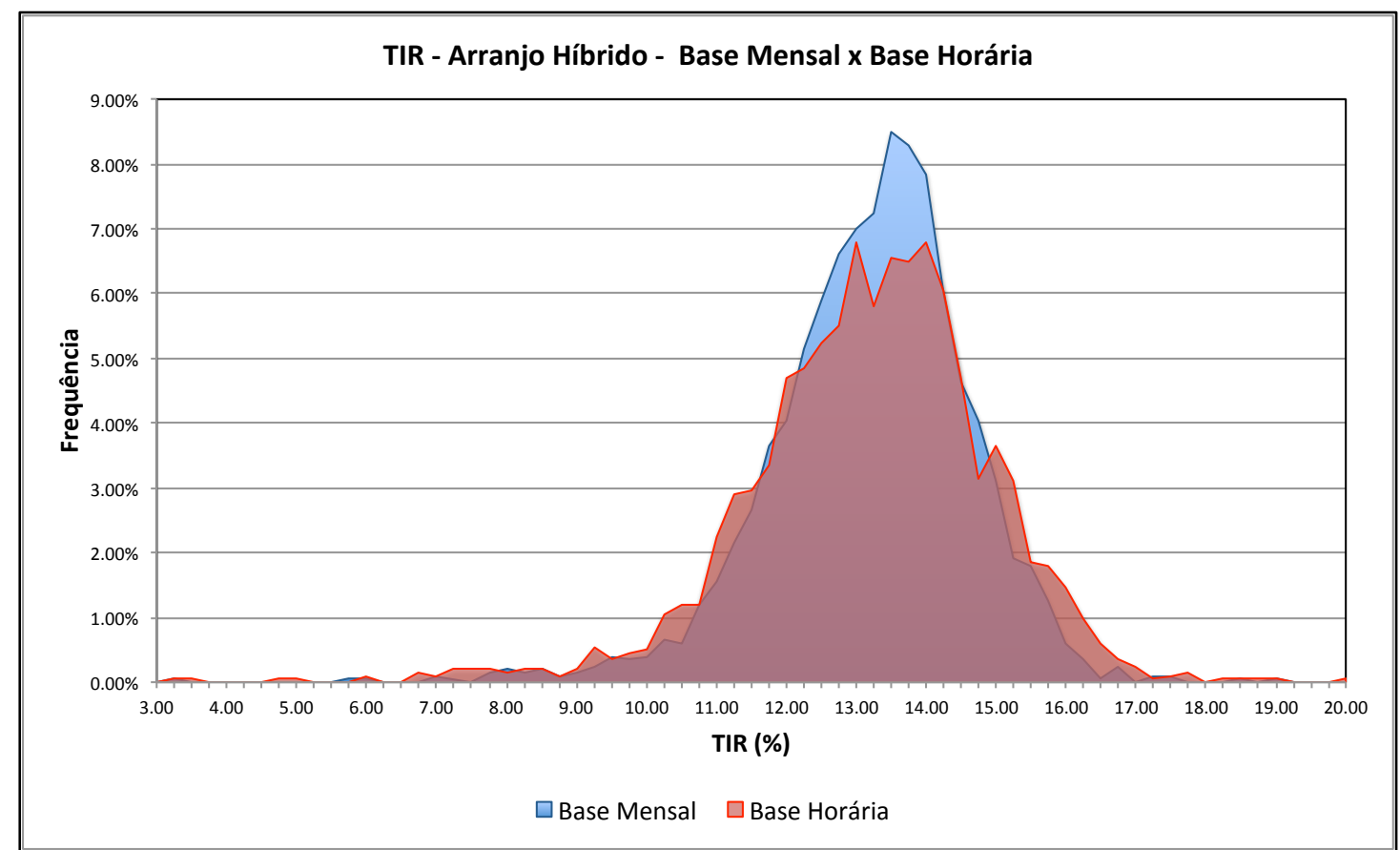

Figura 51 - Comparação entre as Distribuições de TIR da Análise em Base Mensal e em

Base Horária - Arranjo Híbrido

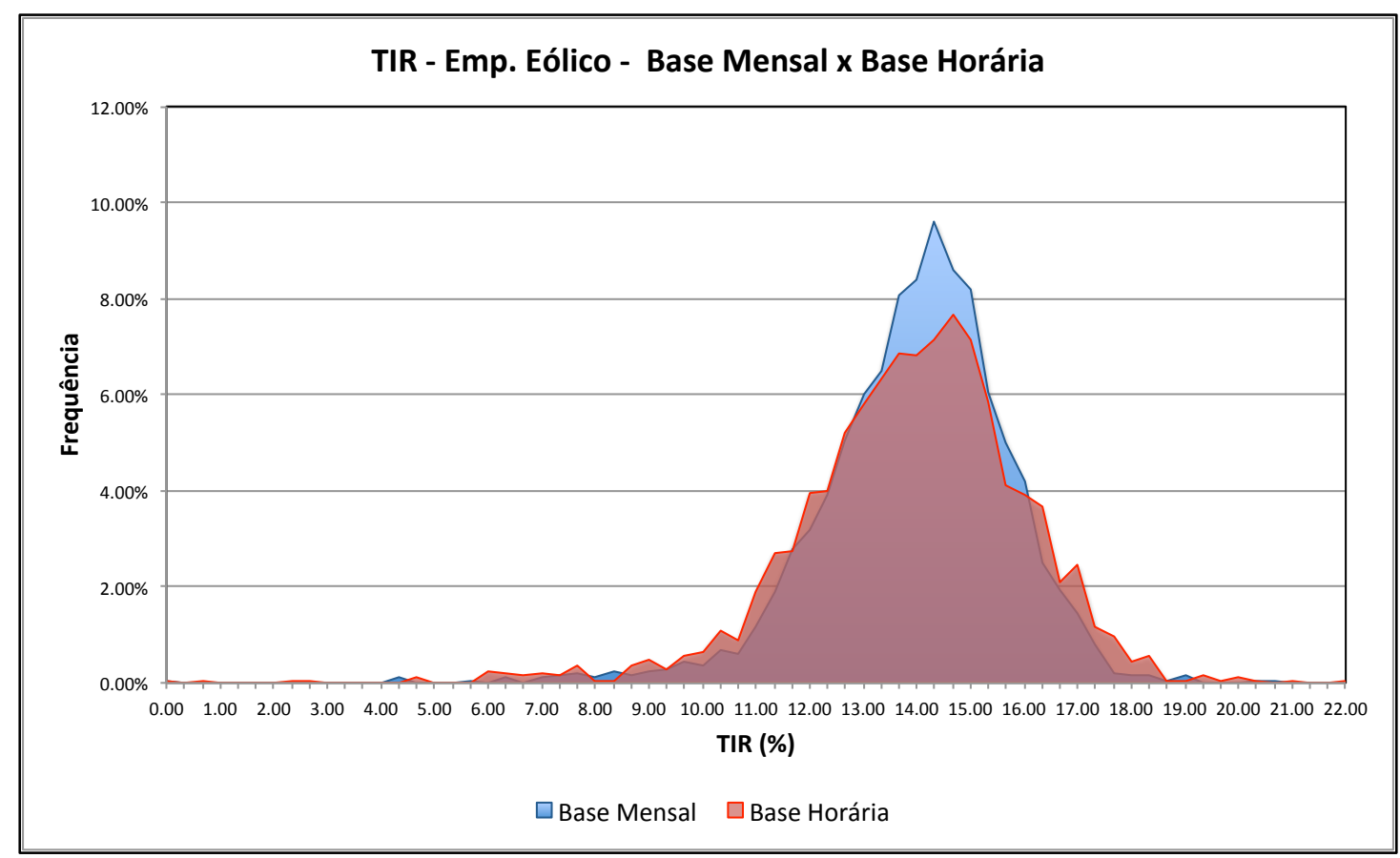

Figura 52 - Comparação entre as Distribuições de TIR da Análise em Base Mensal e em Base Horária - Empreendimento Eólico 


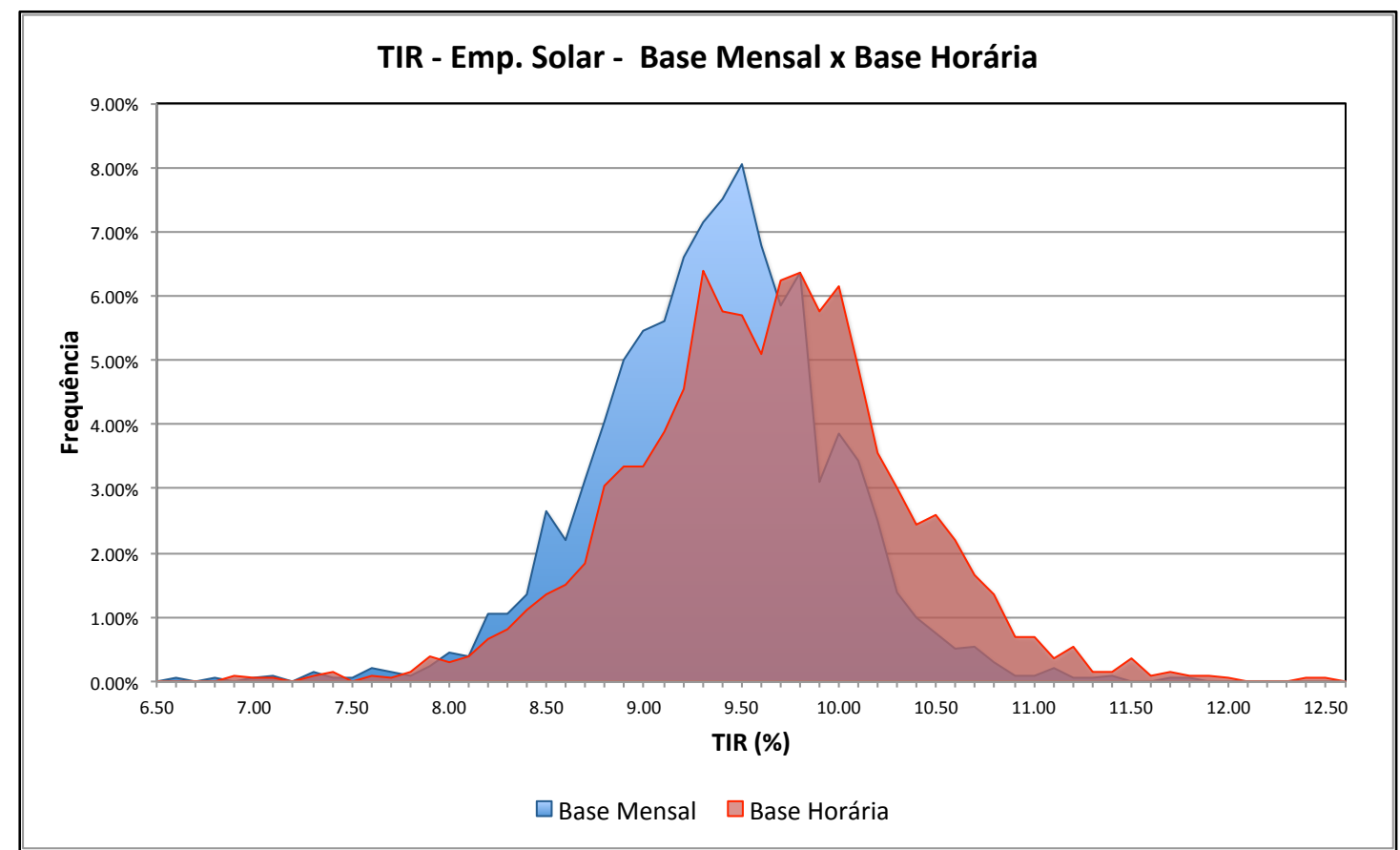

Figura 53 - Comparação entre as Distribuições de TIR da Análise em Base Mensal e em Base Horária - Empreendimento Solar

A Tabela 27 e a Tabela 28 e as Figuras 48 à 53 mostram que, em termos de média e mediana, os resultados considerando a base mensal são próximos dos obtidos nas análises em base horária. Isto é um indicativo de que as análises de fluxo de caixa em base mensal podem ser adequadas para avaliar a viabilidade econômica de projetos de geração no Brasil, mesmo com a introdução do PLD Horário. Assim, a vertente da abordagem metodológica proposta, baseada em discretização mensal, constitui-se em uma alternativa razoável, ou ao menos inicial, para analisar a viabilidade econômica de projetos híbridos, em termos dos riscos considerados.

Não obstante os valores da média e mediana obtidos com as análises mensal e horária estejam próximos, cabe ressaltar que os resultados de VaR e CVaR (ao nível de significância de 95\%) em base horária apresentam valores inferiores aos obtidos nas análises em base mensal. Ou seja, as análises de viabilidade por meio da base horária apontam riscos mais elevados que os indicados pelas avaliações considerando a base mensal. Os resultados apontam que a linha da abordagem metodológica, proposta baseada em discretização horária, embora mais trabalhosa que a mensal, tem maior capacidade de lidar com os valores extremos das distribuições de frequência dos indicadores de viabilidade. Portanto, pode fornecer maiores subsídios para avaliar a viabilidade econômica de projetos híbridos, em termos dos riscos considerados. 
De forma a complementar a análise em estudo, a Tabela 29 apresenta resultados da análise probabilística relativos à TIR Modificada. ASSAF NETO (2014) afirma que a TIR de um projeto somente é válida desde que os fluxos de caixa intermediários sejam reaplicados, até o final de sua vida útil prevista, à própria TIR calculada. Esta premissa pode estar fora da realidade se os valores de TIR forem distantes das taxas praticadas pelo mercado. Além disso, a intercalação de fluxos de caixa positivos e negativos ao longo do período de estudo pode acarretar o encontro de múltiplas TIR. A TIR modificada contorna estas limitações considerando que os fluxos de caixa são reinvestidos ao custo de capital do investidor (SAMANEZ, 2010; BRIGHAM e EHRHARDT, 2020).

Conforme esperado, os valores de TIR modificada apresentados na Tabela 29 se aproximaram do custo de capital próprio adotado na análise (7,90\% a.a.). Verificou-se a reduzida variabilidade de TIR modificada entre os 2.000 cenários avaliados para cada empreendimento. Observa-se também que o pior cenário do arranjo híbrido obteve TIR Modificada de 9,73\% para a análise em base mensal e 9,60\% para análise em base horária. Para estes casos, a TIR padrão não pôde ser obtida, pois os fluxos de caixa levariam a valores de TIR negativos, tal como descrito anteriormente.

Tabela 29 - Resultados da Análise Probabilística - TIR Modificada

\begin{tabular}{|c|c|c|c|c|c|c|}
\hline \multirow{2}{*}{ TIR Modificada (\% a.a.) } & \multicolumn{2}{|c|}{ Arranjo Híbrido } & \multicolumn{2}{c|}{ Eólico } & \multicolumn{2}{c|}{ Solar } \\
\cline { 2 - 7 } & Base Mensal & Base Horária & Base Mensal & Base Horária & Base Mensal & Base Horária \\
\hline Média & 9,75 & 9,62 & 9,82 & 9,66 & 8,57 & 8,67 \\
\hline Mediana & 9,74 & 9,61 & 9,81 & 9,65 & 8,57 & 8,67 \\
\hline Mínimo & 9,73 & 9,60 & 9,80 & 9,64 & 8,44 & 8,52 \\
\hline Máximo & 10,39 & 10,27 & 10,54 & 10,39 & 8,84 & 8,97 \\
\hline Desvio Padrão & 0,03 & 0,04 & 0,04 & 0,04 & 0,01 & 0,01 \\
\hline Desvio Padrão MA* & 0,00 & 0,00 & 0,00 & 0,00 & 0,00 & 0,00 \\
\hline VaR 95\% & 9,73 & 9,61 & 9,80 & 9,65 & 8,56 & 8,66 \\
\hline CVaR 95\% & 9,73 & 9,61 & 9,80 & 9,64 & 8,56 & 8,65 \\
\hline Coef. De Variação & $0,01 \%$ & $0,01 \%$ & $0,01 \%$ & $0,01 \%$ & $0,00 \%$ & $0,00 \%$ \\
\hline Coef. De Variação MA* & $0,01 \%$ & $0,01 \%$ & $0,01 \%$ & $0,01 \%$ & $0,00 \%$ & $0,00 \%$ \\
\hline
\end{tabular}




\section{3}

\section{Análise de Sensibilidade}

Uma das despesas de uma usina de geração de energia elétrica consiste nos investimentos em infraestrutura de transmissão disponibilizada para que a energia gerada chegue à rede básica. De acordo com a Resolução Normativa ANEEL Nº 666, 23 de junho de 2015, para que qualquer montante de energia produzida pela usina possa ser escoada para a rede básica, o gerador deve contratar um Montante de Uso do Sistema de Transmissão (MUST) igual à sua potência instalada subtraída da mínima carga própria. O MUST contratado, em MW, é pago pelo gerador à Tarifa de Uso do Sistema de Transmissão (TUST), em R $\$ / k W$.mês, constituindo uma despesa operacional do empreendimento.

Se, em função de uma possível complementaridade entre as fontes de um arranjo híbrido, for possível contratar um MUST inferior à potência instalada da usina, conforme proposta em análise regulatória no contexto da Consulta Pública 061/2020, note que isto implicaria em uma redução de despesas e de investimentos para esta usina.

Como é possível que exista um nível de complementaridade intra-diária entre as fontes de geração eólica e solar, espera-se que um arranjo híbrido com estas tecnologias tenha probabilidades reduzidas de que a sua geração atinja a potência nominal. Desta forma, faz sentido que a contratação do MUST seja reduzido, reduzindo a ociosidade do sistema de transmissão que liga a usina à rede básica, aumentando a rentabilidade do projeto.

Nesse contexto, com o objetivo de avaliar o arranjo híbrido com a possibilidade de contratação do MUST inferior a soma das potências nominais dos empreendimentos individuais, esta dissertação realizou uma análise de sensibilidade da viabilidade do projeto em relação a este parâmetro. Ou seja, realizou-se uma análise de risco, com 2.000 cenários de fluxo de caixa, para diferentes valores de contratação do MUST. Os cenários de fluxo de caixa foram obtidos conforme previamente descrito no Capítulo 4.

Note que valores do MUST inferiores à potência instalada do empreendimento podem acarretar em redução de investimento em infraestrutura elétrica, composta sobretudo por transformadores e linhas de transmissão, e, consequentemente, na redução das despesas de Operação e Manutenção (O\&M). 
Conforme mencionado anteriormente nesta dissertação, especialistas da Companhia Hidrelétrica do Rio São Francisco (CHESF) foram consultados a respeito da composição do investimento realizado em empreendimentos eólicos e solares fotovoltaicos. Segundo o apurado, do total investido em empreendimentos desta natureza, a parcela referente à infraestrutura elétrica (linhas de transmissão e transformadores) corresponde, aproximadamente, a 7,50\% do total. Do restante, $75 \%$ corresponde ao investimento em turbinas eólicas e aos painéis solares e 17,50\% às obras civis. Adicionalmente, colocou-se que o compartilhamento de instalações elétricas entre uma usina eólica e uma usina solar fotovoltaica permite uma redução de aproximadamente $20 \%$ na parcela do investimento relativo à infraestrutura elétrica.

Como se considera que a infraestrutura elétrica corresponde, aproximadamente, a 7,50\% do investimento total, assumiu-se como premissa que, caso o MUST contratado seja $50 \%$ da potência nominal, considerar-se-á que a usina utilizará $50 \%$ da infraestrutura elétrica original, ou seja, tem-se a redução de $50 \%$ em investimentos relacionados à infraestrutura elétrica, o que corresponde a 3,75\% do investimento total. Caso a contratação do MUST seja 100\% da potência da usina, não há redução do valor original.

Assim, a presente análise de sensibilidade avaliou um conjunto de valores de contratação do MUST entre $100 \mathrm{MW}$ e $200 \mathrm{MW}$. Como dito, por simplicidade, considerou-se que a redução de contratação do MUST leva à uma redução de mesma proporção no investimento em infraestrutura elétrica e nas despesas de O\&M. Estes valores são apresentados na Tabela 30. Em consequência à redução na contratação do MUST, há uma redução de despesas com o pagamento pelo uso do sistema de transmissão.

Assim, discretizou-se a análise de sensibilidade em intervalos de $10 \mathrm{MW}$. Percebe-se na Tabela 30 que, cada 10 MW de redução na contratação do MUST, acarreta em $0,375 \%$ de redução no Investimento Total e, consequentemente, nas despesas de O\&M.

A Tabela 31 e a Figura 54 apresentam os resultados da análise de sensibilidade pela abordagem determinística, os quais mostram uma melhora nos indicadores de viabilidade do projeto com a redução de contratação do MUST. Como nas análises determinísticas parte-se da premissa de que a geração do empreendimento é igual à sua garantia física, a qual, no arranjo híbrido representa 
$48,12 \%$ da potência nominal, a redução de contratação do MUST até $50 \%$ não afeta o crescimento do VPL, uma vez que não há geração acima do MUST.

Tabela 30 - Dados de Investimento com a Variação da Contratação do MUST

\begin{tabular}{|c|c|c|c|c|}
\hline $\begin{array}{c}\text { Percentual de } \\
\text { Contratação } \\
\text { do MUST (\%) }\end{array}$ & $\begin{array}{c}\text { Contratação } \\
\text { do MUST (MW) }\end{array}$ & $\begin{array}{c}\text { Percentual de } \\
\text { Investimento (\%) }\end{array}$ & $\begin{array}{c}\text { Investimento Total } \\
\text { (R\$ Milhões) }\end{array}$ & $\begin{array}{c}\text { O\&M } \\
\text { (R\$̦ Milhões) }\end{array}$ \\
\hline $100 \%$ & 200,00 & $100,000 \%$ & 840,00 & 15,80 \\
\hline $95 \%$ & 190,00 & $99,625 \%$ & 836,85 & 15,74 \\
\hline $90 \%$ & 180,00 & $99,250 \%$ & 833,70 & 15,68 \\
\hline $85 \%$ & 170,00 & $98,875 \%$ & 830,55 & 15,62 \\
\hline $80 \%$ & 160,00 & $98,500 \%$ & 827,40 & 15,56 \\
\hline $75 \%$ & 150,00 & $98,125 \%$ & 824,25 & 15,50 \\
\hline $70 \%$ & 140,00 & $97,750 \%$ & 821,10 & 15,44 \\
\hline $65 \%$ & 130,00 & $97,375 \%$ & 817,95 & 15,39 \\
\hline $60 \%$ & 120,00 & $97,000 \%$ & 814,80 & 15,33 \\
\hline $55 \%$ & 110,00 & $96,625 \%$ & 811,65 & 15,27 \\
\hline $50 \%$ & 100,00 & $96,250 \%$ & 808,50 & 15,21 \\
\hline
\end{tabular}

Tabela 31 - Resultados da Sensibildade de Contratação do MUST para o Caso Determínistico

\begin{tabular}{|c|c|c|c|c|}
\hline Mensal & Arranjo Híbrido & $\begin{array}{c}\text { Arranjo Híbrido } \\
\text { (MUST* }=95 \%)\end{array}$ & $\begin{array}{c}\text { Arranjo Híbrido } \\
\text { (MUST* = 90\%) }\end{array}$ & $\begin{array}{c}\text { Arranjo Híbrido } \\
\text { (MUST* = 85\%) }\end{array}$ \\
\hline VPL (R\$ milhões) & 121,76 & 125,78 & 129,91 & 133,92 \\
\hline TIR (\% a.a.) & 12,87 & 13,05 & 13,24 & 13,42 \\
\hline Mensal & $\begin{array}{c}\text { Arranjo Híbrido } \\
\text { (MUST* }=80 \%)\end{array}$ & $\begin{array}{c}\text { Arranjo Híbrido } \\
\text { (MUST* }\end{array}$ & $\begin{array}{c}\text { Arranjo Híbrido } \\
\text { (MUST* }=\mathbf{7 0 \% )}\end{array}$ & $\begin{array}{c}\text { Arranjo Híbrido } \\
\text { (MUST* = 65\%) }\end{array}$ \\
\hline VPL (R\$ milhões) & 137,94 & 142,07 & 146,08 & 150,10 \\
\hline TIR (\% a.a.) & 13,61 & 13,80 & 13,99 & 14,18 \\
\hline Mensal & $\begin{array}{c}\text { Arranjo Híbrido } \\
\text { (MUST* }\end{array}$ & $\begin{array}{c}\text { Arranjo Híbrido } \\
\text { (MUST* }=55 \%)\end{array}$ & $\begin{array}{c}\text { Arranjo Híbrido } \\
\text { (MUST* }=50 \%)\end{array}$ & - \\
\hline VPL (R\$ milhões) & 154,23 & 158,24 & 162,25 & - \\
\hline TIR (\% a.a.) & 14,38 & 14,57 & 14,76 & - \\
\hline
\end{tabular}

*MUST: Percentual da Potência Nominal 


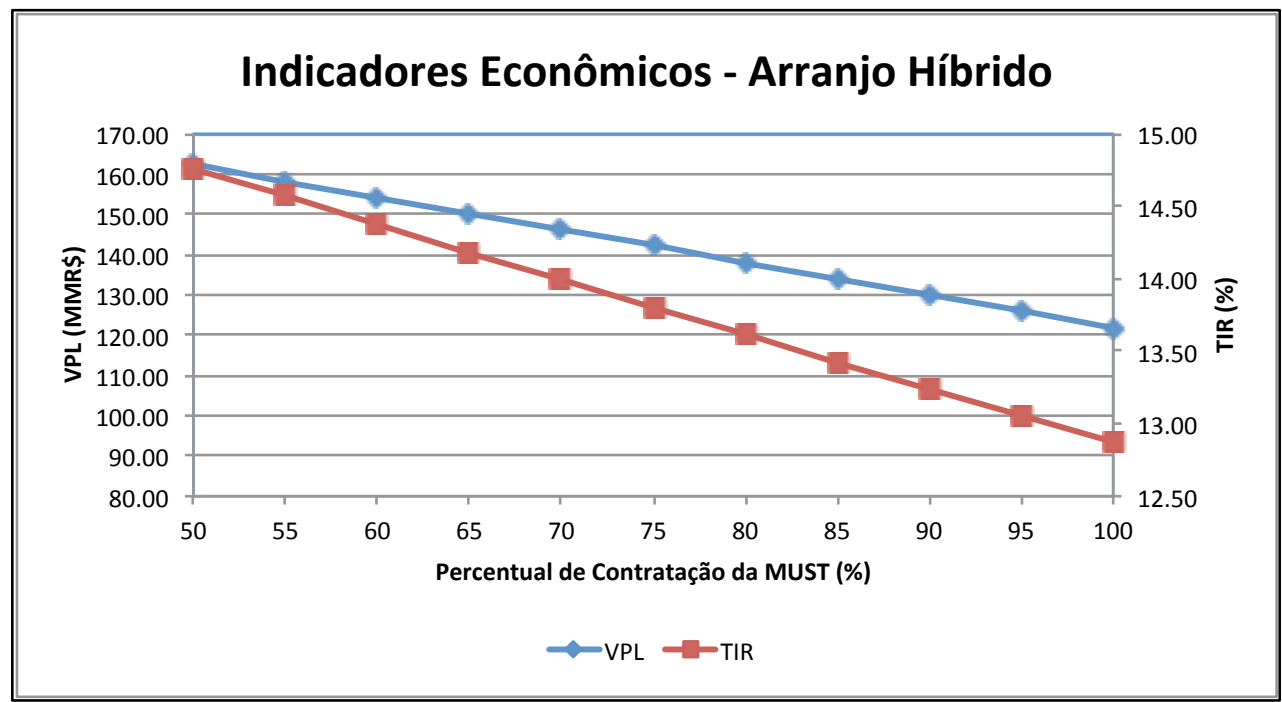

Figura 54 - Resultados da Sensibildade de Contratação do MUST para o Caso Determínistico em Gráfico de Linha

A Figura 55 até a Figura 58 apresentam resultados obtidos com a abordagem probabilística.

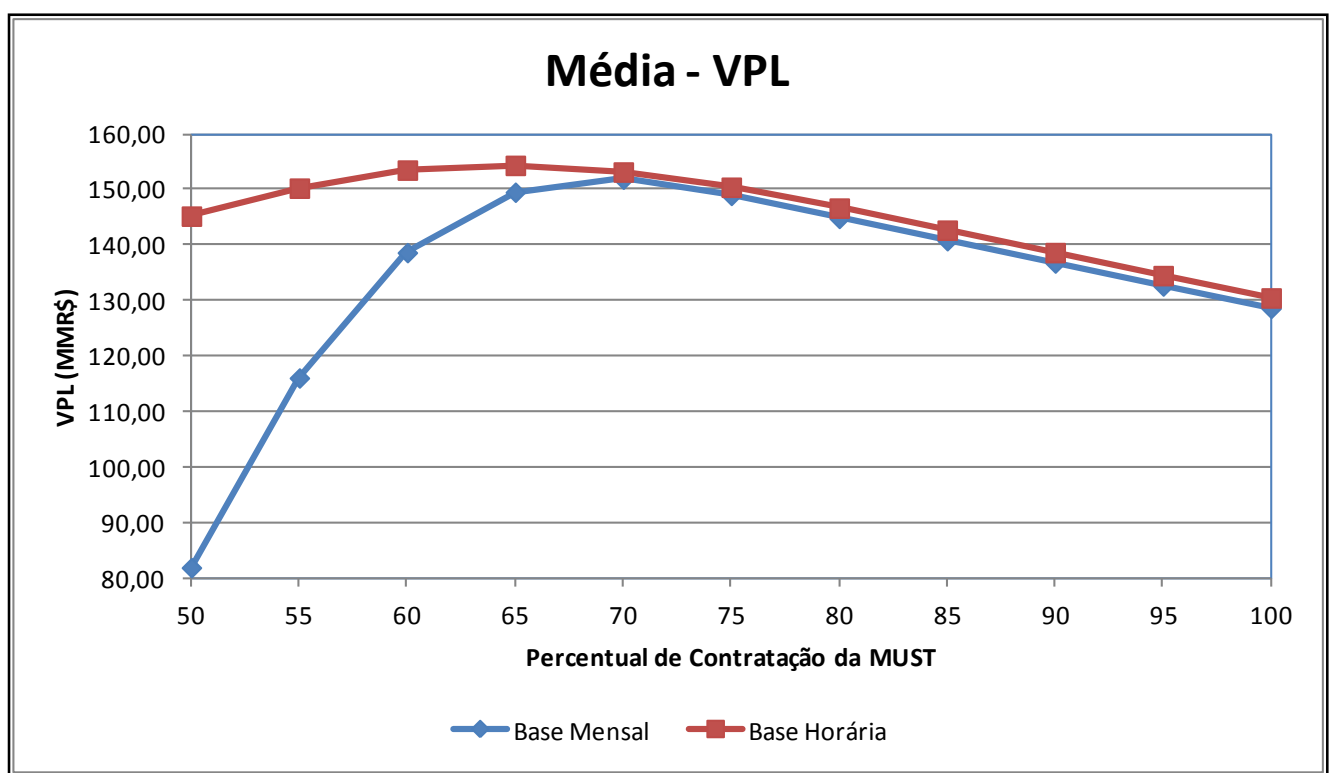

Figura 55 - Dados da Média de VPL para cada Percentual de Contratação do MUST 


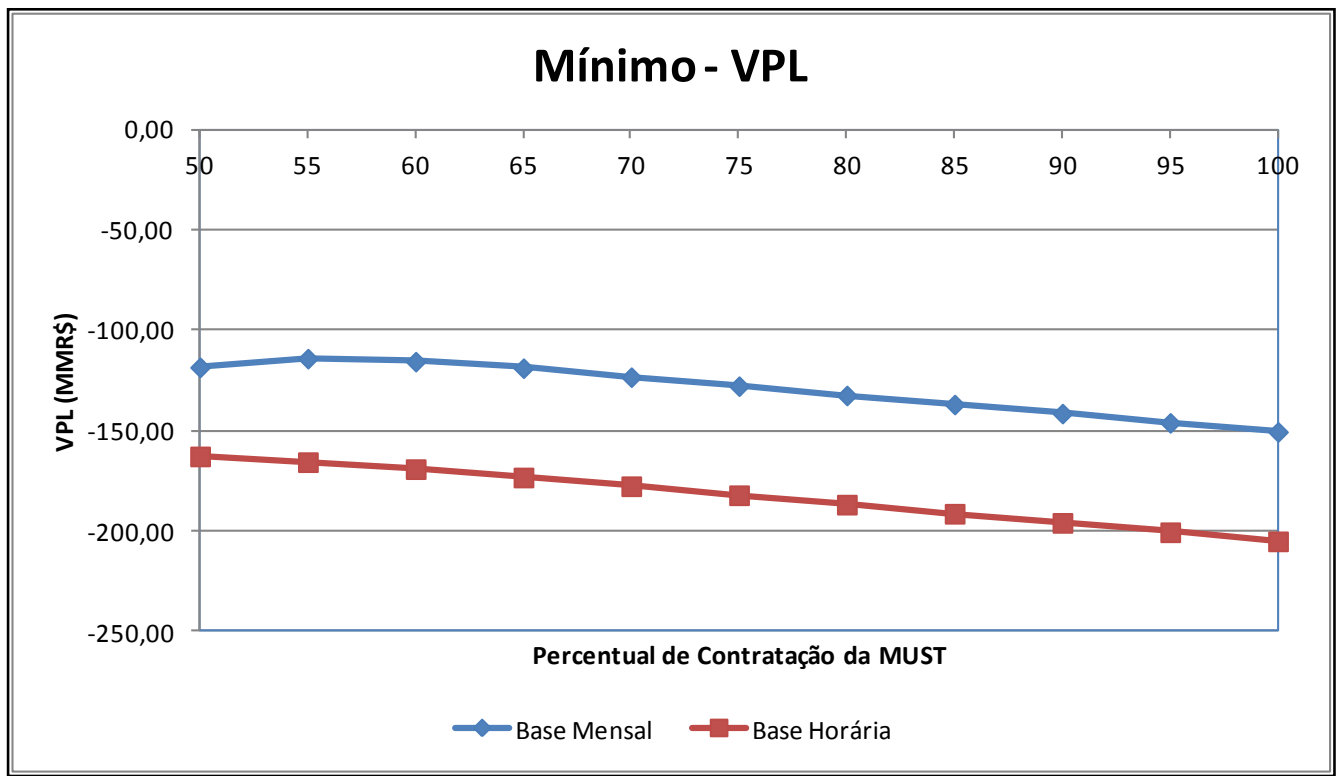

Figura 56 - Dados da Valores Mínimos de VPL para cada Percentual de Contratação do MUST

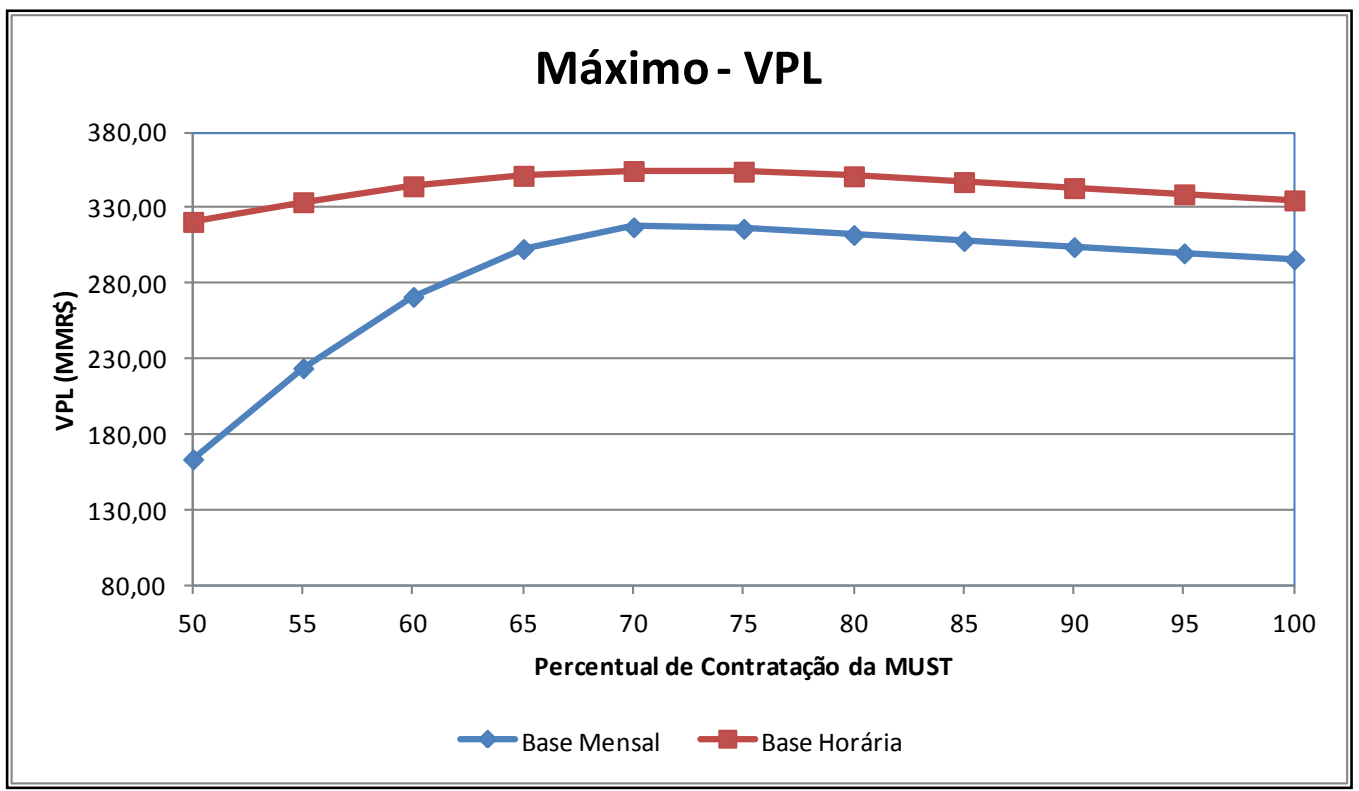

Figura 57 - Dados da Valores Máximos de VPL para cada Percentual de Contratação do MUST 


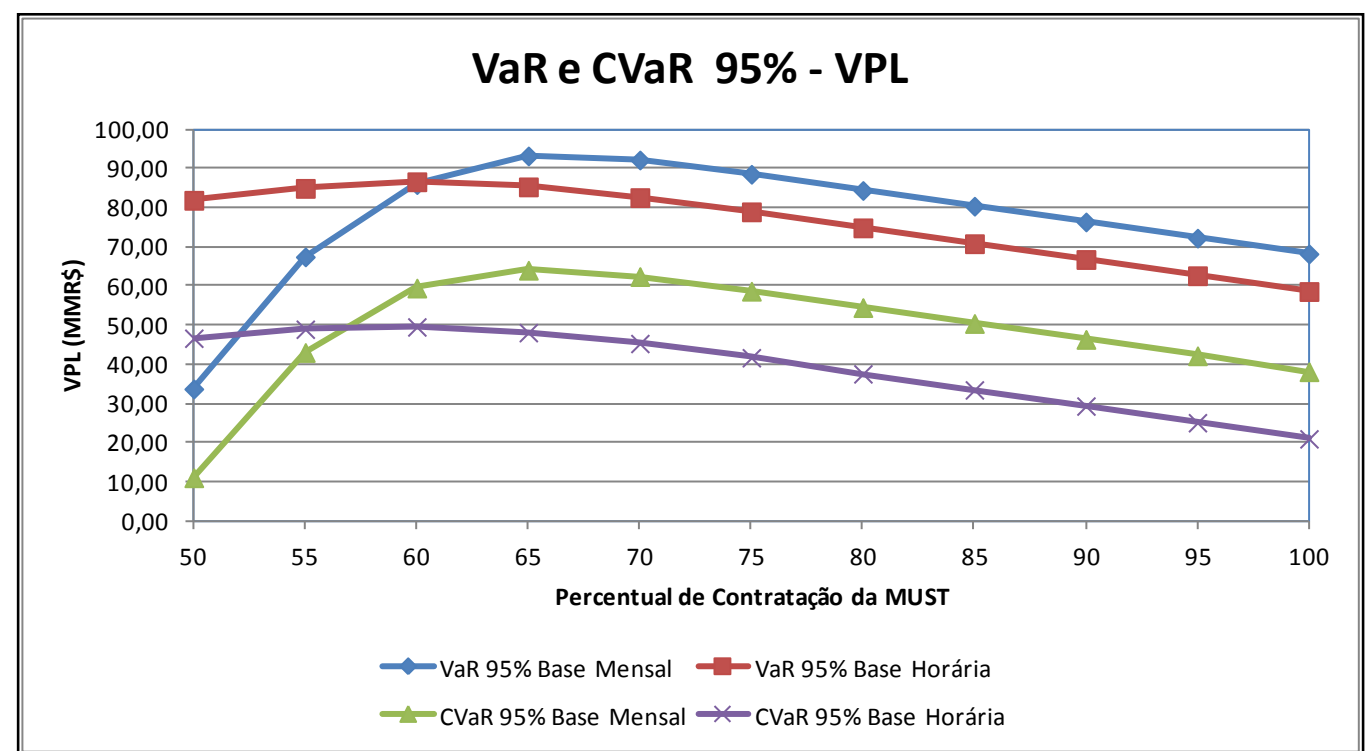

Figura 58 - Dados do VaR e de CVaR 95\% de VPL para cada Percentual de Contratação do MUST

Ao analisar as Figuras 55 à 58, percebe-se que a redução da contratação do MUST resulta em melhora das estatísticas de VPL até um determinado ponto. No caso da média de VPL (Figura 55), ao se reduzir a contratação do MUST, o ponto de maior valor ocorre, na base mensal, em $70 \%$, enquanto que na base horária em $65 \%$.

Já no caso de valor mínimo de VPL (Figura 56), ao se reduzir a contratação do MUST, o ponto de maior valor de mínimo ocorre, na base mensal, em 55\% e na base horária, em 50\%, ou seja, o valor mínimo de VPL sempre melhora ao se reduzir o MUST até este valor.

No caso do valor máximo de VPL (Figura 57), ao se reduzir a contratação do MUST desde $100 \%$, o ponto de maior valor de máximo de VPL é o mesmo na base mensal e na base horária, e ocorre no valor de 70\% de contratação do MUST.

Com relação às métricas de risco (Figura 58), o VaR com 95\% de significância apresenta um máximo (ou menor risco) no ponto de $65 \%$ de contratação do MUST na análise de base mensal, enquanto na base horária este máximo (ou menor risco) ocorre no ponto $60 \%$ de contratação do MUST. As conclusões para CVaR com 95\% de significância são análogas às conclusões do $\mathrm{VaR}$, tanto na base mensal quanto na base horária.

Percebe-se que, ao se reduzir o percentual de contratação do MUST para próximo de $50 \%$ da potência nominal, os valores de VPL em base mensal diminuem com maior intensidade do que os valores em base horária. Isto ocorre porque a receita 
do empreendimento se mostra maior na base horária em função da desagregação da geração e do preço nesta base temporal.

Para as premissas adotadas neste estudo de caso, conclui-se que a melhor opção de contratação do MUST se dá, em média, entre $65 \%$ e $70 \%$, a depender da discretização temporal empregada. Isto mostra que há espaço para que a legislação setorial avance no que tange às regras para o desenvolvimento de usinas híbridas no Brasil, proporcionando um melhor ambiente para o desenvolvimento destas usinas. Mesmo com a impossibilidade de, em determinados momentos, escoar toda a sua produção de energia para a rede básica, os resultados mostram que a redução da contratação do MUST pode ser a opção mais atrativa para investidor.

Adicionalmente, ao contrário do observado nas Figuras 48 à 53, as abordagens mensal e horária podem levar a resultados distintos, mesmo em termos médios, para diferentes valores de contratação do MUST, tal como pode ser observado na Figura 59. Este resultado leva a crer que a análise horária pode levar a resultados mais realistas quando comparada à análise mensal, no sentido contrário ao observado anteriormente.

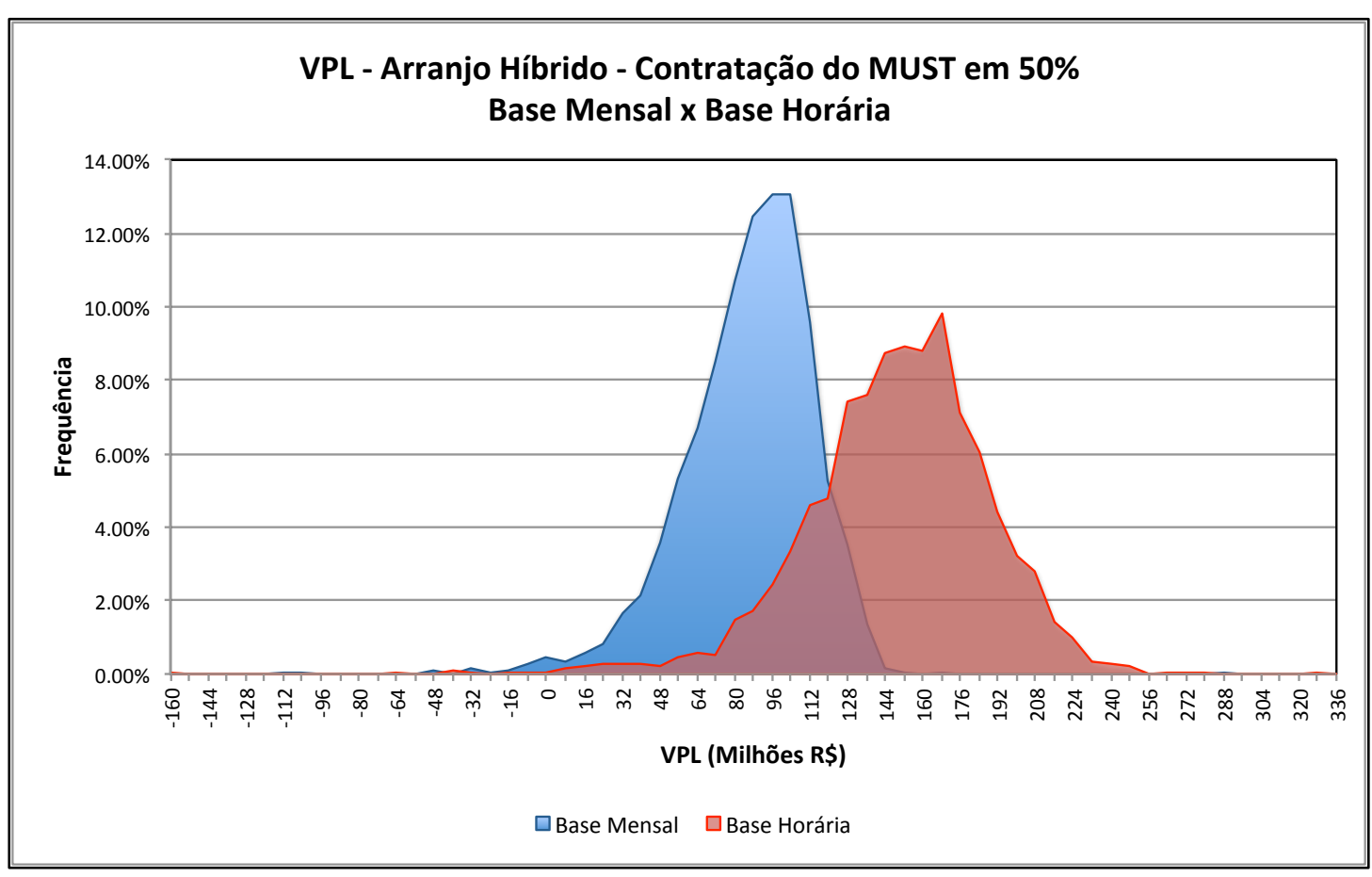

Figura 59 - Comparação entre as Distribuições de VPL da Análise em Base Mensal e em Base Horária para Contratação do MUST em 50\% da Potência Nominal - Arranjo Híbrido 
As Figura 60, Figura 61 e Figura 62 apresentam algumas estatísticas de TIR obtidas ao se realizar a análises probabilísticas com diferentes valores relacionados à contratação do MUST. Não se apresentou aqui as estatísticas de mínimo de TIR, pois, para vários percentuais de contratação do MUST, não se encontrou valor de TIR para o pior cenário de fluxo de caixa.

Todos os dados e outras estatísticas estão presentes no Apêndice B (seção 11.2) nas Tabela 33, Tabela 34 e Tabela 35.

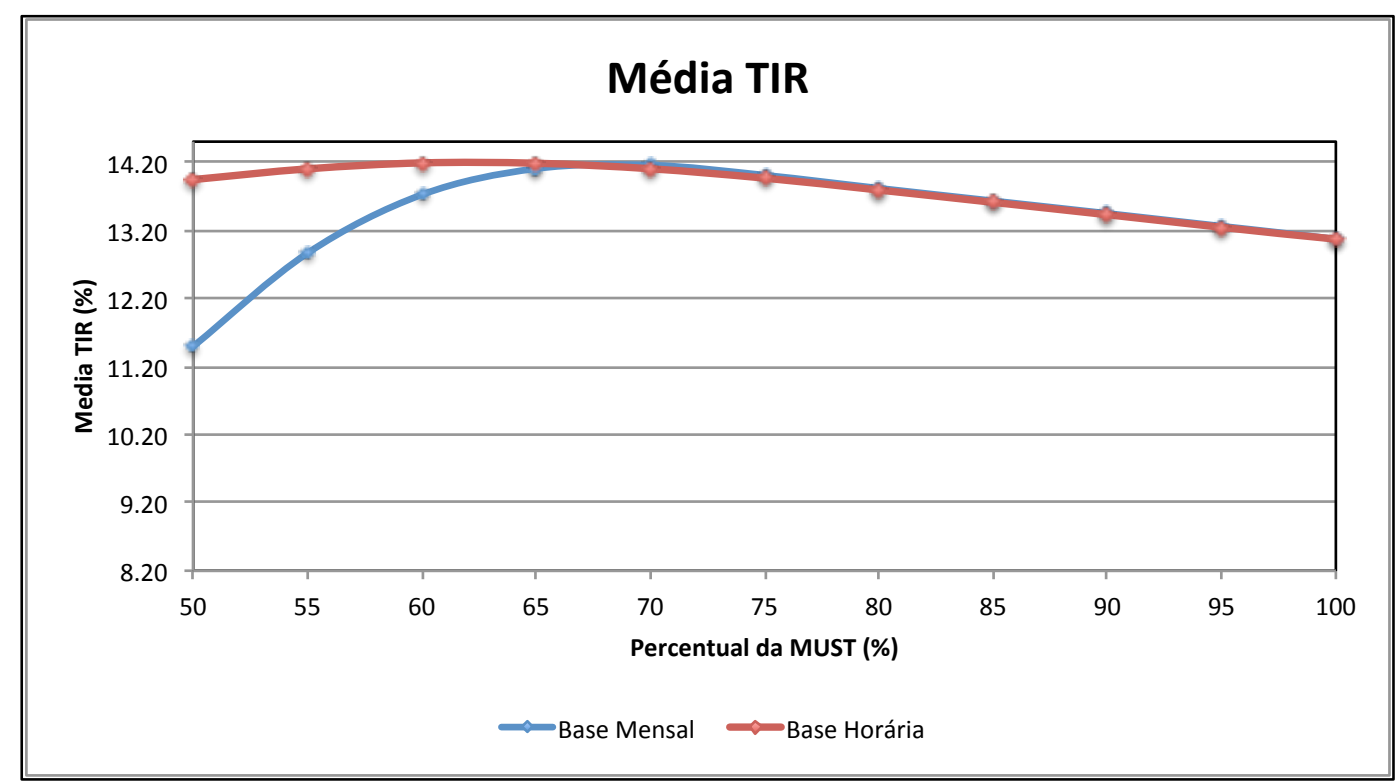

Figura 60 - Dados da Média de TIR para cada Percentual de Contratação do MUST

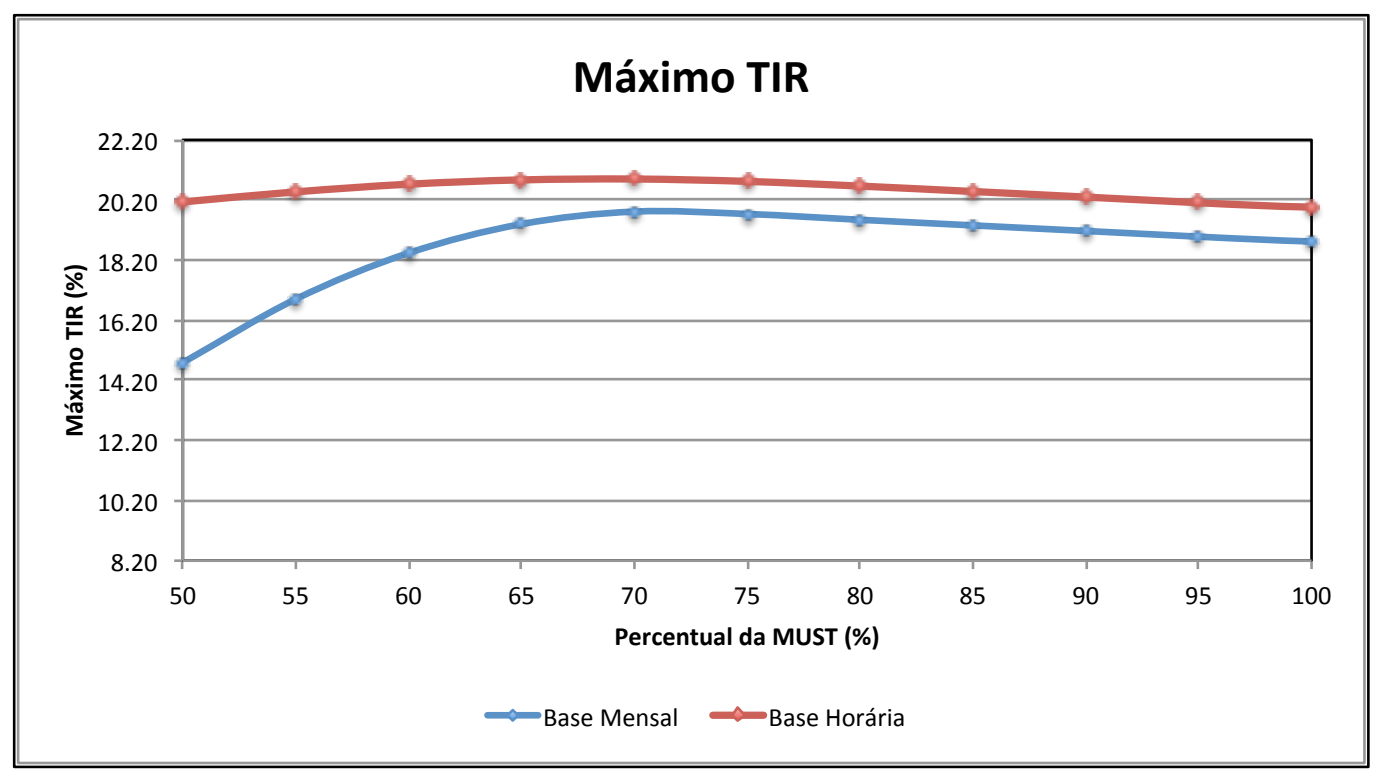

Figura 61 - Dados da Valores Máximos de TIR para cada Percentual de Contratação do MUST 


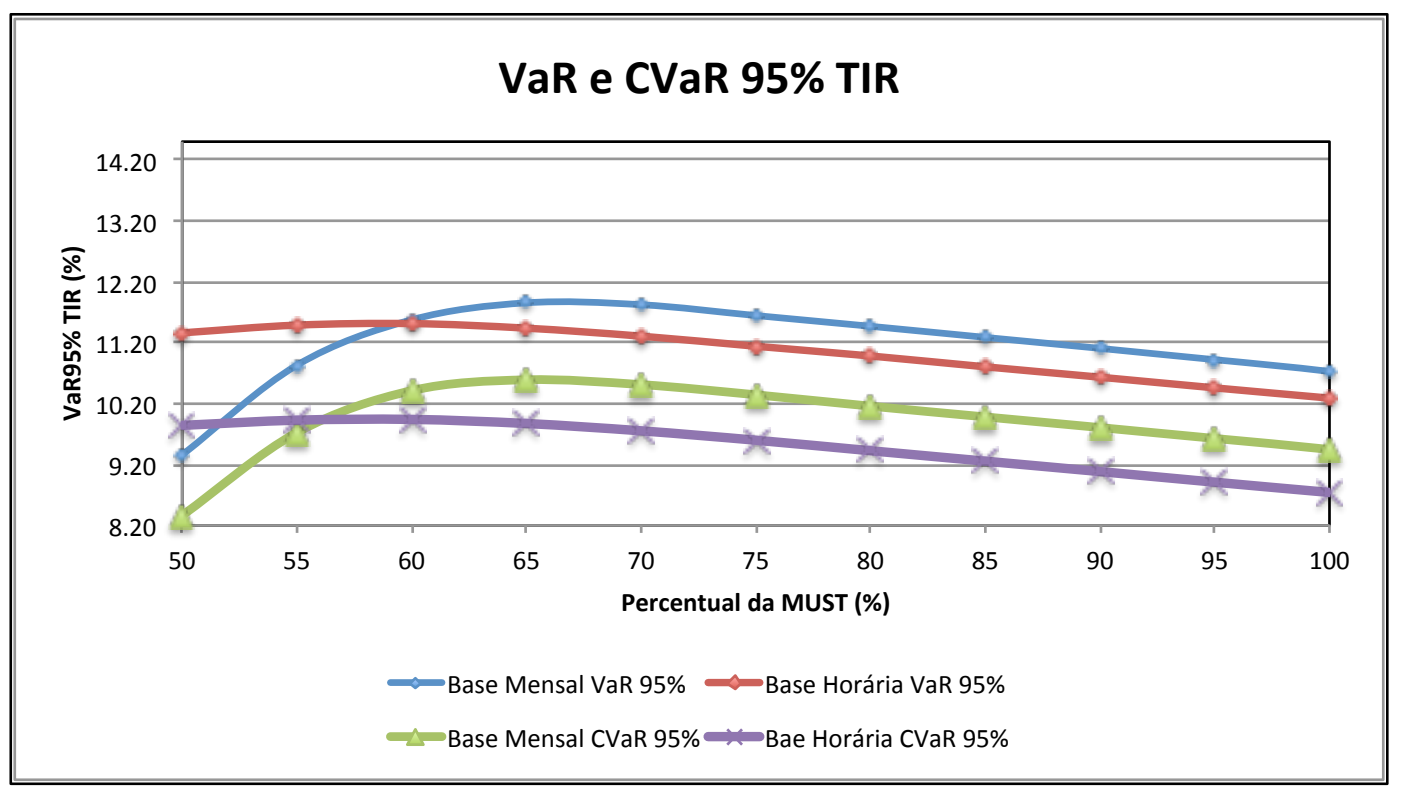

Figura 62 - Dados da VaR e CVaR 95\% de TIR para cada Percentual de Contratação do MUST

A Figura 63 apresenta os resultados da média dos 2.000 cenários de TIR modificada ao se realizar as análises probabilísticas com diferentes valores relacionados à contratação do MUST. Gráficos relativos aos valores máximos, aos valores mínimos e às métricas de risco estão expostas nas Figura 83, Figura 84, Figura 85 e outras estatísticas são apresentadas nas Tabela 39, Tabela 40 e Tabela 41 no Apêndice B (seção 11.2).

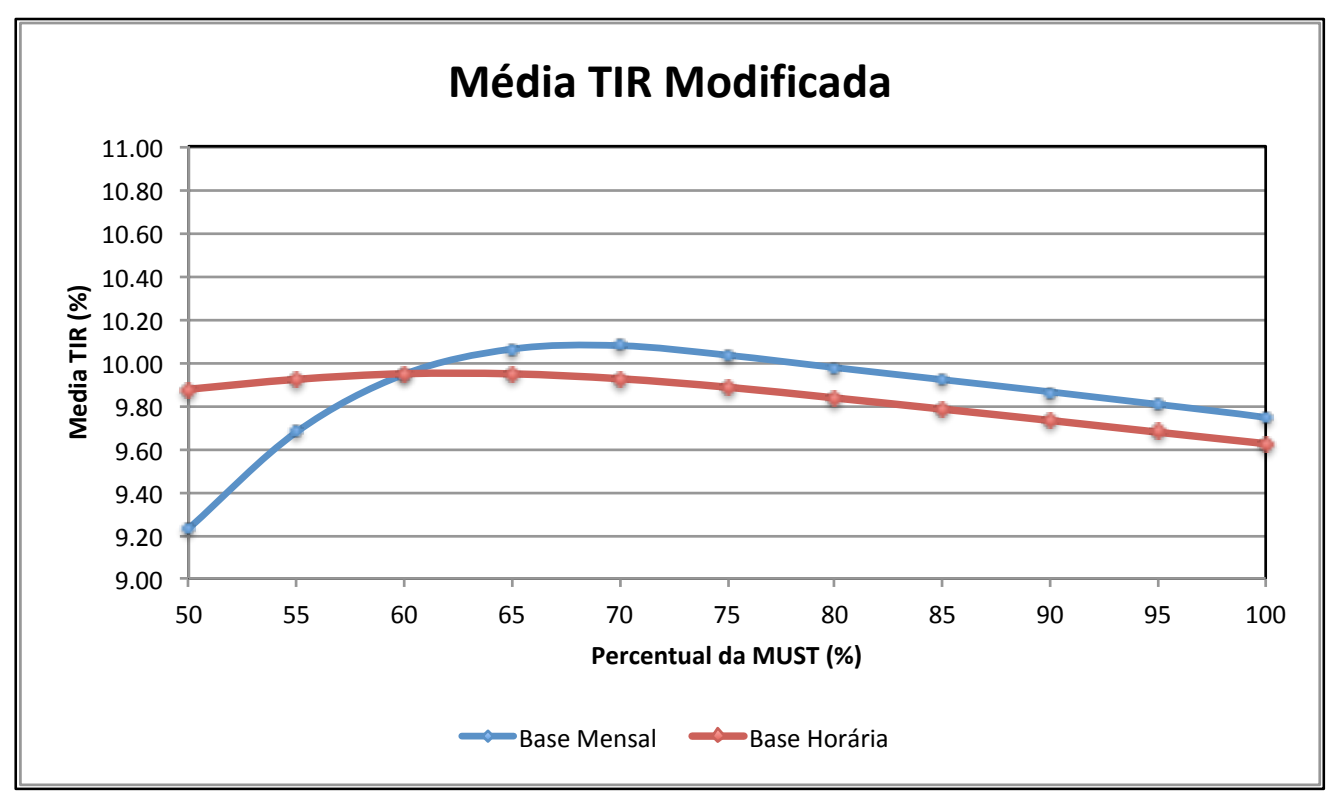

Figura 63 - Dados da Média de TIR Modificada para cada Percentual de Contratação do MUST 
Considerando as estatísticas de média, máximo e a métricas de risco na Figura 60 à Figura 63, percebe-se que, a depender da discretização temporal da análise, a contratação ótima do MUST se dá no intervalo entre $60 \%$ e $70 \%$ da potência instalada do empreendimento.

\subsection{1}

\section{Análise de Risco-Retorno}

Para complementar a análise dos resultados, esta dissertação apresenta uma análise de Risco-Retorno entre as possibilidades de contratação do MUST. As métricas de risco dessa análise foram o VaR e CVaR, ambos a 95\% de significância. Neste caso, quanto maior elas se apresentarem, menor o risco associado.

Apresenta-se na Figura 64 a relação risco-retorno para os casos da sensibilidade em base mensal. Para ambas as métricas de risco, percebe-se nesta figura que a redução da contratação do MUST a partir de 100\% até 70\% do valor do MUST contratado leva a uma redução do risco e a um aumento da média de TIR. De $70 \%$ para $65 \%$, o risco se reduz, mas a média de TIR também diminui a média de TIR. Já de 65\% para 60\% vê-se um aumento de risco e uma redução da média de TIR. Assim, tem-se um fronteira eficiente entre os percentuais de $65 \%$ e $70 \%$ de contratação do MUST. Uma característica dessa fronteira é que, para obter maior retorno (média de TIR), é necessário que o gestor do projeto esteja disposto a aceitar um maior risco, e vice-versa. Pode-se afirmar que os pontos na área abaixo desta fronteira são ineficientes, ou dominados, em termos de risco-retorno (ASSAF NETO, 2020). 


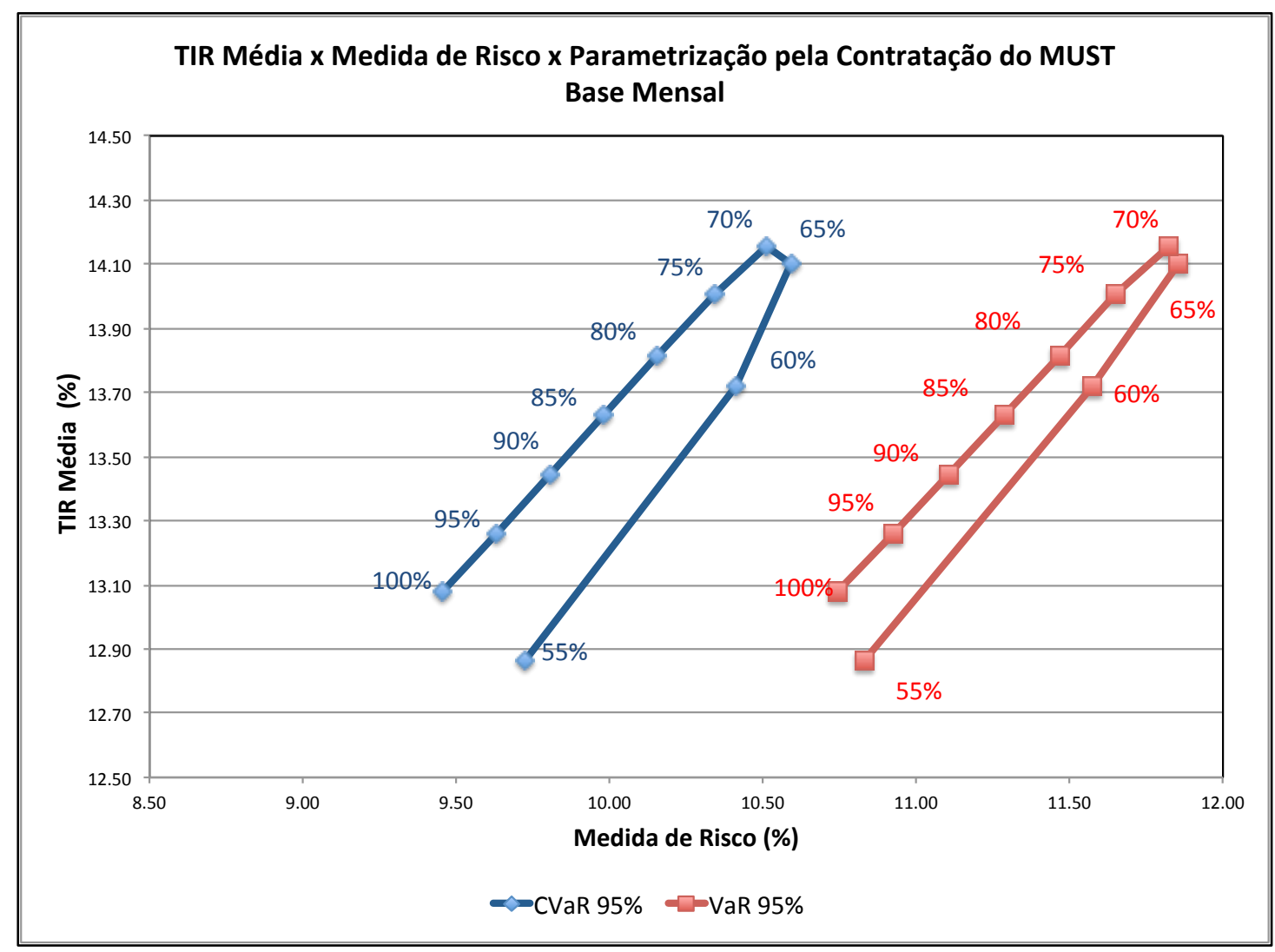

Figura 64 - Relação de VaR e CVaR 95\% com a TIR média para Diferentes Valores de Contratação do MUST - Base Mensal

Na Figura 65, base horária, não se configurou uma fronteira eficiente, mas sim um "ponto" eficiente, o caso de $60 \%$ de contratação do MUST. Observa-se nesta figura que, ao se reduzir o percentual de contratação do MUST de $100 \%$ até $60 \%$, ocorre a redução de risco e o aumento da média de TIR. Entretanto, a partir do ponto de 55\% ocorre aumento de risco e redução de média de TIR, para ambas métricas de risco.

A Figura 66 e a Figura 67 apresentam uma análise semelhante em que se relacionam as métricas de risco com os VPLs médios para os diferentes valores de contratação do MUST, onde se chega às mesmas conclusões das análises da Figura 64 e Figura 65. Ou seja, a análise em base mensal apresenta uma fronteira eficiente entre os percentuais do MUST de $65 \%$ e $70 \%$, e a análise em base horária apresenta um "ponto" eficiente em $60 \%$. 


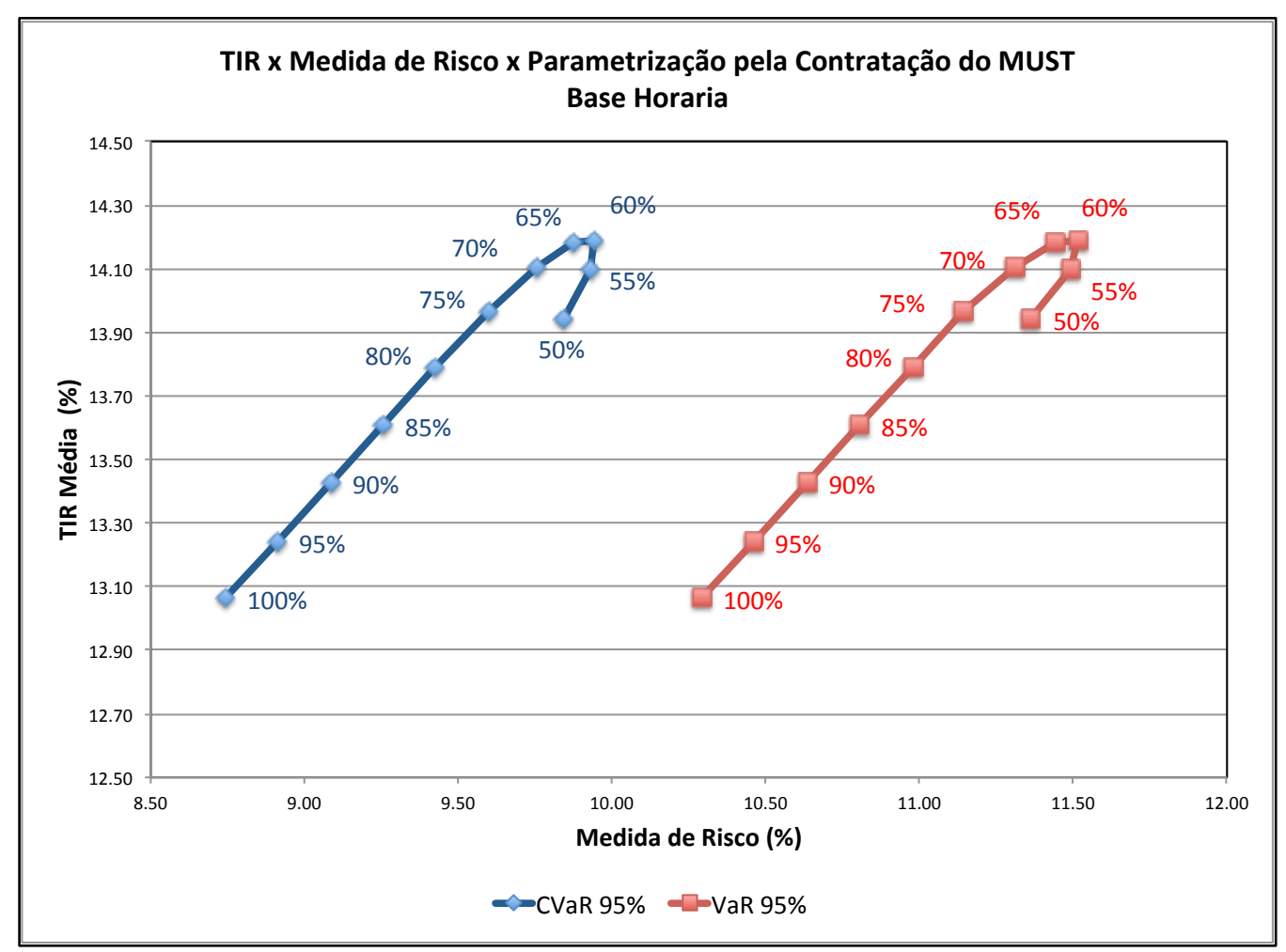

Figura 65 - Relação de VaR e CVaR 95\% com a TIR média para Diferentes Valores de Contratação do MUST - Base Horária

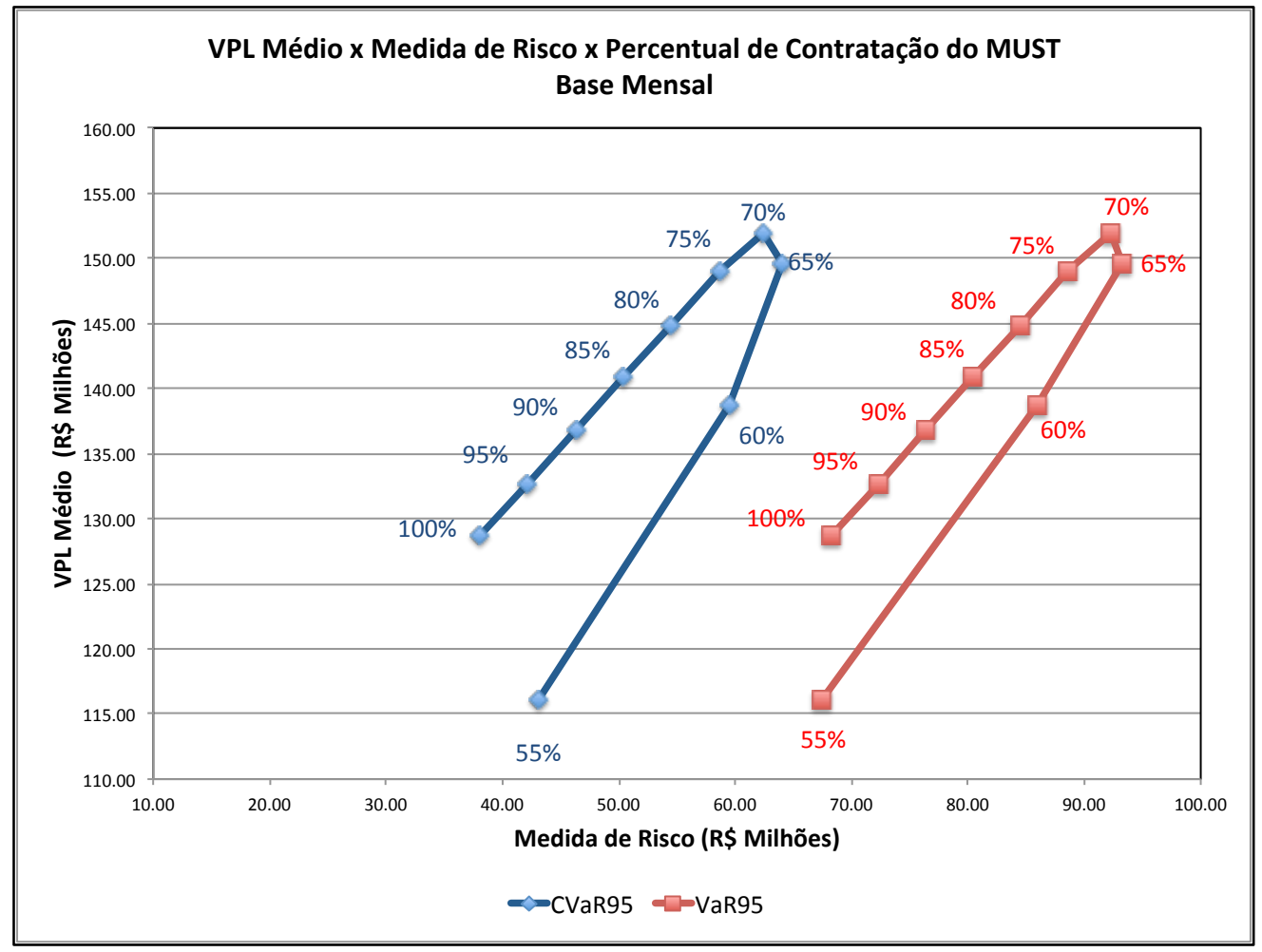

Figura 66 - Relação de VaR e CVaR 95\% com o VPL médio para Diferentes Valores de Contratação do MUST - Base Mensal 


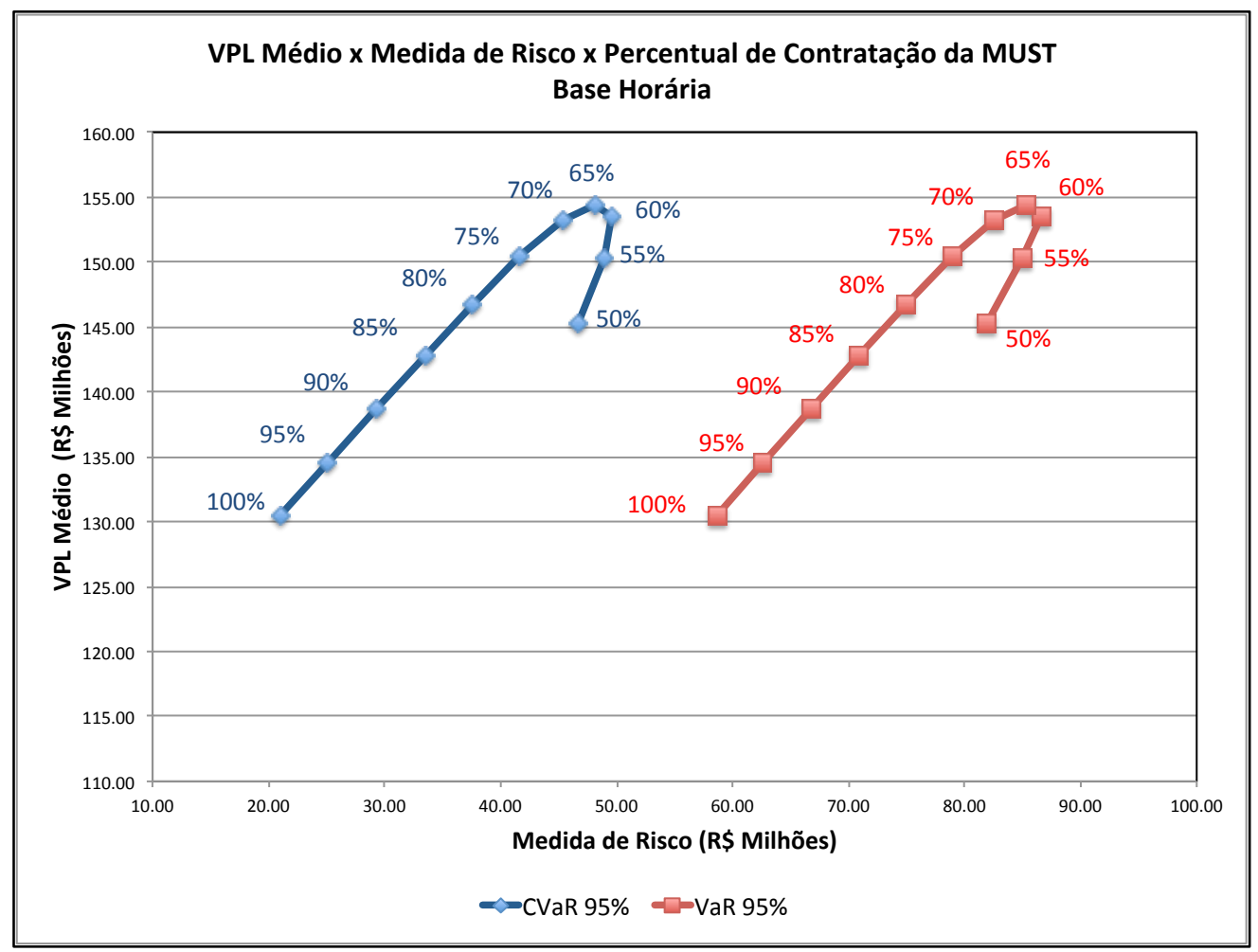

Figura 67 - Relação de VaR e CVaR 95\% com o VPL médio para Diferentes Valores de Contratação do MUST - Base Mensal

Assim, as análises risco-retorno apresentadas nesta seção indicam que a contratação ótima de percentual do MUST encontra-se no intervalo entre $60 \%$ e $70 \%$ da potência instalada do empreendimento analisado, considerando ambas as bases temporais.

\subsection{2}

\section{Avaliação do Curtailment}

Como visto na seção anterior, a redução do valor de contratação do MUST para valores próximos de 50\% ocasiona uma inflexão nos indicadores econômicos. $\mathrm{O}$ ganho com redução de investimento e despesas se torna inferior à receita que se deixa de auferir com a energia excedente ao valor do MUST. Este corte de energia é denominado curtailment (EPE, 2017).

$\mathrm{Na}$ análise de sensibilidade em base horária realizada nesta dissertação, para cada percentual de contratação do MUST e para cada cenário de geração considerado, verificou-se a quantidade de energia que ultrapassou este limite e, consequentemente, não pôde ser escoada para a rede básica. Agrupou-se esta quantidade de energia por 
ano operacional do empreendimento híbrido (21 anos) e por percentual de contratação do MUST.

Ressalta-se que a Resolução Normativa ANEEL No 666, 23 de junho de 2015 estabelece penalidade para o caso de se injetar na rede básica um valor superior ao do MUST contratado. A presente dissertação considerou que o excedente de energia em relação ao MUST contratado não seria escoado para rede básica, e, portanto, não implicando em penalidades. Este excedente de energia seria disponibilizado para outros fins, os quais não foram explicitamente considerados neste trabalho.

Os resultados são apresentados de forma relativa, ou seja, como um percentual do curtailment (geração excedente à contratação do MUST) em relação à Garantia Física do empreendimento, medida em MWh/ano.

As Figura 68, Figura 70 e Figura 71 apresentam os resultados ao longo do período operacional da usina híbrida. Omitiu-se os resultados relativos aos percentuais de contratação do MUST de 100\% (Caso Base), 95\%, 90\% e 85\%, uma vez que os dados de curtailment são iguais ou aproximadamente zero para estes casos.

A Figura 68 apresenta, para cada ano operacional da usina híbrida e para os percentuais de contratação do MUST em análise, a média dos curtailments ocorridos nos 2.000 cenários de fluxo de caixa analisados. Percebe-se que, para percentuais maiores ou iguais a $65 \%$ do MUST contratado, a média de corte de energia é inferior da 2\% da Garantia Física de energia da usina. Já para o caso em que se contrata apenas 50\% do MUST, tem-se a média de corte superior a 10\% da Garantia Física. 


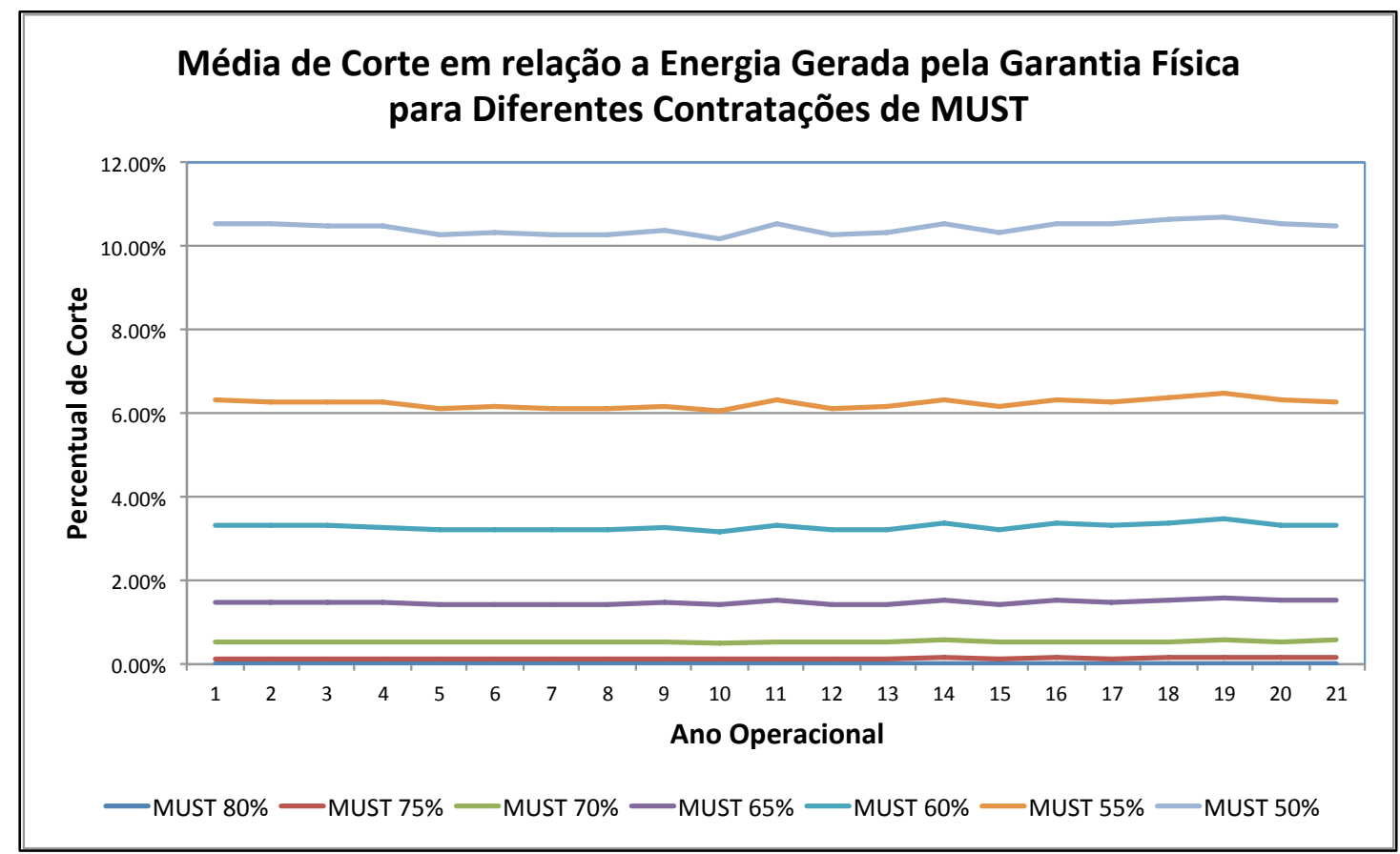

Figura 68 - Média de Corte em relação à Energia Gerada pela Garantia Física

De forma ilustrativa, apresentam-se estatísticas dos cortes de energia para os 2.000 cenários do caso de $60 \%$ de contratação do MUST na Tabela 32. Percebe-se que a média dos cortes ficou em 3,29\% e atingiu valor máximo de 7,74\%. Já a Figura 69 apresenta a distribuição de frequências de corte de energia para este caso de $60 \%$.

Tabela 32 - Estatísticas de cortes de energia para o caso de 60\% de Contratação do MUST

\begin{tabular}{|c|c|}
\hline \multicolumn{2}{|c|}{ Curtailment - MUST $\mathbf{6 0} \%$} \\
\hline Média & $3,29 \%$ \\
\hline Mediana & $3,24 \%$ \\
\hline Mínimo & $0,17 \%$ \\
\hline Máximo & $7,74 \%$ \\
\hline Desvio Padrão & $0,98 \%$ \\
\hline VaR 95\% & $1,72 \%$ \\
\hline CVaR 95\% & $0,94 \%$ \\
\hline Coef. de Variação & 0,30 \\
\hline
\end{tabular}




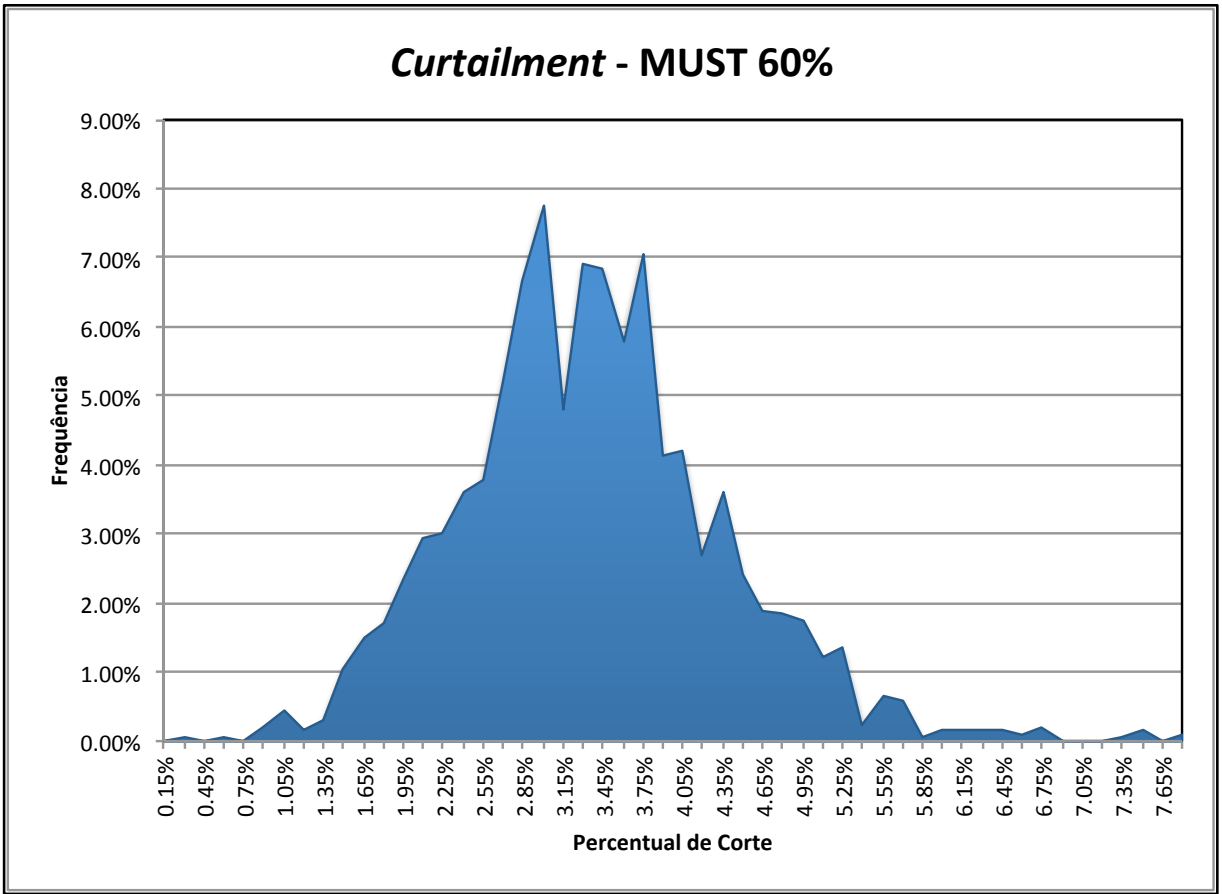

Figura 69 - Distribuição de Probabilidade de Curtailment para o caso de se contratar $60 \%$ do MUST

A Figura 70 mostra, para cada ano operacional da usina híbrida e para os percentuais de contratação do MUST em análise, o maior valor de corte dentre os 2.000 cenários analisados em relação à garantia física. Observa-se que, para o percentual de $50 \%$ MUST contratada, o percentual de corte oscila entre $25 \%$ e $30 \%$ da garantia física durante o período operacional.

Apresenta-se na Figura 71 a métrica de risco VaR para o nível de significância de 95\%, ou seja, o percentil 5\% dos piores casos. Através desta figura é possível afirmar, por exemplo, que ocorre em torno de $18 \%$ de curtailment ao longo do período operacional em pelo menos $5 \%$ dos cenários do caso em que se contrata $50 \%$ do MUST. Já para o caso em que se contrata 65\% do MUST, este valor fica em torno de $4 \%$.

Para ilustrar o potencial efeito positivo da redução do MUST no VPL do projeto, utiliza-se como exemplo a contratação do MUST igual a 60\% da potência nominal do arranjo híbrido estudado. Conforme a Tabela 30, neste caso os investimentos são reduzidos em 3\% com relação ao valor original, ou seja, com contratação de $100 \%$ do MUST. De acordo com a Tabela 32, a média de corte de energia nos 2.000 cenários utilizados é de 3,29\%. 


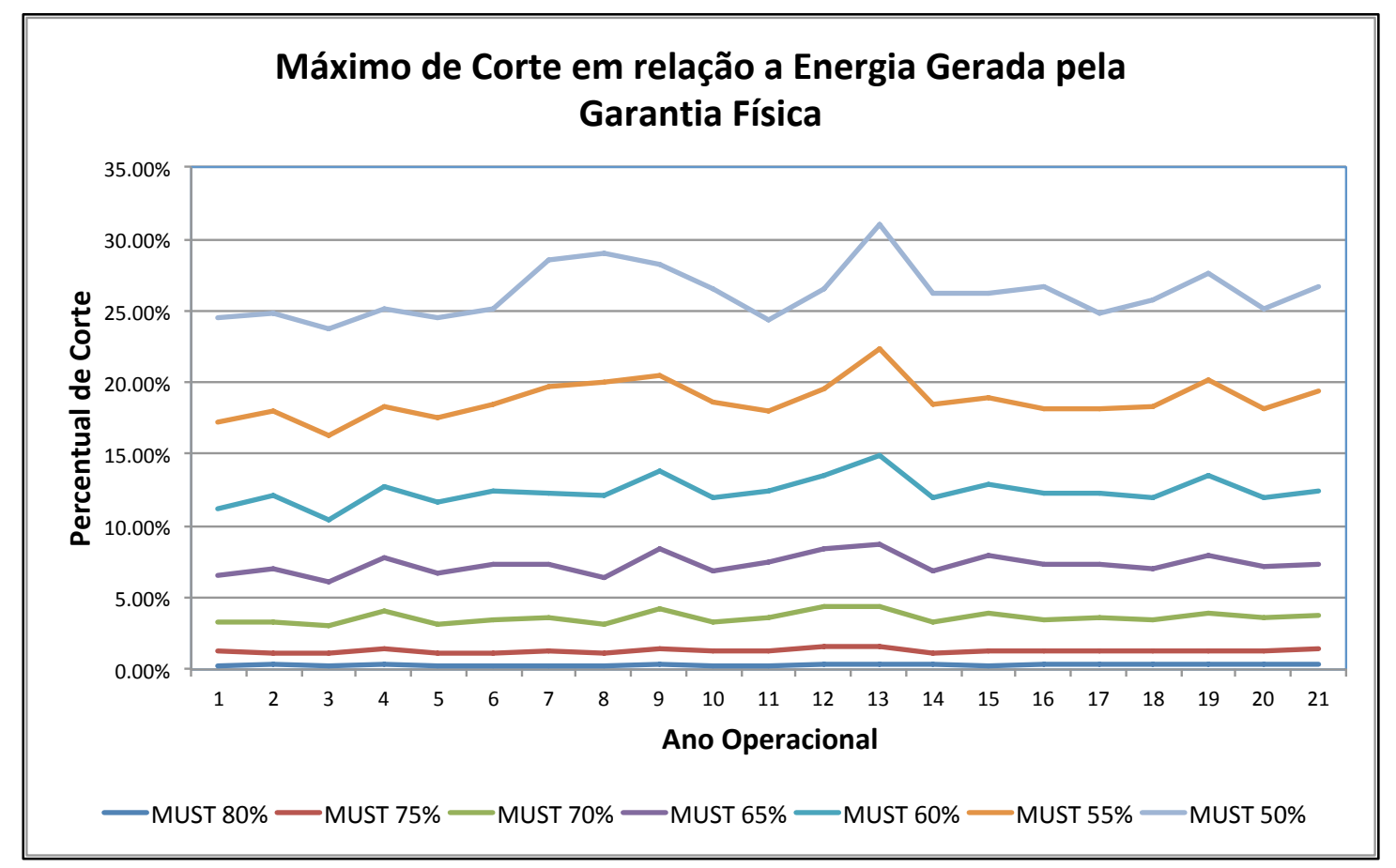

Figura 70 - Máximo de Corte em relação à Energia Gerada pela Garantia Física

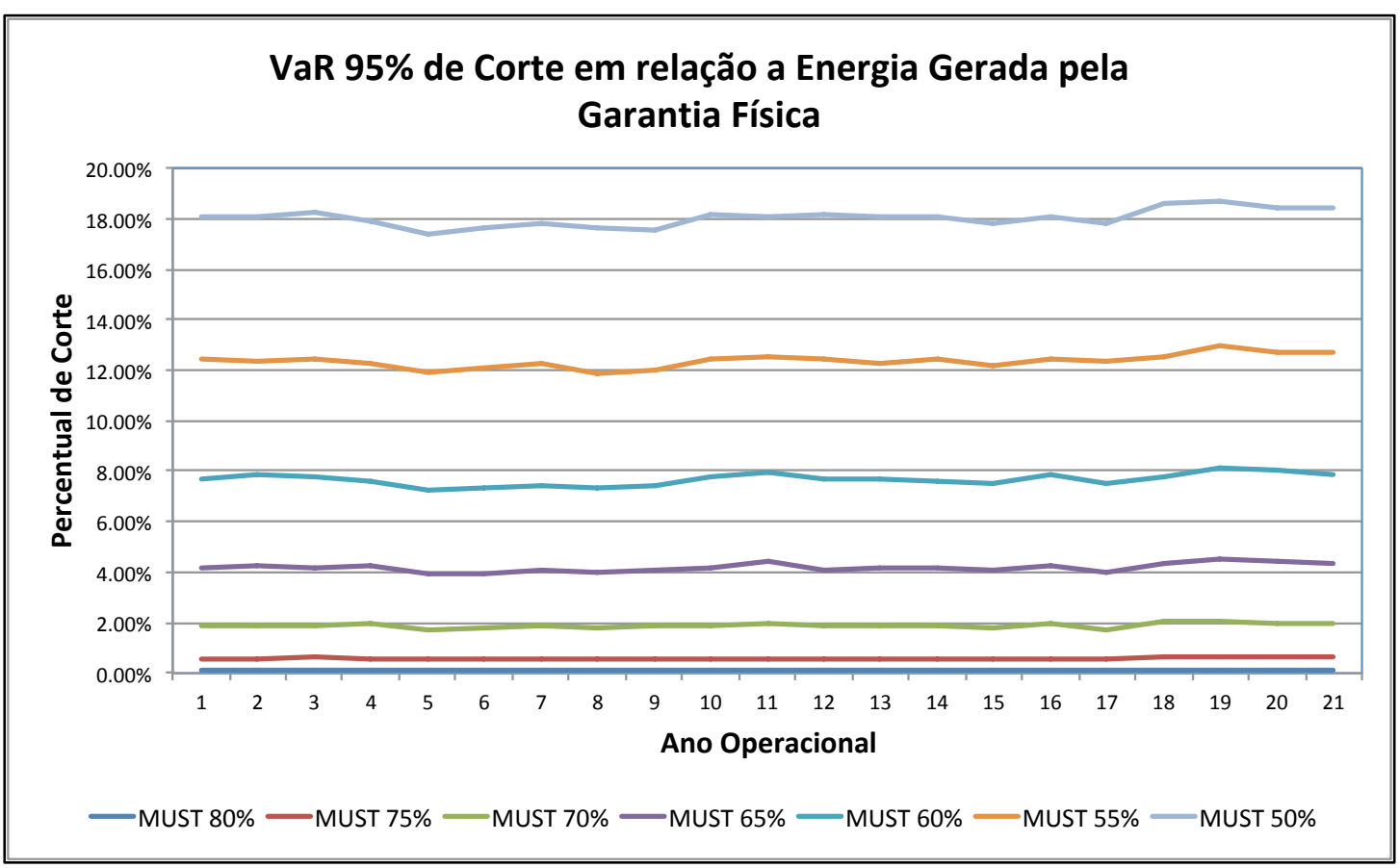

Figura 71 - VaR 95\% do Corte em relação à Energia Gerada pela Garantia Física

As avaliações realizadas indicaram que, para o caso exemplo desta dissertação, a redução da contratação do MUST eleva os valores de curtailment em menor escala. Sendo assim, conclui-se que quanto maior for a complementaridade 
intradiária entres as fontes de geração, maiores as possibilidades de se reduzir a contratação do MUST sem comprometer a viabilidade da usina e a sua capacidade de entregar energia ao sistema. Cabe destacar que os benefícios de redução do MUST são adequadamente capturados em análises com base horária.

Finalmente, como a regulação sobre usinas híbridas ainda está incipiente, as análises aqui efetuadas parecem contribuir para subsidiar futuras decisões setoriais no que tange às regras a serem impostas às usinas híbridas. 


\section{8 \\ Conclusão}

O principal objetivo desta dissertação foi estabelecer uma abordagem metodológica para avaliar a viabilidade econômica de projetos híbridos de geração de energia elétrica, particularmente os que combinam as tecnologias eólica e solar fotovoltaica, levando em consideração dois dos seus principais fatores de risco: o comportamento aleatório da produção de energia elétrica e o seu preço da energia no mercado à vista. Também foi objetivo desta dissertação que a abordagem metodológica utilizada permitisse que os fluxos de caixa do empreendimento fossem projetados em base horária, permitindo avaliar os ganhos deste tipo de projeção comparado à projeções feitas em base mensal, usualmente utilizada por modelos de longo prazo para a projeção de geração de energia elétrica, preço e fluxos de caixa.

Uma vez que o horizonte de projeção dos fluxos de caixa para novos empreendimentos de geração pode alcançar 30 anos ou mais, a estratégia adotada nesta dissertação foi utilizar modelos de longo prazo, com discretização mensal, para projetar os fatores de risco considerados. Em seguida, com base nas séries históricas das variáveis aleatórias (geração e preço), foram construídos fatores para desagregar as variáveis projetadas em base mensal para a base horária. Tais fatores foram chamados Fatores de Desagregação. A sua utilização permitiu que particularidades específicas das fontes de geração analisadas fossem capturadas, tais como a sua complementaridade diária.

A abordagem metodológica elaborada nesta dissertação foi aplicada a um estudo de caso que considerou o desenvolvimento de uma usina híbrida na região nordeste do Brasil, que possui abundância de recursos eólicos e solares. Cabe destacar que o Plano Decenal de Expansão de Energia 2029 projeta um forte crescimento destas fontes no parque gerador brasileiro. Juntamente com a análise da usina híbrida, também foram realizadas análises individuais de ambas as tecnologias. O objetivo foi avaliar os ganhos sinérgicos do arranjo híbrido.

A aplicação da abordagem metodológica a uma usina desenvolvida no Brasil parece oportuna, uma vez que desde janeiro de 2021 passou a vigorar no Setor 
Elétrico Brasileiro, em particular no mercado à vista, o preço horário da energia elétrica. Conforme descrito no Capítulo 2, de Revisão da Literatura, nota-se que a literatura carece de estudos de avaliação de empreendimentos de produção de energia híbridos nesta base temporal.

Os resultados mostraram que é possível observar um ganho sinérgico com o desenvolvimento do arranjo híbrido, tendo em vista que o seu VPL se mostrou superior à soma dos VPLs dos empreendimentos eólicos e solares desenvolvidos separadamente. Para o estudo de caso observado tal ganho se mostrou da ordem, na análise em base mensal, de 4,93 milhões de reais. Para análise em base horária, este ganho foi de 4,79 milhões de reais.

Ao compararmos os resultados obtidos com a projeção dos fluxos de caixa em diferentes bases temporais, ou seja, horária e mensal, verificou-se que, para o caso base, as distribuições de VPL, TIR e TIR modificada se mostraram bastante similares, incluindo os valores médios, a mediana e o desvio padrão da distribuição. Isto é um indicativo de que, para alguns casos, as análises de fluxo de caixa em base mensal podem ser adequadas para avaliar a viabilidade econômica de projetos de geração no Brasil, mesmo com a introdução do PLD Horário.

Atualmente, a legislação vigente no Setor Elétrico Brasileiro exige que empreendimentos de geração contratem um Montante de Uso do Sistema de Transmissão (MUST) igual à sua potência nominal. A proposta de se permitir a contratação de um valor inferior à potência nominal está, atualmente, em processo de regulamentação. Esta dissertação apresentou resultados de uma análise de sensibilidade acerca dos indicadores de viabilidade do empreendimento para diferentes níveis de contratação do MUST, acrescida de uma análise risco-retorno. Para o estudo de caso considerado nesta dissertação, verificou-se a melhor estratégia de contratação do MUST se dá entre $60 \%$ e $70 \%$ da potência instalada do empreendimento, a depender da discretização temporal da análise, ou seja, valores inferiores à potência nominal do empreendimento eólico, o qual representa $80 \%$ da potência total do empreendimento híbrido.

Cabe ainda destacar que, para a contratação de MUSTs inferiores a 70\% da potência total do empreendimento, os resultados das análises em base mensal e horária se distanciaram entre si, em termos médios. Este resultado sugere que a maior ocorrência de curtailments pode tornar a análise de viabilidade em base mensal inadequada para empreendimentos híbridos. 
Por fim, também foi avaliado o curtailment para diferentes níveis de contratação do MUST. Verificou-se que o curtailment anual pode atingir cerca de $30 \%$ da energia gerada quando se tem o MUST contratado igual a 50\% da potência nominal da usina. Neste caso, o curtailment médio de todo o horizonte de estudo se mostrou em torno de 18\%. Para contratação do MUST igual a 65\%, o curtailment médio se mostrou inferior a $2 \%$. As avaliações realizadas indicaram que, para o caso exemplo desta dissertação, a redução da contratação do MUST também eleva os valores de curtailment, porém em menor escala. Sendo assim, conclui-se que quanto maior for a complementaridade intradiária entres as fontes de geração, maiores as possibilidades de se reduzir a contratação de MUST sem comprometer a viabilidade econômica da usina e a sua capacidade de entregar energia ao sistema. 


\section{$9 \quad$ Trabalhos Futuros}

Para trabalhos futuros, sugere-se a inserção de tecnologias de armazenamento ao arranjo híbrido proposto nesta dissertação, as quais, por exemplo, podem armazenar a geração excedente (curtailment) para ser injetada na rede básica em outro momento. Além disso, a tecnologia de armazenamento pode ser utilizada para guardar energia nas horas de preços baixos, injetando esta energia na rede em momentos de preços mais elevados. A inserção de tecnologias de armazenamento poderia ser considerada uma opção de investimento ao empreendimento já considerado, podendo ser valorada, por exemplo, por meio da Teoria das Opções Reais. Neste caso, a análise de fluxos de caixa deveria, obrigatoriamente, ser feita em base horária, aproveitando-se da abordagem metodológica empregada neste trabalho.

Outra proposta de trabalho futuro seria utilizar a metodologia apresentada nesta dissertação para recalcular os fatores de desagregação considerando uma série histórica mais extensa. Dessa forma, espera-se obter um refinamento dos resultados devido ao aumento do tamanho da amostra. Análises sobre outras metodologias para desagregar valores mensais em valores horários também podem ser realizadas.

Sugere-se também para futuros desenvolvimentos a definição de uma metodologia para geração de cenários correlacionados entre o preço da energia no mercado de curto prazo e a produção de energia das tecnologia eólica e solar fotovoltaica.

Outra proposta de trabalho para dar continuidade a presente dissertação consiste em realizar estudos para a definição da composição da usina híbrida de modo a obter os percentuais ótimos de cada tecnologia. Por fim, avaliar outras alternativas para a desagregação horária de valores mensais relativos aos fatores de risco considerados no presente trabalho. Dessa forma, poder-se-ia realizar a comparação dos resultados através de diferentes abordagens. 


\section{Referências}

- Consulta sobre tipos de Leilões de Energia. Disponível em: $<$ http://www.ccee.org.br>. Acesso em: 02/06/2021.

- Consulta Pública 061/2020. Obter subsídios para Análise de Impacto Regulatório - AIR acerca do tratamento regulatório para o estabelecimento de usinas híbridas e associadas. Disponível em <https://www.aneel.gov.br/consultaspublicas?p_auth=yG2PFqYS\&p_p_id=participacaopublica_WAR_participacaopublic aportlet\&p_p_lifecycle $=1 \& p \_p \_s t a t e=$ normal $\& p \_p \_$mode $=v i e w \& p \_p \_c o l \_i d=$ colum n-

2\&p_p_col_pos=1\&p_p_col_count $=2 \& \_$participacaopublica_WAR_participacaopubl icaportlet_ideParticipacaoPublica $=3476 \& \_$participacaopublica_WAR_participacaopu blicaportlet_javax.portlet.action=visualizarParticipacaoPublica $>$. Acesso em: 21/12/2020.

. Consulta sobre Outorgas de Serviço Público feita pela ANEEL. Disponível em:

$<\mathrm{https}: / /$ www.aneel.gov.br/busca?p_p_id $=101 \&$ p_p_lifecycle $=0 \&$ p_p_state $=$ maximiz ed\&p_p_mode $=$ view\&_101_struts_action $=\% 2$ Fasset_publisher $\% 2$ Fview_content $\&$ _1 01_returnToFullPageURL $=\% 2$ Fweb $\% 2$ Fguest $\% 2$ Fbusca\&_101_assetEntryId $=15862$ 426\&_101_type $=$ content\&_101_groupId $=656835 \&$ _101_urlTitle $=$ outorga-deconcessao-de-servico-publico-de-energia-eletrica\&inheritRedirect=true $>$ Acesso em: $12 / 02 / 2021$

. Decreto $\mathrm{n}^{\circ} 5.177$, de 12 de agosto de 2004. Dispõe sobre a organização, as atribuições e o funcionamento da Câmara de Comercialização de Energia Elétrica CCEE. Disponível em: <http://www.planalto.gov.br/ccivil_03/_ato20042006/2004/decreto/d5177.htm>. Acesso em: 12/02/2021. 
. Portaria 1, de 7 de janeiro de 2021. Estabelece as Diretrizes para a realização dos Leilões de Compra de Energia Elétrica Proveniente de Novos Empreendimentos de Geração. Disponível em <https://www.in.gov.br/en/web/dou/-/portaria-normativan-1-de-7-de-janeiro-de-2021-298328496>. Acesso em: 14/07/2021

. Portaria 101, de 22 de março de 2016. Define a metodologia de cálculo da garantia física de energia de novos empreendimentos de geração de energia elétrica do Sistema Interligado Nacional - SIN. Disponível em $<$ https://www.in.gov.br/web/dou/-/portaria-n-101-de-22-de-marco-de-201622549000>. Acesso em: 28/12/2020

- Resolução Normativa 514, de 30 de outubro de 2012. Institui a Convenção de Comercialização de Energia Elétrica. Disponível em $<$ http://www2.aneel.gov.br/cedoc/ren2012514.pdf > . Acesso em: 28/11/2020.

- Resolução Normativa 583, de 22 de outubro de 2013. Estabelece os procedimentos para obtenção da situação operacional e definição de potência instalada e líquida de empreendimento de geração de energia elétrica. Disponível em $<$ http://www2.aneel.gov.br/cedoc/ren2013583.pdf > . Acesso em: 12/02/2021.

. Resolução Normativa 666, de 23 de junho de 2015. Regulamenta a contratação do uso do sistema de transmissão. Disponível em $<$ http://www2.aneel.gov.br/cedoc/ren2015666.pdf $>$. Acesso em: 21/08/2020

AGÊNCIA NACIONAL DE ENERGIA ELÉTRICA. NOTA TÉCNICA No 079/2020-SRG-SRT-SCG. Ano 2020 . Disponível em: $<$ https://www.aneel.gov.br/consultas-

publicas?p_p_id=participacaopublica_WAR_participacaopublicaportlet\&p_p_lifecycl $\mathrm{e}=2 \& \mathrm{p} \_\mathrm{p} \_$state $=$normal $\& \mathrm{p} \_\mathrm{p} \_$mode $=$view $\& \mathrm{p} \_\mathrm{p} \_$cacheability $=$cacheLevelPage $\& \mathrm{p} \_\mathrm{p} \_$ col_id=column-

$2 \&$ p_p_col_pos $=1 \& p \_p \_c o l \_c o u n t=2 \& \_$participacaopublica_WAR_participacaopubl icaportlet_ideDocumento $=41028 \&$ _participacaopublica_WAR_participacaopublicapo 
rtlet_tipoFaseReuniao=fase\&_participacaopublica_WAR_participacaopublicaportlet_ jspPage $=\% 2 F h t m l \% 2 F p p \% 2 F v i s u a l i z a r . j s p>$. Acesso em 21/12/2020.

AGÊNCIA NACIONAL DE ENERGIA ELÉTRICA - ANEEL. < https://www.aneel.gov.br/sala-de-imprensa-exibicao-2//asset_publisher/zXQREz8EVlZ6/content/id/21866628\#: :text=Capacidade\%20instal ada,outorgados $\% 20 \mathrm{em} \% 20$ fase $\% 20 \mathrm{de} \% 20$ constru\%C3\%A7\%C3\%A3o.> Acesso: $09 / 07 / 2021$

AGÊNCIA NACIONAL DE ENERGIA ELÉTRICA. NOTA TÉCNICA No 079/2020-SRG-SRT-SCG. Ano $2020 . \quad$ Disponível em: $<$ https://www.aneel.gov.br/consultas-

publicas?p_p_id=participacaopublica_WAR_participacaopublicaportlet\&p_p_lifecycl

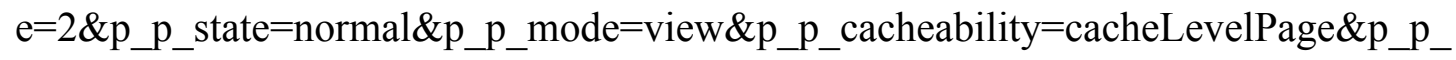
col_id=column-

$2 \&$ p_p_col_pos $=1 \& p \_p \_c o l \_c o u n t=2 \& \_$participacaopublica_WAR_participacaopubl icaportlet_ideDocumento $=41028 \& \_$participacaopublica_WAR_participacaopublicapo rtlet_tipoFaseReuniao=fase\&_participacaopublica_WAR_participacaopublicaportlet_ jspPage $=\% 2$ Fhtml\%2Fpp\%2Fvisualizar.jsp $>$. Acesso em 21/12/2020.

AGÊNCIA NACIONAL DE ENERGIA ELÉTRICA - ANEEL. $30^{\circ}$ Leilão De Energia Proveniente De Novos, 2019.

AGÊNCIA NACIONAL DE ENERGIA ELÉTRICA - ANEEL. $33^{\circ}$ e $34^{\circ}$ Leilões De Energia Proveniente De Novos, 2021.

ASSAF NETO, A. Finanças Corporativa e Valor. $8^{\text {a }}$ ed., São Paulo: Atlas, 2020

AGÊNCIA NACIONAL DE ENERGIA ELÉTRICA - ANEEL. Manual de Controle Patrimonial do Setor Elétrico - MCPSE, 2015.

AGÊNCIA NACIONAL DE ENERGIA ELÉTRICA - ANEEL. < https://www.aneel.gov.br/sala-de-imprensa-exibicao-2/- 
/asset_publisher/zXQREz8EVlZ6/content/id/21866628\#: :text=Capacidade\%20instal ada,outorgados $\% 20 \mathrm{em} \% 20$ fase $\% 20 \mathrm{de} \% 20$ constru\%C3\%A7\%C3\%A3o.> Acesso: $09 / 07 / 2021$

AGRAWAL, M; SAXENA, B. K.; RAO, K.V.S. Feasibility of Establishing Solar Photovoltaic Power Plants at Existing Wind Farms. International Conference On Smart Technologies For Smart Nation, 2017.

BATISTA, F. R. S. et al. The Carbon Market Incremental Payoff in Renewalble Electricity Generation Projects in Brazil: a Real Option Approach. 2012 IEEE Power and Energy Society General Meeting, Volume 26, July 2012, Pages 12411251.

BATISTA, F. R. S. et al. Assessing Investment Analysis of Wind Power Generation Projects in Brazil. In: 19th Power Systems Computational Conference PSCC, 2016, Genoa - Italy. Assessing Investment Analysis of Wind Power Generation Projects in Brazil, 2016.

BATISTA, F. R. S. et al., Análise Da Viabilidade Econômica e da Comercialização de Energia de Empreendimentos Eólicos Desenvolvidos no Brasil Utilizando a Teoria de Opções Reais. $50^{\circ}$ Simpósio Brasileiro de Pesquisa Operacional, Rio de Janeiro, 2018.

BATISTA, F. R. S. et al., Análise Da Viabilidade Econômica De Projetos Solares Fotovoltaicos Considerando Os Riscos Não Sistemáticos Dos Empreendimentos Desenvolvidos No Brasil. 25 Seminário Nacional De Produção E Transmissão De Energia Elétrica, Belo Horizonte, 2019.

BOX, G. E., JENKINS, G. M., Time Series Analysis: Forecasting And Control. Holden-Day, 1970. 
BRIGHAM, E. F., EHRHARDT, M. C. Financial Management: Theory \& Practice. 16 ${ }^{\mathrm{a}}$ ed., Mason, OH: THOMSON, 2020.

CÂMARA DE COMERCIALIZAÇÃO DE ENERGIA ELÉTRICA - CCEE. Consulta sobre 0 PLD Horário. Disponível em: https://www.ccee.org.br/portal/faces/preco_horario_veja_tambem/preco_horario Acesso em 08/08/2020.

CAMPOS, R. Análise da complementaridade de geração de usinas solar e eólica e o papel do armazenamento de energia para usinas híbridas. $87 \mathrm{f}$. Dissertação (Mestrado em Engenharia Civil) - Programa de Pós-graduação em Engenharia Civil da Universidade Federal de Santa Catarina. Florianópolis, 2020.

CARVALHO, D. Impacto Econômico de Sistemas Híbridos Renováveis no ACR Face à Antecipação e Atraso do Empreendimento. 153 f. Dissertação (Mestrado em Engenharia Elétrica) - Programa de Pós-graduação em Engenharia Elétrica da Universidade Federal de Itajubá. Itajubá, 2018.

DAS, K et al. Enhanced Features of Wind-Based Hybrid Power Plants. In: 4th International Hybrid Power Systems Workshop; Creta; May 22-23, 2019.

DE ALENCAR, C. Impacto da Geração Híbrida Hidráulica-Fotovoltaica no Brasil. 97 f. Dissertação (Mestrado em Engenharia Civil). Programa de PósGraduação em Sistemas de Energia - Universidade Tecnológica Federal do Paraná. Curitiba, 2018.

DINIZ, A. L. et al., Short/Mid-Term Hydrothermal Dispatch and Spot Pricing for Large-Scale Systems - the Case of Brazil, In $20^{\text {th }}$ Power Systems Computation Conference, Dublin, Ireland, June 2018.

DINIZ, A. L. et al., Network constrained hydrothermal unit commitment problem for hourly dispatch and price setting in Brazil: the DESSEM model. In: 
6th Int. Workshop on Hydro Scheduling in Competitive Electricity Markets, Norway, 2018.

EMPRESA DE PESQUISA ENERGÉTICA - EPE, MME, Avaliação Da Geração De Usinas Híbridas Eólico-Fotovoltaicas - Proposta Metodológica E Estudos De Caso, EPE-DEE-NT-025/2017-r0, 24 de abril de 2017. 36p.

EMPRESA DE PESQUISA ENERGÉTICA - EPE, MME, Usinas Híbridas - Uma Análise Qualitativa De Temas Regulatórios E Comerciais Relevantes Ao Planejamento, EPE-DEE-NT-011/2018-r0, 11 de junho de 2018. 31p.

EMPRESA DE PESQUISA ENERGÉTICA - EPE, MME, Usinas Híbridas No Contexto Do Planejamento Energético, EPE-DEE-NT-029/2019-r0, 07 de Junho de 2019. 28p.

EMPRESA DE PESQUISA ENERGÉTICA - EPE, MME, Plano Decenal de Expansão de Energia 2029, Ano 2019. Disponível Em: $<$ https://www.epe.gov.br/pt/publicacoes-dados-abertos/publicacoes/plano-decenal-deexpansao-de-energia-2029>. Acesso em: 18/08/2020.

EMPRESA DE PESQUISA ENERGÉTICA - EPE, MME, Custo Marginal do Expansão do Setor Elétrico Brasileiro - Metodologia e Cálculo - 2020. EPE-DEENT-082/2020-r0, 14 de Dezembro de 2020. 15p.

EMPRESA DE PESQUISA ENERGÉTICA - EPE, MME, Plano Decenal de Expansão de Energia 2030, Ano 2021. Disponível Em: $<$ https://www.epe.gov.br/pt/publicacoes-dados-abertos/publicacoes/plano-decenal-deexpansao-de-energia-2030>. Acesso em: 27/03/2021.

EMPRESA DE PESQUISA ENERGÉTICA - EPE, MME, Estudos Plano Decenal de Expansão de Energia 2030: Parâmetros de Custos - Geração e Transmissão, Ano 2021. Disponível Em: <https://www.epe.gov.br/sites-pt/publicacoes-dadosabertos/publicacoes/PublicacoesArquivos/publicacao-490/topico522/Caderno\%20de\%20Par\%C3\%A2metros\%20de\%20Custos\%20\%20PDE\%202030.pdf>. Acesso em: 27/03/2021. 
GAMESA. GAMESA G90-2.0MW. Ano 2007. Disponível em: < https://www.avangridrenewables.com/wps/wcm/connect/www.avangridrenewables.co m25590/44f32ccf-3799-4130-8c6e-b92841a067be/2-

Gamesa_Eolica_G90.pdf?MOD=AJPERES\&CONVERT_TO $=$ url\&CACHEID $=$ ROO TWORKSPACE.Z18_31MEH4C0N8M490Q43LUGGV0000-44f32ccf-3799-41308c6e-b92841a067be-mu0bXvR>. Acesso em 11/11/2020.

GANDELMAN, D. A. Uma Metodologia para o Planejamento da Expansão do Sistema Elétrico Brasileiro Considerando Incertezas. Tese de Doutorado, COPPE/UFRJ, Rio de Janeiro, 2015.

GCPS/ELETROBRÁS - Grupo Coordenador do Planejamento dos Sistemas Elétricos / Centrais Elétricas Brasileiras S.A. Critérios e Procedimentos para o

Planejamento da Expansão da Geração. Relatório Técnico, Dezembro de 1999.

HELSETH, A., MELO, A.C.G.. Scheduling Toolchains in Hydro-Dominated Systems - Evolution, Current Status and Future Challenges for Norway and Brazil. In: SINTEF Energy Research Technical Report, 2020-08-10, May 2020. Disponível em https://sintef.brage.unit.no/sintef-xmlui/handle/11250/2672581?localeattribute $=$ en.

HOELTGEBAUM, H. Generating Joint Scenarios for Renewable Generation: The Case for non-Gaussian Models with Time-Varying Parameters. In: IEEE TPWRS, 2018.

JORION, P. Value at Risk: The New Benchmark for Managing Financial Risk, McGraw-Hill Companies Inc, 1999.

LARAZOV, V. et al. Hybrid Power Systems with Renewable Energy Sources Types, Structures, Trends for Research and Development. In: 11th International Conference On Electrical Machines, Drives And Power Systems; Sofia; Sep 15-16, 2005. 
LiSBOA, M. L., MELO, A. C. G., MACEIRA, M. E. P., SABÓIA, C. H., JUSAN, F. C., SAGASTIZABAL, C., et al. MELP - Modelo de Planejamento da Expansão de Longo Prazo do Sistema de Geração e Troncos de Interligação de Sistemas Elétricos. In V Congresso Latino - Americano de Geração e Transmissão de Eletricidade. São Pedro, SP, Brasil, 2003.

MACEIRA, M. E. P.. Programação Dinâmica Dual Estocástica Aplicada ao Planejamento da Operação Energética de Sistemas Hidrotérmicos com Representação do Processo Estocástico de Afluências por Modelos AutoRegressivos Periódicos. Relatório Técnico CEPEL 237/93, Junho 1993.

MACEIRA, M.E.P. et al. Periodic ARMA Models Applied to Weekly Streamflow Forecasts. In Anais do IEEE Powertech, Budapest., Hungria, 1999.

MACEIRA, M.E.P., TERRY, L.A., COSTA, F.S., DAMÁZIO, J.M., MELO, A.C.G. Chain of optimization models for setting the energy dispatch and spot price in the Brazilian system. In 14th Power Systems Computation Conference - PSCC 2002, Seville, Spain, 2002.

MACEIRA, M. E. P. et al. A Probabilistic Approach to Define the Amount of Energy to be Traded in Hydro Dominated Interconnected Systems, In: 20th Power Systems Computation Conference (PSCC), Dublin, Ireland, 2018.

MACEIRA, M. E. P. et al. Twenty Years of Application of Stochastic Dual Dynamic Programming in Official and Agent Studies in Brazil - Main Features and Improvements on the NEWAVE Model. In: 20th Power Systems Computation Conference (PSCC), Dublin, Ireland, 2018. 
MACEIRA, M. E. P., CRUZ, C. B., PENNA, D. D. J., DINIZ, A. L., MELO, A. C. G.. Combined Representation of Hydropower Plants and Inflow Scenarios ReSampling on Stochastic Dual Dynamic Programming - Application to the Brazilian System. In 15th International Conference on Stochastic Programming, Trondheim, Norway, 2019.

MACEIRA, M. E. P., CRUZ, C. B., PENNA, D. D. J., DINIZ, A. L., TREISTMAN, F., MELO, A. C. G., JUSTINO, T. C.. Representação de Usinas Hidrelétricas Individualmente e de Forma Agregada na Programação Dinâmica Dual Estocástica - A Abordagem Híbrida. In XXV Seminário Nacional de Produção e Transmissão de Energia Elétrica, Belo Horizonte, 2019.

MACEIRA et al., Uma abordagem para a Representação das Incertezas da Fonte de Geração Eólica no Modelo NEWAVE, Cadernos do IME - Série Estatística, v. 48, p. 1-36, 2020.

MELO, A. C. G., PEREIRA, M.V.F., LEITE DA SILVA, A.M. Frequency and Duration Calculations in Composite Generation and Transmission Reliability Evaluation, In: IEEE Trans. on Power Systems, Vol. 7, Nº 2, May 1992.

MELO, A. C. G., et al. Análise de Risco Financeiro em Projetos de Investimento no Setor Elétrico, A.C.G. Melo, M.S. Reis, B.G. Gorenstin, A.M. Oliveira, A.L. Castro, VI Symposium of Specialists in Operational and Expansion Planning - V SEPOPE, Salvador, Bahia, May 1998.

MELO, A. C. G., et al. Sustainable Development of Hydropower in Brazil Technical and Institutional Aspects. In: 44th Biannual CIGRÉ Session, Paris, France, 26-31 August 2012.

MELO, A. C. G. et al. Dominant Contracting Strategies for Hydropower Projects Considering Inflow Uncertainties - Application to the Brazilian Case. In: Probabilistc Methods Applied to Power Systems - PMAPS. Boise, Idaho, USA, 2018. 
MELO, A. C. G. et al. Challenges and Outlook for the Hydropower Development in Brazil. In The International Journal of Hydropower \& Dams, London, vol. 6, p. 42-50, December 2020. ISSN: 1352-2523.

MELO, A. C. G., et al. Metodologia e Determinação de Perfis Típicos Diários de Carga através da Combinação de Técnicas Estatísticas de Análise de Agrupamentos e de Análise Exploratória de Dados. Relatório Técnico CEPEL $10349 / 2018$, agosto de 2018 .

MORETTIN, P., TOLOI, C. Análise de Séries Temporais. 2. ed. São Paulo: Edgard Blucher, 2006. 538p

NADLER, E., PERRELLI, A.. Modelagem de viabilidade econômica para sistemas fotovoltaicos de geração distribuída, Revista de Engenharia e Pesquisa Aplicada, v.5, n. 4, p. 11-19, 2020.

OPERADOR NACIONAL DO SISTEMA ELÉTRICO - ONS. Submódulo 5.5 Consolidação da Previsão de Carga para o Planejamento Anual da Operação Energética - $\quad$ Revisão 2018.12. Disponível em: $<$ http://www.ons.org.br/\%2FProcedimentosDeRede\%2FM\%C3\%B3dulo\%205\%2FS ubm $\% \mathrm{C} 3 \% \mathrm{~B} 3 \mathrm{dul} \% 205.5 \% 2 \mathrm{FSubm} \% \mathrm{C} 3 \% \mathrm{~B} 3 \mathrm{dulo} \% 205.5 \% 202018.12$.pdf $>$. Acesso em: $15 / 10 / 2020$

OPERADOR NACIONAL DO SISTEMA - ONS (b). Consulta sobre os Boletins Mensais de Geração Eólica e Solar Fotovoltaica. Disponível em: http://www.ons.org.br/paginas/conhecimento/acervo-digital/documentos-epublicacoes . Acesso em 04/04/2021.

OPERADOR NACIONAL DO SISTEMA - ONS (a). Plano Mensal de Operação de Outubro de 2021 (PMO Out/2021). Disponível em: http://www.ons.org.br/paginas/sobre-o-sin/o-sistema-em-numeros. Último acesso em $13 / 10 / 2021$. 
PENNA, D.D.J., MACEIRA, M.E.P., DAMÁZIO, J.M. Selective sampling applied to long-term hydrothermal generation planning. In 17th PSCC - Power Systems Computation Conferfence, Stockholm, Sweden, August 2011.

PEREIRA, M.V.F., PINTO, L.M.V.G. Multi-stage stochastic optimization applied to energy planning, Mathematical Programming, v. 52, n.1-3, pp. 359-375, May 1991.

PESSANHA et al. Usando a análise espectral singular na previsão da produção mensal de um parque eólico. In: Anais do XVII Simpósio de Pesquisa Operacional e Logística da Marinha - SPOLM 2014. São Paulo: Blucher, 2014.

PFENNINGER, S. and STAFFELL, I. Long-term patterns of European PV output using 30 years of validated hourly reanalysis and satellite data. Energy 114, pp. 1251-1265. doi: 10.1016/j.energy.2016.08.060. 2016.

$\mathrm{R}$ Core Team. R: A language and environment for statistical computing. $\mathrm{R}$ Foundation for Statistical Computing, Vienna, Austria, 2019. Conjuntos de Programas. URL https://www.R-project.org/.

RODRIGUES, F. R. et al. Impacto dos Riscos Sistemáticos e Não Sistemáticos na Viabilidade Econômico-Financeira de Projetos de Geração de Energia Elétrica no Brasil. $23^{\circ}$ Seminário Nacional De Produção E Transmissão De Energia Elétrica, Foz do Iguaçu, 2015.

SANTOS, T. N. et al. Hourly pricing and day-ahead dispatch setting in brazil: the DESSEM model, In $21^{\text {st }}$ Power Systems Computation Conference (PSCC), 2020.

SOUZA, R. C., OliveIRA, F. L. C.. Análise de Séries Temporais: Os Modelos de Amortecimento Exponencial. Rio de Janeiro, 2015.

SOUZA R. C., CARMAGo M.E. Análise e Previsão de Séries Temporais: os modelos ARIMA. 2a ed., Ijuí: SEDIGRAF, 2004. 
STAFFELL, I. and PFENNINGER, S. Using Bias-Corrected Reanalysis to Simulate Current and Future Wind Power Output. Energy 114, pp. 1224-1239. doi: 10.1016/j.energy.2016.08.068, 2016.

SAMANEZ, C. P. Matemática Financeira. $5^{\text {a }}$ ed., São Paulo: Pearson Prentice Hall, 2010.

TERRY, L.A., PEREIRA, M.V.F., ARARIPE NETO, T.A., SILVA, L.F.C.A., SALES, P.R.H. Coordinating the Energy Generation of the Brazilian National Hydrothermal Electrical Generating System. In Interfaces, 16: 1 January-February, pp.16-38, 1986.

ZAMBElli, M. S.; DE FARIA, J. M.; DIAS, A. A. S. Metodologia Para Análise

De Risco Com PLD Horário. $25^{\circ}$ Seminário Nacional De Produção E Transmissão De Energia Elétrica, Belo Horizonte, 2019.

ZIMMERMANN, M. P. Aspectos Técnicos e Legais Associados ao Planejamento da Expansão de Energia Elétrica no Novo Contexto Regulatório Brasileiro. Dissertação de Mestrado., PUC-RJ, Rio de Janeiro, RJ, Brasil, 2007. 
Apêndices

11.1

Apêndice A - Boxplots para cada Mês da Série Histórica de PLD

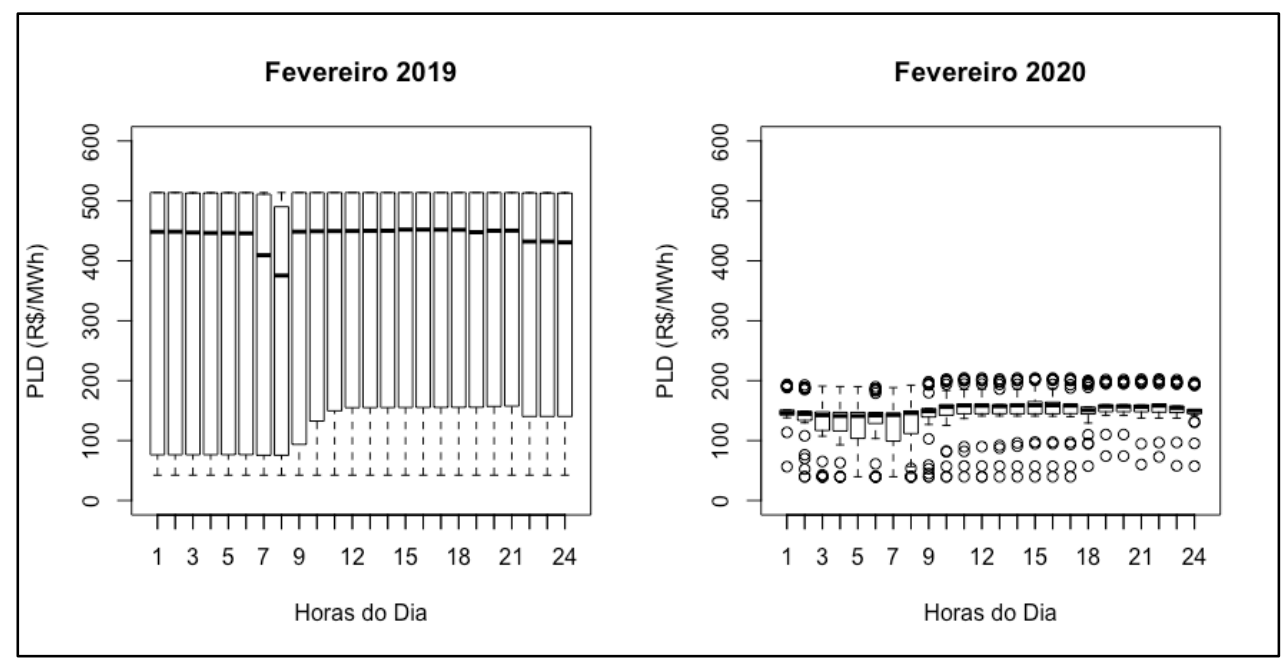

Figura 72 - Boxplots com PLD das horas dos Mês de Fevereiro

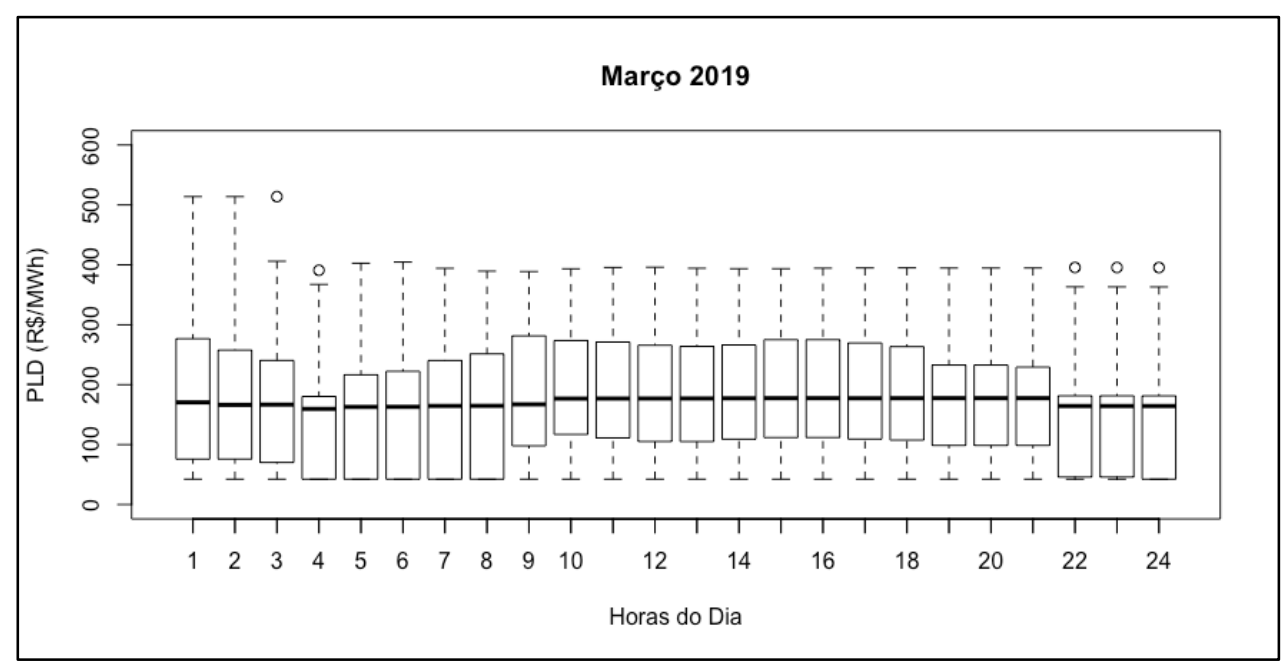

Figura 73 - Boxplots com PLD das horas dos Mês de Março 


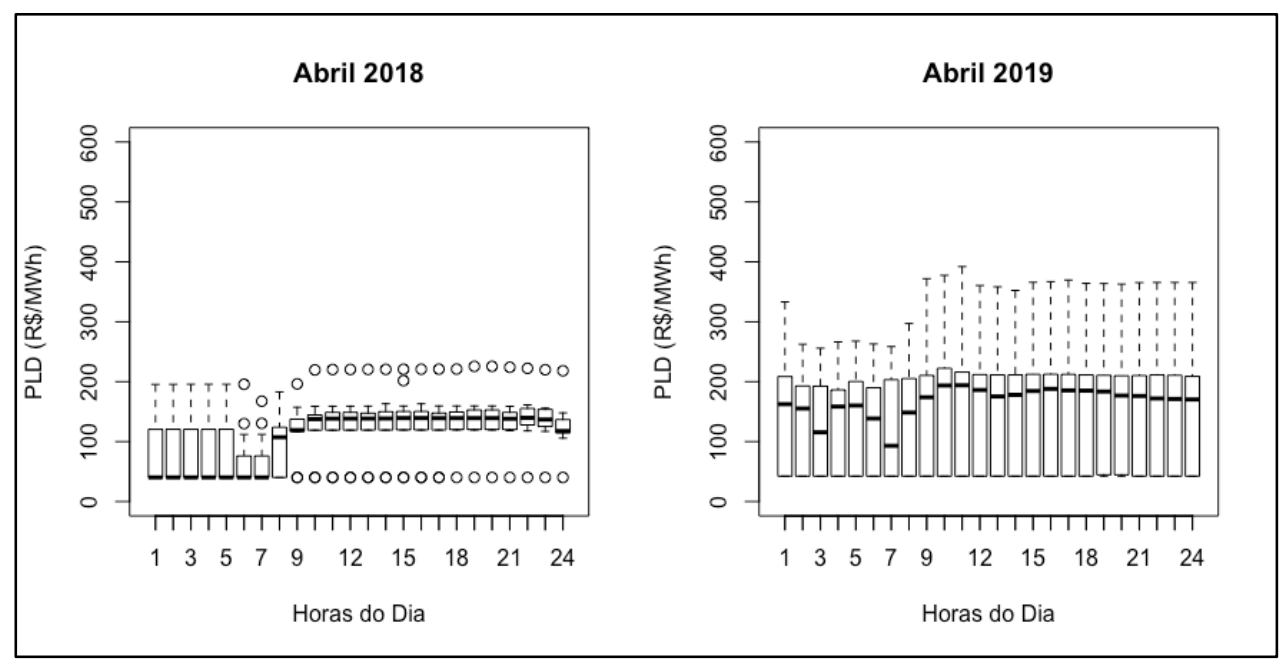

Figura 74 - Boxplots com PLD das horas dos Mês de Abril

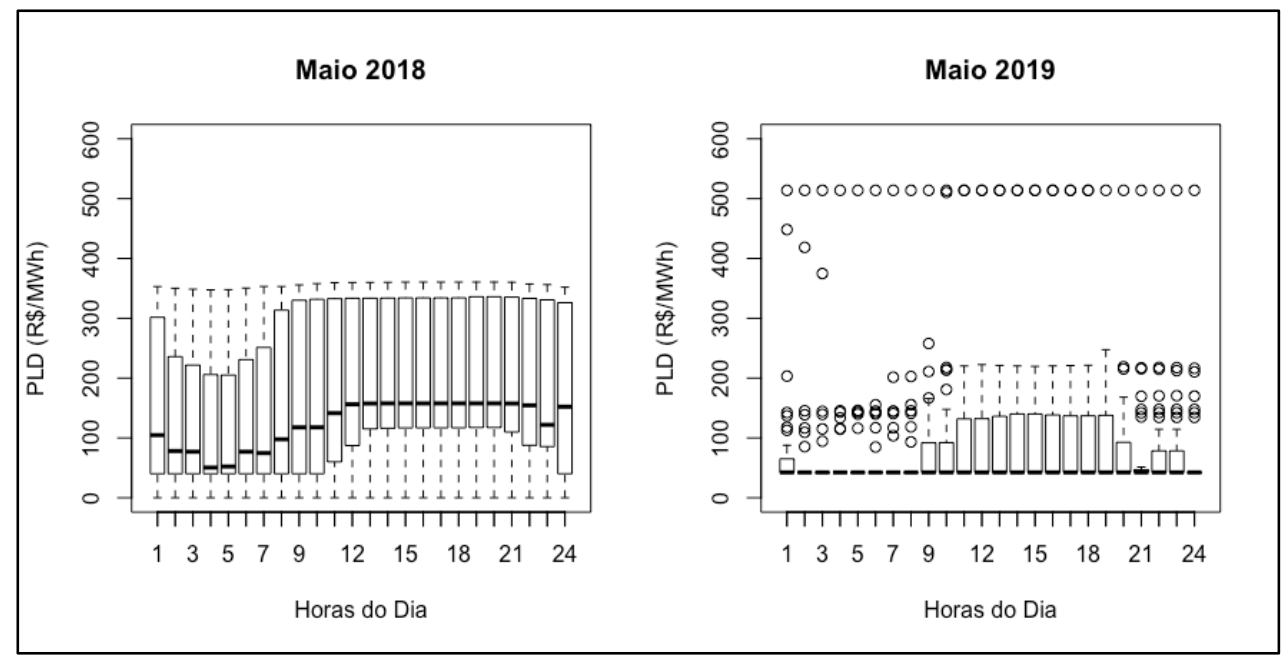

Figura 75 - Boxplots com PLD das horas dos Mês de Maio

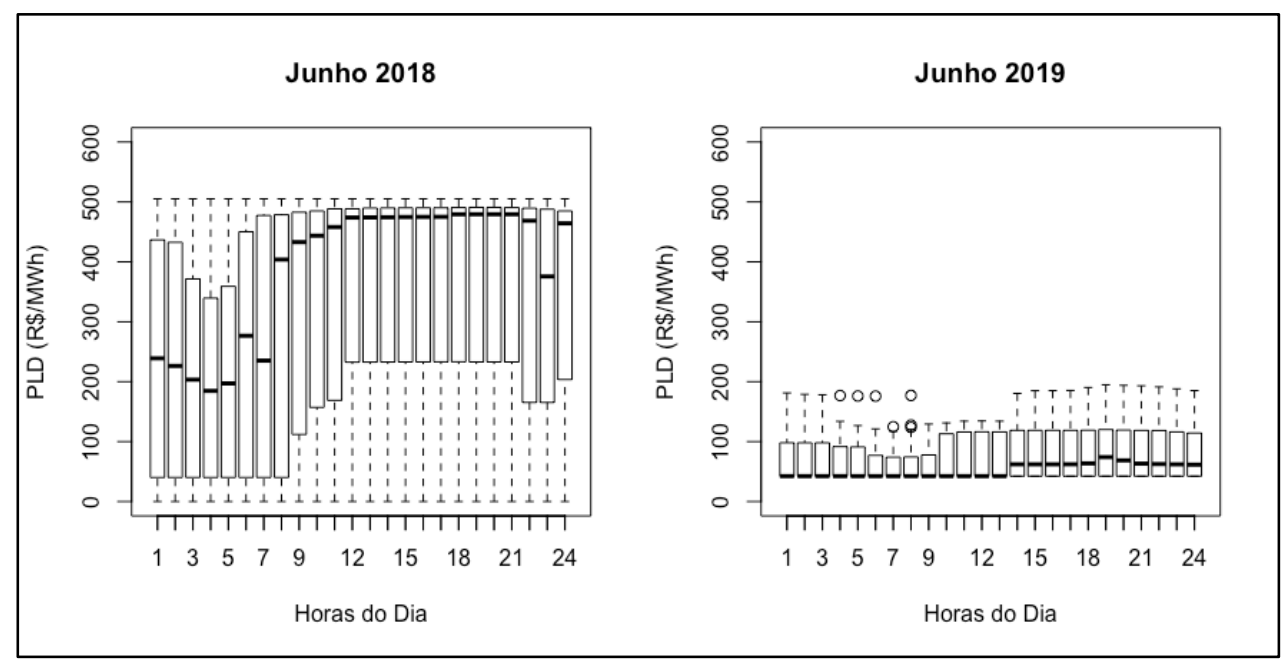

Figura 76 - Boxplots com PLD das horas dos Mês de Junho 


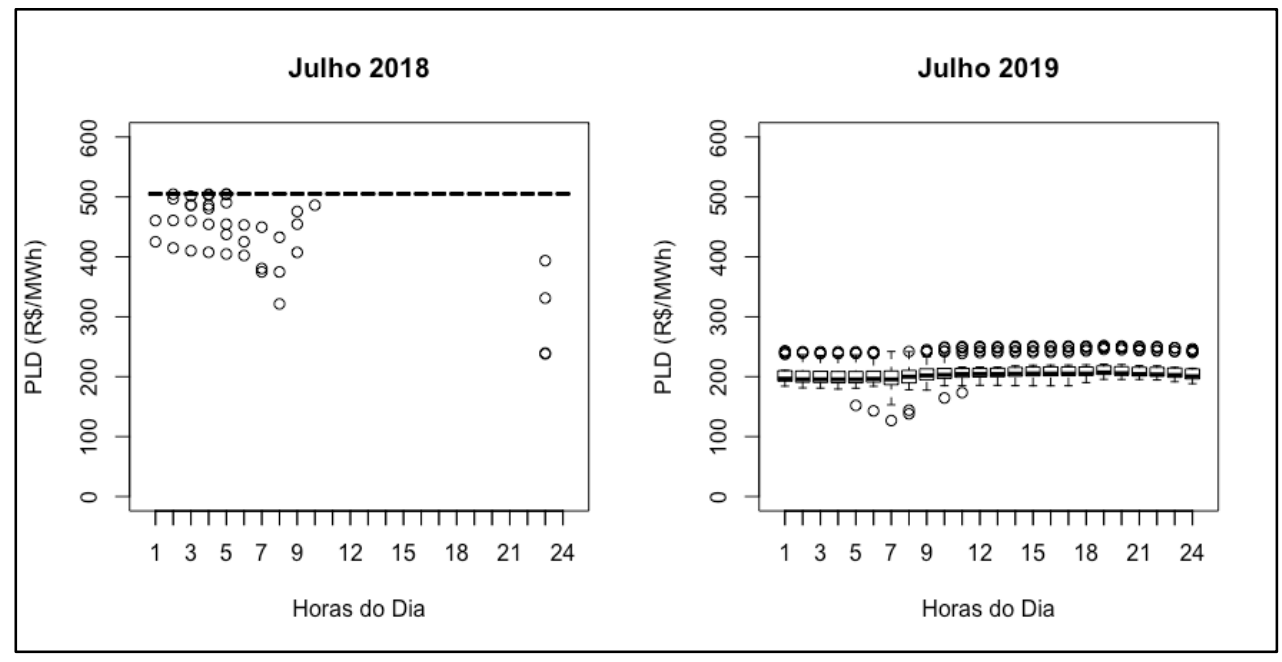

Figura 77 - Boxplots com PLD das horas dos Mês de Julho

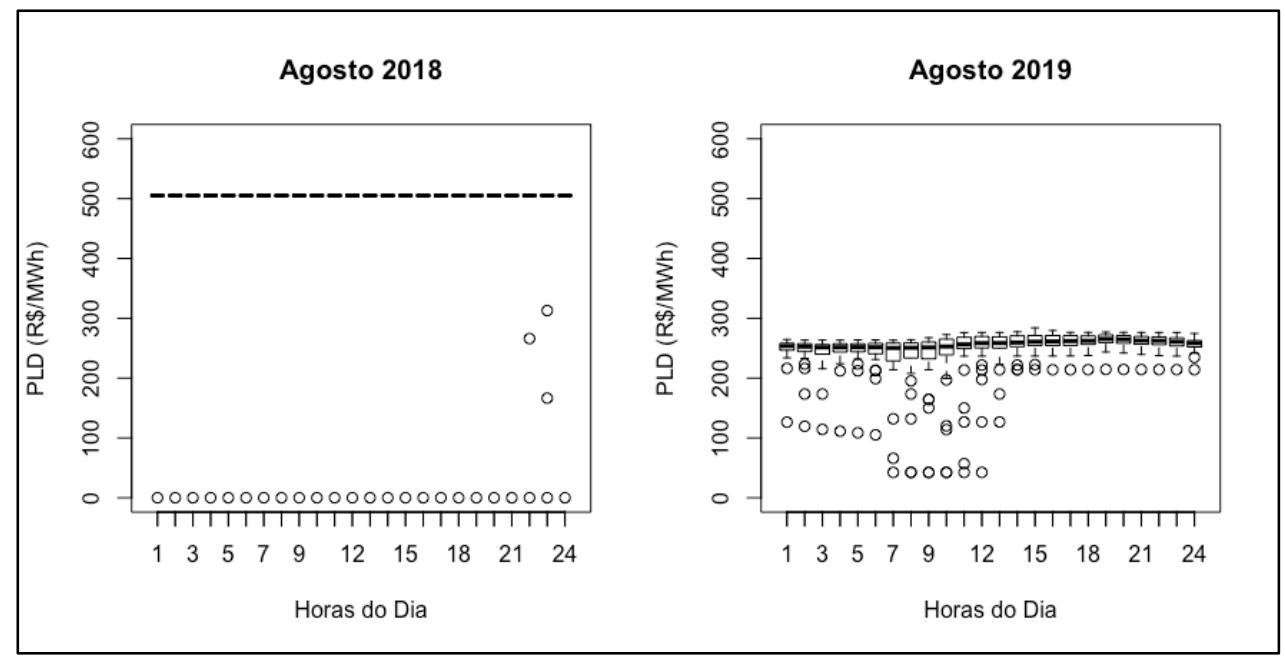

Figura 78 - Boxplots com PLD das horas dos Mês de Agosto

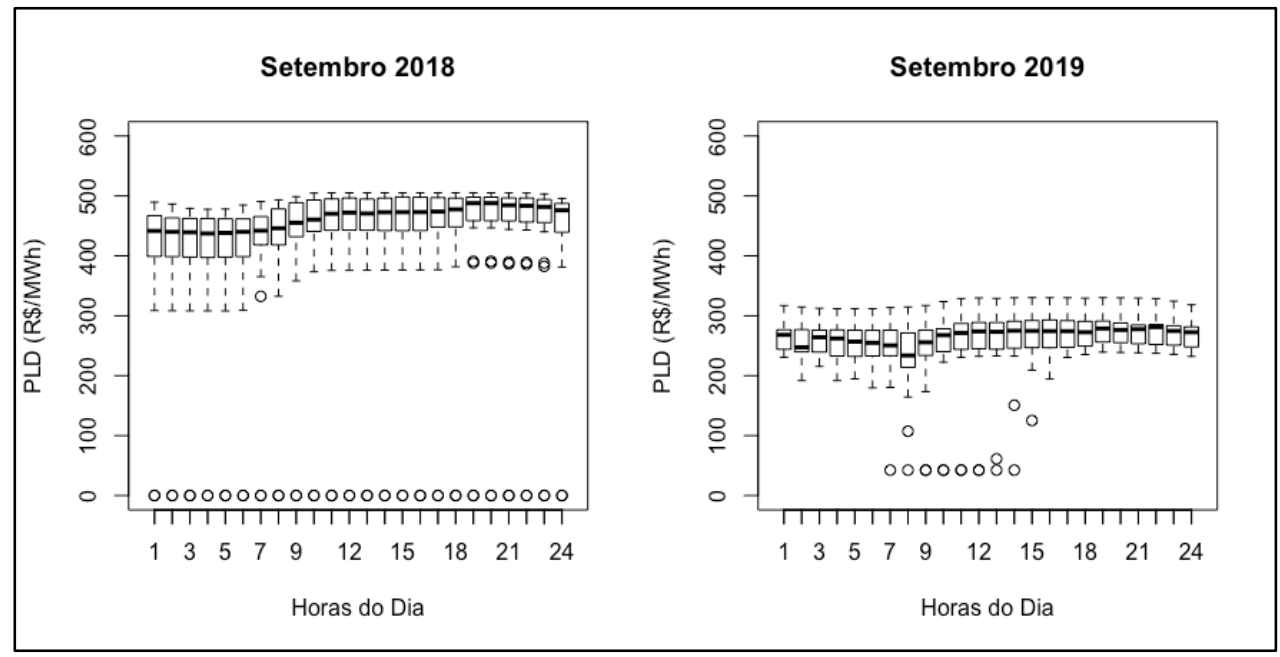

Figura 79 - Boxplots com PLD das horas dos Mês de Setembro 


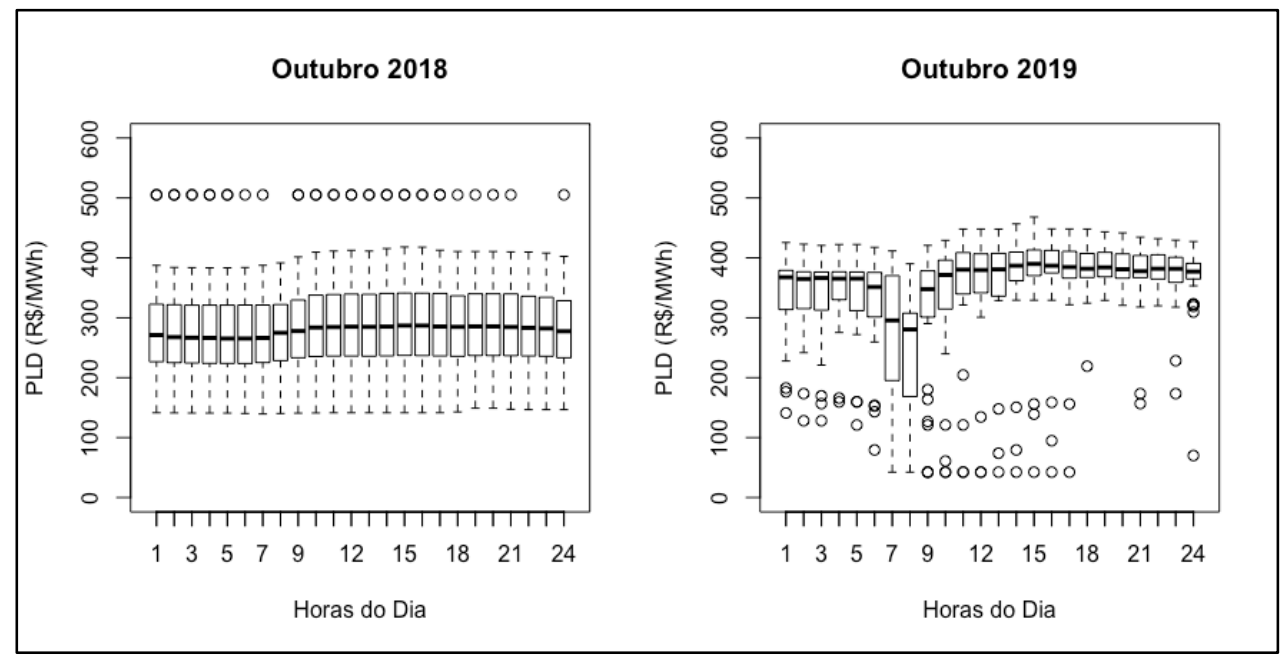

Figura 80 - Boxplots com PLD das horas dos Mês de Outubro

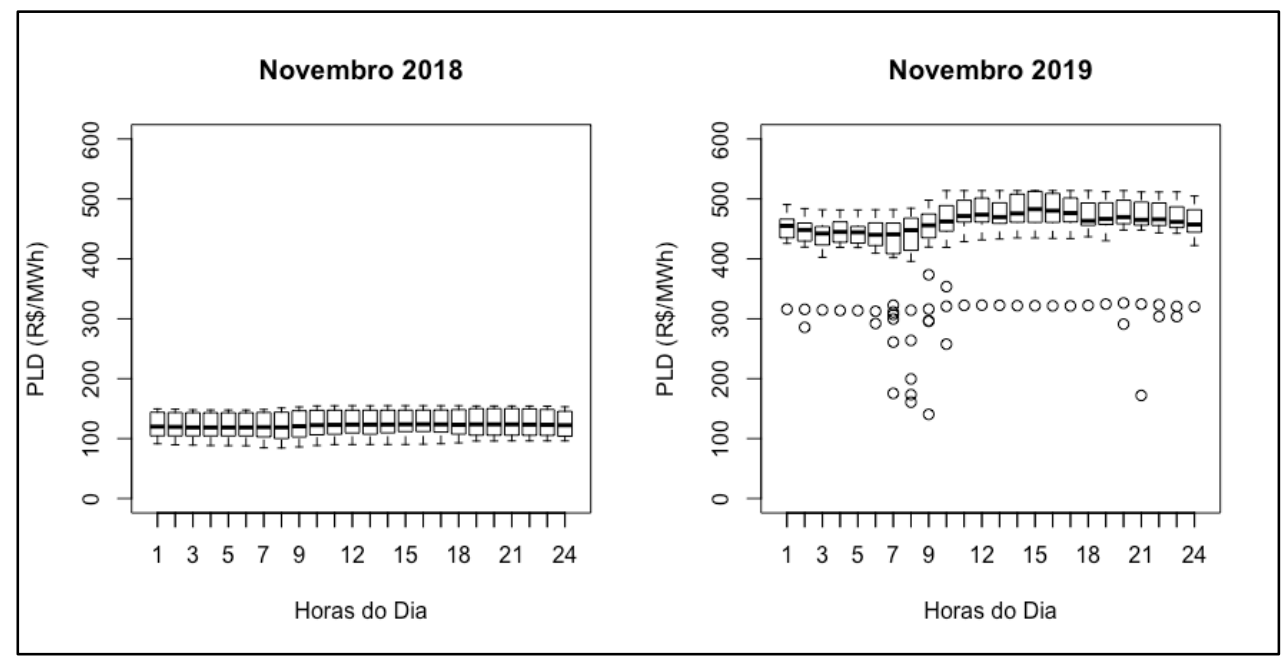

Figura 81 - Boxplots com PLD das horas dos Mês de Novembro 


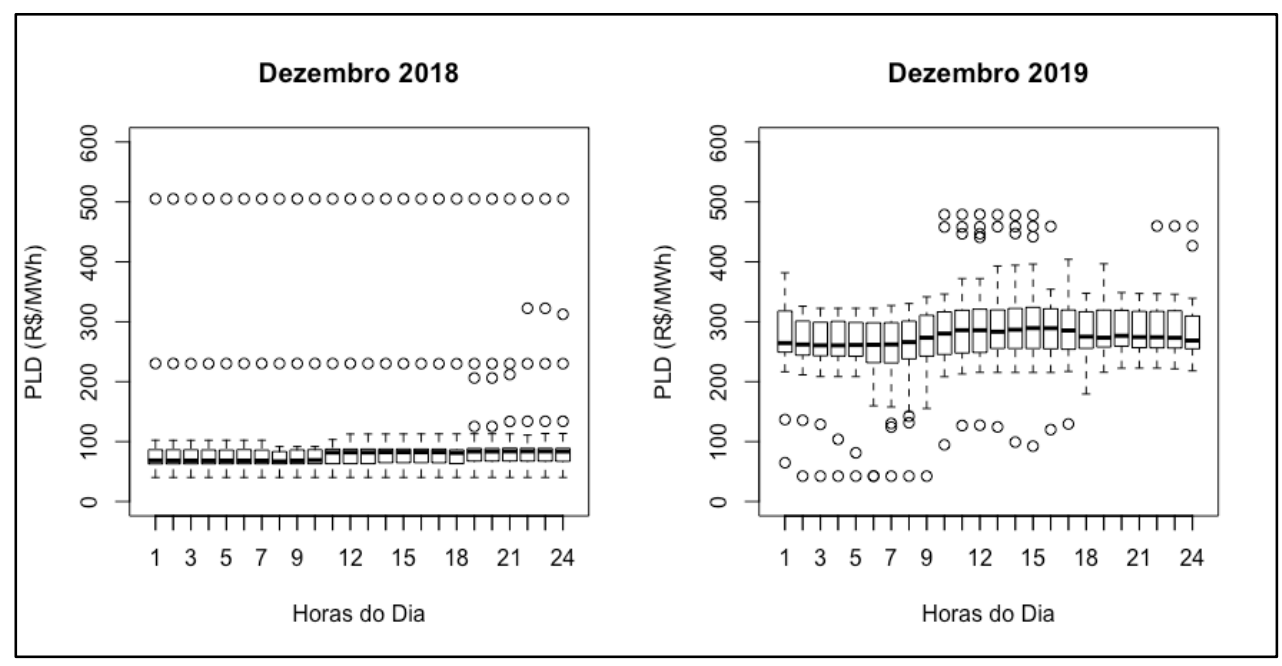

Figura 82 - Boxplots com PLD das horas dos Mês de Dezembro

\section{2}

\section{Apêndice B - Resultados Complementares da Análise de Sensibilidade com Diferentes Contratações do MUST}

Tabela 33 - Estatísticas de VPL para os Casos de Contratação do MUST de 95\%, 90\% e $85 \%$

\begin{tabular}{|c|c|c|c|c|c|c|}
\hline \multirow{2}{*}{$\begin{array}{c}\text { VPL } \\
\text { (R\$ Milhões) }\end{array}$} & \multicolumn{2}{|c|}{ Híbrido (MUST 95\%) } & \multicolumn{2}{c|}{ Hibrido (MUST 90\%) } & \multicolumn{2}{c|}{ Híbrido (MUST 85\%) } \\
\cline { 2 - 7 } & Base Mensal & Base Horária & Base Mensal & Base Horária & Base Mensal & Base Horária \\
\hline Mediana & 132,67 & 134,55 & 136,81 & 138,70 & 140,84 & 142,74 \\
\hline Mínimo & 135,05 & 137,48 & 139,19 & 141,63 & 143,21 & 145,66 \\
\hline Máximo & $-145,97$ & $-200,42$ & $-141,33$ & $-195,75$ & $-136,83$ & $-191,21$ \\
\hline Desvio Padrão & 300,09 & 339,19 & 304,22 & 343,32 & 308,24 & 347,32 \\
\hline Desvio Padrão MA* & 0,82 & 44,50 & 36,77 & 44,48 & 36,76 & 44,45 \\
\hline VaR 95\% & 72,25 & 62,64 & 76,39 & 66,80 & 80,41 & 70,83 \\
\hline CVaR 95\% & 42,19 & 25,10 & 46,38 & 29,35 & 50,45 & 33,47 \\
\hline Coef. De Variação & $27,73 \%$ & $33,07 \%$ & $26,88 \%$ & $32,07 \%$ & $26,10 \%$ & $31,14 \%$ \\
\hline Coef. De Variação MA* & $0,62 \%$ & $0,74 \%$ & $0,60 \%$ & $0,72 \%$ & $0,58 \%$ & $0,70 \%$ \\
\hline Prob VPL< 0 (\%) & $0,30 \%$ & $0,90 \%$ & $0,30 \%$ & $0,65 \%$ & $0,30 \%$ & $0,65 \%$ \\
\hline
\end{tabular}

*Da Variável Aleatória: Média Amostral

Tabela 34 - Estatísticas de VPL para os Casos de Contratação do MUST de 80\%, 75\% e $70 \%$ 


\begin{tabular}{|c|c|c|c|c|c|c|}
\hline VPL & \multicolumn{2}{|c|}{ Hibrido (MUST 80\%) } & \multicolumn{2}{c|}{ Hibrido (MUST 75\%) } & \multicolumn{2}{c|}{ Hibrido (MUST 70\%) } \\
\cline { 2 - 7 } (RS Milhões) & Base Mensal & Base Horária & Base Mensal & Base Horária & Base Mensal & Base Horária \\
\hline Média & 144,86 & 146,71 & 149,00 & 150,47 & 151,92 & 153,22 \\
\hline Mediana & 147,23 & 149,66 & 151,37 & 153,33 & 154,31 & 156,12 \\
\hline Mínimo & $-132,33$ & $-186,67$ & $-127,70$ & $-182,00$ & $-123,22$ & $-177,51$ \\
\hline Máximo & 312,25 & 351,16 & 316,38 & 354,20 & 317,39 & 354,65 \\
\hline Desvio Padrão & 36,75 & 44,41 & 36,74 & 44,23 & 36,25 & 43,79 \\
\hline Desvio Padrão MA* & 0,82 & 0,99 & 0,82 & 0,99 & 0,81 & 0,98 \\
\hline VaR 95\% & 84,43 & 74,87 & 88,57 & 78,97 & 92,21 & 82,60 \\
\hline CVaR 95\% & 54,51 & 37,58 & 58,69 & 41,70 & 62,44 & 45,33 \\
\hline Coef. De Variação & $25,37 \%$ & $30,27 \%$ & $24,66 \%$ & $29,40 \%$ & $23,86 \%$ & $28,58 \%$ \\
\hline Coef. De Variação MA* & $0,57 \%$ & $0,68 \%$ & $0,55 \%$ & $0,66 \%$ & $0,53 \%$ & $0,64 \%$ \\
\hline Prob VPL<0 (\%) & $0,30 \%$ & $0,65 \%$ & $0,30 \%$ & $0,55 \%$ & $0,30 \%$ & $0,55 \%$ \\
\hline
\end{tabular}

*Da Variável Aleatória: Média Amostral

Tabela 35 - Estatísticas de VPL para os Casos de Contratação do MUST de 65\%,60\%, 55\% e $50 \%$

\begin{tabular}{|c|c|c|c|c|c|c|c|c|}
\hline \multirow{2}{*}{$\begin{array}{c}\text { VPL } \\
\text { (R\$̦ Milhões) }\end{array}$} & \multicolumn{2}{|c|}{ Hibrido (MUST 65\%) } & \multicolumn{2}{c|}{ Hibrido (MUST 60\%) } & \multicolumn{2}{c|}{ Hibrido (MUST 55\%) } & \multicolumn{2}{c|}{ Hibrido (MUST 50\%) } \\
\cline { 2 - 9 } & Base Mensal & Base Horária & Base Mensal & Base Horária & Base Mensal & Base Horária & Base Mensal & Base Horária \\
\hline Média & 149,58 & 154,41 & 138,69 & 153,57 & 116,10 & 150,31 & 81,92 & 145,27 \\
\hline Mediana & 152,59 & 157,29 & 141,78 & 156,69 & 119,69 & 153,49 & 85,15 & 148,38 \\
\hline Mínimo & $-118,75$ & $-173,16$ & $-115,47$ & $-169,00$ & $-113,98$ & $-165,52$ & $-118,31$ & $-162,67$ \\
\hline Máximo & 302,96 & 351,47 & 271,22 & 344,53 & 223,94 & 333,97 & 163,61 & 320,94 \\
\hline Desvio Padrão & 34,12 & 43,00 & 31,06 & 41,91 & 28,41 & 40,66 & 27,65 & 39,41 \\
\hline Desvio Padrão MA* & 0,76 & 0,96 & 0,69 & 0,94 & 0,64 & 0,91 & 0,62 & 0,88 \\
\hline VaR 95\% & 93,25 & 85,35 & 85,92 & 86,65 & 67,45 & 84,97 & 33,72 & 81,92 \\
\hline CVaR 95\% & 64,05 & 48,12 & 59,49 & 49,56 & 43,04 & 48,98 & 11,03 & 46,67 \\
\hline Coef. De Variação & $22,81 \%$ & $27,85 \%$ & $22,40 \%$ & $27,29 \%$ & $24,47 \%$ & $27,85 \%$ & $33,76 \%$ & $27,13 \%$ \\
\hline Coef. De Variação MA* & $0,51 \%$ & $0,62 \%$ & $0,50 \%$ & $0,61 \%$ & $0,55 \%$ & $0,62 \%$ & $0,75 \%$ & $0,61 \%$ \\
\hline Prob VPL <0 (\%) & $2,00 \%$ & $0,70 \%$ & $0,30 \%$ & $0,55 \%$ & $2,00 \%$ & $0,70 \%$ & $0,30 \%$ & $0,55 \%$ \\
\hline
\end{tabular}

*Da Variável Aleatória: Média Amostral

Tabela 36 - Estatísticas de TIR para os Casos de Contratação do MUST de 95\%, 90\% e 85\%

\begin{tabular}{|c|c|c|c|c|c|c|}
\hline \multirow{2}{*}{ TIR (\% a.a.) } & \multicolumn{2}{|c|}{ Híbrido (MUST 95\%) } & \multicolumn{2}{c|}{ Híbrido (MUST 90\%) } & \multicolumn{2}{c|}{ Híbrido (MUST 85\%) } \\
\cline { 2 - 7 } & Base Mensal & Base Horária & Base Mensal & Base Horária & Base Mensal & Base Horária \\
\hline Média & 13,26 & 13,24 & 13,45 & 13,43 & 13,63 & 13,61 \\
\hline Mediana & 13,40 & 13,35 & 13,59 & 13,54 & 13,77 & 13,72 \\
\hline Mínimo & 0,00 & 0,00 & 0,00 & 0,00 & 0,00 & 0,00 \\
\hline Máximo & 18,98 & 20,11 & 19,17 & 20,30 & 19,35 & 20,48 \\
\hline Desvio Padrão & 1,45 & 1,73 & 1,45 & 1,74 & 1,46 & 1,74 \\
\hline Desvio Padrão MA* & 0,03 & 0,04 & 0,03 & 0,04 & 0,03 & 0,04 \\
\hline VaR 95\% & 10,92 & 10,46 & 11,11 & 10,63 & 11,29 & 10,80 \\
\hline CVaR 95\% & 9,63 & 8,91 & 9,81 & 9,08 & 9,98 & 9,26 \\
\hline Coef. De Variação & $10,93 \%$ & $13,09 \%$ & $10,81 \%$ & $12,95 \%$ & $10,69 \%$ & $12,81 \%$ \\
\hline Coef. De Variação MA* & $0,24 \%$ & $0,29 \%$ & $0,24 \%$ & $0,29 \%$ & $0,24 \%$ & $0,29 \%$ \\
\hline
\end{tabular}

*Da Variável Aleatória: Média Amostral 
Tabela 37 - Estatísticas de TIR para os Casos de Contratação do MUST de 80\%, 75\% e 70\%

\begin{tabular}{|c|c|c|c|c|c|c|}
\hline \multirow{2}{*}{ TIR (\% a.a.) } & \multicolumn{2}{|c|}{ Hibrido (MUST 80\%) } & \multicolumn{2}{|c|}{ Hibrido (MUST 75\%) } & \multicolumn{2}{|c|}{ Hibrido (MUST 70\%) } \\
\hline & Base Mensal & Base Horária & Base Mensal & Base Horária & Base Mensal & Base Horária \\
\hline Média & 13,82 & 13,79 & 14,01 & 13,96 & 14,16 & 14,10 \\
\hline Mediana & 13,95 & 13,90 & 14,13 & 14,07 & 14,30 & 14,22 \\
\hline Mínimo & 0,00 & 0,00 & 0,44 & 0,00 & 0,67 & 0,00 \\
\hline Máximo & 19,54 & 20,66 & 19,73 & 20,82 & 19,81 & 20,90 \\
\hline Desvio Padrão & 1,46 & 1,75 & 1,46 & 1,75 & 1,45 & 1,74 \\
\hline Desvio Padrão MA* & 0,03 & 0,04 & 0,03 & 0,04 & 0,03 & 0,04 \\
\hline VaR 95\% & 11,47 & 10,98 & 11,65 & 11,14 & 11,82 & 11,31 \\
\hline CVaR 95\% & 10,16 & 9,43 & 10,34 & 9,60 & 10,51 & 9,75 \\
\hline Coef. De Variação & $10,58 \%$ & $12,67 \%$ & $10,45 \%$ & $12,51 \%$ & $10,24 \%$ & $12,32 \%$ \\
\hline Coef. De Variação MA* & $0,24 \%$ & $0,28 \%$ & $0,23 \%$ & $0,28 \%$ & $0,23 \%$ & $0,28 \%$ \\
\hline
\end{tabular}

Tabela 38 - Estatísticas de TIR para os Casos de Contratação do MUST de 65\%, 60\%, 55\% e $50 \%$

\begin{tabular}{|c|c|c|c|c|c|c|c|c|c|}
\hline \multirow{2}{*}{ TIR (\% a.a.) } & \multicolumn{2}{c|}{ Hibrido (MUST 65\%) } & \multicolumn{2}{c|}{ Hibrido (MUST 60\%) } & \multicolumn{2}{c|}{ Hibrido (MUST 55\%) } & \multicolumn{2}{c|}{ Hibrido (MUST 50\%) } \\
\cline { 2 - 10 } & Base Mensal & \multicolumn{1}{c|}{ Base Horária } & \multicolumn{1}{c|}{ Base Mensal } & \multicolumn{1}{c|}{ Base Horária } & \multicolumn{1}{c|}{ Base Mensal } & Base Horária & Base Mensal & Base Horária \\
\hline Média & 14,10 & 14,18 & 13,72 & 14,19 & 12,86 & 14,10 & 11,49 & 13,94 \\
\hline Mediana & 14,26 & 14,30 & 13,86 & 14,32 & 13,01 & 14,23 & 11,66 & 14,08 \\
\hline Mínimo & 0,89 & 0,00 & 1,07 & 0,00 & 1,18 & 0,00 & 1,01 & 0,00 \\
\hline Máximo & 19,40 & 20,87 & 18,43 & 20,72 & 16,90 & 20,47 & 14,79 & 20,13 \\
\hline Desvio Padrão & 1,38 & 1,72 & 1,28 & 1,68 & 1,20 & 1,65 & 1,21 & 1,61 \\
\hline Desvio Padrão MA* & 0,03 & 0,04 & 0,03 & 0,04 & 0,03 & 0,04 & 0,03 & 0,04 \\
\hline VaR 95\% & 11,85 & 11,44 & 11,58 & 11,51 & 10,83 & 11,49 & 9,36 & 11,36 \\
\hline CVaR 95\% & 10,59 & 9,87 & 10,41 & 9,94 & 9,73 & 9,93 & 8,36 & 9,84 \\
\hline Coef. De Variação & $9,76 \%$ & $12,10 \%$ & $9,30 \%$ & $11,87 \%$ & $9,34 \%$ & $11,70 \%$ & $10,54 \%$ & $11,58 \%$ \\
\hline Coef. De Variação MA* & $0,22 \%$ & $0,27 \%$ & $0,21 \%$ & $0,27 \%$ & $0,21 \%$ & $0,26 \%$ & $0,24 \%$ & $0,26 \%$ \\
\hline
\end{tabular}

Tabela 39 - Estatísticas de TIR Modificada para os Casos de Contratação do MUST de 95\%, $90 \%$ e $85 \%$

\begin{tabular}{|c|c|c|c|c|c|c|}
\hline \multirow{2}{*}{$\begin{array}{c}\text { TIR Modificada } \\
\text { (\% a.a.) }\end{array}$} & \multicolumn{2}{|c|}{ Hibrido (MUST 95\%) } & \multicolumn{2}{c|}{ Hibrido (MUST 90\%) } & \multicolumn{2}{c|}{ Híbrido (MUST 85\%) } \\
\cline { 2 - 7 } & Base Mensal & Base Horária & Base Mensal & Base Horária & Base Mensal & Base Horária \\
\hline Média & 9,81 & 9,68 & 9,86 & 9,73 & 9,92 & 9,78 \\
\hline Mediana & 9,80 & 9,67 & 9,85 & 9,72 & 9,91 & 9,77 \\
\hline Mínimo & 9,78 & 9,65 & 9,84 & 9,71 & 9,90 & 9,76 \\
\hline Máximo & 10,44 & 10,32 & 10,50 & 10,38 & 10,55 & 10,43 \\
\hline Desvio Padrão & 0,03 & 0,04 & 0,03 & 0,04 & 0,03 & 0,04 \\
\hline Desvio Padrão MA* & 0,00 & 0,00 & 0,00 & 0,00 & 0,00 & 0,00 \\
\hline VaR 95\% & 9,79 & 9,66 & 9,85 & 9,71 & 9,90 & 9,77 \\
\hline CVaR 95\% & 9,79 & 9,66 & 9,85 & 9,71 & 9,90 & 9,77 \\
\hline Coef. De Variação & $0,01 \%$ & $0,01 \%$ & $0,01 \%$ & $0,01 \%$ & $0,01 \%$ & $0,01 \%$ \\
\hline Coef. De Variação MA* & $0,01 \%$ & $0,01 \%$ & $0,01 \%$ & $0,01 \%$ & $0,01 \%$ & $0,01 \%$ \\
\hline *Dán
\end{tabular}

*Da Variável Aleatória: Média Amostral 
Tabela 40 - Estatísticas de TIR Modificada para os Casos de Contratação do MUST de 80\%, $75 \%$ e $70 \%$

\begin{tabular}{|c|c|c|c|c|c|c|}
\hline \multirow{2}{*}{$\begin{array}{c}\text { TIR Modificada } \\
\text { (\% a.a.) }\end{array}$} & \multicolumn{2}{|c|}{ Hibrido (MUST 80\%) } & \multicolumn{2}{c|}{ Hibrido (MUST 75\%) } & \multicolumn{2}{c|}{ Hibrido (MUST 70\%) } \\
\cline { 2 - 7 } & Base Mensal & Base Horária & Base Mensal & Base Horária & Base Mensal & Base Horária \\
\hline Média & 9,98 & 9,83 & 10,03 & 9,88 & 10,08 & 9,92 \\
\hline Mediana & 9,97 & 9,83 & 10,02 & 9,87 & 10,07 & 9,91 \\
\hline Mínimo & 9,96 & 9,81 & 10,01 & 9,86 & 10,06 & 9,90 \\
\hline Máximo & 10,61 & 10,48 & 10,66 & 10,53 & 10,70 & 10,56 \\
\hline Desvio Padrão & 0,03 & 0,04 & 0,03 & 0,04 & 0,03 & 0,04 \\
\hline Desvio Padrão MA* & 0,00 & 0,00 & 0,00 & 0,00 & 0,00 & 0,00 \\
\hline VaR 95\% & 9,96 & 9,82 & 10,02 & 9,87 & 10,06 & 9,91 \\
\hline CVaR 95\% & 9,96 & 9,82 & 10,02 & 9,87 & 10,06 & 9,91 \\
\hline Coef. De Variação & $0,01 \%$ & $0,01 \%$ & $0,01 \%$ & $0,01 \%$ & $0,01 \%$ & $0,01 \%$ \\
\hline Coef. De Variação MA** & $0,01 \%$ & $0,01 \%$ & $0,01 \%$ & $0,01 \%$ & $0,01 \%$ & $0,01 \%$ \\
\hline *Da Varí́vel Aleatória: Média Amostral & & & & & \\
\end{tabular}

Tabela 41 - Estatísticas de TIR Modificada para os Casos de Contratação do MUST de 65\%, $60 \%, 55 \%$ e $50 \%$

\begin{tabular}{|c|c|c|c|c|c|c|c|c|}
\hline \multirow{2}{*}{$\begin{array}{l}\text { TIR Modificada } \\
\text { (\% a.a.) }\end{array}$} & \multicolumn{2}{|c|}{ Híbrido (MUST 65\%) } & \multicolumn{2}{|c|}{ Híbrido (MUST 60\%) } & \multicolumn{2}{|c|}{ Hibrido (MUST 55\%) } & \multicolumn{2}{|c|}{ Híbrido (MUST 50\%) } \\
\hline & Base Mensal & Base Horária & Base Mensal & Base Horária & Base Mensal & Base Horária & Base Mensal & Base Horária \\
\hline Média & 10,06 & 9,95 & 9,94 & 9,95 & 9,68 & 9,92 & 9,23 & 9,88 \\
\hline Mediana & 10,05 & 9,94 & 9,93 & 9,94 & 9,67 & 9,91 & 9,22 & 9,86 \\
\hline Mínimo & 10,04 & 9,92 & 9,93 & 9,93 & 9,65 & 9,90 & 9,20 & 9,86 \\
\hline Máximo & 10,65 & 10,57 & 10,47 & 10,56 & 10,16 & 10,52 & 9,71 & 10,46 \\
\hline Desvio Padrão & 0,03 & 0,04 & 0,03 & 0,04 & 0,03 & 0,04 & 0,03 & 0,04 \\
\hline Desvio Padrão MA* & 0,00 & 0,00 & 0,00 & 0,00 & 0,00 & 0,00 & 0,00 & 0,00 \\
\hline VaR $95 \%$ & 10,05 & 9,93 & 9,93 & 9,93 & 9,66 & 9,91 & 9,21 & 9,86 \\
\hline CVaR 95\% & 10,05 & 9,93 & 9,93 & 9,93 & 9,66 & 9,90 & 9,20 & 9,86 \\
\hline Coef. De Variação & $0,01 \%$ & $0,01 \%$ & $0,01 \%$ & $0,01 \%$ & $0,01 \%$ & $0,01 \%$ & $0,01 \%$ & $0,01 \%$ \\
\hline Coef. De Variação MA* & $0,01 \%$ & $0,01 \%$ & $0,01 \%$ & $0,01 \%$ & $0,01 \%$ & $0,01 \%$ & $0,01 \%$ & $0,01 \%$ \\
\hline
\end{tabular}




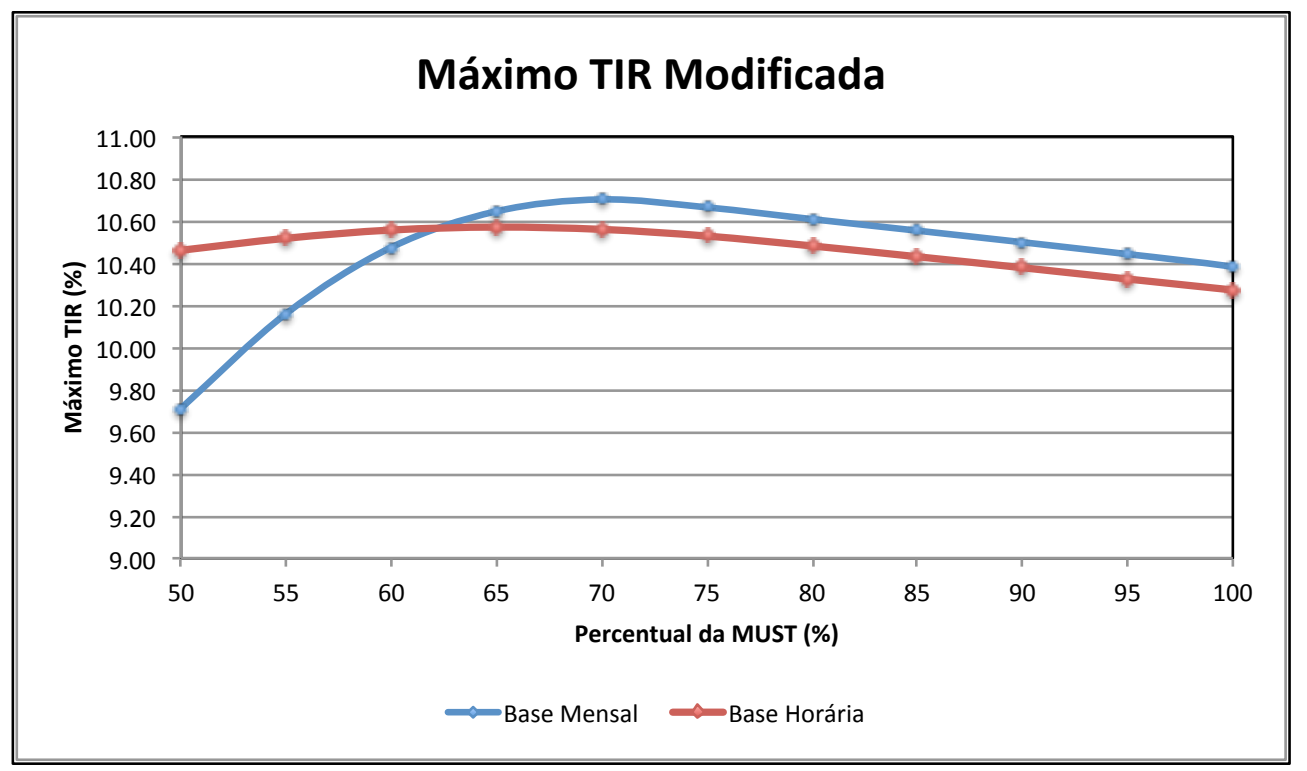

Figura 83 - Dados da Valores Máximos de TIR para cada Percentual de Contratação do MUST

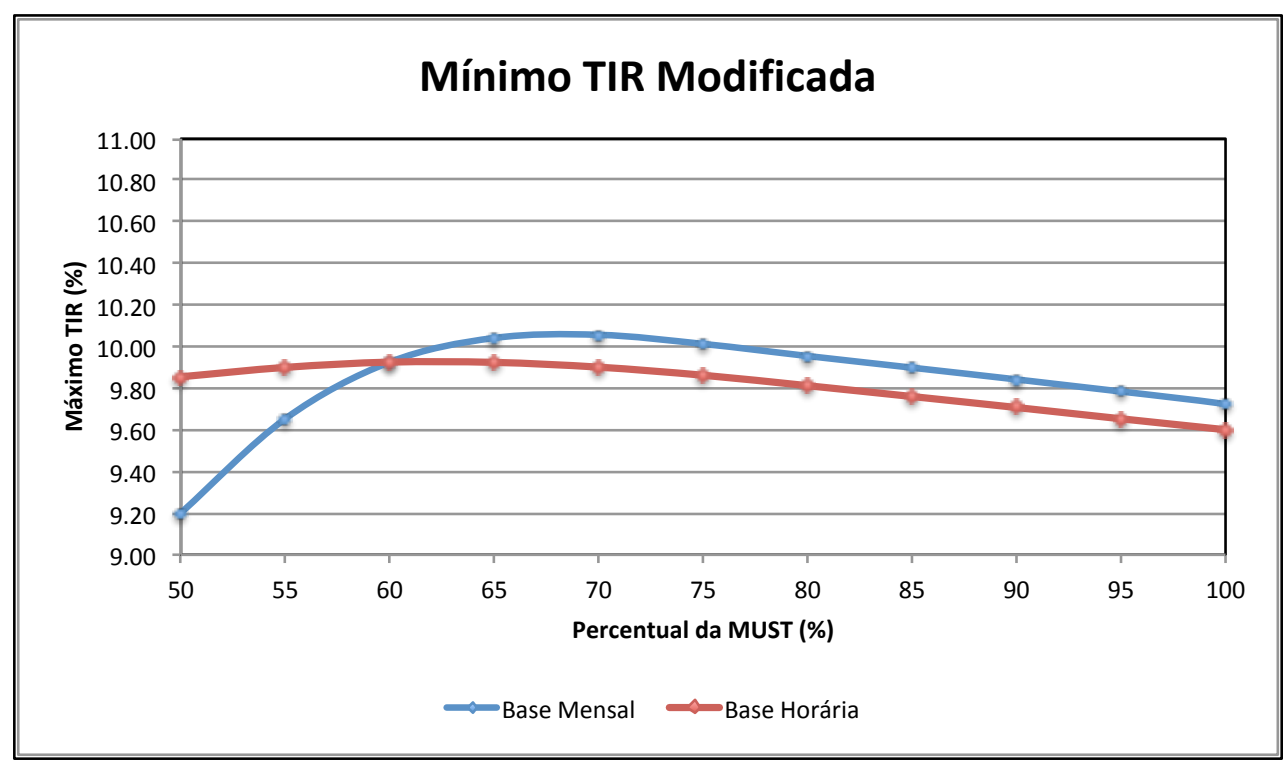

Figura 84 - Dados da Valores Máximos de TIR Modificada para cada Percentual de Contratação do MUST 


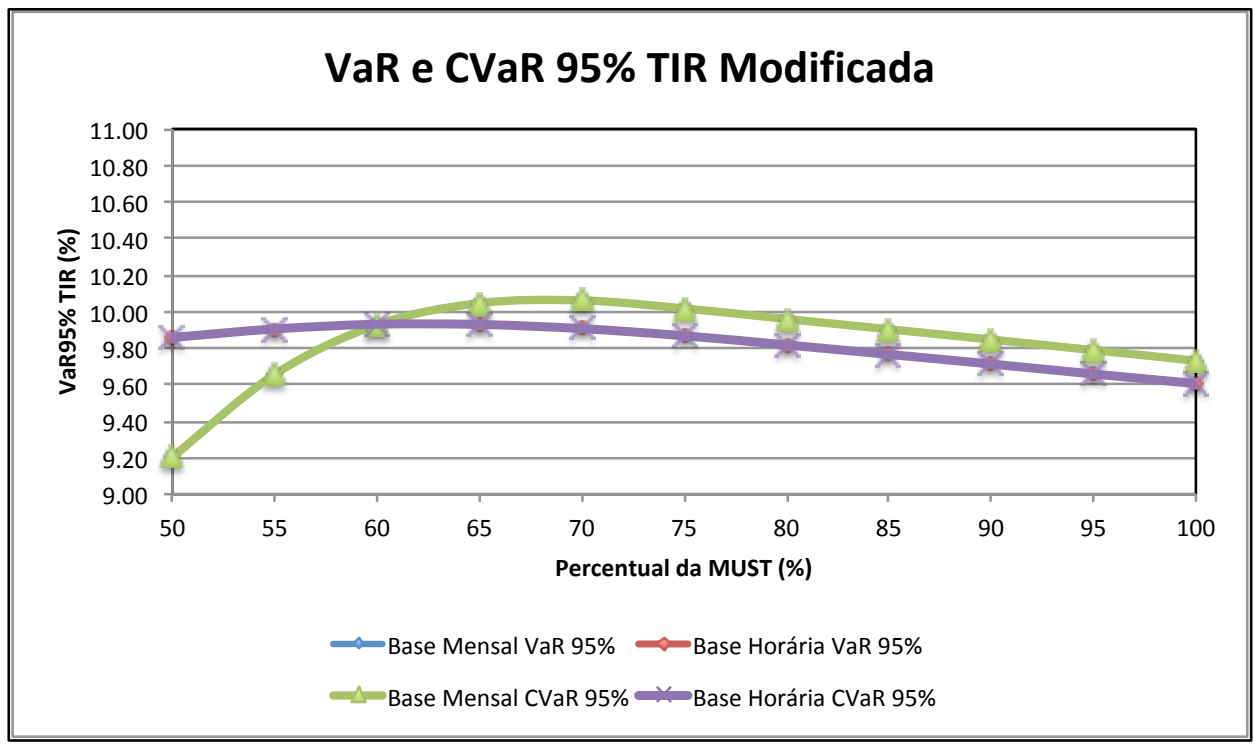

Figura 85 - Dados da VaR e CVaR 95\% de TIR Modificada para cada Percentual de Contratação do MUST 